\title{
Kimberlite Weathering: Effects of Organic reagents
}

\author{
By \\ BONGANI NDLOVU
}

A dissertation submitted in partial fulfillment of the requirements for the degree

\section{MASTER OF ENGINEERING \\ (METALLURGICAL ENGINEERING)}

\author{
in the \\ Faculty of Engineering, Built Environment and Information Technology \\ University of Pretoria
}

Pretoria

2013

(C) University of Pretoria 


\title{
Kimberlite Weathering: $\quad$ Effects of Organic reagents
}

STUDENT:

SUPERVISORS:

DEPARTMENT:

DEGREE:
BONGANI NDLOVU

J. MORKEL AND N. NAUDÉ

MATERIALS SCIENCE AND

METALLURGICAL ENGINEERING

MASTER OF ENGINEERING

(METALLURGICAL ENGINEERING)

\begin{abstract}
Diamonds are commonly present in an ore called kimberlite. Kimberlites vary extensively in mineralogy and therefore can complicate the processing and the extraction of diamonds. Weathering of kimberlite was investigated in this study and refers to the rapid physical breakdown of the kimberlite material. Kimberlite weathering by organic molecule adsorption was investigated utilising organic solutions; ethanol, formamide, n-hexane, oxalic acid, urea, pentanoic acid and acetic acid, was investigated. The extent of weathering was measured by XRD, TGA and FTIR analysis as well as by evaluating changes in the particle size distribution. The idea to predict the susceptibility of weathering of kimberlite based on TGA analysis was discredited as it was found that there was no correlation between the smectite content and the \% weight loss from TGA analysis.
\end{abstract}

In XRD analysis studies to relate the d-spacing to the extent of weathering, it was found that the technique was not sensitive enough to enable direct prediction of weathering behaviour. Organic solutions at $0.5 \mathrm{M}$ generally did not significantly alter the d-spacing. In the case of utilising pure organic solutions, it was observed that switching from diluted to pure organic solutions did not increase the d-spacings but rather lowers the space. Cation pretreatment prior to organic weathering resulted in d-spacings up to 2 water layers (12.6 ̊ being equal to 1 water layer, $15.6 \AA$ equal to 2 layers and $18.6 \AA$ equal to 
3 layer). The general trend was that the divalent cations $\mathrm{Mg}^{2+}$ and $\mathrm{Ca}^{2+}$ increased the d-spacings whereas monovalent cations $\mathrm{Na}^{+}$and $\mathrm{K}^{+}$decreased the spacing. In the case of pre-organic treatment prior to organic weathering, it was observed that the resulting d-spacing increased to 2 and 3 water layers.

TGA analysis confirmed that the kimberlite structure did absorb organic reagents during weathering. It was observed that the amount of organic reagents adsorbed decrease in the following order: oxalic acid $>$ urea $>$ pentanoic acid $>$ formamide $>$ ethanol $>$ n-hexane $>$ acetic acid, with oxalic acid having been adsorbed the greatest. In addition, it was also shown that the extent of inorganic cation adsorption was more than that of organic solutions. The analysis also showed that organic pretreatments yielded promising results and the order followed was dimethyldioctadecylammonium chloride > cetylpyridium chloride $>$ dodecylamine $>$ pyridine in encouraging subsequent organic adsorption.

FTIR analysis results indicated the mechanism by which organic molucules attached onto the mineral surface. It was observed that there was a disturbance of the bond between water in the interlayer and the silicate structure by a stronger $\mathrm{H}$-bond gained through organic molecule attachment. Oxalic acid was observed to cause a structural change due to proton attack of the silicate structure.

It was found that kimberlite weathering, in essence, occurred in the first 24 hours of contact with the solution. Oxalic acid was found to be the most effective weathering agent compared to the rest of the tested organic solutions. The effect of the tested solutions, at $0.5 \mathrm{M}$ concentration, on kimberlite weathering followed the series $\mathrm{Cu}^{2+}>$ oxalic acid > ethanol $>$ acetic acid $>$ formamide $>$ n-hexane $>$ distilled water. This study therefore showed that the accelerated weathering of kimberlite utilising organic solutions was not as efficient as the $\mathrm{Cu}^{2+}$ solution. Comparing $\mathrm{Cu}^{2+}$ and oxalic acid treatments, results showed that $67 \%$ of the particles passed $12 \mathrm{~mm}$ screen size due to $\mathrm{Cu}^{2+}$ weathering as opposed to $48 \%$ in oxalic acid.

In investigating the effects of variables, it was found that time of exposure had a small effect in the weathering of kimberlite. Increasing the organic concentration from $0.025 \mathrm{M}$ to $0.5 \mathrm{M}$ saw an increase in the amount of particles passing the $12 \mathrm{~mm}$ screen size by 
20\%. There was however no improved weathering when the solution temperature was increased from approximately $25^{\circ} \mathrm{C}$ to $40^{\circ} \mathrm{C}$.

In the study of kinetics involved during organic weathering utilising oxalic acid and comparing with $\mathrm{Cu}^{2+}$ medium, a high mineral dissolution was observed in the first 24 hours of contact with the weathering solution. However, different weathering mechanisms were observed between $\mathrm{Cu}^{2+}$ and oxalic acid. Inorganic solutions foster weathering by interlayer cation exchange which results in the reduction of the surface energy and this encourages further crack propagation. Oxalic acid weathering mechanism was by proton attack of the structural cations which was then limited thereafter by oxalate salts precipitation. $\mathrm{Al}^{3+}$ and $\mathrm{Mg}^{2+}$ were the dominant cations in solution during weathering (reaching $40 \mathrm{mmol} / \mathrm{L}$ ) at higher oxalic acid concentration. This indicated that the dissolution of the clay's octahedral structure occurred, making oxalic acid a more effective agent than the rest of the tested organic solutions.

An alternative method to transform non-swelling clay minerals to swelling in kimberlites was highlighted. It was observed that cation exchange treatment in conjunction with acid and oxidation treatments on kimberlites containing non-swelling minerals: mica or forsterite that are at least $30 \%$ in quantity may result in the presence of swelling clays after these treatments. Kimberlite that contained serpentine minerals was more resistant to alteration under these conditions.

KEYWORDS: Kimberlite, organic weathering, FTIR analysis, TGA analysis, clay minerals, oxalic acid 


\section{ACKNOWLEDGEMENT}

First and foremost I give thanks to the almighty GOD and Lord Jesus Christ for the divine enablement throughout the course of this long and sometimes frustrating work. I also want to thank my family, the Ndlovus, and Miss Nolubabalo Tantsi for their continued moral and physical support. Special thanks also go to my supervisors Dr. Jacqueline Morkel and Dr. Natasia Naudé for their technical assistance as well as editing this document. Dr. Groot for the technical and moral support. I am grateful to the University of Pretoria, the Department of Materials Science and Metallurgical Engineering as a whole, for the financial support and more so Prof. Madeleine du Toit, Mrs. Sarah Havenga and Mrs. Louise Ackermann for administrative functions, their kindness and friendliness. I am also thankful to De Beers Group, especially Mr. Pete Sergeant, for the financial support as well as facilitating the supply of the ore resource. 


\section{TABLE OF CONTENTS}

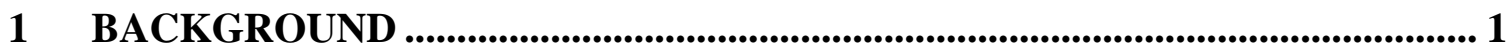

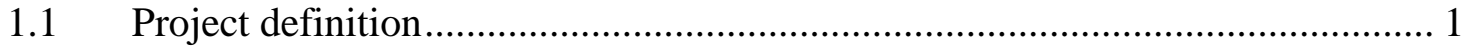

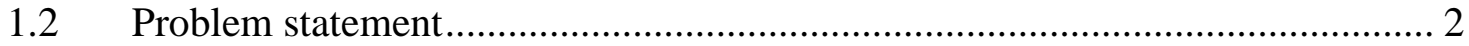

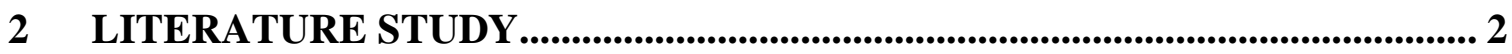

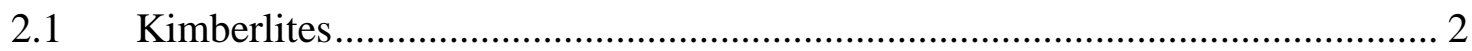

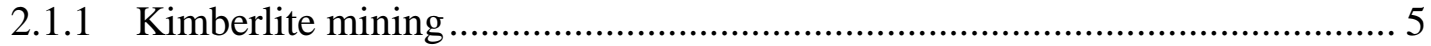

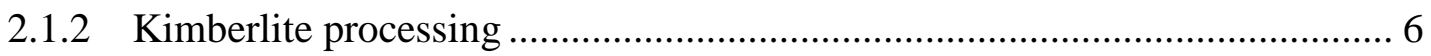

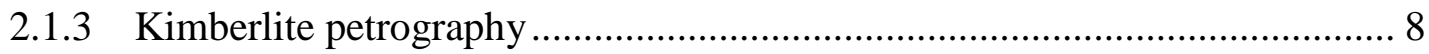

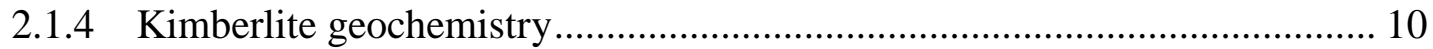

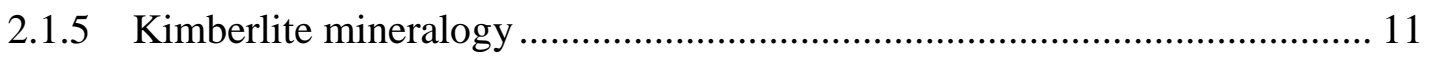

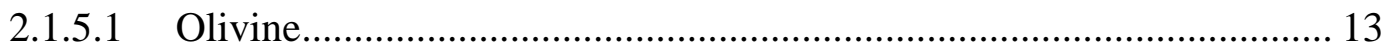

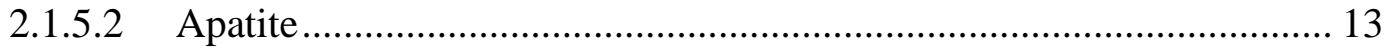

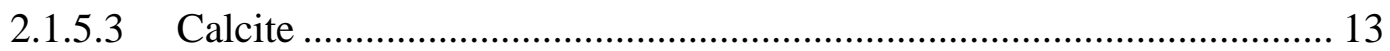

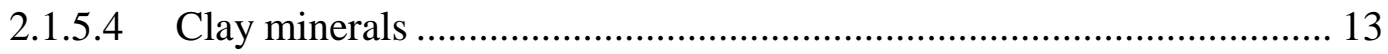

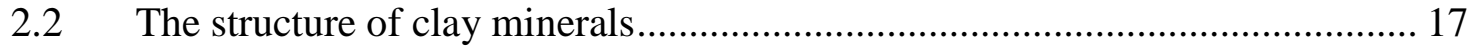

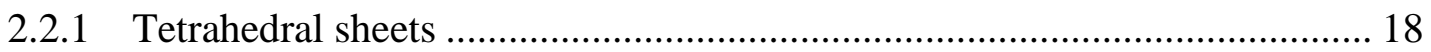

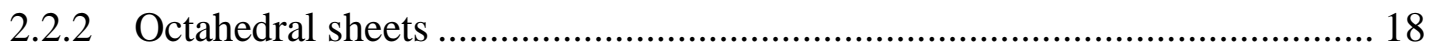

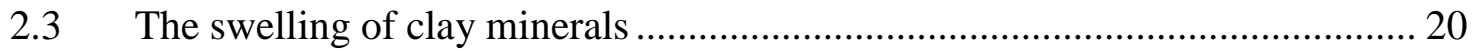

2.4 Organic sorption on clay minerals .......................................................... 20

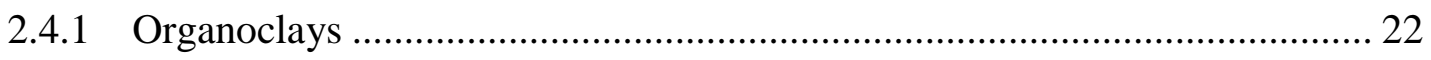

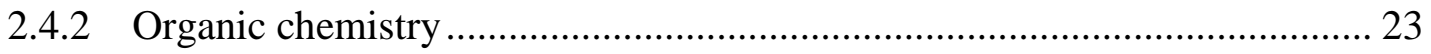

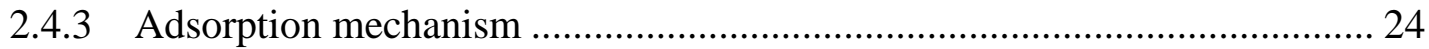

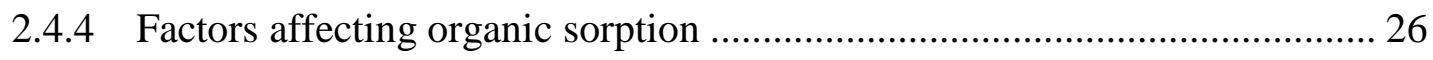

2.4.4.1 Effect of exchangeable cations on organic sorption .......................... 26

2.4.4.2 Effect of surface charge density ................................................. 27

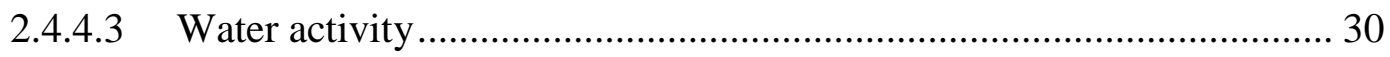

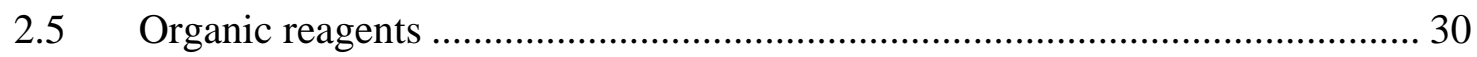

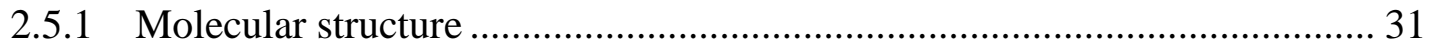

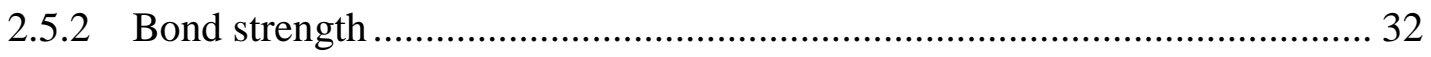

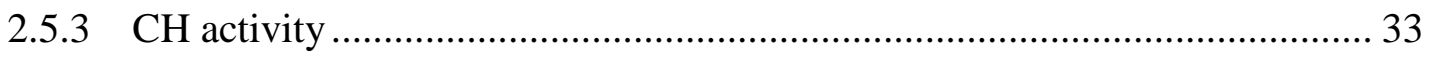

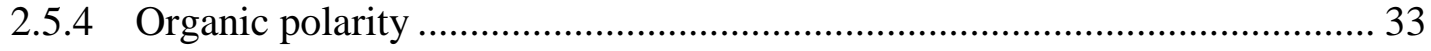

(C) University of Pretoria $\quad \mathrm{v}$ 


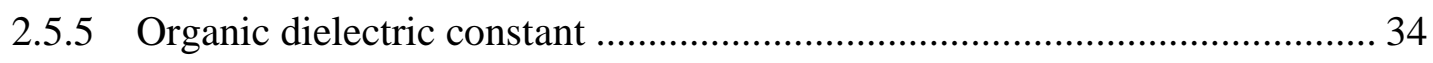

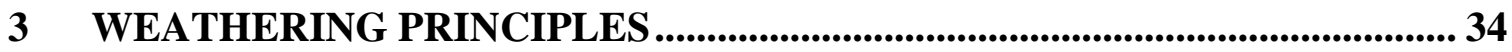

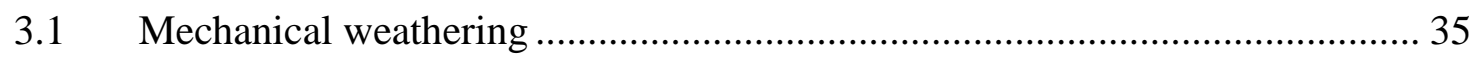

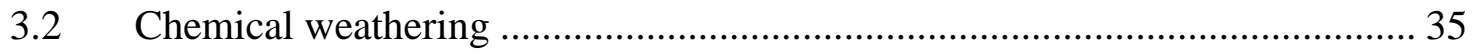

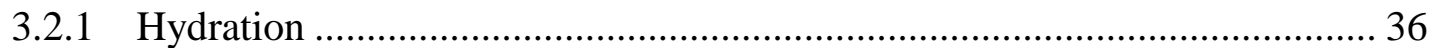

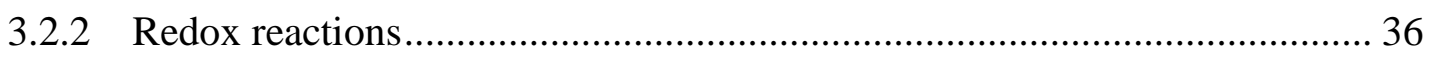

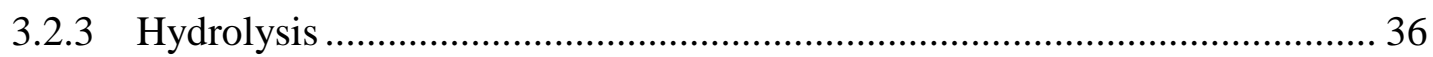

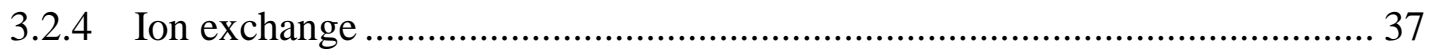

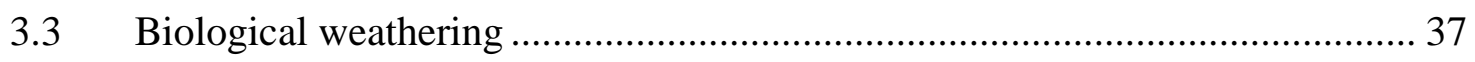

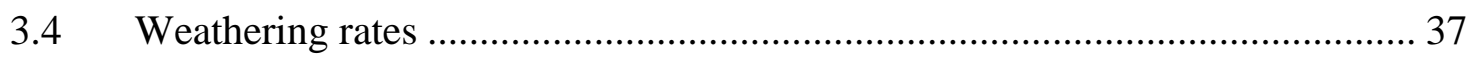

3.5 Experimental determination of weathering rates ......................................... 39

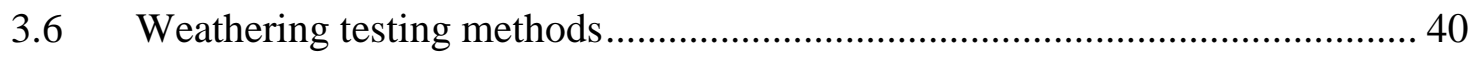

4 KIMBERLITE ACCELERATED WEATHERING ...................................... 43

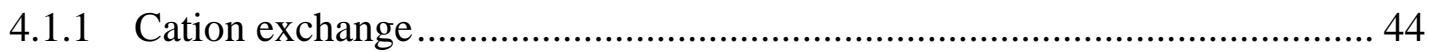

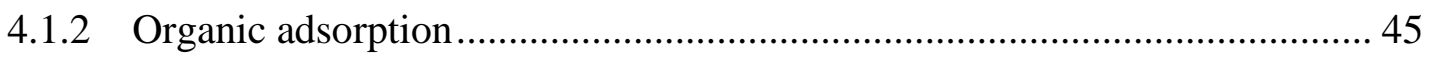

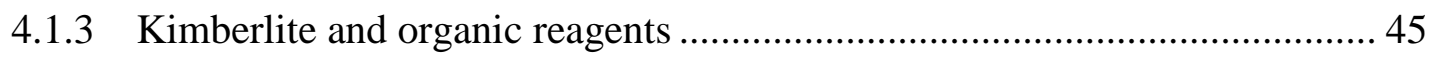

5 ALTERATION OF MINERALS IN KIMBERLITE ..................................... 47

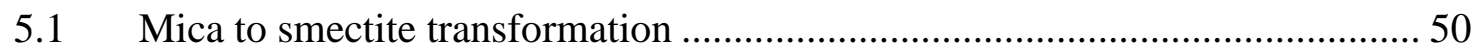

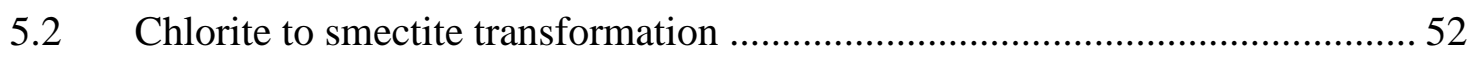

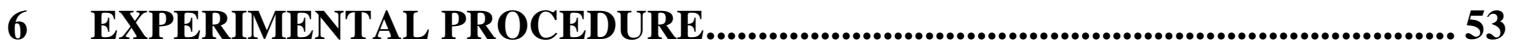

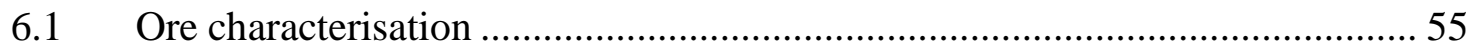

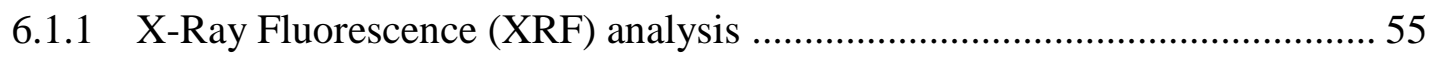

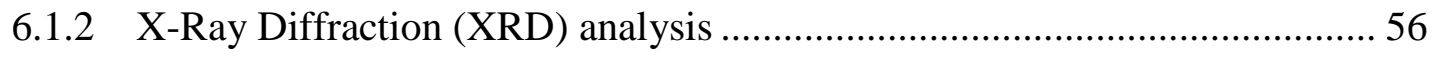

6.1.3 Cation Exchange Capacity (CEC) determination ..................................... 56

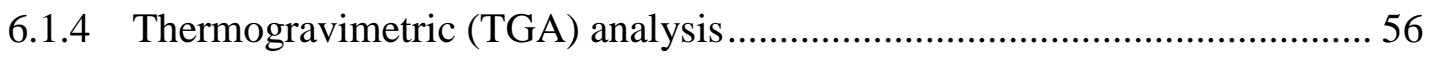

6.1.5 Fourier Transform Infrared Spectroscopy (FTIR) analysis ....................... 56

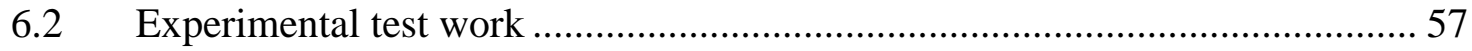

6.2.1 Correlation between smectite content and TGA analysis ......................... 57

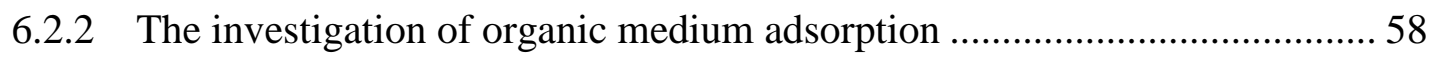

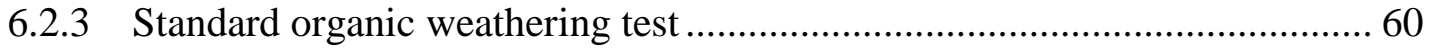

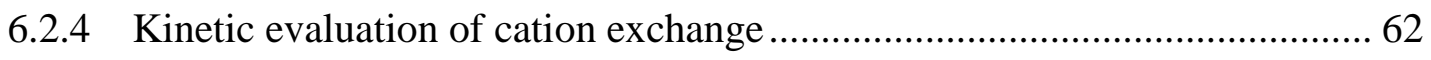

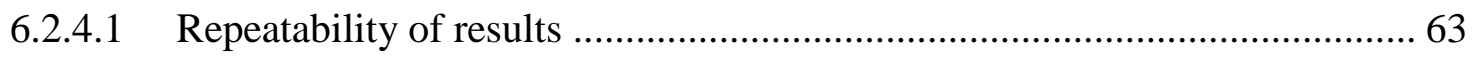

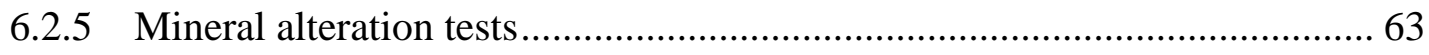

(C) University of Pretoria vi 


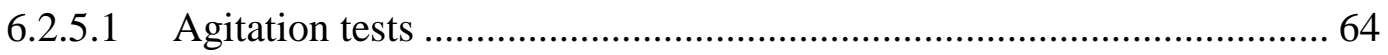

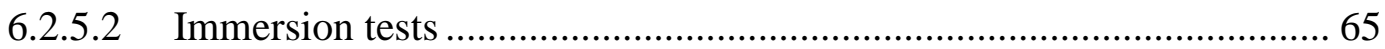

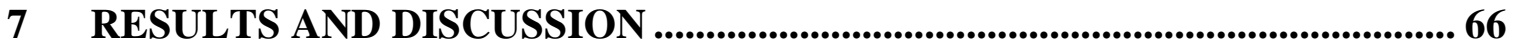

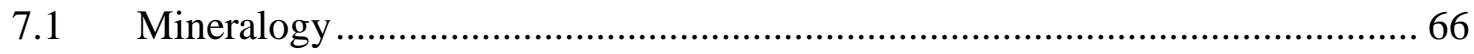

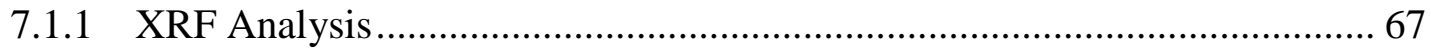

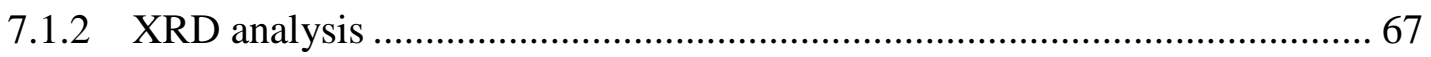

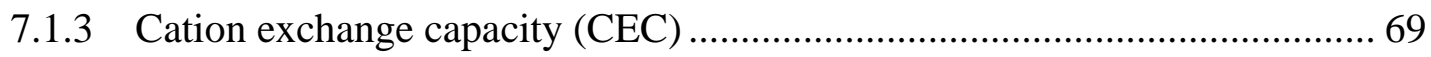

7.1.4 Correlation between smectite content and TGA analysis ........................... 70

7.2 The investigation of organic medium adsorption ........................................ 74

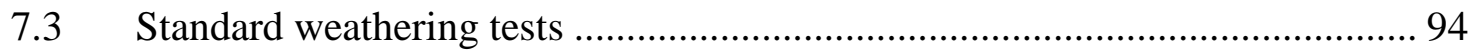

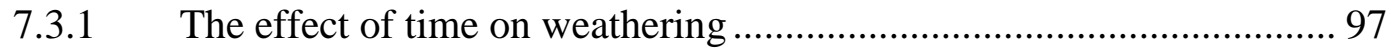

7.3.2 The effect of concentration on weathering .................................... 98

7.3.3 The effect of temperature on weathering ...................................... 99

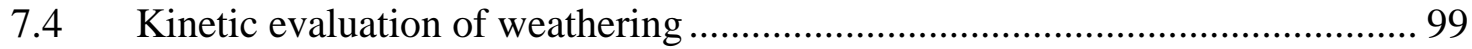

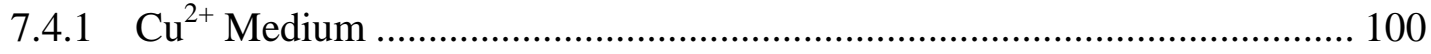

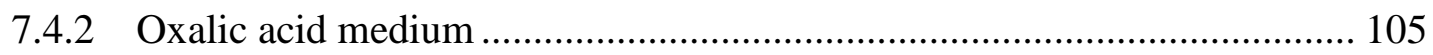

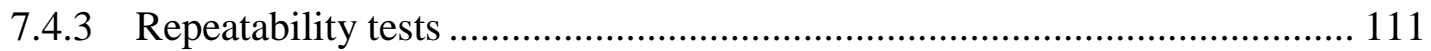

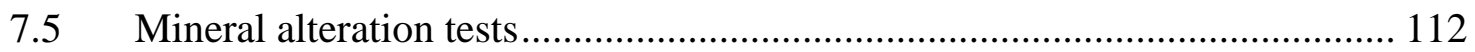

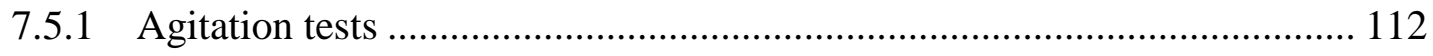

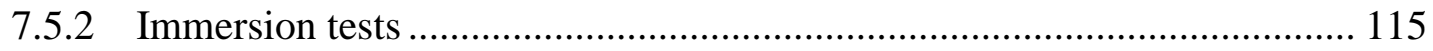

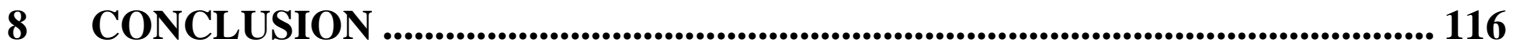

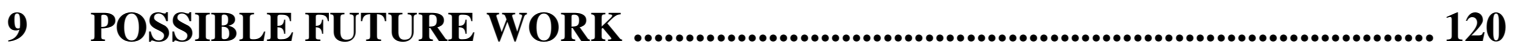

10 REFERENCES............................................................................................. 121

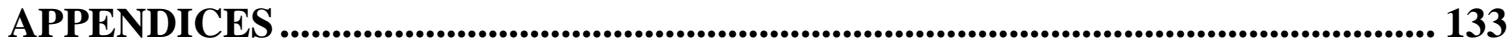

APPENDIX A: XRD analysis results for the Finsch, the Koffiefontein and the Venetia

K1 ores.

A1: XRD analysis results for the Finsch ore .................................................. 134

A2: XRD analysis results for the Koffiefontein ore ......................................... 135

A3: $\quad$ XRD analysis results for the Venetia K1 ore ........................................... 136

APPENDIX B: Correlation between smectite content and TGA analysis results ...... 137 APPENDIX C: XRD results for oxalic acid treatment that had a $\mathrm{Na}^{+}$pretreatment and with no d-spacing detection on the Koffiefontein ore 
APPENDIX D: Standard weathering tests particle size distribution data for the Finsch ore

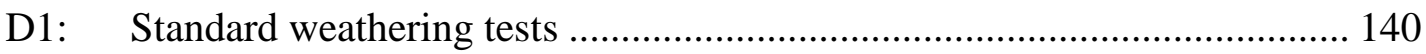

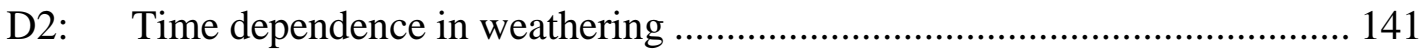

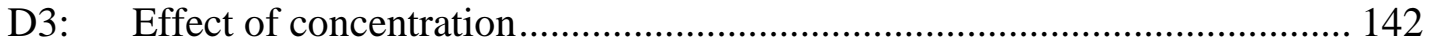

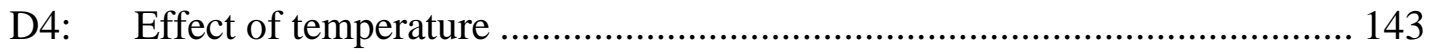

APPENDIX E: XRD analysis results of agitation tests for pre-cation treatment prior to oxalic acid treatment for the Venetia K1 ore 144

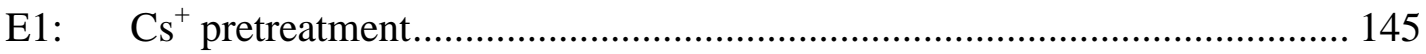

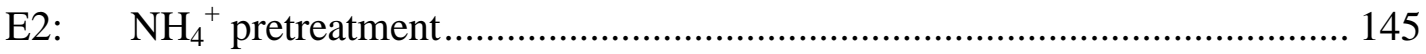

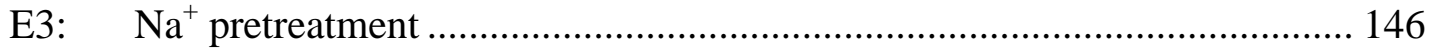

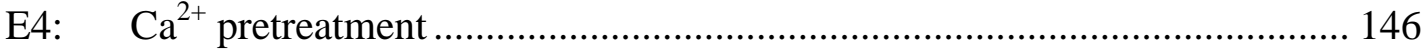

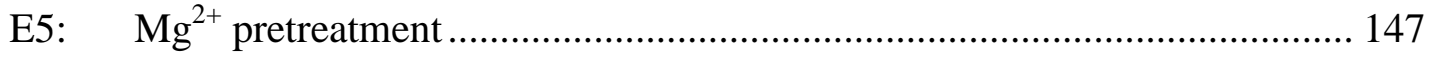

APPENDIX F: XRD analysis results of alteration tests for the VUE ore ................. 148

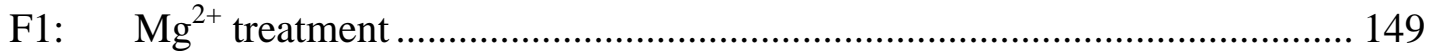

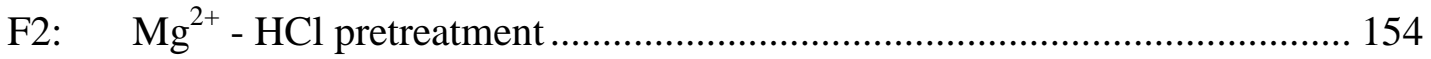

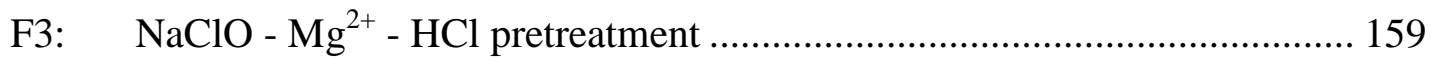




\section{LIST OF FIGURES}

Figure 1: A model illustrating the kimberlite pipe (Mitchell, 1986).

Figure 2: Map showing the location of kimberlite-hosted diamond mines in Southern

Africa subdivided into structural units (Field et al., 2008)............................................ 4

Figure 3: Schematic illustration of a diamond processing plan (Hodgson, 1981)............. 7

Figure 4: The different stages of olivine, pyroxene and mica alteration (Dawson, 1980). 8

Figure 5: A textural-genetic classification of kimberlites (Clement \& Skinner, 1985)..... 9

Figure 6: A single tetrahedron (left) and the tetrahedral sheet structure (right) of $\mathrm{SiO}^{4+}$ tetrahedra (Bland \& Rolls, 1988).

Figure 7: The single octahedron (left) and octahedral sheet structure (right) of an octahedral sheet (Bland \& Rolls, 1998).

Figure 8: The crystal structure of 2:1 clay mineral (Klein, 2002).

Figure 9: Montmorillonite with organic interlayer cations in the dried state (left) and with organic molecules in maximum swollen state (right) (Weiss, 1989).

Figure 10: Hydrated radii for various cations (Mohan et al., 1999).

Figure 11: A illustration of the possible interlayer arrangement of BODMA smectites with layer charge densities of $(\mathrm{A})<0.8 \mathrm{e}^{-}$and $(\mathrm{B})>0.8 \mathrm{e}^{-}$per $\mathrm{O}_{20}(\mathrm{OH})_{4}$. The distance between alkylammonium units are inversely related to the layer charge density (Gates, 2004).

Figure 12: Basal spacing, $\mathrm{d}_{\mathrm{L}}$, as a function of number of alkylammonium carbon atoms $\left(\mathrm{n}_{\mathrm{C}}\right)$ in contact with $\mathrm{n}$-hexane; $\mathrm{n}$-dodecane; cyclohexane; cis-decaline. Broken line:

spacing of dried sample at $65^{\circ} \mathrm{C}$ in vacuum (Lagaly \& Malberg, 1990).

Figure 13: Morphology of montmorillonite particles with: (A) frayed edges; and (B) restricted areas of contact (predetermined breaking points) (Lagaly \& Malberg, 1990). 35

Figure 14: The $-16+13.2 \mathrm{~mm}$ Finsch sample as received. 53

Figure 15: The $65 \mathrm{~mm}$ Koffiefontein kimberlite drillcore samples as received. 54

Figure 16: The $215 \mathrm{~mm}$ diameter Venetia K1 kimberlite drillcore samples. 54

Figure 17: Venetia expansion project drillcore samples with diameters ranging from 40 to $65 \mathrm{~mm}$. 55

Figure 18: Experimental setup for weathering tests utilising $16 \mathrm{~g}$ of $80 \%$ passing $100 \mu \mathrm{m}$ Koffiefontein sample exposed to $250 \mathrm{ml}$ of various organic solutions for seven days. ... 59

Figure 19: The standard weathering test utilising $300 \mathrm{~g}$ of $-16+13.2 \mathrm{~mm}$ Finsch

kimberlite exposed to $1 \mathrm{~L}$ of various organic weathering media. 61

(c) University of Pretoria ix 
Figure 20: Experimental setup for weathering tests utilising $50 \mathrm{~g}$ of $80 \%$ passing $100 \mu \mathrm{m}$ Venetia K1 sample agitated in $800 \mathrm{ml}$ of various organic solutions for 24 hours. 64

Figure 21: Oxidation treatment with $\mathrm{NaOCl}$ in a waterbath at $70{ }^{\circ} \mathrm{C}$ 66

Figure 22: TGA analysis results for the various VUE ore drillcores. 71

Figure 23: The $\%$ weight loss at $1000{ }^{\circ} \mathrm{C}$ for respective drillcore Ids. 72

Figure 24: The $\%$ weight loss at $1000{ }^{\circ} \mathrm{C}$ as a function of smectite content. 73

Figure 25: The $\mathrm{d}_{75}$ as a function of $\%$ weight loss at $1000{ }^{\circ} \mathrm{C}$ 73

Figure 26: TGA results of $0.5 \mathrm{M}$ organic solutions on the $80 \%$ passing $100 \mu \mathrm{m}$ Koffiefontein ore sample. 76

Figure 27: An illustration of the TGA results on the $80 \%$ passing $100 \mu \mathrm{m}$ Koffiefontein ore sample showing relative amounts adsorbed for the organic reagents tested, with the untreated sample as the reference.

Figure 28: FTIR scans for Koffiefontein samples treated with $0.5 \mathrm{M}$ organic solutions. 78 Figure 29: TGA results of pure organic reagents on the $80 \%$ passing $100 \mu \mathrm{m}$ Koffiefontein ore sample showing a higher \% weight loss on formamide treated sample.

Figure 30: An illustration of the TGA results on Koffiefontein ore sample showing relative adsorbed pure organic reagents, with the untreated sample as the baseline reference.

Figure 31: FTIR scans for Koffiefontein samples treated with pure organic reagents..... 82 Figure 32: TGA results of formamide adsorption after cation conditioning of Koffiefontein ore sample.

Figure 33: An illustration of the \% formamide adsorbed with various pre-cation treatments, on the Koffiefontein ore sample with reference to an untreated sample 84 Figure 34: TGA results of the adsorption of various organic solution treatments on $\mathrm{Mg}^{2+}$ pre-treated Koffiefontein ore sample.

Figure 35: Amounts of adsorbed organic reagents, as percentages, on $\mathrm{Mg}^{2+}$ pre-treated before $0.5 \mathrm{M}$ organic solutions and only $0.5 \mathrm{M}$ organic solution treatments of Koffiefontein ore sample.

Figure 36: FTIR scans for Koffiefontein samples treated with $0.5 \mathrm{M}$ organic solutions after pretreatments in $0.5 \mathrm{M}$ solution of $\mathrm{Mg}^{2+}$ in comparison to an untreated sample. ... 87 Figure 37: FTIR scans for Koffiefontein samples treated with $0.5 \mathrm{M}$ organic solutions after pretreatments in $0.5 \mathrm{M}$ solution of $\mathrm{Ca}^{2+}$ in comparison to an untreated sample. ..... 88 
Figure 38: FTIR scans for Koffiefontein samples treated with $0.5 \mathrm{M}$ organic solutions after pretreatments in $0.5 \mathrm{M}$ solution of $\mathrm{Na}^{+}$in comparison to untreated sample. 88

Figure 39: FTIR scans for Koffiefontein samples treated with $0.5 \mathrm{M}$ organic solutions after pretreatments in $0.5 \mathrm{M}$ solutions of $\mathrm{K}^{+}$in comparison to untreated sample..... 89 Figure 40: TGA results of the Koffiefontein ore sample treated with $0.5 \mathrm{M} \mathrm{Mg}^{2+}, \mathrm{Ca}^{2+}$, $\mathrm{Na}^{+}$and $\mathrm{K}^{+}$.

Figure 41: An illustration of TGA results on the Koffiefontein ore sample showing relative adsorbed cations in comparison to an untreated sample.

Figure 42: TGA results of various organic reagents treatments with a prior P, CPC,

DDAC and DDA before formamide on the Koffiefontein ore sample. 92

Figure 43: An illustration of the amount of formamide adsorbed due to pretreatment of $\mathrm{P}$, CPC, DDAC and DDA on the Koffiefontein ore sample.

Figure 44: FTIR scans for untreated Koffiefontein sample in comparison to the P, DDA, CPC and DDAC organic reagents treatment prior to formamide saturation on the Koffiefontein ore sample.

Figure 45: The particle size distribution for weathering of Finsch ore $(-16+13.2 \mathrm{~mm})$ for 6 days at room temperature with $0.5 \mathrm{M} \mathrm{Cu}^{2+}$ and $0.5 \mathrm{M}$ ethanol, formamide, $\mathrm{n}$-hexane, oxalic acid, urea and acetic acid.

Figure 46: The $\%$ passing $12 \mathrm{~mm}$ for the Finsch sample $(-16+13.2 \mathrm{~mm})$ treated with distilled water, $\mathrm{Cu}^{2+}$, ethanol, formamide, $\mathrm{n}$-hexane, oxalic acid, urea and acetic acid all at $0.5 \mathrm{M}$ and at room temperature.

Figure 47: Results of the effect of exposure time on the weathering of Finsch samples $(-16+13.2 \mathrm{~mm})$ utilising $0.5 \mathrm{M}$ oxalic acid at room temperature.

Figure 48: Results of the effect of oxalic acid concentration on Finsch samples $(-16+13.2 \mathrm{~mm})$ weathered for 6 days at room temperature.

Figure 49: Results of the effect of temperature tested at 25 and $40{ }^{\circ} \mathrm{C}$ on Finsch samples $(-16+13.2 \mathrm{~mm})$ in $0.5 \mathrm{M}$ oxalic acid weathered for 6 days

Figure 50: ICP results displaying the release of $\mathrm{Mg}^{2+}, \mathrm{Ca}^{2+}, \mathrm{Na}^{+}, \mathrm{K}^{+}$and $\mathrm{Al}^{3+}$ for (a) $0.025 \mathrm{M}$, (b) $0.1 \mathrm{M}$, (c) $0.5 \mathrm{M} \mathrm{Cu}^{2+}$ solution.

Figure 51: ICP results displaying the release of $\mathrm{Na}^{+}$from Finsch ore into solution at 0.025 $\mathrm{M}, 0.1 \mathrm{M}$, and $0.5 \mathrm{M} \mathrm{Cu}^{2+}$ concentrations.

Figure 52: Plots of $\log (\mathrm{dC} / \mathrm{dt})$ against $\log \left(\mathrm{C}-\mathrm{C}_{\infty}\right)$ for (a) 0.025 , (b) 0.1 and (c) $0.5 \mathrm{M}$ $\mathrm{Cu}^{2+}$ solution. 104 
Figure 53: ICP results displaying the release of $\mathrm{Mg}^{2+}, \mathrm{Ca}^{2+}, \mathrm{Na}^{+}, \mathrm{K}^{+}$and $\mathrm{Al}^{3+}$ for (a) $0.025 \mathrm{M}$, (b) $0.1 \mathrm{M}$, (c) $0.5 \mathrm{M}$ oxalic acid.

Figure 54: ICP results displaying the release of $\mathrm{Na}^{+}$from Finsch ore into solution at $0.025 \mathrm{M}, 0.1 \mathrm{M}$, and $0.5 \mathrm{M}$ oxalic acid concentrations. 108

Figure 55: Plots of $\log (\mathrm{dC} / \mathrm{dt})$ against $\log \left(\mathrm{C}-\mathrm{C}_{\infty}\right)$ for (a) 0.025 , (b) 0.1 and (c) $0.5 \mathrm{M}$ oxalic acid solution.

Figure 56: ICP results showing the release of $\mathrm{Mg}^{2+}, \mathrm{K}^{+}$and $\mathrm{Al}^{3+}$ with time from Set Point Laboratories and from UIS Analytical Service.

Figure 57: XRD scans for Venetia K1 sample treated with organic reagents.

Figure 58: XRD scans for Venetia K1 sample treated with organic reagents after EG treatment.

\section{LIST OF TABLES}

Table 1: The general composition of an average kimberlite compared to a micaceous kimberlite (Dawson, 1980).

Table 2: A summary of the Kimberlite mineral phases (Morkel, 2006).

Table 3: Groups of main clay minerals in kimberlite and the species under each group. 14 Table 4: Structure of the adsorption layer for various surfactant adsorption rates of BDDAC on Montmorillonite (Tahani et al., 1999).

Table 5: Porosities and external surface area for various n-alkylammonium montmorillonites, where $\mathrm{n}_{\mathrm{C}}$ is the number of carbon atoms in the alkyl chain (Lagaly \& Malberg, 1990).

Table 6: Weatherability of the rock based on the slake durability index (Morkel, 2006). 42 Table 7: Functional groups, industrial names and chemical formulas of organic compounds tested on kimberlite (Morkel \& Pieters, 2007). 46

Table 8: XRF analysis results for Finsch, Koffiefontein and Venetia K1 samples.

Table 9: XRD analysis results for samples utilised.

Table 10: The phase compositions of the VUE samples (Courtesy of Venetia mine underground expansion project).

Table 11: The CEC and the smectite content of Finsch, Koffiefontein and Venetia K1 samples. 
Table 12: XRD analysis ( $\mathrm{d}_{001}$-spacing results) on the effect of organic solutions on the 80

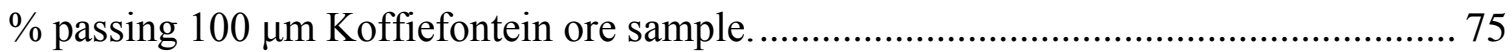

Table 13: Properties of the organic reagents utilised in the test work.

Table 14: XRD analysis ( $\mathrm{d}_{001}$-spacing) results for the effect of pure organic reagents on the $80 \%$ passing $100 \mu \mathrm{m}$ Koffiefontein ore sample.

Table 15: XRD analysis ( $\mathrm{d}_{001}$-spacing) results for the effect of pre-cationic treatment prior to organic weathering on the $80 \%$ passing $100 \mu \mathrm{m}$ Koffiefontein ore sample.

Table 16: XRD analysis ( $\mathrm{d}_{001}$-spacing) results for the effect of organic pretreatment prior to formamide treatment on the $80 \%$ passing $100 \mu \mathrm{m}$ Koffiefontein ore sample.

Table 17: ICP analysis results of $\mathrm{Cu}^{2+}$ and oxalic acid weathering of Finsch

$(-16+13.2 \mathrm{~mm})$

Table 18: Results of fitting kinetic equation (3) on a straight line for $\mathrm{Cu}^{2+}$ tests.

Table 19: Results of fitting kinetic equation (3) on a straight line for oxalic acid tests. 110

Table 20: Statistical analysis of repeatability tests.

Table 21: A summary of the XRD analysis results on VUE samples that were subjected to various treatments.

\section{ABBREVIATIONS}

$\begin{array}{ll}\mathrm{cm}: & \text { Centimeters } \\ \mathrm{cmol} / \mathrm{kg}: & \text { Centimole per kilogram } \\ \mathrm{d}_{\mathrm{L}}: & \text { Basal spacing } \\ \mathrm{d}: & \text { Interlayer spacing } \\ \mathrm{g}: & \text { gram } \\ \mathrm{kg}: & \text { Kilogram } \\ \mathrm{mm}: & \text { Millimeters } \\ \mathrm{n}_{\mathrm{C}}: & \text { Number of carbon atoms } \\ \%: & \text { Percent } \\ \AA & \text { Angström }\end{array}$

ARC: $\quad$ Agricultural Research Council of South Africa

BDDAC: Benzyldimethyldodecyl ammonium chloride

BODMA: Benzyloctadecyldimethylammonium

BODMAC: Benzyloctadecyldimethylammonium chloride 
CEC: $\quad$ Cation Exchange Capacity

CPC: $\quad$ Cetylpyridium Chloride

DDAC: Dimethyldioctadecylammonium Chloride

DDA: Dodecylamine

DMS: $\quad$ Dense Medium Separation

DPB: Dodecylpyridinium bromide

EG: $\quad$ Ethylene Glycol

FTIR: $\quad$ Fourier Transform Infrared Spectroscopy

HDTMA: Hexadecyltrimethylammonium

HDPC: Hexadecylpyridium chloride

ICP: $\quad$ Inductively Coupled Plasma

I/S: Illite-smectite

K1: $\quad$ Venetia K1 Tuffisitic Kimberlite Breccia East

P: $\quad$ Pyridine

PSD: $\quad$ Particles Size Distribution

TGA: Thermogravimetric Analysis

VR: $\quad$ Venetia Red

VUE: Venetia underground expansion project

XRF: $\quad$ X-Ray Fluorescence

XRD: $\quad$ X-Ray Diffraction

\section{LIST OF APPENDIXES}

APPENDIX A: XRD analysis results for the Finsch, the Koffiefontein and the Venetia K1 ores

APPENDIX B: Correlation between smectite content and TGA analysis results

APPENDIX C: XRD results for oxalic acid treatment that had $\mathrm{Na}^{+}$pretreatment and with no d-spacing detection on the Koffiefontein ore

APPENDIX D: Standard weathering tests particle size distribution data for the Finsch ore

APPENDIX E: XRD analysis results of agitation tests for pre-cation treatment prior to oxalic acid treatment for the Venetia K1 ore

APPENDIX F: XRD analysis results of alteration tests for the VUE ore 


\section{BACKGROUND}

\subsection{Project definition}

Kimberlite is one of the primary sources of diamonds and is processed for diamonds all over the world. Kimberlite can vary to a large extent in mineralogical properties. Kimberlite forms due to high temperature and pressure and the rapid cooling causes a heterogeneous nature in this rock. Weathering (alteration) over the years by exposure to chemical and physical agents has contributed to the complexity observed in kimberlite due to the formation of various altered products, including clay minerals. This study investigates the weathering of kimberlite, but the focus is rather on the physical breakdown of the kimberlite material over short periods of time. The clay species and the physical breakdown of kimberlite into very fine particles can result in challenges in the processing of this material. The results of weathering can affect crushing, scrubbing, screening, dewatering as well as dense medium separation. Crushers become less effective due to clogging by the moist sticky ore, while the DMS circuit may run the risk of fines contamination. Fine particles increase the medium viscosity and thereby reduce the separation efficiency as well as the recovery of diamonds in DMS (Wills, 1997). The dewatering stage is rendered inefficient by the very fine particle suspension that does not agglomerate easily causing difficulties in settling, dewatering and disposal of fine material.

The De Beers Group is one of the leading producers of diamonds in the world and has extensively been involved in research on this topic. The interest is firstly to improve the current best practice in plant operations and secondly, to investigate the option of utilising accelerated weathering as a processing option for recovering diamonds. Diamond ores are mined at extremely low grades with the diamond content varying between 0.03 and 0.15 parts per million (ppm) (Wills, 1997). Maximizing the recovery is therefore crucial for an economically viable process. Diamond breakage in crushers is common and results in extensive value losses. Accelerated weathering with chemicals would not only reduce diamond breakage but would also drastically reduce the energy consumption. The weathering could also be utilised as a pretreatment stage to the roll crushers to soften the rock prior to comminution. 
Previous studies on accelerated weathering of kimberlite have been performed utilising cationic salts, i.e. inorganic solutions (Boshoff et al., 2007; Morkel, 2006; Morkel et al., 2007; Morkel \& Pieters, 2007). The results showed that swelling clay minerals, especially the smectite species, exchange cations and this accelerated the breakdown of the material. Internal pressures generated during swelling decreases the bulk strength of the rock, causing the breakdown of the material. Swelling clay minerals can also adsorb organic species (Grim, 1968) and this current study investigated the effect of organic species on the weathering of kimberlite in comparison with the previous work on cationic salts.

\subsection{Problem statement}

It has been shown by many authors such as Grim (1968), Weiss (1989) and Chin (1991) that organic molecules can be adsorbed onto clay surfaces, which in turn influence the clay interlayer spacing. Clays with the ability to swell, such as smectites and vermiculite, have shown the highest degree of adsorption of organic species (Gates, 2004; Tahani et al., 1999). If kimberlite contains swelling clays, the expansion pressure exerted upon swelling can cause the kimberlite to weather (disintegrate). The project aims to prove that kimberlites containing swelling clay minerals (smectites and vermiculites) can be weathered to an accelerated extent utilising organic solutions.

\section{LITERATURE STUDY}

\subsection{Kimberlites}

Kimberlite is one of the principal sources of diamonds together with alluvial gravel, marine gravel and lamproites (ultrapotassic mantle-derived volcanic rocks with low $\mathrm{CaO}$, $\mathrm{Al}_{2} \mathrm{O}_{3}, \mathrm{Na}_{2} \mathrm{O}$, high $\mathrm{MgO}$ and high $\mathrm{K}_{2} \mathrm{O} / \mathrm{Al}_{2} \mathrm{O}_{3}$ ratio). Mineralogical properties of kimberlite vary to a large extent from one area to another. Both kimberlite and lamproite deposits can display properties of being "weathered and claggy" as compared to alluvial. Alluvial deposits range from simple free flowing alluvial gravels but can also occur as conglomerates, or sticky ores with different levels of clay and laterite (Hart, 2003). 
Kimberlites are defined as complex hybrid volcanic rocks that fall into potassic ultrabasic (containing high proportions of oxides of $\mathrm{Fe}, \mathrm{Mg}$ and $\mathrm{Ca}$ to silica) rocks with diverse minerals constituting the matrix. Some of the minerals in kimberlites are carbonates, garnet, olivine, phlogopite, pyroxene, serpentine and upper mantle rock. The complexity of kimberlite comes about as a result of being made up of phases not only crystallizing from liquid magma but also crystalline fragments or single crystals from various xenoliths (fragments of foreign rocks) (Benvie, 2007). The visual description of kimberlites is that they appear in various colours ranging from green to greenish-grey to bluish-black to bluish-green, or may appear with a faint purple colour. To some extent, the various shades can be attributed to certain alteration products.

Origins of kimberlites are from vertical explosions of very hot material (magma) from the mantle-lithospheric boundary $(\sim 150 \mathrm{~km}$ below the earth's surface). These explosions brought with them a mixture of magma, minerals, rock fragments, and occasionally diamonds, hence kimberlites being referred to as "vehicles which brought diamonds to the earth's surface". This process resulted in the formation of pipes shaped like champagne flute glasses, as they approached the earth's surface. Figure 1 is a schematic illustration of a kimberlite pipe (diatreme). Kimberlites may also appear as dykes and sills (Field et al., 2008).

Figure 2 shows the diamond mines in Southern Africa of kimberlite hosted deposits. Gerryts (1951) gave a description of the typical geology, petrography and appearance of various types of kimberlites found in South Africa. 


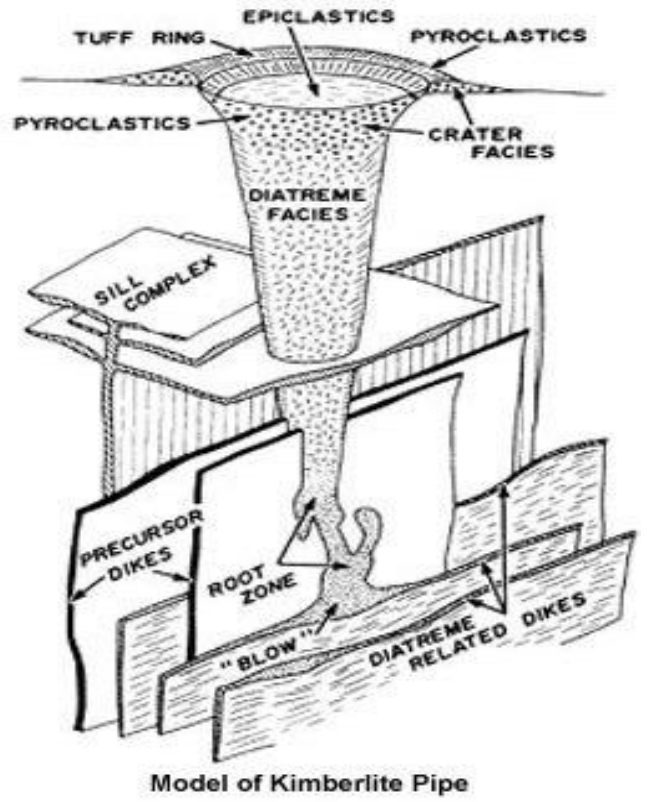

Figure 1: A model illustrating the kimberlite pipe (Mitchell, 1986).

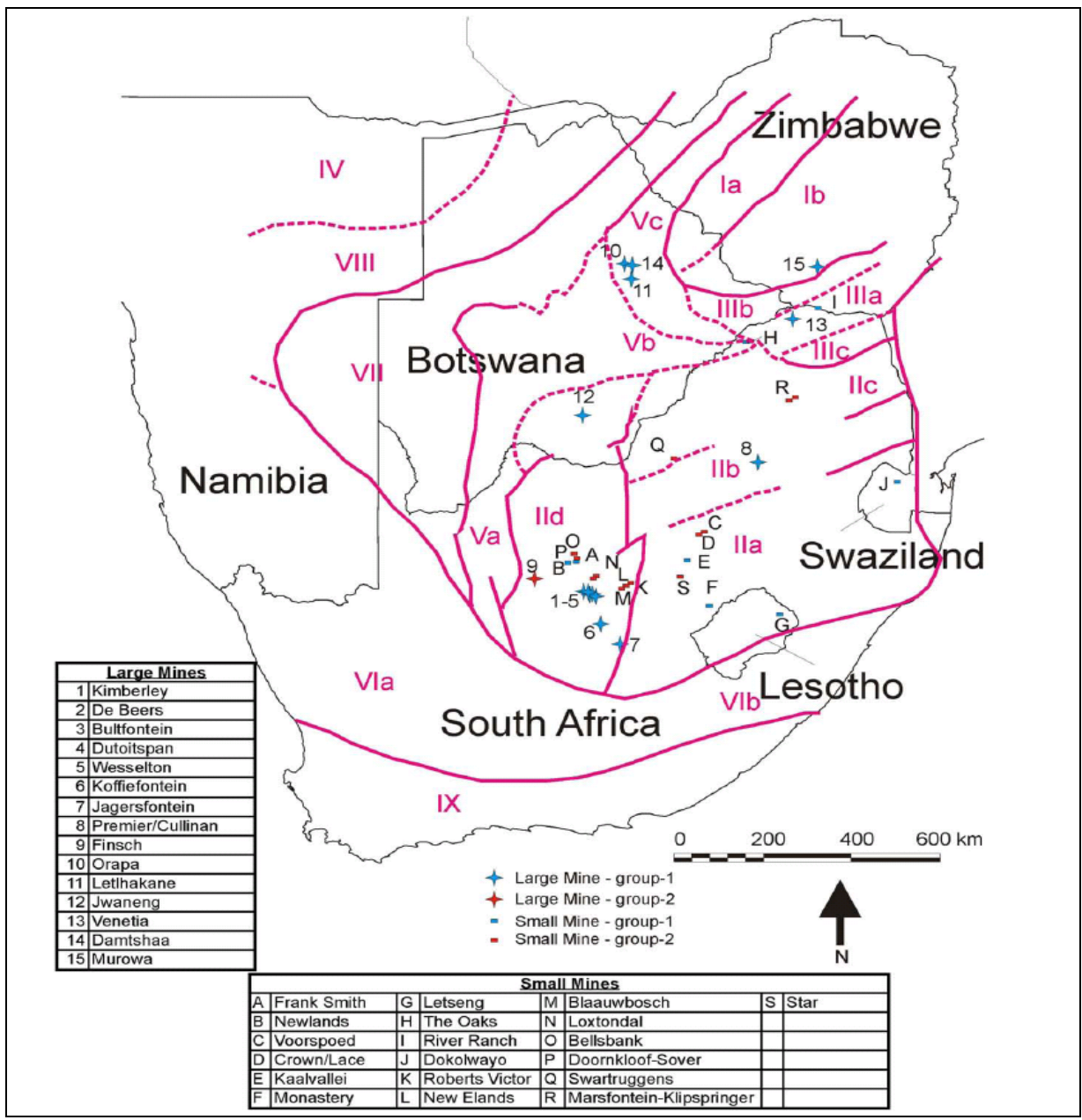

Figure 2: Map showing the location of kimberlite-hosted diamond mines in Southern Africa subdivided into structural units (Field et al., 2008). 


\subsubsection{Kimberlite mining}

There are four main kimberlite mining methods, namely conventional open pit, mechanized underground (also known as hard-rock mining), placer and off-shore mining.

\section{- Open pit}

Open pit or open cast mining is a method whereby minerals are extracted from the earth by mining an open pit or burrow. Open pit excavation is utilised when the material covering the deposit (overburden) is relatively thin and/or the minerals are imbedded in a structurally unstable earth not suitable for tunneling. Kimberlites are extracted utilising this method if the deposit is close to the earth's surface.

\section{- Underground mining}

Underground mining refers to the various techniques utilised in mining ore bodies through tunneling and creating underground rooms or stopes supported by timber pillars of standing rocks. Accessing the ore body is normally performed by a shaft (vertical tunnel which runs adjacent to the ore) or a decline. Almost all of the kimberlite mining in South Africa is conducted through this method and most mines are owned and operated by De Beers Consolidated Mines (Janse \& Sheahan, 1995).

\section{- Placer}

Placer kimberlite mining, also known as sand bank mining is known for extracting minerals from alluvial secondary deposits. It is a form of open cast mining utilised to extract minerals from the earth's surface without tunneling. Excavation is done by utilising water pressure (hydraulic mining), mechanised surface excavating equipment or digging by hand (artisanal mining).

\section{- Off-shore}

Off-shore mining or marine mining is quite a recent commercially accepted mining method. Marine ore sources are secondary diamond deposits that are derived from weathering of the principal hosts being kimberlite and lamproite. The technique employs 
both vertical and horizontal methods to extract diamonds from off-shore deposits. The De Beers Group is processing diamonds on the coastline of Namibia and Cape Town utilising this technique.

\subsubsection{Kimberlite processing}

A generalised flowsheet of a diamond processing plant is shown in Figure 3. The process starts with the run-of-mine ore being crushed in two or three stages followed by scrubbing stage to wash off fine particles $(<1 \mathrm{~mm})$ which are removed through screening. The fine material is thickened and dumped as tailings whilst the water is recovered and recycled. The washed ore is screened into various size fractions which are sent for further treatment in the DMS circuit. The primary concentration utilises DMS whilst final concentration usually employs grease tables followed by X-Ray sorting. The waste from fines processing is dumped as tailings whereas that from the coarse stream is sent for re-crushing to ensure that smaller diamonds are liberated before discarding the gangue material.

Kimberlite weathering poses several problems during plant processing. On the mining side, the effects include sudden collapse of tunnels due to the decrease in bulk strength of the rock. This obviously endangers the machinery and more so the personnel operating underground. On the processing side, the efficiency of the crushing stage is greatly reduced due to clogging of the crusher surface by the sticky clayey ore. The power consumption of liberation is significantly increased and damaging of diamonds is a greater risk. Fines produced during weathering significantly influence operation of the DMS and specifically alter the viscosity of the DMS and the medium. According to Wills (1997), coarser mineral particles (larger than $3 \mathrm{~mm}$ ) are more easily separated by DMS, even at a specific gravity difference of 0.1 or less. Therefore fine particles tend to reduce the efficiency of DMS by increasing the medium viscosity. 


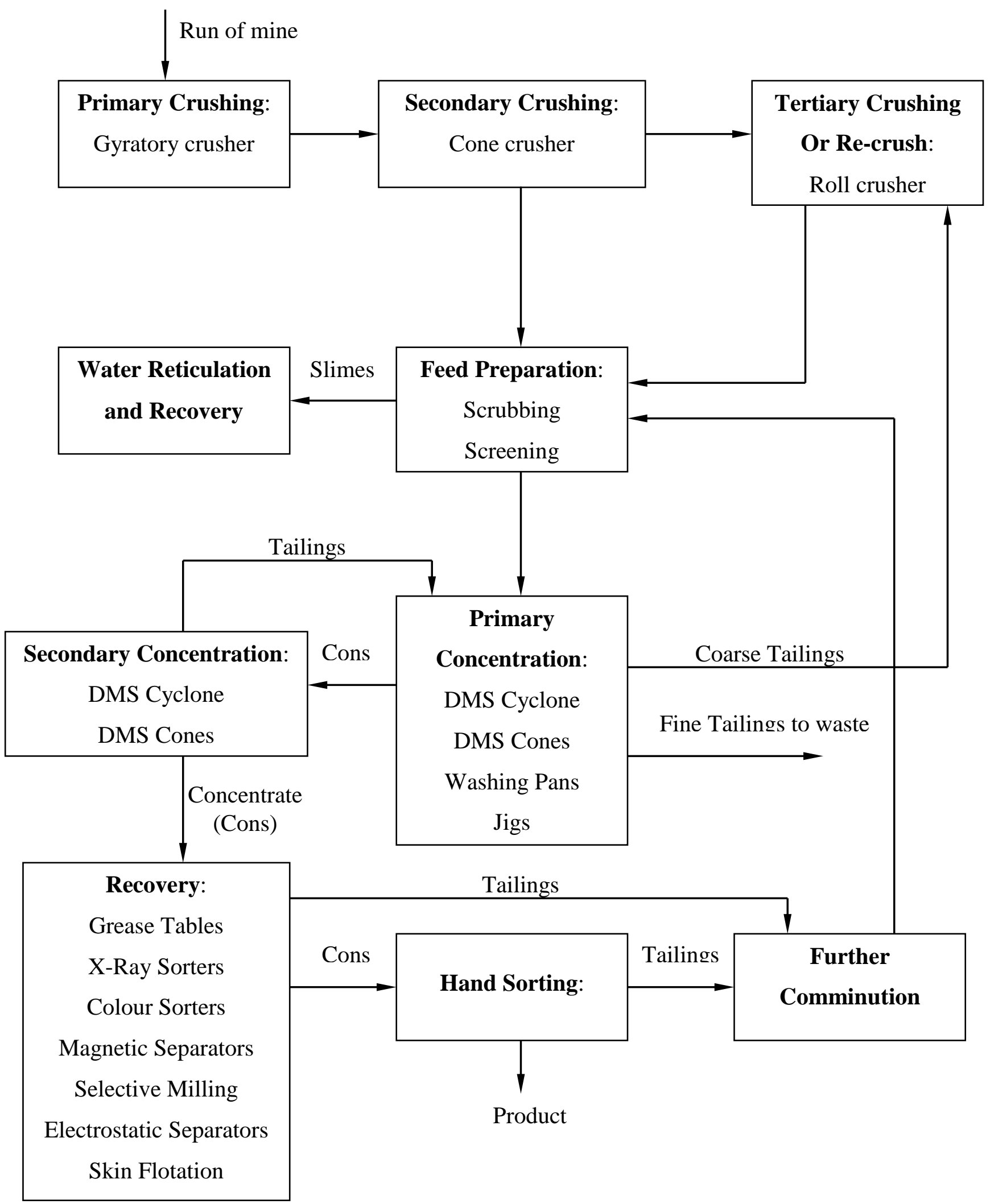

Figure 3: Schematic illustration of a diamond processing plan (Hodgson, 1981). 


\subsubsection{Kimberlite petrography}

Kimberlites are described as inequigranular textures consisting of crystal and mantle derived xenoliths (fragments of foreign rocks) and xenocrysts (single mineral derived from disintegration of xenoliths) (Benvie, 2007). The macrocrysts are generally round in shape and can be up to $15 \mathrm{~cm}$ in size, even though $0.5-3 \mathrm{~cm}$ is a more common size. The macrocrysts are also described as anhedral, ferromagnesian, typical mantle derived minerals namely olivine, phlogopite, chromian spinel clinopyroxene (commonly chromian diopside), orthopyroxene (commonly enstatite), magnesian garnet, pricoilmenite and diamond (a very rare constituent). These macrocrysts are imbedded in a fine-grained matrix (groundmass) of second generation primary olivine and/or phlogopite as well as serpentine, perovskite, calcite, chlorite and dolomite (carbonates) and spinels. The weathering process such as carbonation and serpentisation often alter the early formed groundmass minerals. This causes the replacement of primary olivine, phlogopite, monticellite and apatite by serpentine, calcite and chlorite as shown in Figure 4. A highly weathered kimberlite can be dominated by clay minerals such as calcite, serpentine, chlorite, smectite and magnetite (Dawson, 1980).

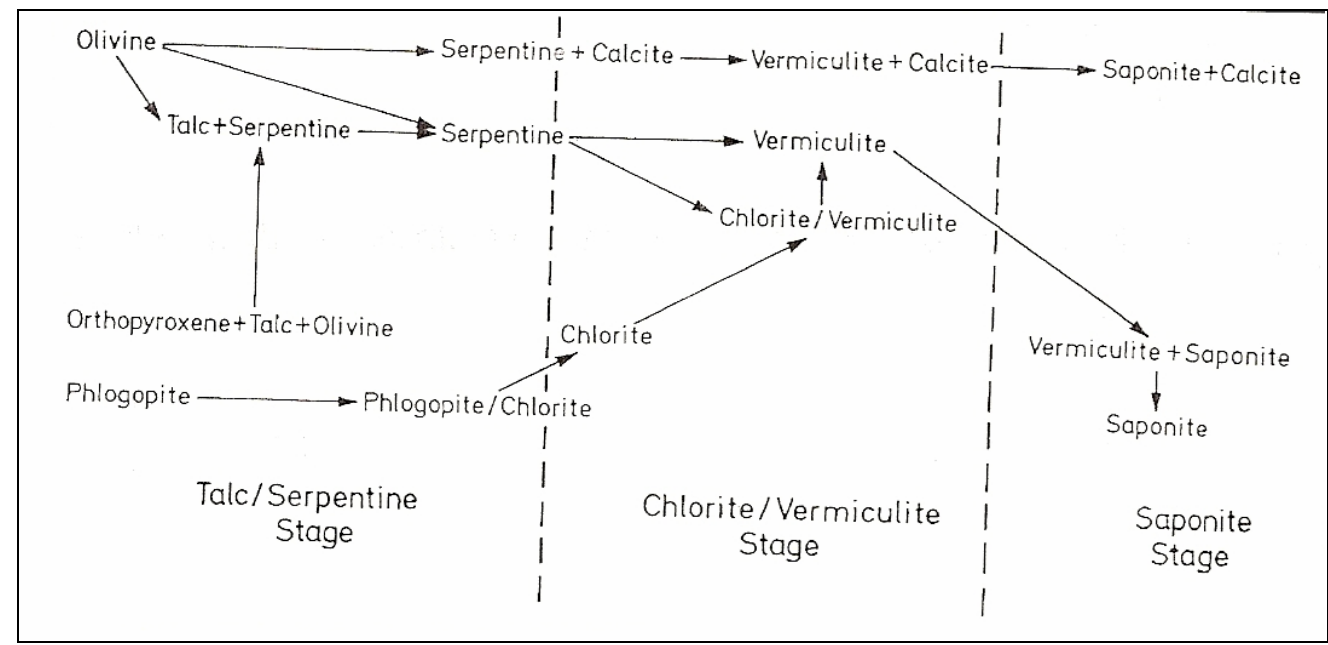

Figure 4: The different stages of olivine, pyroxene and mica alteration (Dawson, 1980).

Many textural classification models have been developed for Southern African kimberlites. Authors such as Field et al. (2008) have given an overview describing the texture and mineralogy of Southern African kimberlites. A well known and generally accepted classification was done by Clement and Skinner (1985), which is based on macroscopic textural features and is related to the different kimberlite near-surface 
emplacement and pipe forming processes. Figure 5 shows the classification with facies that branches into rock types and further into textural differences. A facies is the characteristics of a rock body or part of a rock body that differentiate it from others for instance in appearance and composition.

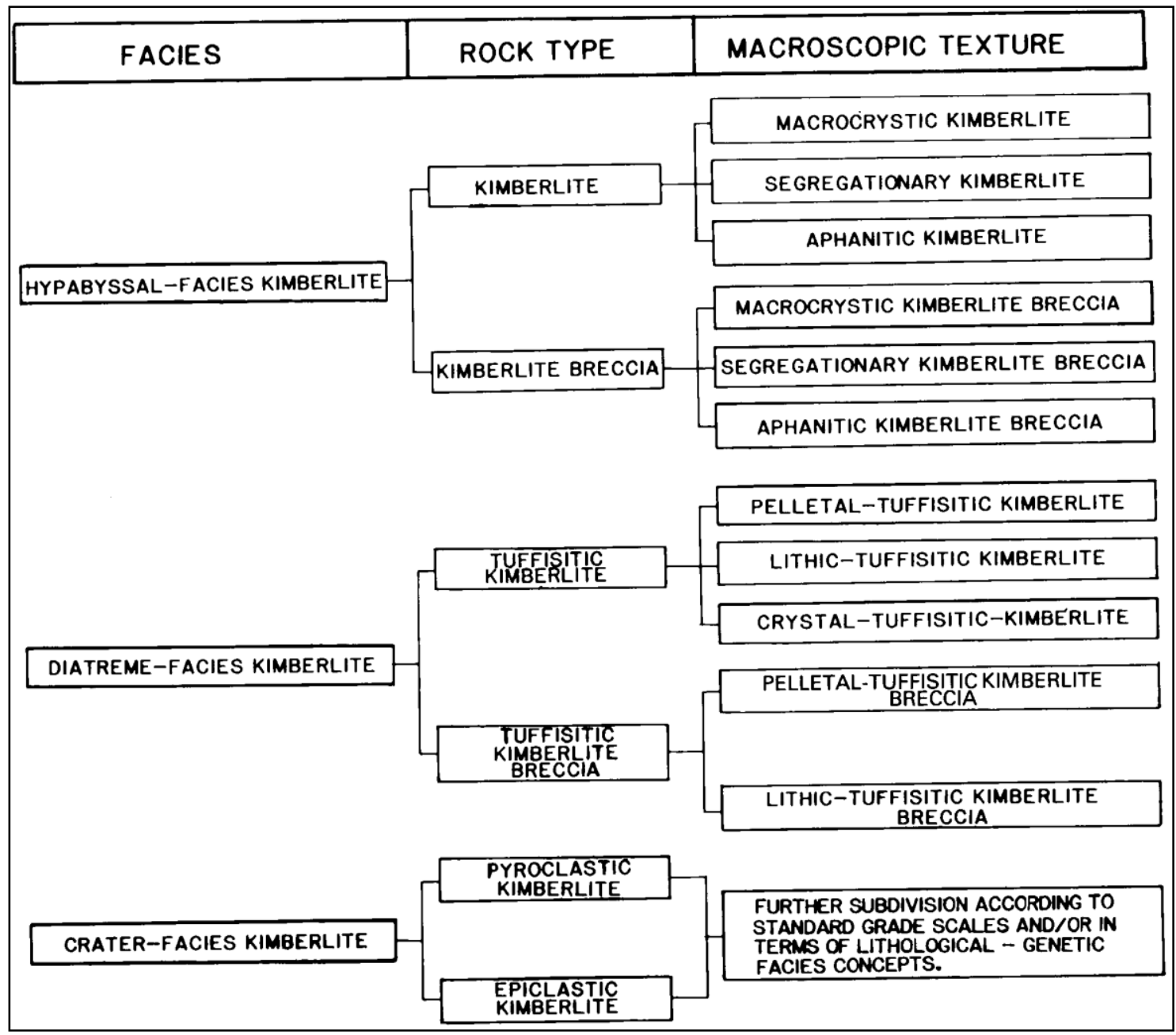

Figure 5: A textural-genetic classification of kimberlites (Clement \& Skinner, 1985).

Notable features in the classifications shown in Figure 5 include; the crater facies kimberlite that is recognized by sedimentary features; the diatreme facies that is recognized by pelletal lapilli (discrete, smooth, spherical-elliptical fragments of primary igneous material) and other features formed during degassing; and the hypabyssal facies which is commonly recognized by segregationary textures and the presence of abundant calcite. The division between breccia and non-breccia terms (column two - Rock Type) in Figure 5 is based on the volume percent of macroscopically visible fragments. A rock with greater than $15 \%$ by volume of visible fragments is termed breccia. Further 
sub-division on macroscopic textures, are discussed in detail by Clement and Skinner (1985).

\subsubsection{Kimberlite geochemistry}

Kimberlites that contain a high proportion of cafemic (Ca-, Fe-, and $\mathrm{Mg}$-rich) oxides to silica are ultrabasic rocks with low $\mathrm{Mg} / \mathrm{Fe}$ and very high $\mathrm{K} / \mathrm{Na}$ and $\mathrm{Fe}^{3+} / \mathrm{Fe}^{2+}$ ratios. Micaceous kimberlites are ultrapotassic containing excessive amounts of $\mathrm{K}_{2} \mathrm{O}, \mathrm{Al}_{2} \mathrm{O}_{3}$, $\mathrm{TiO}_{2}, \mathrm{FeO}, \mathrm{CaO}, \mathrm{CO}_{2}, \mathrm{P}_{2} \mathrm{O}_{5}$ and $\mathrm{H}_{2} \mathrm{O}$ as major elements. Table 1 shows the chemical composition for an average kimberlite sample and that of a micaceous kimberlite. Kimberlites also contain trace elements such as $\mathrm{Sc}, \mathrm{V}, \mathrm{Cr}, \mathrm{Co}, \mathrm{Ni}, \mathrm{Cu}, \mathrm{Zn}, \mathrm{Cl}, \mathrm{B}, \mathrm{Mo}, \mathrm{Pt}$, and $\mathrm{Cd}$. Rare-earth elements are present in apatite and perovskite, and lesser quantities are present in garnet, diopside and phlogopite.

Isotope activity has also been reported in kimberlites (Glover \& Groves, 1981). Hydrogen and Oxygen isotopes may also be present due to water fixation in serpentine and phlogopite. In addition, there may also be carbon, strontium $\left({ }^{86} \mathrm{Sr}\right.$ and $\left.{ }^{87} \mathrm{Sr}\right)$ and Lead $\left({ }^{204} \mathrm{~Pb},{ }^{206} \mathrm{~Pb}\right.$ and $\left.{ }^{207} \mathrm{~Pb}\right)$ isotope activities. Kimberlites have high $\mathrm{U}$ and $\mathrm{Th}$ but the ratios of $\mathrm{Th} / \mathrm{U}$ are very different from the crystal values of 3.7 (Glover \& Groves, 1981).

Table 1: The general composition of an average kimberlite compared to a micaceous kimberlite (Dawson, 1980).

\begin{tabular}{|c|c|c|}
\hline Phase & Average & Micaceous \\
\hline $\mathrm{SiO}_{2}$ & 35.2 & 31.1 \\
\hline $\mathrm{TiO}_{2}$ & 2.32 & 2.03 \\
\hline $\mathrm{Al}_{2} \mathrm{O}_{3}$ & 4.4 & 4.9 \\
\hline $\mathrm{Fe}_{2} \mathrm{O}_{3}$ & - & - \\
\hline $\mathrm{FeO}$ & 9.8 & 10.5 \\
\hline $\mathrm{MnO}$ & 0.11 & 0.10 \\
\hline $\mathrm{MgO}$ & 27.9 & 23.9 \\
\hline $\mathrm{CaO}$ & 7.6 & 10.6 \\
\hline $\mathrm{Na}_{2} \mathrm{O}$ & 0.32 & 0.31 \\
\hline $\mathrm{K}_{2} \mathrm{O}$ & 0.98 & 2.1 \\
\hline $\mathrm{H}_{2} \mathrm{O}^{+}$ & 7.4 & 5.9 \\
\hline $\mathrm{CO}_{2}$ & 3.3 & 7.1 \\
\hline $\mathrm{P}_{2} \mathrm{O}_{5}$ & 0.7 & 0.7 \\
\hline
\end{tabular}




\subsubsection{Kimberlite mineralogy}

Kimberlites are present in original form as well as altered rocks. This makes their mineralogical description more complex. Kimberlite mineralogy varies from country to country due to varying emplacements and climate conditions. Three types of host rocks have been identified namely massive, brecciated and tuffisitic. Each type of host rock is further divided into basaltic variety in which olivine is the dominant phenocryst (macrocrystals) or a micaceous variety with mica forming more than $5 \%$ of the phenocrysts (Glover \& Groves, 1981). Table 2 shows a summary of phases found in kimberlite. For a full description of these phases the reader is referred to Morkel (2006).

Some other elements found in South African kimberlites include platinum group minerals, graphite and diamond (an isometric polymorph of carbon). Sulphide minerals that have been identified include pentlandite, pyrhottite (common inclusion in diamonds), chalcopyrite and pyrite (associated with secondary minerals such as serpentine) whilst one of the sulphates that has been identified is gypsum. Spinel group phases, magnesian ilmenite, perovskite, iron hydroxides and quartz are examples of oxides and hydroxides present in kimberlite. Calcite, magnesian calcite, siderite and dolomite are common carbonate varieties in kimberlites with apatite and monazite as two main phosphates.

The mineral content of kimberlites has led to its classification according to mineralogy. Classification of kimberlites was originally based on (1) basaltic, poor in mica variety and (2) micaceous or lamprophyric due to the dominance of phlogopite (Gerryts, 1951). Later a proposition was made to divide them based on some of the five dominant matrix mineral for example serpentine giving "serpentine kimberlite" or monticellite giving "monticellite kimberlite" and so forth (Dawson, 1980). The former classification became more widely accepted based on two distinct varieties according to geochemistry, namely Group-1 (G1) which are basaltic and Group-2 (G2) which are micaceous kimberlites. G1 kimberlites contain $\mathrm{Sr}-\mathrm{Nb}$ isotopes which are slightly depleted whilst $\mathrm{G} 2 \mathrm{~s}$ are significantly enriched relative to the bulk of the earth. G1s contain also radiogenic $\mathrm{Pb}$ whereas G2 have non-radiogenic $\mathrm{Pb}$. G1 and G2 differ in their suit of mantle xenoliths and xenocrysts. 
Table 2: A summary of the Kimberlite mineral phases (Morkel, 2006).

\begin{tabular}{|c|c|c|c|c|}
\hline Mineral Name & $\begin{array}{l}\text { Specific } \\
\text { Gravity }\end{array}$ & Hardness & Chemical Structure & Appearance \\
\hline Apatite & $3.15-3.2$ & 5.0 & $\mathrm{Ca}_{5}\left(\mathrm{PO}_{4}\right)_{3}(\mathrm{~F}, \mathrm{Cl}, \mathrm{OH})$ & - \\
\hline Calcite & 2.17 & 3.0 & $\mathrm{CaCO}_{3}$ & - \\
\hline Chlorite & $2.6-3.3$ & $2.0-2.5$ & $\begin{array}{l}(\mathrm{Mg}, \mathrm{Fe})_{3}(\mathrm{Si}, \mathrm{Al})_{4} \mathrm{O}_{10} \\
(\mathrm{OH})_{10} \cdot(\mathrm{Mg}, \mathrm{Fe})_{3}(\mathrm{OH})_{6}\end{array}$ & Green colour \\
\hline Diopside & 3.2 & $5.0-6.0$ & $\mathrm{CaMgSi}_{2} \mathrm{O}_{6}$ & $\begin{array}{l}\text { White to light } \\
\text { green } \\
\text { pyroxene }\end{array}$ \\
\hline Dolomite & 2.85 & $3.5-4$ & $\mathrm{CaMg}\left(\mathrm{CO}_{3}\right)_{2}$ & - \\
\hline Halloysite & $2.0-2.2$ & $1.0-2.0$ & $\mathrm{Al}_{2} \mathrm{Si}_{2} \mathrm{O}_{5}(\mathrm{OH})_{4} \cdot 2 \mathrm{H}_{2} \mathrm{O}$ & \\
\hline Ilmenite & 4.7 & $5.5-6.0$ & $\mathrm{FeTiO}_{3}$ & - \\
\hline Kaolinite & 2.6 & 2.0 & $\mathrm{Al}_{2} \mathrm{Si}_{2} \mathrm{O}_{5}(\mathrm{OH})_{4}$ & - \\
\hline Magnetite & 5.18 & 6.0 & $\mathrm{Fe}_{3} \mathrm{O}_{4}$ & Spinel group \\
\hline Monticellite & 3.2 & 5.0 & $\mathrm{CaMgSiO}_{4}$ & $\begin{array}{l}\text { Rare olivine } \\
\text { alteration } \\
\text { product }\end{array}$ \\
\hline Montmorillonite & 2.5 & $1.0-1.5$ & $\begin{array}{l}(\mathrm{Al}, \mathrm{Mg})_{8}\left(\mathrm{Si}_{4} \mathrm{O}_{10}\right)_{4} \\
(\mathrm{OH})_{8} \cdot 12 \mathrm{H}_{2} \mathrm{O}\end{array}$ & $\begin{array}{l}\text { Al-rich } \\
\text { Smectite }\end{array}$ \\
\hline Olivine & $3.27-4.37$ & $6.5-7.0$ & $(\mathrm{Mg}, \mathrm{Fe})_{2} \mathrm{SiO}_{4}$ & $\begin{array}{l}\text { Green } \\
\text { groundmass } \\
\text { material }\end{array}$ \\
\hline Perovskite & 4.03 & 5.5 & $\mathrm{CaTiO}_{3}$ & - \\
\hline Phlogopite & 2.86 & $2.5-3.0$ & $\mathrm{KMg}_{3}\left(\mathrm{AlSi}_{3} \mathrm{O}_{10}\right)(\mathrm{OH})_{2}$ & $\begin{array}{l}\text { Yellow-brown } \\
\text { mica }\end{array}$ \\
\hline Pyrope & 3.58 & 7.0 & $\mathrm{Mg}_{3} \mathrm{Al}_{2} \mathrm{Si}_{3} \mathrm{O}_{12}$ & Garnet \\
\hline Rutile & $4.18-4.25$ & $6.0-6.5$ & $\mathrm{TiO}_{2}$ & $\begin{array}{l}\text { Reddish } \\
\text { brown }\end{array}$ \\
\hline Serpentine & 2.3 & $3.0-5.0$ & $\mathrm{Mg}_{3} \mathrm{Si}_{2} \mathrm{O}_{5}(\mathrm{OH})_{4}$ & $\begin{array}{ll}\text { Green } \\
\text { yellow }\end{array}$ \\
\hline Spinel & $3.5-4.1$ & 8.0 & $\mathrm{MgAl}_{2} \mathrm{O}_{4}$ & - \\
\hline Talc & $2.7-2.8$ & 1.0 & $\mathrm{Mg}_{3} \mathrm{Si}_{4} \mathrm{O}_{10}(\mathrm{OH})_{2}$ & - \\
\hline Vermiculite & 2.4 & 1.5 & $\begin{array}{l}(\mathrm{Mg}, \mathrm{Ca})_{0.3}(\mathrm{Mg}, \mathrm{Fe}, \mathrm{Al})_{3.0} \\
(\mathrm{Al}, \mathrm{Si})_{4} \mathrm{O}_{10}(\mathrm{OH})_{4} 8 \cdot \mathrm{H}_{2} \mathrm{O}\end{array}$ & $\begin{array}{l}\text { Altered } \\
\text { (biotite) mica }\end{array}$ \\
\hline
\end{tabular}

Kimberlite basically consists of various silicate minerals. Typical silicates contained are nesosilicates (olivine group, garnet, humite group and spurrite-afwillite group), sorosilicates (melilite group, epidote group and prehnite), inosilicates (pyroxene and amphiboles), tektosilicates and phyllosilicates. Alteration of primary kimberlite minerals results in the formation of clay minerals, which are part of the phyllosilicate group. The most important minerals found in kimberlite which are olivine, apatite, calcite, serpentine and clay minerals which are briefly discussed below. 


\subsubsection{Olivine}

Olivine $\left((\mathrm{Mg}, \mathrm{Fe})_{2} \mathrm{SiO}_{4}\right)$ is mentioned by Mitchell (1986) as the most common mineral in kimberlite. It occurs as large $(>1 \mathrm{~cm})$ round megacrysts, groundmass $(<0.5 \mathrm{~cm})$ and round macrocrysts $(0.5-1 \mathrm{~cm})$. The alteration of olivine results in the formation of various types of serpentine that may also be replaced by other phases such as calcite, phologopite or magnetite.

\subsubsection{Apatite}

Apatite $\left(\mathrm{Ca}_{5}\left(\mathrm{PO}_{4}\right)_{3}(\mathrm{~F}, \mathrm{Cl}, \mathrm{OH})\right)$, a phosphate mineral (Klein, 2002), constitutes the groundmass with less than $0.01 \mathrm{~mm}$ grains. Kimberlites rich in carbonates or calcite often contain apatite, although it is often replaced by calcite.

\subsubsection{Calcite}

Calcite $\left(\mathrm{CaCO}_{3}\right)$ is usually present at very low quantities but can be in calcite rich kimberlite phase representing more than $50 \%$ ). It is the most common carbonate in kimberlite. Other carbonates such as strontianite $\left(\mathrm{SrCO}_{3}\right)$ may also be present in very small quantities.

\subsubsection{Clay minerals}

Clay minerals are hydrous aluminum silicates also known as phyllosilicates. Phyllosilicates in kimberlites consist of various types of silicate minerals present as high-temperature phases such as mica (biotite and phlogopite) or late-stage minerals formed within kimberlite groundmass. Some of the phyllosilicates that have been identified, in addition to mica, are smectites, vermiculites and chlorites. The type and amount of clay minerals vary in different intrusions due to differing formation and weathering processes. Table 3 gives the main groups of clay minerals in kimberlite and the subspecies. A description of typical kimberlite clay minerals is provided in Table 3. 
Table 3: Groups of main clay minerals in kimberlite and the species under each group.

\begin{tabular}{|l|l|}
\hline \multicolumn{1}{|c|}{$\begin{array}{c}\text { Clay mineral } \\
\text { group }\end{array}$} & \multicolumn{1}{c|}{ Sub-group minerals } \\
\hline Serpentine & Lizardite, Amesite, Antigorite, Berthierine, Chrysotile \\
\hline Mica & Phlogopite, Biotite, Muscovite and Hydrophlogopite \\
\hline Chlorites & - \\
\hline Smectites & $\begin{array}{l}\text { Montmorillonite, Hectorite, Beidellite, Nontronite, Sauconite, and } \\
\text { Saponite }\end{array}$ \\
\hline Vermiculite & - \\
\hline
\end{tabular}

\section{(i) Serpentine}

Serpentine minerals usually have larger particle sizes than the typical clay minerals. The serpentine group $\left(\left(\mathrm{Mg}_{3} \mathrm{Si}_{2} \mathrm{O}_{5}(\mathrm{OH})_{4}\right)\right.$ is essentially a tri-octahedral sheet silicate. The common identified serpentine minerals are lizardite and amesite (platy material), antigorite, berthierine (iron-rich) and chrysotile (small fibers in massive or splintery material) mostly referred to as just serpentine. Lizardite and antigorite have a layered structure while chrysotile is fibrous. Serpentine, a product of olivine alteration, can be replaced by various combinations of calcite, dolomite, talc, phlogopite and perovskite.

\section{(ii) Mica}

Mica is a hard layered phyllosilicate. These silicates fall under the sheet silicate group with a perfect lamellar cleavage (Deer et al., 1966). It was mentioned by Deer et al. (1966) that micas have an ideal electrical charge of -1 per formula unit. Common mica minerals include phlogopite, biotite, and muscovite, with hydrophlogopite being a notable constituent as well. These different mica minerals are discussed in more detail.

\section{- Phlogopites}

Phlogopite $\mathrm{KMg}_{3}\left(\mathrm{AlSi}_{3} \mathrm{O}_{10}\right)(\mathrm{F}, \mathrm{OH})_{2}$, is a silvery bronze mineral, normally occurring in micaceous kimberlite up to $50 \mathrm{vol}$ \% (Mitchell, 1986) as macrocrysts or as a constituent of the groundmass, but is usually absent in olivine- or serpentine-rich kimberlites. The groundmass micas vary from intrusion to intrusion but usually contain inclusions of 
perovskite and magnetite. They are classified into type I (iron-rich) and type II (magnesian-rich, low in $\mathrm{TiO}_{2}$ and $\mathrm{Al}_{2} \mathrm{O}_{3}$ and significant $\mathrm{Fe}^{3+}$ in tetrahedral sites). Phlogopite crystals are between $5 \mathrm{~mm}$ and $10 \mathrm{~cm}$ in diameter and are often replaced by calcite, chlorite and serpentine especially along cleavage planes. The fine fraction $(-5 \mathrm{~mm})$ is what defines the mica fraction of phlogopite. Weathering of phlogopite produces 'clay mica' analogous to illite produced from muscovite and further weathering of 'clay biotites' converts them to vermiculites (Deer et al., 1966).

\section{- Biotites}

Biotite is an iron-rich, hydrated ferromagnesian silicate with chemical formula $\mathrm{K}(\mathrm{Mg}, \mathrm{Fe})_{3}\left(\mathrm{AlSi}_{3}\right) \mathrm{O}_{10}(\mathrm{~F}, \mathrm{OH})_{2}$. In kimberlite it appears as cores in phlogopite groundmass containing 17-21\% $\mathrm{FeO}$ (Mitchell, 1986). Biotite is replaced by vermiculite in the alteration sequence.

\section{- Muscovites}

Muscovite $\left(\mathrm{KAl}_{2}\left(\mathrm{AlSi}_{3} \mathrm{O}_{10}\right)(\mathrm{F}, \mathrm{OH})_{2}\right)$ and phlogopite are relatively transparent micas and contain relatively low iron content. The principal isomorphous replacements that occur in muscovite take place by $\mathrm{K}^{+}$for either the elements $\mathrm{Na}^{+}, \mathrm{Rb}^{+}, \mathrm{Cs}^{+}, \mathrm{Ca}^{2+}$ or $\mathrm{Ba}^{2+}$. In the octahedral sites the typical replacement takes place by $\mathrm{Al}^{3+}$ for either the elements $\mathrm{Mg}^{2+}$, $\mathrm{Fe}^{2+}, \mathrm{Fe}^{3+}, \mathrm{Mn}^{2+}, \mathrm{Li}^{+}, \mathrm{Cr}^{3+}, \mathrm{Ti}^{2+}$ or $\mathrm{V}^{2+}$ while $\mathrm{OH}^{-}$replaced for $\mathrm{Fe}^{2+}$ (Deer et al., 1966). The colour of muscovite ranges from pink (in rose-muscovite) to pale green to brown.

\section{- Hydrophlogopites}

Hydrophlogopite is an interstratified, intermediate phase occurring on edges during the vermiculitisation process of phlogopite. It is a mixed layer phlogopite/vermiculite (1:1 mix) clay phase, regularly ordered, and analogous to hydrobiotite.

\section{(iii) Chlorites}

Chlorites are characterised as sheet silicates having the structural formula: $(\mathrm{Fe}, \mathrm{Mg}, \mathrm{Al})_{6}(\mathrm{Si}, \mathrm{Al})_{4} \mathrm{O}_{10}(\mathrm{OH})_{8}$. In kimberlite, chlorite is found in the late stages of alteration as products of serpentinised olivine. Nodules of chlorite are typically $1-4 \mathrm{~cm}$ 
in size and are classified according to the iron content; high, intermediate and low iron chlorites (Mitchell, 1986). The low iron content chlorites are the most dominant in kimberlites. Chlorites can also substitute for phlogopite along cleavage planes to form colourless, to pale green, to bright emerald green chlorites in highly weathered micaceous kimberlites. Primary groundmass chlorites are identified by blue-green platelets of approximately $0.05 \mathrm{~mm}$ in size. They tend to be present in calcite rich samples and very rarely occur in phlogopite and serpentine rich kimberlites (Mitchell, 1986). Chlorite minerals do not undergo hydration or swelling.

\section{(iv) Smectite}

The smectite group is sub-classified into montmorillonite, hectorite, beidellite, nontronite, sauconite, and saponite (Deer et al., 1966). Due to their large specific area $\left(\sim 750 \mathrm{~m}^{2} / \mathrm{g}\right)$ and a high structural charge (up to $1000 \mathrm{meq} / \mathrm{kg}$ ), their presence influences the physico-chemical properties of geological formations (Schlegel et al., 1999). Montmorillonite has received much attention in smectite studies (Gates et al., 2000; Gates, 2004; Kawamura et al., 1999; Madejová et al., 1999; Salles et al., 2007; Tahani et al., 1999; Zemanová et al., 2006). All smectites display the property of expanding and contracting their structure by uptake of water or organic liquids between their structural layers (Deer et al., 1966). Smectites are the last stage product of the alteration process and therefore are common in kimberlite that has experienced a large extent of weathering.

Smectites are layered aluminium hydrosilicates termed bidimensional phyllosilicates. Smectites occur as a 2:1 structure where an octahedral layer formed by $\mathrm{Al}, \mathrm{Mg}$ or Fe-oxide is present in between two tetrahedral layers of $\mathrm{SiO}_{4}{ }^{4-}$. Smectites can either be dioctahedral or trioctahedral, referring to the divalent or trivalent interlayer cation. Isomorphic substitution of cations results in particles having a negative charge on the faces of the layers. In the tetrahedral sites, $\mathrm{Si}^{4+}$ can be replaced by $\mathrm{Al}^{3+}$ to form beidellite smectites and in the octahedral sites $\mathrm{Mg}^{2+}$ can replace $\mathrm{Al}^{3+}$ to form montmorillonite smectite. Excess negative charges are compensated by interlayer cations such as $\mathrm{Na}^{+}, \mathrm{Li}^{+}$, $\mathrm{K}^{+}, \mathrm{Mg}^{2+}, \mathrm{Ca}^{2+}, \mathrm{Ni}^{2+}$ or $\mathrm{Cu}^{2+}$ which diffuse and are adsorbed in between layers in the hexagonal cavities created by shared oxygens and form an electrical double layer 
(M'bodj et al., 2004). The resulting structure is not rigid but is rather flexible to give smectites a characteristic plastic and elastic property.

\section{(v) Vermiculites}

Vermiculites, with chemical structure $(\mathrm{Mg}, \mathrm{Ca})_{0.3}(\mathrm{Mg}, \mathrm{Fe}, \mathrm{Al})_{3.0}(\mathrm{Al}, \mathrm{Si})_{4} \mathrm{O}_{10}(\mathrm{OH})_{4} 8 \cdot \mathrm{H}_{2} \mathrm{O}$, are laminated 2:1 silicates with an expanding structure. Compared to smectite, vermiculites have a more perfect structure due to more uniform distribution of the negative charges produced by heterovalent isomorphism between $\mathrm{Al}^{3+}$ and $\mathrm{Si}^{4+}$ in between the elementary structural layers, creating the negative charge of the layers (Tvardovski et al., 1994). Vermiculites have a layer charge density range between that of smectites and mica. They are the intermediate minerals in the natural alteration sequence of micas to smectites. In kimberlites, vermiculite, together with stevensite, is a product of late stage kimberlite alteration emanating from earlier biotite, phlogopite, chlorite- and serpentine-group phases.

Vermiculites are swelling clays where $\mathrm{Al}^{3+}$ is replaced for $\mathrm{Si}^{4+}$ in the tetrahedral layer (Caballero \& Poncelet, 2000(b)). The CEC for vermiculites ranges between $100-180 \mathrm{meq} / 100 \mathrm{~g}$; which is higher than the typical values for smectites that are in the range 80 - $140 \mathrm{meq} / 100 \mathrm{~g}$ (Daryn \& Thomas, 2002).

\subsection{The structure of clay minerals}

The term clay generally refers to a natural earthy, fine-grained material which develops plasticity when mixed with a limited amount of water (Grim, 1968) and it hardens when dried or fired (Guggenheim \& Martin, 1995). It was suggested by Guggenheim and Martin (1995) to define clay minerals as the less than $2 \mu \mathrm{m}$ material rather than the classification based on mineralogical features.

Clay minerals vary in chemical and physical properties but predominantly have a platy morphology and a perfect (001) cleavage that gives the characteristic layered atomic structure and layer charges on this plane. The clay structure also varies for different mineral types. Clay minerals are classified as $1: 1$ or as $2: 1$ structures. The clay minerals with a single octahedral sheet linked to a single tetrahedral sheet by weak intermolecular 
forces (induced dipole-dipole forces) are known as 1:1 clays. Alternatively, structures that consist of three sheets; an octahedral sheet sandwiched by silica tetrahedral sheets on both sides, are known as 2:1 layer clays. A brief discussion of the tetrahedral sheet, octahedral sheet and 2:1 clay structure is provided.

\subsubsection{Tetrahedral sheets}

Figure 6 shows the structure of the tetrahedral sheets. The dominant cation $(\mathrm{T})$ in the tetrahedral sheet is $\mathrm{Si}^{4+}$ and is often substituted by $\mathrm{Al}^{3+}$ and occasionally by $\mathrm{Fe}^{3+}$. Cations are bonded to oxygen $(\mathrm{O})$ to produce a T/O ratio of $\mathrm{T}_{2} \mathrm{O}_{5}$ that forms a two dimensional infinitely extended sheet. Each tetrahedron in a single plane shares the oxygen at all the three corners with three other tetrahedra while the fourth oxygen points in the direction normal to the base. The general structure is hexagonal with a $\mathrm{Si}-\mathrm{O}$ bond distance of $1.62 \AA$ (Ångström) and the O-O distance approximately $2.64 \AA$ (Moore \& Reynolds, 1989). Replacement of $\mathrm{Si}^{4+}$ by $\mathrm{Al}^{3+}$ distorts the structure due to the $\mathrm{Al}-\mathrm{O}$ bond having a distance of $1.77 \AA$.
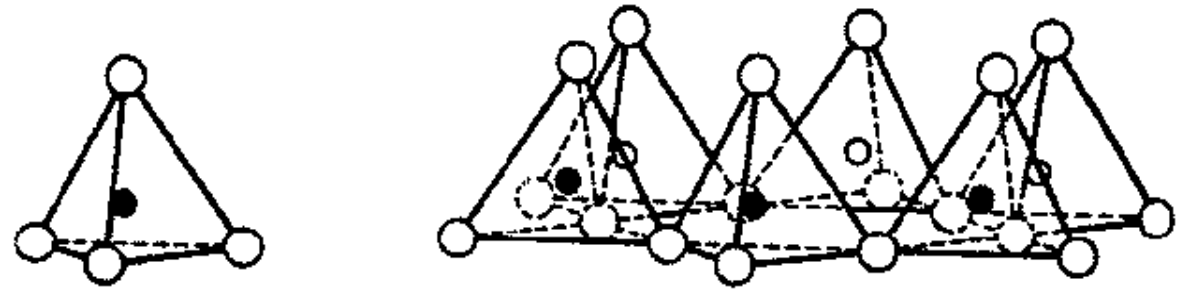

Figure 6: A single tetrahedron (left) and the tetrahedral sheet structure (right) of $\mathrm{SiO}^{4+}$ tetrahedra (Bland \& Rolls, 1988).

\subsubsection{Octahedral sheets}

An octahedral sheet consists of two planes of closest-packed oxygen ions with cations placed in the resulting octahedral sites between the two planes. The connected centers of the six oxygen ions packed around an octahedral cation site form an octahedron (Figure 7). An indefinite extension of a two dimensional sheet is formed due to bonding of neighboring oxygen ions to form an edge-linked octahedral structure. Cations that occupy the cation sites of the octahedral sheet are usually $\mathrm{Al}^{3+}, \mathrm{Mg}^{2+}, \mathrm{Fe}^{2+}$ or $\mathrm{Fe}^{3+}$. 

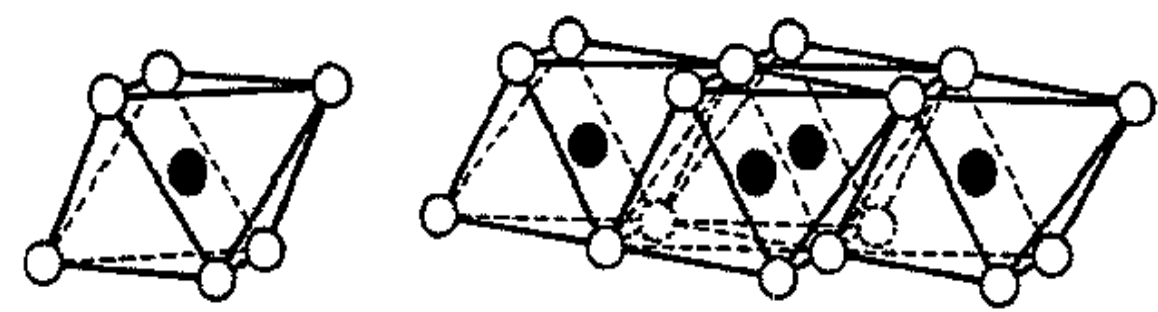

Figure 7: The single octahedron (left) and octahedral sheet structure (right) of an octahedral sheet (Bland \& Rolls, 1998).

\section{The structure of a 2:1 clay}

The 2:1 clay has a thickness of $\sim 10 \AA$ per layer. Figure 8 is an illustration of the 2:1 clay structure comprising of a tetrahedral and octahedral sheets bonded by van der Waals forces.

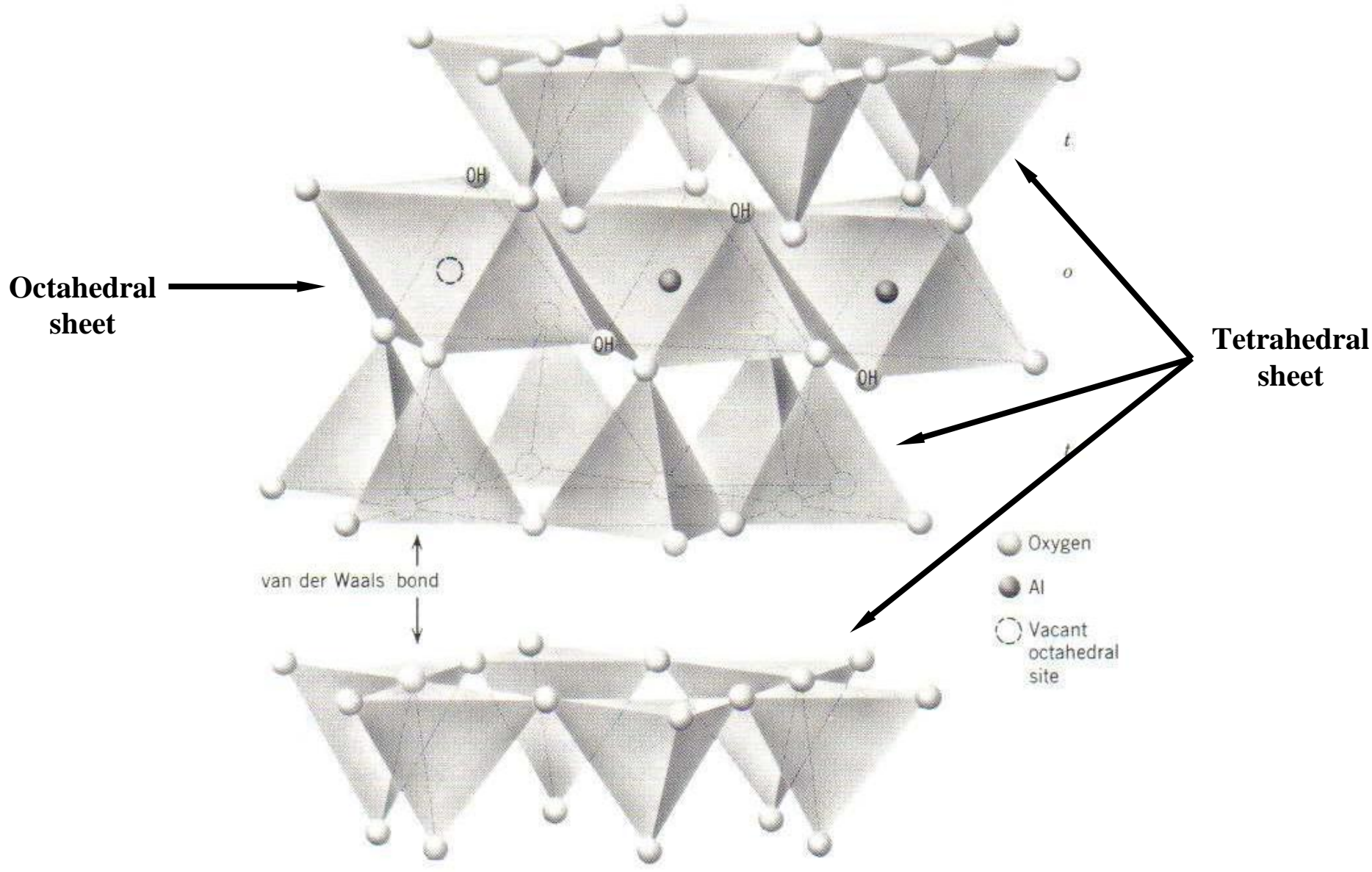

Figure 8: The crystal structure of 2:1 clay mineral (Klein, 2002). 


\subsection{The swelling of clay minerals}

Clay minerals that have a tendency to swell when exposed to water undergo the process of intercalation (reversible uptake of atoms, ions, molecular cations or molecules) because of their layered structure (Lerf, 2004). Clay minerals are usually negatively charged host lattices that contain large amounts of redox active transition metals (mostly Fe ions) in the octahedral layers. The negative charge results due to substitution of ions in the tetrahedral and/ or octahedral layers. However, according to $\mathrm{Li}$ and $\mathrm{Xu}$ (2008), depending on the $\mathrm{pH}$, clay particles can be negatively or positively charged on the $\mathrm{O}$ (oxygen) faces and at the edges due to direct $\mathrm{H}^{+} / \mathrm{OH}^{-}$transfer from aqueous solution. Generally the net particle charge is negative but under acidic conditions both negative and positive charges exist on the surface of the particles. If clays have a net neutral charge, they are bonded by van der Waals forces. Otherwise, charge compensating ions can occupy positions in the van der Waals gap (Figure 8), if the structure is charged either positively or negatively. Thus, interlayer spaces can act as active sites for adsorption, for instance, of positively charged ions. Adsorption of positively charged ions into the interlayer causes changes of these spaces resulting in a different interlayer spacing. Depending on the species, either inorganic or organic ions, that enters the interlayer space; the interlayer space will either expand or contract. Swelling allows additional ions to enter the structure which causes further expansion of the interlayer distance. Kimberlite contains various sheet silicates and clay minerals (discussed in section 2.1.5) but not all have the ability to swell. The minerals present in kimberlite with the ability to swell are smectites and vermiculites (Morkel, 2006).

The adsorption of cations can be quantified by the characteristic known as the cation exchange capacity (CEC), which is the measure of the ability of a sample to absorb cations (in milliequivalents (meq) of charge/100g of sample).

\subsection{Organic sorption on clay minerals}

Early studies of organic adsorption on clay minerals started in the 1930's (Grim, 1968). Studies show that when organic molecules are adsorbed, the interlayer spaces become organophilic, resulting in a limited swelling in water but a rather improved swelling in 
organic solvents. Normally, bimolecular organic layers are formed between the silicate layers (Figure 9) and the structure of the clay becomes loose with highly polar compounds (Weiss, 1989). Both low and high molecular weight organic compounds such as polycarboxylic acids; citric acid, oxalic acid, malic acid as well as other organic solutions such as fulvic acid and humic acid decompose minerals by reacting with polyvalent cations at the mineral surface to form water-soluble or water insoluble complexes (Chin \& Mills, 1991). Wang et al. (2005) confirmed that organic acids and their anions may enhance mineral weathering through the formation of $\mathrm{Al}$ complexes of organic acids at the mineral surface.

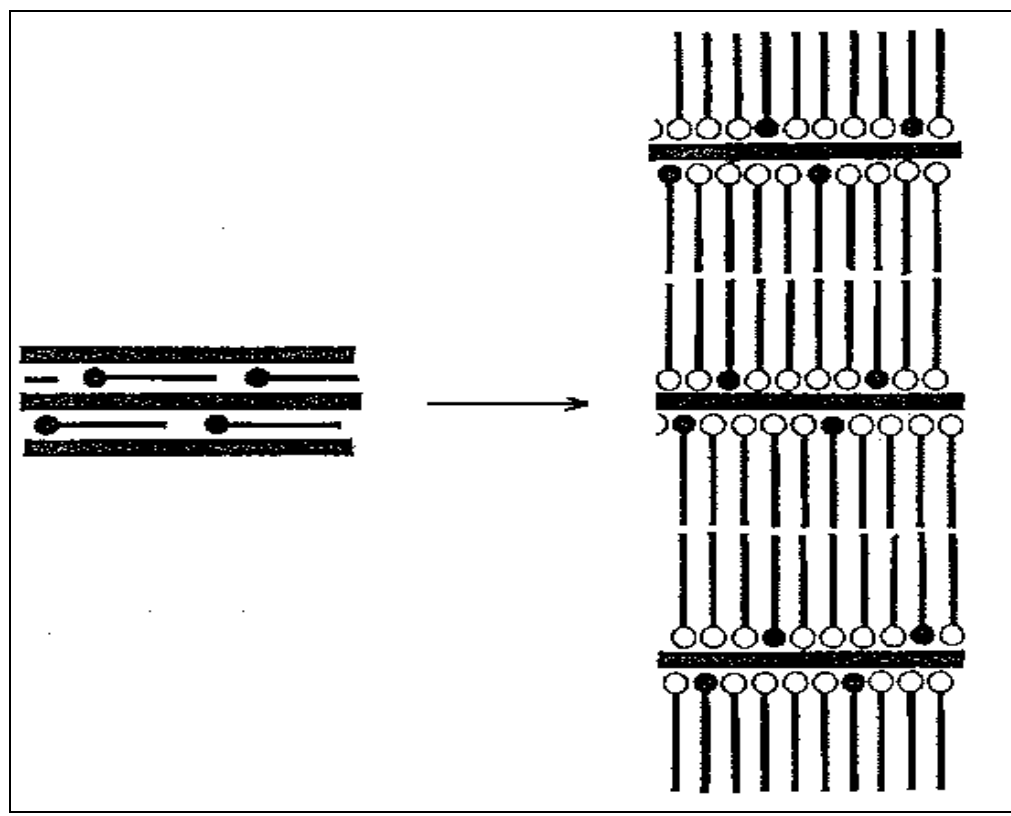

Figure 9: Montmorillonite with organic interlayer cations in the dried state (left) and with organic molecules in maximum swollen state (right) (Weiss, 1989).

A vast amount of research is available on organic swelling of clay minerals, specifically on smectites and vermiculites. The studies determined the extent of swelling by measuring the uniaxial stress produced during swelling (Crawford et al., 1991) and in other cases by determining the interlayer spacing $\left(\mathrm{d}_{001}\right.$-spacing), utilising X-ray diffraction (XRD) (Daryn \& Thomas, 2002; Morkel, 2006). The interlayer space in smectites has been measured for water and exchange cations as well as for certain organic cations and various organic liquids (Deer et al., 1966). Polar organic liquids such as glycol can be adsorbed in integral number of layers and yield regular layer sequences with characteristic basal spacings. The swelling of vermiculite utilising organic cations 
has been investigated by Crawford et al. (1991) and a combination of surfactants and organic molecules was investigated by Daryn and Thomas (2002).

\subsubsection{Organoclays}

The adsorption behavior of clay surfaces towards water and hydrocarbons can be improved by prior adsorption of organic compounds onto clays to form organoclays. In most cases this treatment enhances subsequent hydrocarbon adsorption accompanied by a decrease in water adsorption due to the surface becoming more oleophilic (having a stronger affinity for oils than water) or organophilic (Van Olphen, 1968). Organoclays are clays in which the charge balancing inorganic cations in the interlayer have been replaced by cationic organic surfactants usually long chain quaternary alkylammonium such as dimethyldioctodecyl ammonium (Hedley et al., 2007), centrimmonium chloride (Hanna \& Vieira, 2004), or organic amines (Van Olphen, 1963).

Surfactant modified vermiculite increased in layer spacing when an organic solvent hexadecyltrimethylammonium (HDTMA, $\mathrm{C}_{19} \mathrm{H}_{42} \mathrm{~N}$ ), was added (Crawford et al., 1991). The increase in interlayer spacing was observed in single chain saturated vermiculite. The author suggested that surfactants create a hydrophobic interior (amphiphilic intercalated clay) to allow the uptake of additional organic solvents. The effect of a surfactant in this instance is similar to that of large cations with a smaller hydration radius which encourages the organic molecule adsorption into layers resulting in enhanced clay swelling.

Intercalation of surfactant ions converts the initially hydrophilic clay particles into hydrophobic organoclays. The modified clay exhibits a lower surface energy and is more compatible with organic polymers. Montmorillonite has been observed to swell in n-alkanols after saturation in various alkylammonium cations producing 27 times more expansion compared to swelling induced by water alone (Jordan, 1963). Hanna \& Vieira (2004) showed an increase in $\mathrm{d}_{001}$ from 12.35 to $19.69 \AA$ on organic modification of a Na-based smectite. Gates (2004) illustrated that organo-modified clays have more swelling capacity in organic solvents such as ethanol. In this study, organic modification of montmorillonite was obtained by saturation in an organic cation 
benzyloctadecyldimethylammonium chloride (BODMAC, $\mathrm{C}_{27} \mathrm{H}_{50} \mathrm{ClN}$ ) which resulted in the smectite being able to adsorb an ethanol-water mixture. Swelling induced by ethanol or toluene on organo-modified clays is reversible. Another cationic surfactants which has been shown to adsorb on smectite is dodecylpyridinium bromide (DPB, $\mathrm{C}_{17} \mathrm{H}_{30} \mathrm{BrN}$ ).

The influence of organic cations and polar organic molecules on the adsorption behaviour of clays varies as discussed by Van Olphen (1968). Organic cations are preferentially adsorbed at exchange sites on the clay surface at the expense of inorganic cations. This result in the elimination of the water adsorbed by ion hydration bonding while the water adsorbed by hydrogen bonding is reduced to a large extent due to blocking of the adsorption sites by large organic cations. Hydrocarbon adsorption is then further promoted by the presence of organic cations which are associated with the hydrocarbon molecules through van der Waals forces (Van Olphen, 1968). Alternatively, polar organic molecules are adsorbed on the clay surface while the counterions still remain associated with the clay particles to compensate for the negative interior lattice charge. Adsorption of water by ion hydration is not necessarily eliminated in the presence of organic molecules due either charged counter and/or polar organic molecules. However competition by these organic molecules for the oxygen sites reduces water adsorption by hydrogen bonding.

\subsubsection{Organic chemistry}

Organic molecules mainly consist of chains of carbon atoms covalently bonded to each other. Depending on the molecular engineering, other elements such as nitrogen, hydrogen, oxygen, chloride etc, can be attached to the carbons to form a unique molecule. In some instances carbon atoms are connected to form a ring; with hydrogen bonded to the carbon to form a structure known as the benzene ring. Organic molecules are usually classified by the functional group, which refers to a group of atoms within a molecule which gives a characteristic chemical behaviour. Hence organic molecules are classified into alkanes, alkenes, alkyls, halides, alcohols, ethers, amines, nitriles, thiols, carbonyls, aldehydes, ketones, carboxylic, esters, amides etc. 
Organic molecules can also be divided into polar, non-polar, and ionic compounds. Polar molecules normally have high boiling and melting points due to strong intermolecular interactions. Polar compounds are more soluble in polar solvents. Polarity of these compounds is brought about by the oxygen-hydrogen or nitrogen-hydrogen linkages in which oxygen or nitrogen draws most of the electrons shared in the bond and the molecule becomes electronegative. The resulting dipole moment leads to dipole-dipole interactions between molecules. Ionic compounds (also known as organic salts) dissolve well in water because of hydrogen bonding and strong dipole interactions that stabilize the ion in solution. These salts dissolve less well in other organic polar solvents and are practically insoluble in non-polar solvents (Hendrickson et al., 1970). An exception to this is the quaternary ammonium salts with large alkyl groups that are fairly soluble in non-polar solvents as they provide a hydrocarbon surface to the solvent.

\subsubsection{Adsorption mechanism}

According to Lerf (2004), charged host lattices (positively or negatively) can undergo ion exchange and/or solvation reactions. The exchange of inorganic ions by organic cations changes the wetting behaviour of silicates. For non-swelling clay minerals only the space between the external basal faces of two neighbouring crystals changes when exposed to organic molecules. In swelling clays, the interlayer spaces expand when bimolecular organic layers are fixed by van der Waals forces as well as coulombic forces. Small ions may be adsorbed up to the CEC whereas larger ions may be adsorbed more than the smaller ions. Larger ions are also more strongly adsorbed than smaller ions (Grim, 1968). Many proposal have been made as to the mechanism by which organic reagents species adsorb on swelling clay surfaces. Simplified results have been obtained from nonswelling silicates such as mica (Tahani et al., 1999). Ghiaci et al. (2004) acknowledged the complexity of the mechanism of surfactants adsorption on swelling layer silicates as compared to non-swelling clays because reaction conditions influence the structure of the adsorbed cationic surfactants in the swelling clay interlayers. HDTMA chloride can be randomly arranged on the surface of clays while hexadecylpyridium chloride (HDPC) would be organized into monolayers slightly tilted from the normal plane to the basal surface with an alternate orientation of the cationic polar head group (Patzko \& Dekany, 1993). 
Depending on the structure of the adsorbed layer surfactant-coated clay particles may aggregate or disperse (Tahani et al., 1999). The long-range hydrophobic forces between the alkyl chains play a role in the aggregation of the particles. Subsequent adsorption of the surfactant at adsorption beyond the CEC will result in the dispersion of particles. The dispersion is due to an alternate surfactant bilayer configuration perpendicular to the basal space coexisting with a compact flat bilayer (Tahani et al., 1999). Lee and Kim (2002) also reported that layered silicates treated with surfactants beyond the CEC of that clay are partially delaminated into single layers. Table 4 gives the various structures based on surfactant adsorption. The surfactant utilised in this case was benzyldimethyldodecyl ammonium chloride (BDDAC, $\mathrm{C}_{21} \mathrm{H}_{38} \mathrm{CIN}$ ) on montmorillonite clay.

Table 4: Structure of the adsorption layer for various surfactant adsorption rates of BDDAC on Montmorillonite (Tahani et al., 1999).

\begin{tabular}{|c|c|c|c|}
\hline BDDA $^{+}$adsorption & $\mathbf{d}_{\mathbf{0 0 1}}(\mathbf{\AA})$ & $\begin{array}{c}\mathbf{B D D A}^{+} \text {orientation } \\
\text { relative to clay } \\
\text { basal surface }\end{array}$ & $\begin{array}{c}\text { BDDA }^{+} \\
\text {intercalation }\end{array}$ \\
\hline$<0.8$ CEC & $14.6-18$ & Random & Monolayer \\
\hline $0.8-1.38$ CEC & 18 & Flat & Bilayer \\
\hline $1.38-1.7$ CEC & 18 & Flat & Bilayer \\
\hline$>1.7$ CEC & 33 & Perpendicular & Alternate bilayer \\
\hline
\end{tabular}

The extent to which the solvating organic reagents change the structure or the orientation of the alkyl chains initially adsorbed on the clay interlayer space influences the degree of swelling. For benzyloctadecyldimethylammonium (BODMA) saturated smectite solvated in ethanol to further swell the clay structure, ethanol at intermediate concentrations interrupts the attractive van der Waals forces and H-bonding operating in the BODMA smectites which balances the repulsive electric double layer of the clay surface (Gates, 2004). The influence of the solvent further depends on the dielectric constant and surface tension (Gates, 2004). Changes in the orientation of the organic cation in the interlayer space influenced by layer charge may also have an effect on solvent reactions. When chains in the interlayer space move to an upward position and separate the layers even more, higher amounts of the solvent can be adsorbed. Van Olphen (1968) mentioned 
the use of pyridine modified clay followed by benzene solvation in which case the adsorption of benzene on pyridine-clay caused reorientation of the pyridine rings between the unit layers from parallel to a tilted position with benzene rings assuming the same tilted position between the pyridine rings. Before the sorption process, the flatly laying alkyl chains are strongly held in contact with the surface by van der Waals forces. This force is overcome by the energy gained through adsorption (adsorption energy). Thus, optimal swelling requires a high liquid adsorption energy on the silicate surface and a high solvation energy of the interlayer organic cation.

\subsubsection{Factors affecting organic sorption}

Organic sorption is affected by exchangeable cations, the surface charge and the water activity. Factors are discussed in more detail.

\subsubsection{Effect of exchangeable cations on organic sorption}

A monolayer hydration of beidellite smectite was observed by Chappell et al. (2005) to be more conducive for hydrophobic organic conditioning by utilising atrazine (2-chloro-4-(ethylamine)-6-(isopropylamine)-s-triazine, $\mathrm{C}_{8} \mathrm{H}_{14} \mathrm{ClN}_{5}$ ), which is a weakly polar organic compound. The extent of crystalline swelling had a large influence on atrazine sorption affinity. For an organic molecule to be adsorbed onto the clay interlayer, a threshold expansion pressure is required. The threshold pressure is induced by exchangeable cations that reduce the energy required for entrance of organic molecules into the layers for further expansion. The exchangeable cations therefore play a vital role in the sorption of organic molecules.

The extent to which the exchangeable interlayer cation gets hydrated (hydration radius) affects the amount of water within the layers. Depending on the cation ionic potential (ratio of the cation valence to its ionic radius), the cation with a high ionic potential will give a high hydration (Morkel et al., 2007). Therefore, cations can make the space between layers either hydrophilic or hydrophobic. Small cations usually make the layers hydrophilic while larger cations create a hydrophobic region favouring intercalation of neutral organic species (Daryn \& Thomas, 2002). 
Figure 10 shows the hydrated radii for various cations. Unlike $\mathrm{Na}^{+}, \mathrm{Li}^{+}, \mathrm{Ca}^{2+}, \mathrm{Mg}^{2+}$ and $\mathrm{Cu}^{2+}$ the cations $\mathrm{K}^{+}, \mathrm{NH}_{4}{ }^{+}$, and $\mathrm{Cs}^{+}$are expected to reduce the amount of water sorption into interlayers. This was also confirmed by authors Chappell et al. (2005) as well as Boshoff et al. (2007). However, Chappell et al. (2005) concluded that the sorption affinity of a smectite for atrazine was more sensibly predicted by the extent of hydration of the clay interface than only considering the nature of the cation saturated. This fact was also supported by Salles et al. (2007) who investigated the driving force behind the swelling of clays utilising the first column elements $\mathrm{Li}^{+}$to $\mathrm{Cs}^{+}$. Usually cycles of wetting and drying affect the extent of hydration of the smectites.

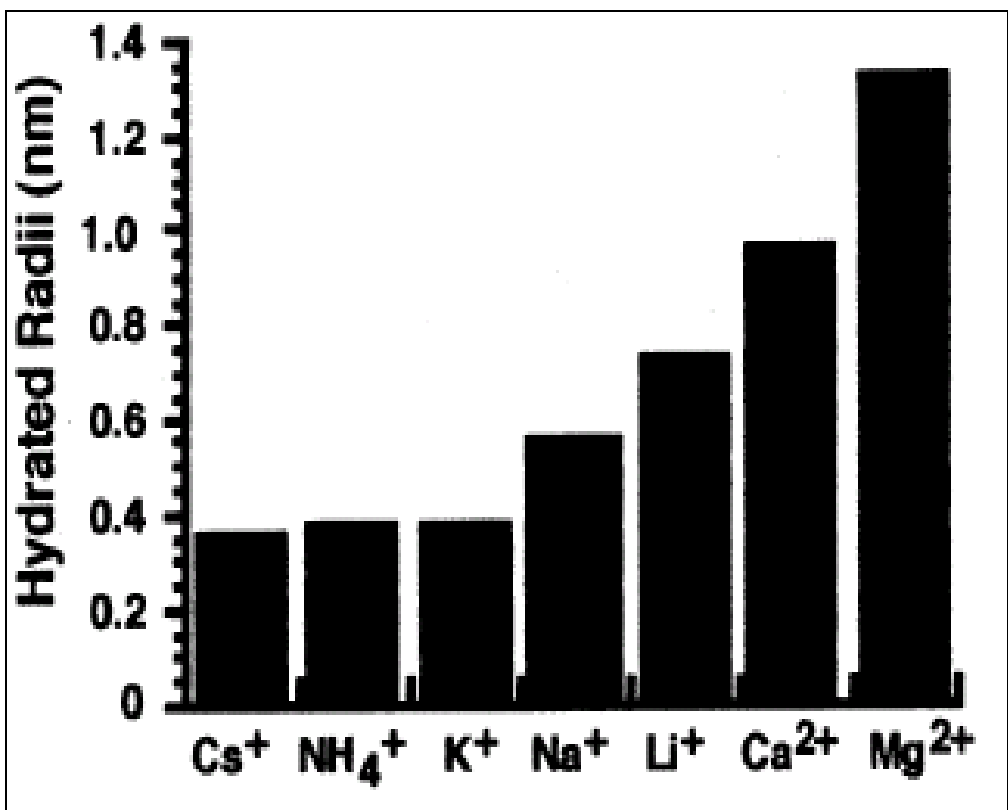

Figure 10: Hydrated radii for various cations (Mohan et al., 1999).

\subsubsection{Effect of surface charge density}

Research has shown the importance of surface charge density on the adsorption affinity of smectites for organic solutions such as atrazine as reported by Chappell et al. (2005) and Gates (2004). An inverse relationship exists between the sorption of aromatic compounds and the layer charge of organo-modified smectites (Lee et al, 1990). The lower the charge on the smectite interlayer surface, the higher the amount of non-polar organic molecules that can be adsorbed. A hypothetical uncharged smectite surface assumes hydrophobicity which encourages a positive interaction with organic molecules on an uncharged surface. 
The layer charge also influences the orientation of organic molecules in the interlayer spaces. Published work by Gates (2004) shows that for smectite with a layer charge less than $0.8 \mathrm{e}^{-}$per unit cell (where $\mathrm{e}^{-}$is an elemental charge equal to $1.602 \times 10^{-19}$ coulombs), the BODMA molecules were postulated to lie flat with the benzyl groups projecting outward from the clay surface at an angle of $\sim 30^{\circ}$. This means that more solvent molecules can be accommodated in the interlayer space resulting in further expansion of the clay structure. For a surface charge greater than $0.8 \mathrm{e}^{-}$per unit cell a significant overlap of aliphatic tails cause an inclination of $\sim 30^{\circ}$ relative to the interlayer surfaces which reduces the area of the interlayer surface occupied by individual molecules. Figure 11 illustrates the organic cation orientation as a result of clay layer charge. When clays are pre-modified by alkylammonium ions, adsorption is however increased with an increase in layer charge (Grim, 1968). At lower surface charge densities, ions arranged in a flat configuration whilst at higher charge densities the ions are more erect due to hydrogen atoms of the $\mathrm{RNH}_{3}$ group forming hydrogen bonds with the oxygen atoms of the six-membered $\mathrm{SiO}$ rings with no distortion of their valence angle.

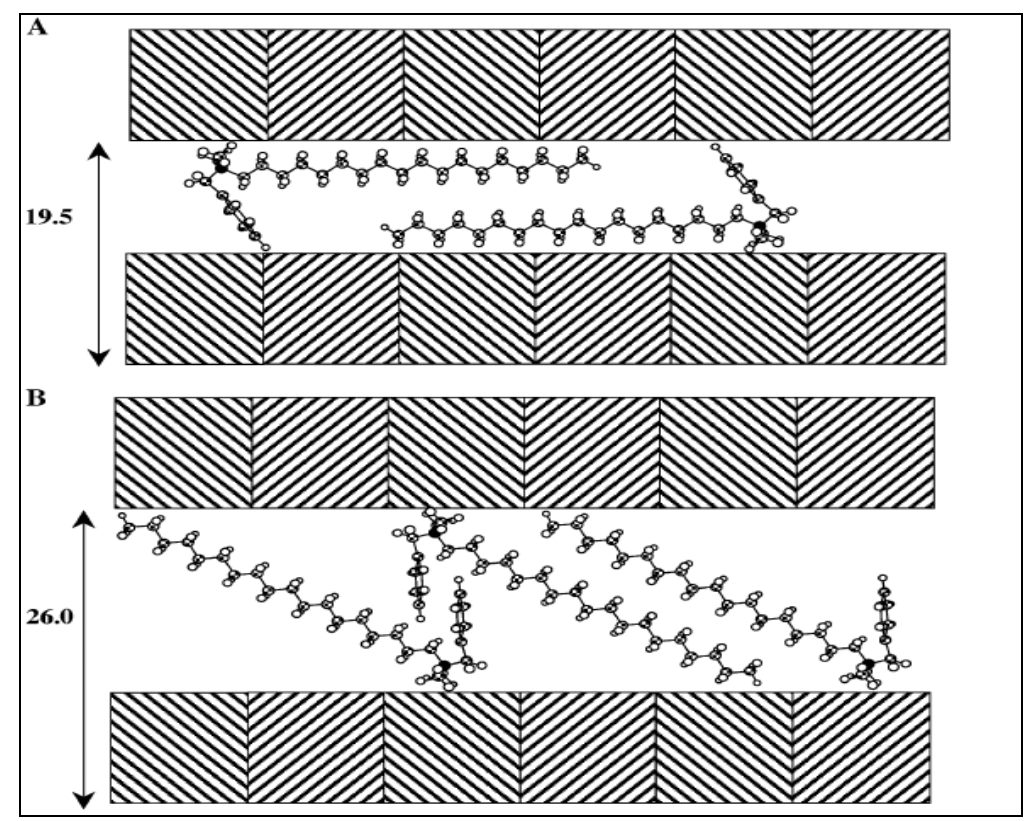

Figure 11: A illustration of the possible interlayer arrangement of BODMA smectites with layer charge densities of $(\mathrm{A})<0.8 \mathrm{e}^{-}$and $(\mathrm{B})>0.8 \mathrm{e}^{-}$per $\mathrm{O}_{20}(\mathrm{OH})_{4}$. The distance between alkylammonium units are inversely related to the layer charge density (Gates, 2004). 
Campos et al. (2008) identified various pretreatment procedures that reduce the negative charge on clay minerals. These include an acid treatment, adsorption of small cations and $\mathrm{Fe}^{2+}$ oxidation and are explained below.

\section{- Acid treatment}

Washing the material with acid (e.g. nitric acid) followed by calcining or ultrasound radiation in the presence of $\mathrm{H}_{2} \mathrm{O}_{2}$ or dealumination by thermal treatment with water vapour as a pretreatment procedure can reduce the layer charge.

\section{- Adsorption of small cations}

Loss in cation exchange capacity CEC enhances the expandability of smectites (Zemanová et al., 2006). It has been reported that small cations such as $\mathrm{Li}^{+}$not only reduce CEC but also artificially reduce the negative charge on smectites and hence improve expandability (Gates et al, 2000; Komadel et al., 2006). The mechanism suggests that $\mathrm{Li}^{+}$migrates to vacant octahedral position of the structure. The effect of Li-fixation has been shown to improve with increase in temperature in the ranges 100 to $300{ }^{\circ} \mathrm{C}$ (Madejová et al., 1999; Komadel, 2003; Komadel et al., 2006). Zemanová et al. (2006) showed that microwave heating was the most efficient process for $\mathrm{Li}^{+}$fixation. The choice of background electrolyte is therefore an important aspect.

\section{- $\mathrm{Fe}^{2+}$ oxidation}

Structural Fe ions in clay minerals can be involved in redox reactions as these intercalated species can act as oxidizing or reducing agents. The presence of $\mathrm{Fe}$ in smectites can be utilised to modify the clay properties. The $\mathrm{Fe}^{2+} / \mathrm{Fe}^{3+}$ reaction in smectites affects many fundamental properties of the mineral which include layer charge, CEC, cation fixation, swelling pressure, water holding capacity, specific surface area, hydraulic conductivity, colour, etc. Oxidation of $\mathrm{Fe}^{2+}$ to $\mathrm{Fe}^{3+}$ (for instance by $\mathrm{H}_{2} \mathrm{O}_{2}$ tested in vermiculites) or the presence of adsorbed $\mathrm{Fe}^{3+}$, reduces the CEC of smectites (Favre et al., 2006; Komadel et al., 2006) due to contracting the interlayer space as well as development of a net positive charge on the clay surface (Kavanagh \& Quirk, 1978). Under neutral and alkaline conditions, $\mathrm{Fe}^{2+}$ oxidation causes a large decrease in surface 
charge and an expanded smectite is formed (Yatsu, 1988). Unfortunately Fe occurs mainly as $\mathrm{Fe}$ (III) in various dioctahedral smectites including most montmorillonites, beidellites and illites and is also the dominant central atom in octahedral sheets of nontronites (Komadel, 2003).

\subsubsection{Water activity}

Many properties of clay minerals such as plasticity, bonding, compaction and suspension capabilities are related to the water attached to edges and to the 001 surfaces of clays (Moore \& Reynolds, 1989). Water in the interlayer spacing of clay minerals is controlled by (1) the polar nature of the water molecule which results in H-bonding onto the interlayer surface of clay; (2) cation size and charge; and (3) the amount and localisation of the charge on silicate layers. In expandable clays, water is confined in layer sheets which are presented in integral numbers, $0,1,2, \ldots$, according to the extent of hydration which is a function of the humidity (the activity of water). Each hydration state is given by a discrete interlayer spacing or d value: $9.6, \sim 12.4, \sim 15.2$, and $\sim 18.0 \AA$.

In terms of layer charge reduction, Zemanová et al. (2006) reported a low negative charge reduction on Li-saturated montmorillonite even at high $\mathrm{Li}^{+}$concentrations. This was due to the very high water content utilised in the dispersions coupled with the high hydration enthalpy for $\mathrm{Li}^{+}$. When considering the group $\mathrm{I}_{\text {cations }} \mathrm{Li}^{+}$to $\mathrm{Cs}^{+}$, the hydration of the cations decrease going down the column (Salles et al., 2007). High water content means a barrier for effective layer charge distribution due to re-hydration of $\mathrm{Li}^{+}$cations.

\subsection{Organic reagents}

In order to evaluate the suitability of organic reagents in this study, a number of facts such as organic molecular structure, bond strength, $\mathrm{CH}$ activity, polarity and the dielectric constant was investigated and discussed. 


\subsubsection{Molecular structure}

The structure of the alkyl group has an influence on the extent of clay organic solvation. Generally the longer the carbon chain, the less the sorption of organic molecules. This is caused by a reduction in the amount of micropores into which organic solvents can penetrate into the interlayer spaces once a certain amount of organic reagents get attached. This is illustrated in Table 5, which shows a decrease in micropore volume with a decrease in external surface area, with an increase in the number of carbon atoms $\left(\mathrm{n}_{\mathrm{C}}\right)$ of the alkyl chain. An example given by Lagaly and Malberg (1990) is that of montmorillonite with methylammonium ions having to ingress in between hexagons of the surface oxygen atoms with a basal spacing of $1.16 \mathrm{~nm}$ which is considerably smaller than required for monolayers of alkyl chains $(1.36 \mathrm{~nm})$. If the methylammonium is adsorbed on the surface, the micropores in between the molecules will not be sufficient to allow unconstrained interlamellar sorption of a solvent. With increasing chain length, a part of the pores become too narrow, and adsorptive molecules can only have access to the free space between the chains only when some chains change their position or orientation in the interlayer space. A possible solution to this is by either increasing the temperature or by an increase in polarity of the solvent such as changing from cyclohexane to alcohol. However the increased solvent adsorption that may be observed can be due to not all the interlayer spaces being filled with alkyl molecules and so organic solvent molecules can, to an extent, get adsorbed on vacant sites.

Table 5: Porosities and external surface area for various n-alkylammonium montmorillonites, where $\mathrm{n}_{\mathrm{C}}$ is the number of carbon atoms in the alkyl chain (Lagaly \& Malberg, 1990).

\begin{tabular}{|c|c|c|c|c|c|c|c|}
\hline $\mathbf{n}_{\mathbf{C}}$ & 1 & 4 & 6 & 8 & 10 & 14 & 18 \\
\hline \multicolumn{8}{|c|}{ Micropore volume, $v_{\mu}\left(\mathrm{ul} \mathrm{g}^{-1}\right)$} \\
\hline Nitrogen & 84 & 60 & 20 & 8 & - & 0 & 0 \\
\hline Cyclohexane & 39 & 62 & 36 & 17 & - & 0 & 0 \\
\hline Ethanol & 103 & 78 & 59 & 28 & - & 3 & 6 \\
\hline \multicolumn{8}{|c|}{ External surface area, $a_{e}\left(m^{2} g^{-1}\right)$} \\
\hline Nitrogen & 45 & 35 & 26 & 29 & 16.4 & 13 & 13 \\
\hline Cyclohexane & 45 & 42 & 33 & 32 & 22.0 & 23 & 24 \\
\hline Ethanol & 53 & 59 & 46 & 60 & 66.0 & 55 & 61 \\
\hline
\end{tabular}


However, Moraru (2001) stated that swelling of clays is insignificant at alkyl chains containing $\mathrm{n}_{\mathrm{C}}$ less than 10 and a maximum swelling would be experienced at $\mathrm{n}_{\mathrm{C}}$ equal to 12. The author showed that a large basal spacing of $\mathrm{d}_{001}=2.35-2.52 \mathrm{~nm}$ was achieved for derivatives of montmorillonite containing long-chain organic cations as opposed to short-chain organic cations that did not cause swelling. As the size of the molecule increases, the van der Waals interactions are also enhanced due to an increased number of contact points. This was also confirmed by Lagaly and Malberg (1990) and is shown in Figure 12. An increase in the basal spacing $\left(d_{L}\right)$ is observed at $n_{C}$ greater than 10 . Swelling was also observed to be enhanced when the alkyl chains contained double bonds or aromatic groups.

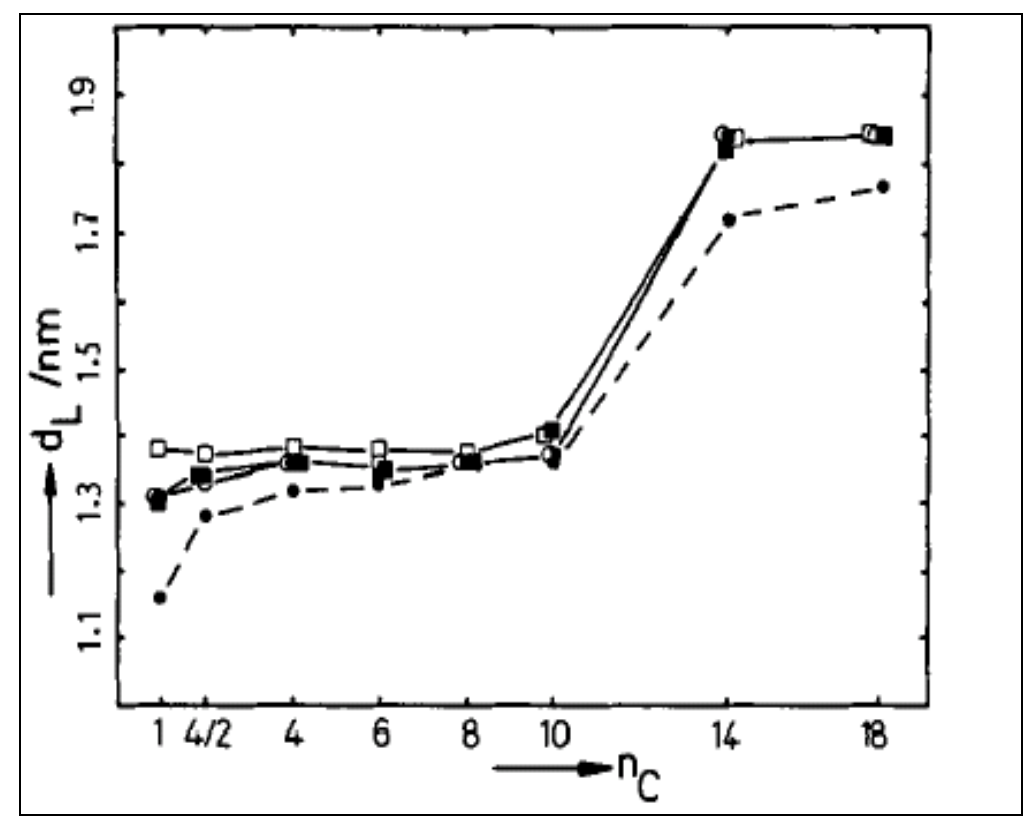

Figure 12: Basal spacing, $d_{L}$, as a function of number of alkylammonium carbon atoms $\left(\mathrm{n}_{\mathrm{C}}\right)$ in contact with n-hexane; n-dodecane; cyclohexane; cis-decaline. Broken line: spacing of dried sample at $65^{\circ} \mathrm{C}$ in vacuum (Lagaly \& Malberg, 1990).

\subsubsection{Bond strength}

The affinity (bonding strength) of alkylammonium ions for smectite sharply decrease in the series $\mathrm{RNH}_{3}{ }^{+}, \mathrm{R}_{2} \mathrm{NH}_{2}{ }^{+}$and $\mathrm{R}_{3} \mathrm{NH}^{+}$, where $\mathrm{R}$ is the alkyl functional group (Weiss, 1963). Quaternary alkyl-ammonium ions $\mathrm{R}_{4} \mathrm{~N}^{+}$behave rather differently with asymmetrical ions such as trimethylcetyl and dimethyl-di-n-octadecylammonium ions being classified as primary ammonium ions whilst symmetrical ions ranked behind 
secondary ammonium ions. As a result of bulkiness of the groups, the bonding strengths of $\mathrm{R}_{2} \mathrm{NH}_{2}{ }^{+}, \mathrm{R}_{3} \mathrm{NH}^{+}$and symmetrical $\mathrm{R}_{4} \mathrm{~N}^{+}$also decrease rapidly with increasing charge of the montmorillonite layers. The behaviour of sulfonium and oxonium ions is similar to that of $\mathrm{R}_{3} \mathrm{NH}^{+}$. However, Theng (1974) disputed this fact on the grounds that there was no experimental work which was conducted to prove the bonding strength effect.

\subsubsection{CH activity}

A useful index of character in many aliphatic chain molecules is the $\mathrm{CH}$ activity. $\mathrm{CH}$ activity arises from the activation of methylene groups by neighbouring electron-withdrawing structures such as $\mathrm{C}=\mathrm{O}$ and $\mathrm{C} \equiv \mathrm{N}$. Molecules containing many carbonyl or nitrile groupings adjacent to methylene have greater $\mathrm{CH}$ activity. The greater the $\mathrm{CH}$ activity for a molecule the more likely it is to be strongly adsorbed. However, Theng (1974) indicated that the $\mathrm{CH}$ activity is not consistently correlated with adsorption behaviour

\subsubsection{Organic polarity}

Dispersibility of clays in organic solvent does not only depend on the kind and degree of hydrophobisation, the extent of intercrystalline swelling and the aggregation-disaggregation properties of the clays but also on the polarity and chemical nature of the solvent molecules. Polarity refers to the dipole-dipole intermolecular forces between the slightly positively charged-end of a molecule to the negative end of another or of the same molecules. Nonpolar solvents such as n-hexane, n-dodecane, cyclohexane and cis-decaline have no tendency to disaggregate particles and the dispersions are generally less stable. In many polar solvents such as alcohols, cyclohexanones, ketones, amides, nitriles, toluene, esters, etc, disaggregations has been observed (Lagaly \& Malberg, 1990). With highly polar compounds such as formamides, nitrobenzene and benzonitrile, swelling is said to be so strong that the structure of sealing layers becomes loose and the permeability increases. 


\subsubsection{Organic dielectric constant}

The dielectric constant represents the ability of a substance to separate charge and/or to orient its molecular dipoles in external electric field (Sild \& Karelson, 2002). Organo-modified clays have been observed to possess the capacity to swell more in organic solvents with lower dielectric constants than cation saturated clays (Gates, 2004). Ethanol has a relatively lower dielectric constant, dipole moment and surface tension as compared to water, and so it can penetrate in organo-clays with more ease. This means that the dielectric constant of an organic solvent may play an important role in the chemical reactivity in the swelling of clays. However, almost all organic solvents have a dielectric constant less than that of water. The lists of dielectric constant values for organic molecules are given by Maryott and Smith (1951) and Sild and Karelson (2002). A comparison of dielectric constant values could be of interest when comparing various solvents to each other.

\section{WEATHERING PRINCIPLES}

Weathering in geological terms has several definitions. A widely accepted definition is that it is the alteration of rock minerals in situ, at or near the surface of the earth and under the conditions which prevail there (Yatsu, 1988). The process usually takes place naturally and normally over a long period of time but depends on the intensity of the conditions. The process is normally a combined effect of mechanical, chemical and/or biological actions. A detailed description of each of these activities on rocks has been reported by authors such as Yatsu (1988), Bland \& Rolls (1998) and Morkel (2006).

Weathering can take place either at macro- and/or micro-levels. Macro level involves the breakdown of bulk rock to produce coarse fragments whilst micro breakdown is usually related to the disaggregation of elements or particles constituting the rock. Both forms of weathering increase the surface area of the rock. Grains disaggregate at sites where the area of contact between neighboring layers is small. Micro-weathering can increase the external surface area at the expense of internal surface area. Two processes that have been highlighted by Lagaly and Malberg (1990) to increase the external surface area are: (1) the wedge-shaped openings of the interlayer spaces in the edge region (frayed edges) are widened and some layers lose their mutual contacts (A in Figure 13), and (2) 
particle breakage at predetermined breaking points ( $\mathrm{B}$ in Figure 13). The types of weathering are discussed further.

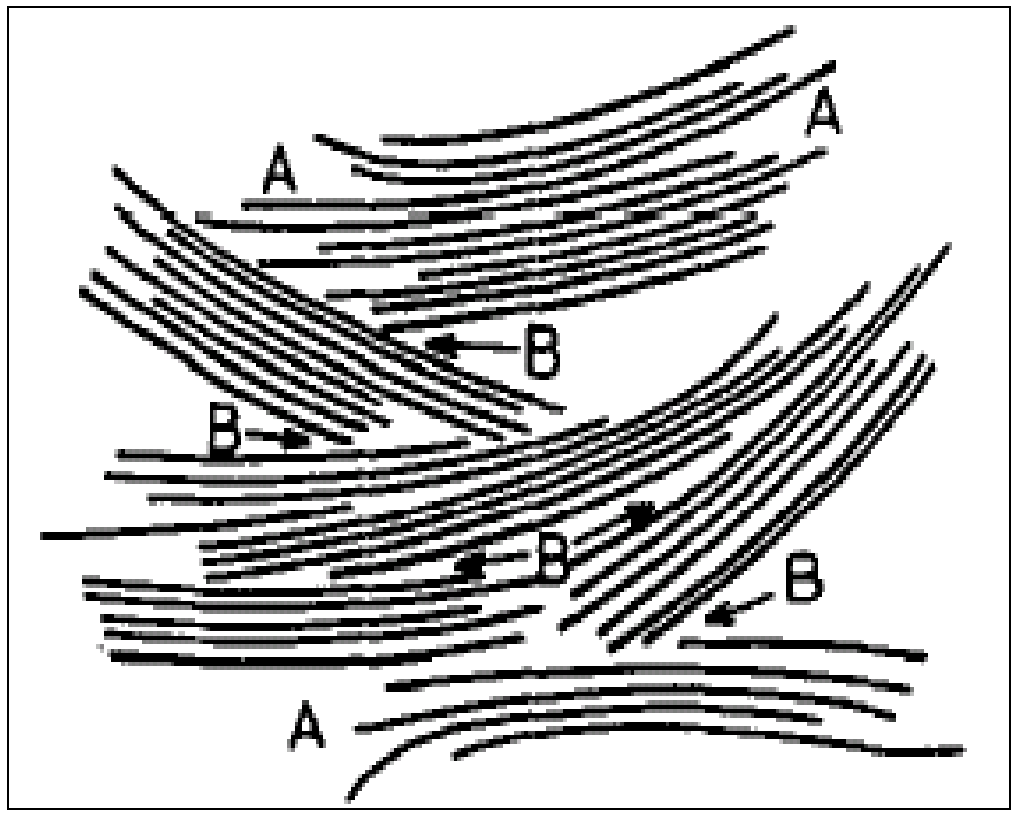

Figure 13: Morphology of montmorillonite particles with: (A) frayed edges; and (B) restricted areas of contact (predetermined breaking points) (Lagaly \& Malberg, 1990).

\subsection{Mechanical weathering}

Mechanical weathering is the physical breaking down of rocks with no chemical involvement even though chemical action enhances the process. In mechanical weathering, a volumetric change induced by internal pressures caused by cycles of freezing and thawing of water is one of the processes that improves weathering. This occurs in rocks that have the ability to adsorb water into their microscopic structure and/or when water seeps into pre-existing cracks and then widens them even further. Related to this process is the cycle of wetting and drying which also induces swelling pressures in susceptible rocks (Bland \& Rolls, 1998). Insolation (the influence of temperature on rock disintegration) and pressure release weathering are weathering mechanisms which are included under mechanical weathering.

\subsection{Chemical weathering}

Chemical weathering involves the change in the rock composition leading to the breakdown of its structure. This process is mainly through the action of water (hydration 
process), oxygen (oxidation process), carbon dioxide ( $\mathrm{pH}$ alterations) as well as exchangeable ions. The mechanisms that prevail are hydration, redox reactions, hydrolysis and ion exchange.

\subsubsection{Hydration}

Hydration is a type of weathering that involves a rigid attachment of $\mathrm{H}^{+}$and $\mathrm{OH}^{-}$ions from water to ions, atoms and molecules of a rock. Some ions in the rock retain associated water molecules in the solid state to form hydrates. Increase in the volume when a rock mineral takes up water creates physical stresses within the rock that can only be released by disaggregation. Sorption of water on the surface or into the structure of some clay minerals is also named hydration (Yatsu, 1988). This process causes clays to swell upon wetting because of the internal pressures exerted by hydration water between the stacking of unit layers and this results in mechanical weathering of clay-containing rocks.

\subsubsection{Redox reactions}

Redox reactions, mainly oxidation reactions, can also be responsible for mineral alteration in rocks to alter the rock properties. Normally, oxygen is the prominent agent involved in the oxidation processes but the $\mathrm{Fe}^{2+} / \mathrm{Fe}^{3+}$ conversion in $\mathrm{Fe}$ containing rocks can play a role as well. Morkel (2006) gave a typical example of two common micas found in soils; biotite and muscovite. Biotite is said to be more easily weatherable than muscovite due to the presence of Fe which can undergo a redox reaction. A reduction reaction is a less common mechanism under this mode of weathering; though organic matter has been identified as an example of a reducing agent (Bland \& Rolls, 1998).

\subsubsection{Hydrolysis}

Hydrolysis is a chemical reaction which can occur under acidic, neutral or basic conditions resulting in the alteration of the $\mathrm{pH}$. This is normally due to one of the $\mathrm{O}-\mathrm{H}$ bonds in water being broken down to form a metal ion-hydroxide bond and thereby releasing a proton into the solution. A distinction between hydration and hydrolysis is 
that hydration is a chelation reaction in which the lone pair of electrons on oxygen in the water structure is bonded to a cation forming a hydration sphere. There are no bonds broken during hydration. In hydrolysis water ionizes slightly and reacts with a mineral resulting in a new compound known as a hydroxide $\left(\mathrm{M}^{\mathrm{n}+}(\mathrm{OH})_{\mathrm{n}}\right)$.

\subsection{4 lon exchange}

Weathering products such as fine soil particles making up clay or humus colloidal particles can also act as surfaces for ion exchange. The most common exchangeable cations are $\mathrm{H}^{+}, \mathrm{Na}^{+}, \mathrm{K}^{+}, \mathrm{Al}^{3+}, \mathrm{Mg}^{2+}$ which neutralize the charge imbalance (negative charge) earlier created within the clay interlayers due to replacement of the $\mathrm{Si}^{4+}$ by either $\mathrm{Al}^{3+}$ or $\mathrm{Mg}^{2+}$ in the structure. Adsorbed cations can undergo hydration on contact with water which will result in swelling of the clay. As discussed in 3.2.2, swelling results in mechanical weathering which will further disintegrate the clay-containing rock.

\subsection{Biological weathering}

Biological weathering is a process furthered by micro- and macro-organisms such as bacteria, lichens, algae, fungi, plant roots and/or organic matter in a state of decay. The contribution of organisms to weathering can either be physical by application of stresses or chemically instigated through the production of substances such as $\mathrm{CO}_{2}$ or secretion of waste material. Chemicals produced may undergo further changes through chain reactions to produce chemicals capable of attacking or disintegrating the soil or the ore structure. Yatsu (1988), Bland \& Rolls (1998) and Morkel (2006) gave a detailed explanation on how various biological agents further the weathering process.

\subsection{Weathering rates}

The rate at which rocks and minerals break down in a specified time is known as the weathering rate (Bland \& Rolls, 1998). Generally weathering involves many factors and parameters. Accurately describing or measuring weathering is rather complex. 
Weathering rates can be described in units such as distance per unit time, in units of volume or mass per unit time. A more general approach to obtain a measure of weathering is the analysis of the particle size distribution before and after weathering has taken place over a given period of time. Units for measuring weathering can be expressed in two forms; (1) measurement of weathering by ionic losses, (2) units for expressing loss/change.

\section{Units of weathering by ionic losses}

- $\quad \mathrm{mol} \mathrm{ha} \mathrm{C}^{-1}\left(\mathrm{or}_{\mathrm{cm}}^{-2}\right)$ (moles per hectare, or per square centimeter);

- $\quad$ meq $\mathrm{m}^{-2}$ (milliequivalents per square meter)

- $\mathrm{mol} \mathrm{g}^{-1}$ (moles per gram)

\section{Units for expressing loss/change}

- $\mu \mathrm{m}$ (micrometers);

- $\mathrm{mm}$ (millimeters)

\section{Units of weathering rates where alteration is linear or non-linear over time}

- mol ha ${ }^{-1}\left(\mathrm{~cm}^{-2}\right) \mathrm{a}^{-1}\left(\mathrm{~s}^{-1}\right)$ (moles per hectare (per square centimeter) per year (per second));

- $\quad$ meq $\mathrm{m}^{-2} \mathrm{a}^{-1}$ (milliequivalence per square meter per year);

- $\mu \mathrm{ma}^{-1}$ (micrometers per 1000 years);

- $\mathrm{mol} \mathrm{g}^{-1} \mathrm{~h}^{-1}$ (moles per gram per hour);

- $\quad \mathrm{km}^{-2} \mathrm{a}^{-1}$ (tonnes per square kilometer per year)

In non-linear or non-uniform weathering, the relationship between weathering and time may be expressed. An example illustrated by Bland \& Rolls (1998) for the accumulation of clay in the B horizon of an Antarctic soil, rate was expressed as an equation of the following manner:

$$
Y=a+(b \log X)
$$

where $\mathrm{Y}$ is clay present as a percentage, $\mathrm{a}$ and $\mathrm{b}$ are regression coefficients and $\mathrm{X}$ is time in years. 


\subsection{Experimental determination of weathering rates}

Laboratory determination of weathering allows the investigation of the effects of various parameters such as time, mineralogy, surface area of the substance being investigated, solution concentration, temperature etc. Most laboratory experiments tend to accelerate the weathering process which could have occurred over longer periods of time under normal natural environment conditions. This is due to relatively more vigorous conditions implemented in laboratory tests. A number of parameters have been identified that influence the weathering of minerals (Morkel, 2006). These parameters include mineral structure, time and the type of weathering solution.

\section{- Mineral structure}

The original as well as the developing structure of a mineral can affect its weathering rate. At the beginning of section 3 it was highlighted that weathering occurs rapidly on sites where the area of contact between neighbouring layers is small such as crystal defects, dislocations, twin boundaries or microfractures. The weathering rate will therefore depend on whether these weak points become enlarged (rate maintained or increased), or blocked with secondary products (rate retardation). Diffusion paths are easily blocked if the structure of the weathering mineral and of its secondary products is similar. Bland \& Rolls (1998) described the formation of clay units produced during weathering that are too large to occupy diffusion avenues resulting in a higher olivine weathering rate. The process results in low initial weathering rates which later increases as different weathering products form.

\section{- Time}

Weathering is a time dependent process. The weathering rate can either decrease or increase with time. A decrease in the rate with time can be explained by a precipitation layer which forms on the mineral surface. The layer product acts as a barrier to further weathering resulting in the slowdown of the weathering process. The initial rapid rate can also be influenced by the sample preparation technique. For example grinding may leave a fine powder on the mineral surface which will react rapidly with the weathering agent until it dissolves. The high initial rate will fall away as the fine particles dissolve. 
Alternatively, the kinetics may be improved by a continuous removal of the product layer to continually expose the mineral to the weathering agent.

\section{- Weathering Solution}

The properties of the weathering solution can also influence the rate of weathering. The $\mathrm{pH}$ of the solution can influence the weathering rate especially the release rates of aluminium, magnesium and silicon. Presence of substances such as cations, salts (both inorganic reagents) as well as organic chelating agents in solution may also affect the rate of weathering. The current study will focus mainly on the effects of organic solutions in mineral weathering.

\subsection{Weathering testing methods}

Various weathering testing methods that can be utilised to quantify weathering will be discussed.

\section{- X-Ray Fluorescence analysis}

$\mathrm{X}$-Ray Fluorescence (XRF) analysis is a technique that determines the chemical composition of a sample. The material is ground into powder and compressed into a pellet utilising a binder. In the analysis procedure, the sample is irradiated with a beam of high-energy X-rays. As the excited electrons in the sample fall back to a ground state, they emit X-rays that are characteristic of those elements present in the sample. The individual X-ray wavelengths are then separated and measured via a system of crystals, optics, and detectors. Elemental concentrations in unknown samples are quantified by comparing the X-ray intensities against known calibration standards.

XRF analysis has an advantage of analyzing both conducting and nonconducting materials as well as inorganic and organic matrices. For quantification of weathering, $\mathrm{XRF}$ can be utilised to measure the rate of release of elements such as $\mathrm{Mg}$ or Si. In weathering studies, XRF analysis has a disadvantage of being ineffective if the released elements are redeposited in the mineral such as clays. XRF has another drawback of not being able to provide information on the mineral phases as well as their 
quantities. The method is therefore optimally utilised in conjunction with X-Ray Diffraction (XRD) analysis which determines the mineral phases present.

\section{- X-Ray Diffraction analysis}

$\mathrm{X}$-ray diffraction (XRD) analysis is an analytical technique that measures the X-ray scattering from crystalline or polymorphic materials. Each material produces a unique $\mathrm{X}$-ray "fingerprint" of X-ray intensity versus scattering angle that is characteristic of its crystalline atomic structure. Qualitative analysis is possible by comparing the XRD pattern of an unknown material with a library of known patterns. Although its principles are different, XRD can be considered complementary to XRF. For example, XRF can give details whether a material is composed of iron and/or sulfur, but XRD can tell you that both iron sulfide $(\mathrm{FeS})$ and elemental iron $(\mathrm{Fe})$ are present.

In the current study, XRD can be utilised to identify products of weathering if a comparison is made of the minerals before and after a weathering test. The clay mineral composition will be one of the items that will be considered. Accurate identification of clay minerals with XRD is complicated due to overlapping reflections. Morkel (2006) cited various sample treatment methods described by various authors that can be performed in order to identify various clay minerals such as smectites and vermiculites. The interlayer spacing value (d), which is the c spacing between the clay layers, can be utilised as a measure of the extent of weathering in swelling clay containing ore. For instance, an interlayer spacing below $10 \AA$ corresponds to 0 water layers, $12.6 \AA$ to 1 water layer, $15.6 \AA$ with 2 layers, $18.6 \AA$ to 3 layers $21.6 \AA$ to 4 layers and above this to more water layers (Lide, 2005).

\section{- Changes in the chemical composition of the weathering solution}

The release of elements into the weathering solution can also be utilised as a measure of weathering. An investigation on kimberlite was made by Morkel (2006) to determine the amounts of $\mathrm{Ca}^{2+}, \mathrm{Mg} 2+$ and $\mathrm{Fe}^{2+}$ released with time into the solution in weathering conditions of $9 \mathrm{M}$ sulphuric acid at $70{ }^{\circ} \mathrm{C}$. In the study, all three elements were found to 
increase with time, reaching constant levels after 24 hours. $\mathrm{Mg}^{2+}$ and $\mathrm{Fe}^{2+}$ were found to have the highest concentrations that were twice as high as that of $\mathrm{Ca}^{2+}$.

\section{- Assessment based on the mechanical properties of the material}

Various techniques were listed and described in detail by Morkel (2006) and Morkel and Saydam (2008) to assess weathering based on the mechanical properties of the material. These methods include the Schmidt hammer, the pendulum, the drop weight and the compression tests.

\section{- The slake durability test}

The slake durability test combines the effect of cyclic swelling (chemical weathering) and abrasion (mechanical weathering) to accelerate the weathering rate. The test procedure is standardised by the American Society for Testing and Materials (ASTM D4644-04). Ten pieces of rock particles weighing between 40 and $50 \mathrm{~g}$ each are contained in a steel drum that is partially immersed in a water bath containing a weathering solution. The steel drum is constructed of mesh wire that allows particles smaller than $2 \mathrm{~mm}$ sieve to pass through into a solution bath. The test is conducted by 10 min cycles of wetting, with oven drying at approximately $80{ }^{\circ} \mathrm{C}$ for $8-12$ hours in between the wetting cycles. The output of the test is the slake durability index which is the percentage of the final weight to initial weight after each cycle. Table 6 gives the measure of the weatherability of a rock based on the slake durability index.

Table 6: Weatherability of the rock based on the slake durability index (Morkel, 2006).

\begin{tabular}{|c|c|}
\hline $\begin{array}{c}\text { Weatherability of the } \\
\text { ore }\end{array}$ & \begin{tabular}{c} 
Slake durability index (\%) \\
\hline Very low
\end{tabular} \\
\hline Low & $0-25$ \\
\hline Medium & $50-50$ \\
\hline High & $75-95$ \\
\hline Very high & $95-100$ \\
\hline
\end{tabular}


In the study by Jahn (2008), the slake durability test was performed on Finsch and Venetia kimberlites. The study showed that the test is not the most appropriate method of evaluating weathering as the cutpoint at $2 \mathrm{~mm}$ is not the most efficient point to evaluate weathering. Utilising a different cutpoint on a particle size distribution (PSD) would improve the sensitivity of the test. This means a full PSD should be determined after the test and an appropriate cut point (for instance $\mathrm{d}_{50}, \mathrm{~d}_{75}$, etc) would be utilised to evaluate and compare the extent of weathering.

\section{KIMBERLITE ACCELERATED WEATHERING}

Accelerated weathering refers to the application of physical and/or chemical means to speed up the disintegration of rocks. Practical work by De Beers in the mid-70s was mainly on comparing physical and chemical methods of kimberlite weathering (Hopwood \& Webb, 1975). Physical methods investigated in this study included the use of microwave heating, ultrasonic breaking and heating (in the range 50 to $900{ }^{\circ} \mathrm{C}$ ) followed by quenching in water. The results of these tests showed reduced liberation from the violent shuttering, with no softening, of the kimberlite by microwave heating. Slight degradation of the kimberlite was observed with ultrasonic treatment whilst toughening of the kimberlite occurred due to chemical changes in the structure when chemical methods were utilised. The chemical methods involved water and chemical solutions such as acids and bases. Samples were exposed to room temperature and elevated temperatures up to the boiling points of the solution for up to 60 hours. It was concluded that water is necessary for the weathering process to take place. Samples immersed and heated in aluminium salts (chloride and sulphates) yielded successful results. The use of aluminium proved the theory that aluminium must enter the lattice for serpentine to be transformed to phyllosilicates. The clay like material formed was then removed by ultrasonics and therefore new surfaces of the kimberlite were exposed for further attack. Lower ultrasonic frequency had an improved effect on the breaking down.

In addition to microwave heating and ultrasonics, this investigation also included test work with light. It was found that light does contribute to the process of natural kimberlite weathering. The kimberlite was exposed to sunlight for up to 5 weeks. It was also found that infra-red light combined with air and water exposure caused cracking 
whilst ultra-violet light had no effect over a 60 hour period. The effect of sunlight was however later discredited by Roberts (1976) due to an error in the experimental set up. The hessian sack utilised to screen the sample from sunlight also caused changes in the atmosphere around the specimen and so the changes were not exclusively only for sunlight. A metal shield was therefore utilised to prevent sunlight penetration and the results showed that the sample weathered at the same rate as the control specimen exposed to the sunlight.

Recent studies in kimberlite weathering have rather focused more on chemical weathering through the manipulation of the CEC exhibited by swelling clays in kimberlite (Boshoff et al., 2007 and Morkel et al., 2007). Swelling of clays due to hydration and/or ion exchange produces pressures exerted between the clay stacking layers and this result in mechanical weathering of the ore (Yatsu, 1988). Studies of cations and organic molecules as ways of accelerating weathering are discussed further.

\subsubsection{Cation exchange}

Cations occupying swelling clay interlayers can be replaced by other cations in solution causing changes in the interlayer spacing. If the exchange causes further separation of these layers it can result in the disintegration of kimberlite. Boshoff et al. (2007) observed a maximum interlayer spacing of $15.6 \AA$ corresponding to 2 water layers when $\mathrm{Mg}^{2+}$ and $\mathrm{Cu}^{2+}$ were exchanged in kimberlite. This is the maximum interlayer spacing for ambient conditions (after drying the sample).

Moore and Reynolds (1989) investigated the exchange of cations in montmorillonite. The result showed that the ease of replacing or exchange cations followed the order: $\mathrm{Na}^{+}>\mathrm{K}^{+}>\mathrm{Ca}^{2+}>\mathrm{Mg}^{2+}>\mathrm{NH}_{4}{ }^{+}$. Therefore, $\mathrm{Ca}^{2+}$ is more stable in the interlayer space than $\mathrm{Na}^{+}$and is not replaced as easily as $\mathrm{Na}^{+}$. Kimberlites can contain appreciable amounts of expanding clays (up to 60\%, Morkel, 2006), the cation exchange capacity (CEC) is a useful tool in studying the weathering of kimberlites. The study by Morkel (2006) also showed a correlation between the CEC and the amount of swelling clays and between CEC and the weathering behaviour. Morkel (2006) observed that in cases where kimberlite or clay minerals have a tendency to exchange cations, the properties of the ore 
can be altered depending on the type of cation present in solution. Morkel concluded that the extent of kimberlite disintegration decreased in the order $\mathrm{Cu}^{2+}>\mathrm{Fe}^{3+}>\mathrm{Mg}^{2+}>\mathrm{Li}^{+}>$ $\mathrm{Ni}^{2+}>\mathrm{Ca}^{2+}>\mathrm{Al}^{3+}>\mathrm{Na}^{+}>\mathrm{NH}_{4}^{+}>\mathrm{K}^{+}$, with $\mathrm{K}^{+}$retarding disintegration. The parameters that can influence the extent of cation exchange include the ion concentration in solution, the acid concentration, temperature, the cycles of wetting and drying as well as use of microwaves.

\subsubsection{Organic adsorption}

Similar to the adsorption of cations, organic molecules can also be adsorbed on clay species. This will also influence the clay interlayer space and can cause disintegration of the kimberlite. The adsorption of organic species has been discussed in detail in sections 2.4 and 2.5 and includes test results on the adsorption of various organic species on clay minerals. The current investigation was performed through the fact that the presence of swelling clays in kimberlite will result in the absorbtion of organic molecules in the kimberlite structure. The use of organic molecules for accelerated weathering of kimberlite is therefore available as a potential processing route.

\subsubsection{Kimberlite and organic reagents}

Investigations on the use of organic solutions in kimberlites weathering have been initiated by Morkel and Pieters (2007), and Jahn (2008). The investigation by Jahn (2008) noted that formaldehyde, urea and oxalic acid yielded the highest degree of weathering under the test conditions. The technical report presented to De Beers by Morkel and Pieters (2007) showed results for a Dutoitspan kimberlite $(-26.5+22.4 \mathrm{~mm})$ utilising the organic reagents listed in Table 7. Parameters which were investigated included the effect of the carbon chain length, concentration, use of pure organic solutions, organic modification and adding a cation to an organic mixture. Results were interpreted by evaluating the particle size distribution of the product after a period of exposure to a given weathering solution. Measurements of the interlayer spacing (d) were however not part of this work. Some of the results of this study by Morkel and Pieters (2007) are discussed further. 
Table 7: Functional groups, industrial names and chemical formulas of organic compounds tested on kimberlite (Morkel \& Pieters, 2007).

\begin{tabular}{|l|c|c|c|c|}
\hline \multicolumn{1}{|c|}{$\begin{array}{c}\text { Functional } \\
\text { Group }\end{array}$} & $\begin{array}{c}\text { Industrial } \\
\text { Name }\end{array}$ & $\begin{array}{c}\text { Chemical } \\
\text { Formula }\end{array}$ & $\begin{array}{c}\text { Solubility in } \\
\text { Water }\end{array}$ & pK \\
\hline Alcohol & Ethanol & $\mathrm{C}_{2} \mathrm{H}_{6} \mathrm{O}$ & Soluble & 16 \\
\hline Nitrile & Glycerol & $\mathrm{C}_{2} \mathrm{H}_{4} \mathrm{O}_{2}$ & $1000 \mathrm{~g} / \mathrm{l}$ & 14.15 \\
\hline Sulfoxide & Acetonitrile & $\mathrm{CH}_{3} \mathrm{CN}$ & Soluble & 25 \\
\hline Sulfone & sulfoxide & $\mathrm{C}_{2} \mathrm{H}_{6} \mathrm{OS}$ & $1000 \mathrm{~g} / \mathrm{l}$ & 25 \\
\hline Ketone & Dimethyl & $\mathrm{C}_{2} \mathrm{H}_{6} \mathrm{O}_{2} \mathrm{~S}$ & $150 \mathrm{~g} / \mathrm{l}$ & 25 \\
\hline Aldehyde & Acetone & $\mathrm{CH}_{3} \mathrm{COCH}_{3}$ & Soluble & 20 \\
\hline Carboxylic acid & Oxalic acid & $\mathrm{C}_{2} \mathrm{H}_{4} \mathrm{O}_{4}$ & $220 \mathrm{~g} / \mathrm{l}$ & 1.23 \\
\hline Ester & Methyl acetate & $\mathrm{CH}_{3} \mathrm{H}_{6} \mathrm{O}_{2}$ & Soluble & - \\
\hline $\begin{array}{l}\text { Carboxylic acid } \\
\text { anhydride }\end{array}$ & $\begin{array}{c}\text { Acetic } \\
\text { anhydride }\end{array}$ & $\mathrm{C}_{4} \mathrm{H}_{6} \mathrm{O}_{3}$ & Soluble & - \\
\hline Amine & Ethylamine & $\mathrm{C}_{2} \mathrm{H}_{5} \mathrm{ONH}_{2}$ & $69 \mathrm{~g} / \mathrm{l}$ & 10.63 \\
\hline
\end{tabular}

\section{Carbon chain length}

The effect of increase in the carbon chain length was tested with carboxylic acids and alcohols at $0.4 \mathrm{M}$ concentration. The carboxylic acids; oxalic acid, tartaric acid, citric acid and adipic acid showed the capability of enhancing weathering. The effect of chain length was not conclusive because of the varying molecular structures of the test reagents (Pieters et al, 2006). The other reason was the low solubility of adipic acid $\left(\mathrm{n}_{\mathrm{c}}=6\right)$ in water resulting in less weathering in comparison with tartaric acid $(n c=4)$. For alcohols: propanol, butanol, pentanol, cyclohexanol and naphthol showed an increase in weathering with increasing chain length, with naphthol $\left(\mathrm{n}_{\mathrm{C}}=10\right)$ producing $\sim 65 \%$ passing $16 \mathrm{~mm}$. 


\section{Concentration}

Increase in concentration showed no significant effect on weathering when butanol was utilised at concentrations of $0.1,0.17,0.2,0.4$, and $0.8 \mathrm{M}$. Similar results of $\sim 45 \%$ passing $16 \mathrm{~mm}$ were obtained.

\section{Pure organic compound}

The pure organic solutions of cyclohexanol, butanol, pentanol, docosanol and pentanol were tested to investigate the effect of utilising pure organic solutions. The samples were exposed to the organic solutions for 2 days. No weathering took place for all the reagents except docosanol and pentanol which gave improved weathering results of $55 \%$ passing $16 \mathrm{~mm}$.

\section{Organic modification}

Kimberlite was saturated in separate solutions of dodecylamine, pentanol and acetonitrile for 2 days to render the smectite organophilic. The organic compounds listed in Table 7 were then tested for a further 4 day period. Results showed all compounds increased the weathering with acetonitrile, dodecylamine and pentanol giving $85 \%, 78 \%$ and $55 \%$ passing $16 \mathrm{~mm}$ respectively.

\section{Effect of cations}

Two 0.4 M oxalic acid solutions were prepared for the test. In one of the solutions, $0.01 \mathrm{M} \mathrm{Ca}^{2+}$ was added to observe the effect of cations. Results showed an improvement in weathering from $47 \%$ to $62 \%$ passing $16 \mathrm{~mm}$ on addition of $\mathrm{Ca}^{2+}$ with the oxalic acid.

\section{ALTERATION OF MINERALS IN KIMBERLITE}

Not all kimberlites contain swelling clay minerals. The kimberlite ore investigated by Morkel (2006) varied in swelling clay content, $30 \%$ to $60 \%$ by weight. It was reported that kimberlites without swelling clay minerals were not susceptible to weathering under any of the tested conditions. Therefore the accelerated weathering capability of kimberlite material depends on its mineralogical features. 
It is possible that the presence of non-swelling clays in kimberlite is due to insufficient alteration to form smectites. This could also be caused by a solid state alteration of the swelling clay minerals into non-swelling, usually mixed-layer, clays. Smectites can further dissolve to form mixed-layered illite-smectite (I/S) clays (Kim et al., 2004) or can become kaolinite via mixed-layer kaolinite-smectite (Środoń, 1999). The presence of illite in interstratified clays affects the flexibility and swelling properties of clays (M'bodj et al., 2004). Formation of illite is attributed to $\mathrm{Fe}^{2+}$ formation at the expense of $\mathrm{Fe}^{3+}$ by microbes which results in a decrease of the positive charge in the octahedral sheet accompanied by $\mathrm{K}^{+}$uptake (Kim et al., 2004). I/S clays are difficult to identify and quantify as smectite can be indistinguishable from illite if sample treatment and preparation is not performed properly (Šucha et al., 2001).

One of the suggested kimberlite weathering mechanisms is accompanied by the loss of $\mathrm{Mg}$ and $\mathrm{Ca}$ as bicarbonate ions, accompanied in turn by the addition of $\mathrm{Al}$ and $\mathrm{Fe}$ ions (Roberts \& Hopwood, 1975). Increasing $\mathrm{CO}_{2}$ pressure has been suggested in order to promote carbonate formation and provide a means for the removal of $\mathrm{Mg}$. Natural weathering of kimberlite from olivine to serpentine can allow carbonisation of the resulting serpentine to talc and magnesite (a $\mathrm{Mg}$-carbonate); a signature mineral that indicates that weathering has taken place. Other minerals contained in kimberlite such as garnet, ilmenite and zircon are extremely resistant to weathering, but these minerals are not prominent in kimberlite

Kimberlite with a predominance of micas, serpentine and chlorites will not react to accelerate weathering conditions. An alternative that was investigated in this study was to render non-weatherable kimberlite weatherable, by transforming non-swelling clays into swelling clays. It explored a method that would accelerate the alteration to another mineral, such as chlorites or mica, to smectite. Yatsu (1988) mentioned the possibility of the transformation of chlorites and micas because of the structural similarities between phyllosilicates that allow them to form other interstratified minerals.

Alteration is the transformation of an original constituent of the rock to a different or related phase. The process normally occurs in solution and at elevated temperatures, 
known as hydrothermal alteration (Hodgson, 1981), although some laboratory experiments on clays have been performed at room temperature (Lin \& Clemency, 1981(a)). Alteration of minerals involves the dissolution of cations in the mineral structure such as $\mathrm{Si}, \mathrm{Mg}$ and $\mathrm{Al}$, with a subsequent formation of new phases (Kukovskii, 1976). In essence, this is a weathering process, as a volume weight loss usually takes place. Mineral alteration has been extensively studied on sheet silicates such as mica (Pal et al., 2001; Taylor et al., 2000; Kretzschmar et al., 1997; Kalinowski \& Schweda, 1996; Lin \& Clemency (b) \& (c), 1981; Hoda \& Hood, 1972) and chlorites (Senkayi et al., 1981; Ross \& Kodama, 1976; Ross, 1975) and for other principal clay minerals (Cuadros \& Linares, 1996).

Previously, laboratory alteration experiments performed in acidic conditions, or under oxidizing conditions, included a cation exchange step. When acids such as sulphuric, hydrochloric and nitric acid are utilised, they dissolve the structural cations in order to precipitate these cations into other phases. Oxidizing conditions usually encourage the redox $\mathrm{Fe}^{2+} / \mathrm{Fe}^{3+}$ reaction in the silicate layers that support clay mineral alteration. A cation exchange step, which is incorporated into both treatments, aims to achieve the following:

- To act as an indicator for the formation of expandable silicates from layered silicates as a result of an improved CEC, as well as an increase in the interlayer spacing (Ross \& Kodama, 1976; Ross, 1975) or adsorption of organic molecules (Vali \& Hesse, 1992).

- The pillaring of the interlayer to expand and maintain the interlayer spaces (up to $18 \AA$ ), even at high temperatures (Caballero \& Poncelet, 2000 (a) \& (b)).

- The removal of potassium $\left(\mathrm{K}^{+}\right)$ions, the dominant charge-compensating interlayer cation in the case of phlogopite, a nonexpanding mica. The $\mathrm{K}^{+}$ion can be replaced by either inorganic cations or organic ligands.

Possible alteration routes for both micas and chlorites into expandable clays are described in more detail below. 


\subsection{Mica to smectite transformation}

Mica is a hard, layered phyllosilicate with pronounced cleavage planes and so can be split into sheets. Mica may alter with time into smectite through vermiculite, or mixed layer clay minerals, through a combined attack of acid and organic ligands (Egli et al., 2001). Smectites may be produced at the expense of micas in the form of biotite (trioctahedral mica), as well as from muscovite (dioctahedral mica) (Egli et al., 2003). Conversion of mica to smectites can be achieved in one or all of the steps described below. The interlayer region is the initial point of attack, resulting in the replacement of interlayer $\mathrm{K}^{+}$ by hydrated cations. This is normally accompanied by a reduction in the structural charge due to $\mathrm{Fe}^{2+}$ oxidation, and finally by a hydroxyl orientation. An alternate transformation method is the selective leaching of $\mathrm{Al}^{3+}$, accompanied by its replacement with $\mathrm{Si}^{4+}$.

\section{$\mathbf{K}^{+}$release}

Potassium $\left(\mathrm{K}^{+}\right)$is located at the outer surface and the interlayers in mica. Its release from this structure promotes alteration of mica. The balance of charge is normally obtained by hydrated cations inserted between silicate layers, resulting in the formation of vermiculite. The release of $\mathrm{K}^{+}$can be encouraged by chemical means utilising $\mathrm{HCl}$ (Gates et al., 2002), barium chloride $\left(\mathrm{BaCl}_{2}\right)$, sodium tetraphenylboron $\left(\mathrm{NaBPh}_{4}\right)$, or biologically utilising fungus species. The release of $\mathrm{K}^{+}$from biotite may, however, be inhibited by muscovite weathering when the two micas co-exist (Pal et al., 2001). Yatsu (1988) highlighted the method followed by previous authors to alter di- and trioctahedral micas to vermiculite by extracting $\mathrm{K}^{+}$chemically utilising $\mathrm{NaBPh}_{4}$.

The mechanism suggested is as follows:

1. Replacement of $\mathrm{K}^{+}$by $\mathrm{Na}^{+}$at interlayer sites,

2. Release of structural $\mathrm{OH}^{-}$ions exposed by replacement of $\mathrm{K}^{+}$, which decreases the negative charge allowing the structure to expand and more $\mathrm{K}^{+}$to be replaced,

3. Oxidation of $\mathrm{Fe}^{2+}$ ions by the reaction

$$
4 \mathrm{Fe}^{2+}+4 \text { structural }\left(\mathrm{OH}^{-}\right)+\mathrm{O}_{2} \rightarrow 4 \mathrm{Fe}^{3+}+4 \text { structural }\left(\mathrm{O}^{2-}\right)+2 \mathrm{H}_{2} \mathrm{O}
$$


4. Release of divalent octahedral ions, possibly through the hole which remains when structural $\mathrm{OH}^{-}$is lost.

\section{$\mathrm{Fe}^{2+}$ oxidation}

$\mathrm{Fe}^{2+}$ oxidation is assumed to be associated with a reversible deprotonation of the hydroxyl ions (Kalinowski \& Schweda, 1996). $\mathrm{Fe}^{2+}$ is found in the hydroxyl interlayer as well as in the octahedral structure. The hydroxyl interlayer is easily accessible as compared to the octahedral structure. According to Środon (1999), $\mathrm{Fe}^{2+}$ location plays an important role in the extent of mica alteration.

Depending upon the $\mathrm{pH}$, mica can be altered into either smectite or vermiculite through oxidation of $\mathrm{Fe}^{2+}$. Oxidation of $\mathrm{Fe}^{2+}$ in biotite under neutral and alkaline conditions forms an expanded crystal lattice of smectite due to a large decrease in surface charge. However, under acid conditions vermiculite is more likely to be formed when the balance of $\mathrm{Fe}^{2+}$ oxidation is achieved through the loss of octahedral iron and magnesium, which results in the total octahedral layer charge remaining high (Yatsu, 1988). In section 2.1.5.4(v), vermiculite is considered as an intermediate mineral with an expanding structure in the transformation of micas into smectite. In addition, oxidation of $\mathrm{Fe}^{2+}$ can aid the release of $\mathrm{K}^{+}$; also an important step in mica transformation. Oxidants that have been examined with biotite transformation include $\mathrm{O}_{2}, \mathrm{NaOCl}, \mathrm{H}_{2} \mathrm{O}_{2}$ and $\mathrm{Br}_{2}$ (Yatsu, 1988). Of these, $\mathrm{O}_{2}$ was observed to produce a relatively low oxidizing power due to its low aqueous solubility.

Because oxidation and $\mathrm{K}^{+}$release are the two important stages that should take place during mica transformation, the extent of each stage may have an effect upon the other. In the case of oxidation prior to $\mathrm{K}^{+}$release, Gilkes (1973) reported variation in the exchangeability of $\mathrm{K}^{+}$in biotite from adjacent sheets. Oxidation induces some structural change. For instance, an altered hydroxyl orientation, distorted or contracted tetrahedral sheets or loss of hydroxyl species and so the extent of structural changes may affect the release of $\mathrm{K}^{+}$. It is worth investigating the effect of the sequence of stages until the point of mica transformation. 


\section{Selective $\mathrm{Al}^{3+}$ leaching}

The conversion of dioctahedral micas to smectite necessitates lowering of the total charge. Transformations of trioctahedral micas require a decrease in tetrahedral $\mathrm{Al}^{3+} / \mathrm{Si}^{4+}$ ratio (Kalinowski \& Schweda, 1996). This was concluded by tests performed at pH 1 to 4 , at room temperature. The procedure utilised to decrease the $\mathrm{Al}^{3+} / \mathrm{Si}^{4+}$ ratio is a complicated one, as it requires the replacement of the leached $\mathrm{Al}^{3+}$ by $\mathrm{Si}^{4+}$. The available $\mathrm{Si}^{4+}$ atoms needed to fill the $\mathrm{Al}^{3+}$ vacancies would have to be supplied from solution in the form of uncharged $\mathrm{Si}(\mathrm{OH})_{4}$ complexes. At the same time, leaching of $\mathrm{Al}^{3+}$ will increase the layer charge, as a $+3\left(\mathrm{Al}^{3+}\right)$ charge will be replaced by a $+4\left(\mathrm{Si}^{4+}\right)$ charge. To counter this increase, Kalinowski and Schweda (1996) suggested the protonation of structural oxygens to form $\mathrm{H}_{2} \mathrm{O}$ or $\mathrm{OH}^{-}$.

From this study it is evident that micas with high charge densities and high $\mathrm{K}^{+}$cannot expand, nor can they take up water in the interlayer spacing; this is confirmed by Lerf (2004). Large cations such as $\mathrm{NH}_{4}{ }^{+}, \mathrm{Rb}^{+}$and $\mathrm{Cs}^{+}$with low hydration energy cannot expand the interlayer space sufficiently to release the interlayer $\mathrm{K}^{+}$. It has been reported that an exchange of $\mathrm{K}^{+}$for n-alkylammonium in micas (Van Olphen, 1963), and $\mathrm{K}^{+}$for dodecylammonium in micas (Theng, 1974), results in lattice expansion.

\subsection{Chlorite to smectite transformation}

Similarly to micas, chlorites can alter into vermiculite and interstratified minerals of chlorite-vermiculite or chlorite-smectite. The process involves the loss of $\mathrm{Fe}$ and $\mathrm{Mg}$ to the extent that the mineral loses its trioctahedral character (Środoń, 1999). One of the processes that may allow this transformation is the extraction of hydroxide sheets. This, however, has not been achieved utilising chemical techniques. The oxidation technique which utilises saturated bromine in water on a steam bath is reported by Yatsu (1988). The mechanism involves the oxidation of $\mathrm{Fe}^{2+}$ to produce either vermiculite or smectite. The amount of ferrous $\mathrm{Fe}$ in chlorite, as well as its distribution between the hydroxide and the 2:1 units, determines the reaction rates and the products obtained (Senkayi et al., 1981). A rapid Fe oxidation and removal occurs if Fe occurs in the interlayer hydroxide sheets. If, however, most of the Fe is located in the octahedral 
positions of the 2:1 units, the reaction will be slower and will result in a reduction of charge and the formation of smectite instead of vermiculite.

\section{EXPERIMENTAL PROCEDURE}

Ore samples were received from three De Beers diamond mines: Finsch, Koffiefontein and Venetia mine. The Finsch ore was received, crushed and screened to a $-19+13.2$ milimeter (mm) size fraction (Figure 14) and the Koffiefontein ore was received as $65 \mathrm{~mm}$ diameter drillcores (Figure 15). Various Venetia samples were received as drillcore samples: (i) $215 \mathrm{~mm}$ diameter drillcores shown in Figure 16, which were named K1 Tuffisitic Kimberlite Breccia East (K1) and (ii) drillcores from a number of sites, obtained courtesy of the Venetia mine underground expansion project (VUE), ranging from $40 \mathrm{~mm}$ to $65 \mathrm{~mm}$ in diameter (Figure 17). The Finsch and the Koffiefontein ore samples weighed approximately $200 \mathrm{~kg}$ each. The Venetia mine sample was about $300 \mathrm{~kg}$ in total for the $\mathrm{K} 1$ type, and approximately $80 \mathrm{~kg}$ in total weight for the VUE samples. The ore samples received as drillcores were crushed utilising a laboratory jaw crusher to a size of $-26 \mathrm{~mm}$. The Venetia $\mathrm{K} 1$ ore was first broken down into smaller pieces utilising a sledgehammer before jaw crushing. After crushing, the samples were split utilising the Eriez rotary splitter into representative samples weighing approximately $300 \mathrm{~g}$ each.

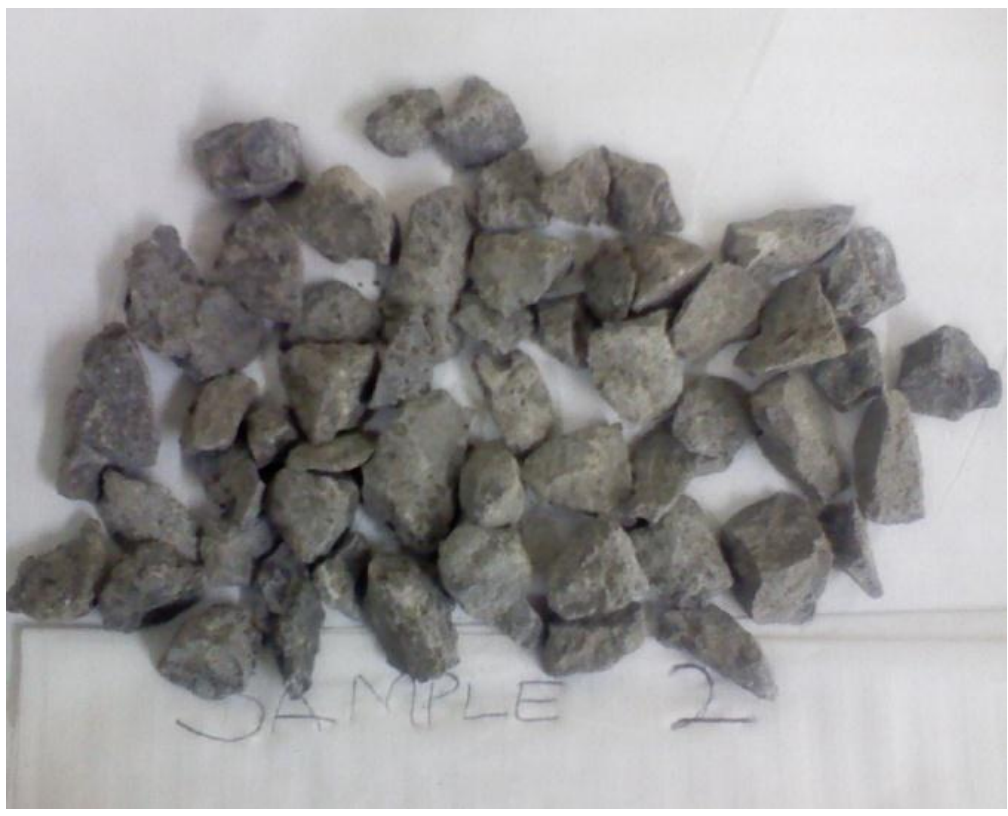

Figure 14: The $-16+13.2 \mathrm{~mm}$ Finsch sample as received. 


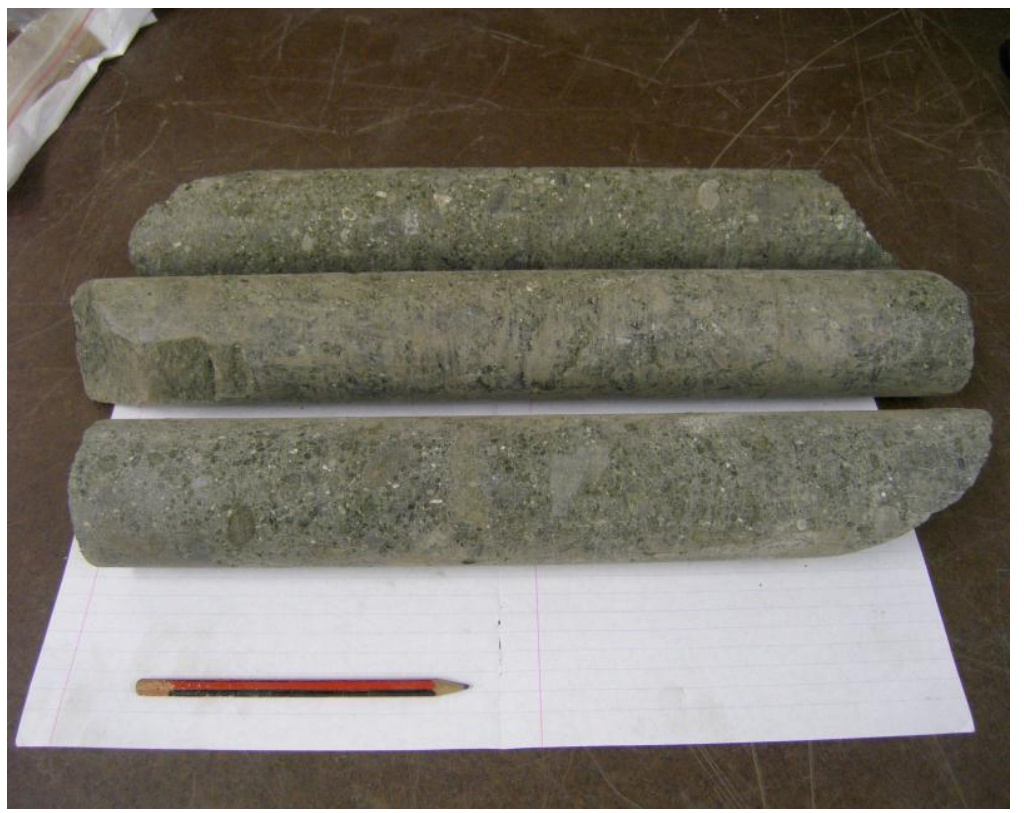

Figure 15: The $65 \mathrm{~mm}$ Koffiefontein kimberlite drillcore samples as received.

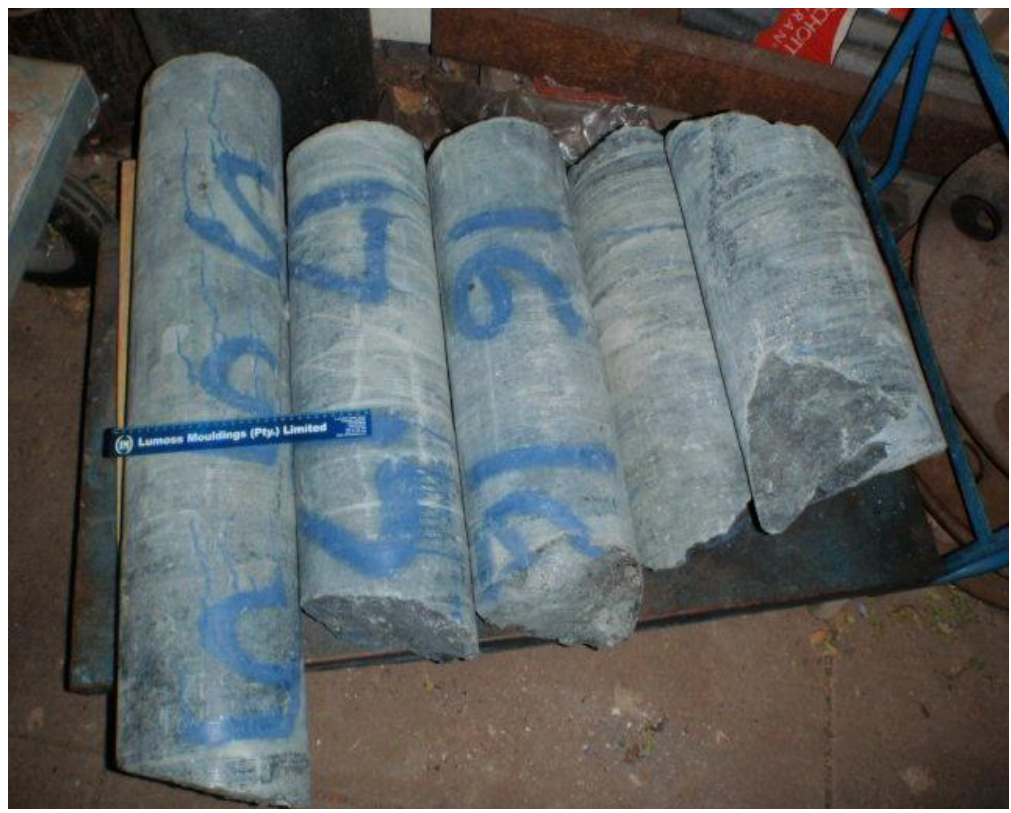

Figure 16: The $215 \mathrm{~mm}$ diameter Venetia K1 kimberlite drillcore samples. 


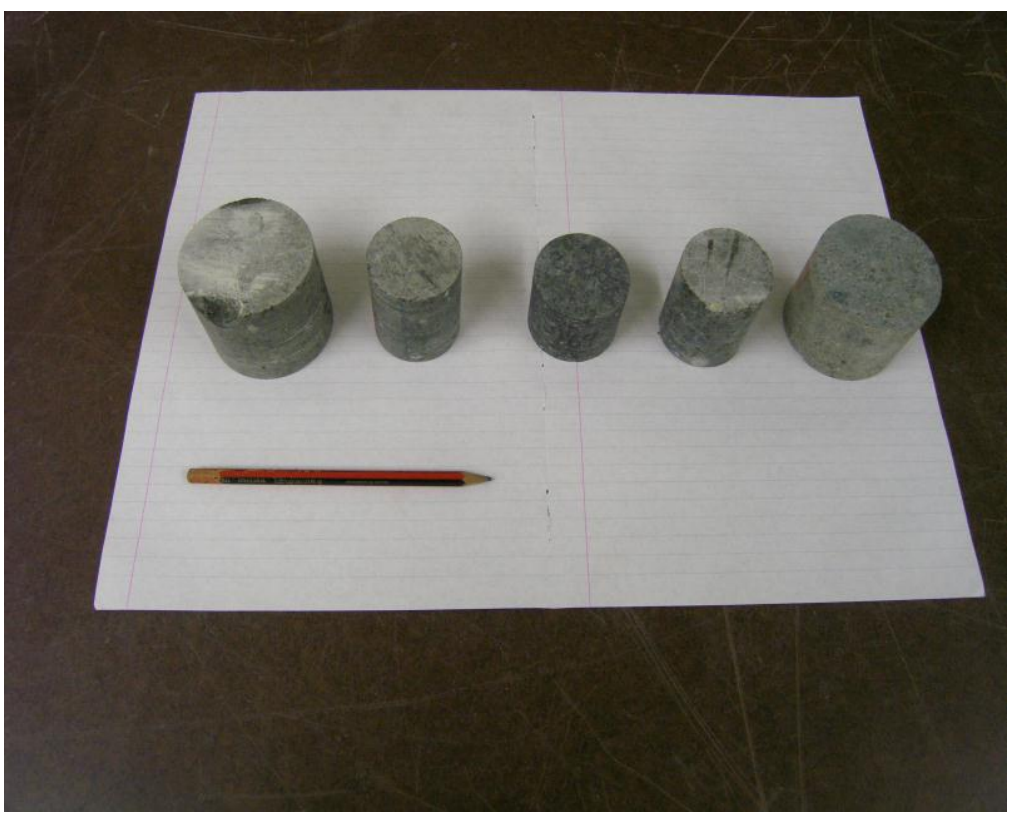

Figure 17: Venetia expansion project drillcore samples with diameters ranging from 40 to $65 \mathrm{~mm}$.

\subsection{Ore characterisation}

Characterisation of the mineralogical features of the Finsch, Koffiefontein and the Venetia K1 ore samples was performed. The mineralogy for the VUE samples was provided by the mine as mineralogical characterisation had already been completed on these samples. A $300 \mathrm{~g}$ representative sample of the Finsch, the Koffiefontein and the Venetia K1 samples was milled utilising a laboratory ball mill to about $50 \mu \mathrm{m}$. The product, after milling, was sent for mineralogical analysis, which included XRD, XRF as well as CEC measurements. For the VUE samples, only XRD and XRF results were available.

\subsubsection{X-Ray Fluorescence (XRF) analysis}

$\mathrm{XRF}$ analysis was performed at the University of Pretoria. The samples were prepared as pressed powder briquettes and introduced to the ARL 9400XP+ XRF spectrometer. Analysis was executed utilising the UniQuant software program. The software analyses for all elements in the periodic table between $\mathrm{Na}$ and $\mathrm{U}$, and only elements found above the detection limits, were reported. The values were normalised as no loss on ignition (LOI) was performed to determine crystal water and oxidation state changes. Elements were expressed as oxides in the results. 


\subsubsection{X-Ray Diffraction (XRD) analysis}

XRD analysis was performed at the University of Pretoria. The analysis was executed on a PANalytical X'Pert Pro powder diffractometer with X'Celerator detector with Fe-filtered $\operatorname{CoK} \alpha$. Relative phase amounts (weight \%) were estimated utilising the Rietveld method (Autoquan Program). Ethylene glycol (EG) treatments were performed to test the presence of swelling clay minerals, which were reported as smectites.

\subsubsection{Cation Exchange Capacity (CEC) determination}

CEC measurements were performed at the Agricultural Research Council of South Africa (ARC) Institute for Soil, Climate and Water. For this test, the sample was leached with a $1 \mathrm{M}$ ammonium acetate solution at $\mathrm{pH}$ 7. The total amount of ammonium retained by the sample (after washing it free of excess ammonium acetate with $80 \%$ alcohol) was regarded as an estimate of the cation exchange capacity. The adsorbed ammonium was released by leaching the sample with an acidified potassium chloride solution, and the amount released subsequently determined, first by distillation, and then by titration with 0.05 M Sulphuric acid. Results were reported in centimole per kilogram $(\mathrm{cmol} / \mathrm{kg})$. For this method, the detection limit was approximately $1.0 \mathrm{cmol} / \mathrm{kg}$.

\subsubsection{Thermogravimetric (TGA) analysis}

TGA analysis was conducted at the University of Pretoria. Analysis was performed by placing $20 \mathrm{mg}$ samples into $150 \mu \mathrm{l}$ Alumina pans. These were then put into the TGA/SDTA machine, model A851 ${ }^{\mathrm{e}}$, supplied by Mettler Toledo. The samples were heated from 25 to $1000{ }^{\circ} \mathrm{C}$ at $10{ }^{\circ} \mathrm{C} / \mathrm{min}$ with a gas flow rate of $50 \mathrm{ml} / \mathrm{min}$ in a nitrogen environment. Results were reported as \% weight loss as a function of temperature in ${ }^{\circ} \mathrm{C}$.

\subsubsection{Fourier Transform Infrared Spectroscopy (FTIR) analysis}

FTIR analysis was conducted at the University of Pretoria. The KBr method was utilised. The procedure involved $3 \mathrm{mg}$ of sample that was mixed with $200 \mathrm{mg}$ of $\mathrm{KBr}$ and pressed into a disc utilising a manual hydraulic press. The disk was then inserted into the 
Spectrum GX machine by Perkin Elmer utilising the Spectrum GX FT-IR version 5.3 software program. The scan range was from $4000 \mathrm{~cm}^{-1}$ to $400 \mathrm{~cm}^{-1}$, at 8 scans per sample, at a resolution of $4 \mathrm{~cm}^{-1}$. Results were reported as $\%$ Transmittance $(\% \mathrm{~T})$ as a function of frequency $\left(\mathrm{cm}^{-1}\right)$.

\subsection{Experimental test work}

The study was divided into five parts, namely: (i) Investigating the possibility of a relationship between smectite content and TGA analysis, (ii) Investigation of organic medium adsorption, (iii) Standard organic weathering tests, (iv) Kinetic evaluation of weathering, and (v) Mineral alteration tests. The various tests and conditions are described.

\subsubsection{Correlation between smectite content and TGA analysis}

An investigation was conducted to test if there is a relationship between the smectite content and the TGA analysis results. It has been shown that smectite content can, to some extent, predict the weathering behaviour of kimberlite (Morkel, 2006). The aim of the investigation was to test the correlation between smectite content and TGA analysis results, and to test whether there is a correlation between the weathering behaviour and TGA analysis results.

These tests were performed on $18 \mathrm{VUE}$ (Venetia mine underground expansion project) samples. The VUE was utilised as the ore contained a wide mineralogical content. The smectite content in the ore was ranging between 0 and $51.5 \%$. The following drillcores were tested; UCM 1, 12, 16, 24, 62, 64, 83, 85, 86, 89, 97, 99, 101, 103, 117, 132, 134 and 138. The ore samples were crushed to $-26 \mathrm{~mm}$ utilising a laboratory jaw crusher and then milled to $80 \%$ passing $100 \mu \mathrm{m}$ utilising a laboratory ball mill. The product was then split utilising the Eriez rotary splitter into $20 \mathrm{~g}$ samples that were sent for TGA analysis. TGA analysis was performed at the University of Pretoria. The \% weight loss with increase in temperature was reported from $125^{\circ} \mathrm{C}$ to $1000{ }^{\circ} \mathrm{C}$. 


\subsubsection{The investigation of organic medium adsorption}

Organic medium tests were performed utilising the Koffiefontein ore sample. The aim of these tests was to investigate the relationship between the clay interlayer space ( $\mathrm{d}_{001}$-spacing) and the extent to which organic reagents were adsorbed during this process. The mechanism with which the organic reagents react on the ore particles' surface was also investigated.

The $300 \mathrm{~g}$ samples of $-26 \mathrm{~mm}$ size of the Koffiefontein ore sample were milled utilising a laboratory ball mill to $80 \%$ passing $100 \mu \mathrm{m}$. Splitting was performed into $20 \mathrm{~g}$ samples utilising the Eriez rotary splitter. The $16 \mathrm{~g}$ samples were immersed in $250 \mathrm{ml}$ ( $\sim \%$ solids by mass) of a given $0.5 \mathrm{M}$ organic solution, for 7 days at room temperature $\left(\sim 25^{\circ} \mathrm{C}\right)$, in flat bottomed plastic containers as shown in Figure 18. Evaporation of the soulition was minimal over the test period. The organic solutions tested under these conditions were ethanol, n-hexane, formamide, oxalic acid, urea, pentanoic acid and acetic acid. After the test run, samples were air dried for 1 day and analysed utilising three techniques: XRD analysis (for d-spacing determinations), Thermogravimetric analysis (TGA) (for the extent of organic adsorption) and Fourier Transform Infrared Spectroscopy analysis (FTIR) (for information about the mechanism of attachment on the particle surface). 


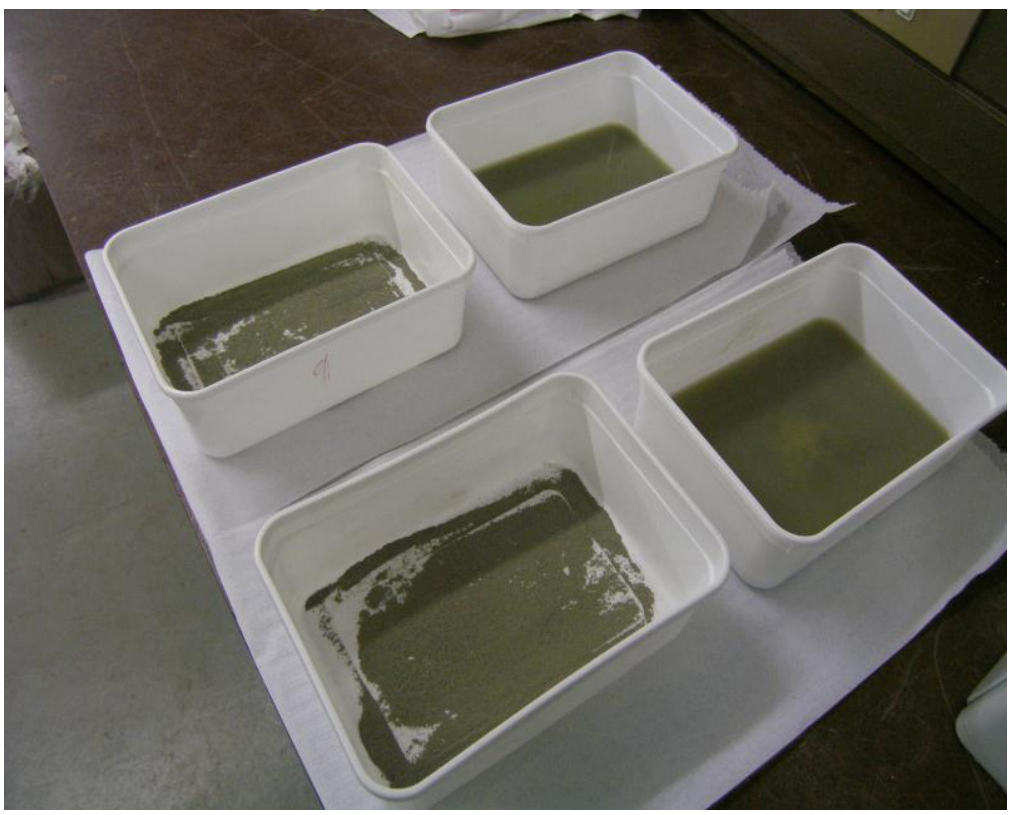

Figure 18: Experimental setup for weathering tests utilising $16 \mathrm{~g}$ of $80 \%$ passing $100 \mu \mathrm{m}$ Koffiefontein sample exposed to $250 \mathrm{ml}$ of various organic solutions for seven days.

Other tests conducted under the investigation of organic medium adsorption were:

- The effect of pure organic reagents on adsorption

- The effect of pre-cationic treatment on organic adsorption

- The effect of pre-organic treatment on organic adsorption

\section{The effect of pure organic reagents on adsorption}

The Koffiefontein ore sample was utilised to test the effect of utilising pure organic solutions as weathering media. The $16 \mathrm{~g}$ samples of the $80 \%$ passing $100 \mu \mathrm{m}$ milled Koffiefontein ore were immersed in $250 \mathrm{ml}$ of pure organic solution for 7 days at room temperature $\left(\sim 25^{\circ} \mathrm{C}\right)$ in flat bottomed plastic containers. Organic solutions tested under these conditions were ethanol, n-hexane, formamide, pentanoic acid and acetic acid. Oxalic acid and urea were excluded from this test, as they were only available in solid form. Dissolving these in another organic was not considered, so as to avoid the dilution effect, as well as interaction between organic reagents. After the test run, samples were air dried for 1 day and then submitted for XRD, TGA and FTIR analysis. 


\section{The effect of pre-cationic treatment on organic adsorption}

The effect of cation pretreatment prior to organic weathering was investigated utilising the Koffiefontein ore sample. A $16 \mathrm{~g}$ sample of the $80 \%$ passing $100 \mu \mathrm{m}$ milled Koffiefontein ore was first immersed in $250 \mathrm{ml}$ of $0.5 \mathrm{M}$ cation solution for 7 days at room temperature $\left(\sim 25^{\circ} \mathrm{C}\right)$ in flat bottomed plastic containers. The cations tested in separate solution were $\mathrm{Mg}^{2+}, \mathrm{Ca}^{2+}, \mathrm{Na}^{+}$, and $\mathrm{K}^{+}$. After 7 days, the samples were removed and air dried. After drying for 1 day, the samples were then immersed in $0.5 \mathrm{M}$ organic solutions for 7 days at room temperature. Organic solutions that were tested under these conditions were ethanol, n-hexane, formamide, oxalic acid, urea, pentanoic acid and acetic acid. After 7 days, the samples were air dried for 1 day, and then submitted for XRD, TGA and FTIR analysis.

\section{The effect of pre-organic treatment on organic adsorption}

The investigation of the effect of organic pretreatment prior to organic weathering was conducted by utilising the Koffiefontein sample and followed the similar test procedure to that of pre-cation treatment, except that organic reagents, instead of cations, were utilised as pretreatment media. The pretreatment organic solutions tested at $0.05 \mathrm{M}$ were pyridine $(\mathrm{P})$, cetylpyridium chloride (CPC), dimethyldioctadecylammonium chloride (DDAC) and dodecylamine (DDA). After 7 days in the organic media, samples were air dried for 1 day. After drying, the samples were immersed in $0.5 \mathrm{M}$ formamide organic medium at room temperature. Formamide was utilised as it had produced a slightly larger d-spacing during the initial organic immersion tests. After 7 days the samples were air dried for 1 day, and then submitted for XRD, TGA and FTIR analysis.

\subsubsection{Standard organic weathering test}

The Finsch ore sample was utilised for the standardized organic tests. The $300 \mathrm{~g}$ ore samples of $-16+13.2 \mathrm{~mm}$ size fraction was immersed in $1 \mathrm{~L}$ of the organic solution in flat bottomed plastic containers as shown in Figure 19. In the containers, particles were spread in a single layer with no touching. The test was conducted at room temperature $\left(\sim 25^{\circ} \mathrm{C}\right)$, at a solution concentration of $0.5 \mathrm{M}$ and an immersion period of 6 days. The 
organic solutions tested were: ethanol, n-hexane, formamide, oxalic acid, urea and acetic acid, as well as distilled water and $0.5 \mathrm{M} \mathrm{Cu}^{2+}$ in chloride form for comparison purposes. After weathering for 6 days, the sample was removed and air dried for 1 day. Dry sieving was performed utilising a set of sieves stacked in a Tyler series from $13200 \mu \mathrm{m}$ to $38 \mu \mathrm{m}$ and shaken utilising the Retsch AS 200 model sieve shaker. Sieving was performed to determine the particle size distribution (PSD) after weathering. The PSD curves were plotted with the arithmetic mean sieve size on the $\mathrm{x}$-axis and the cumulative \% passing screen size on the y-axis. All the tested solutions were then compared to each other, with the distilled water result as the base case.

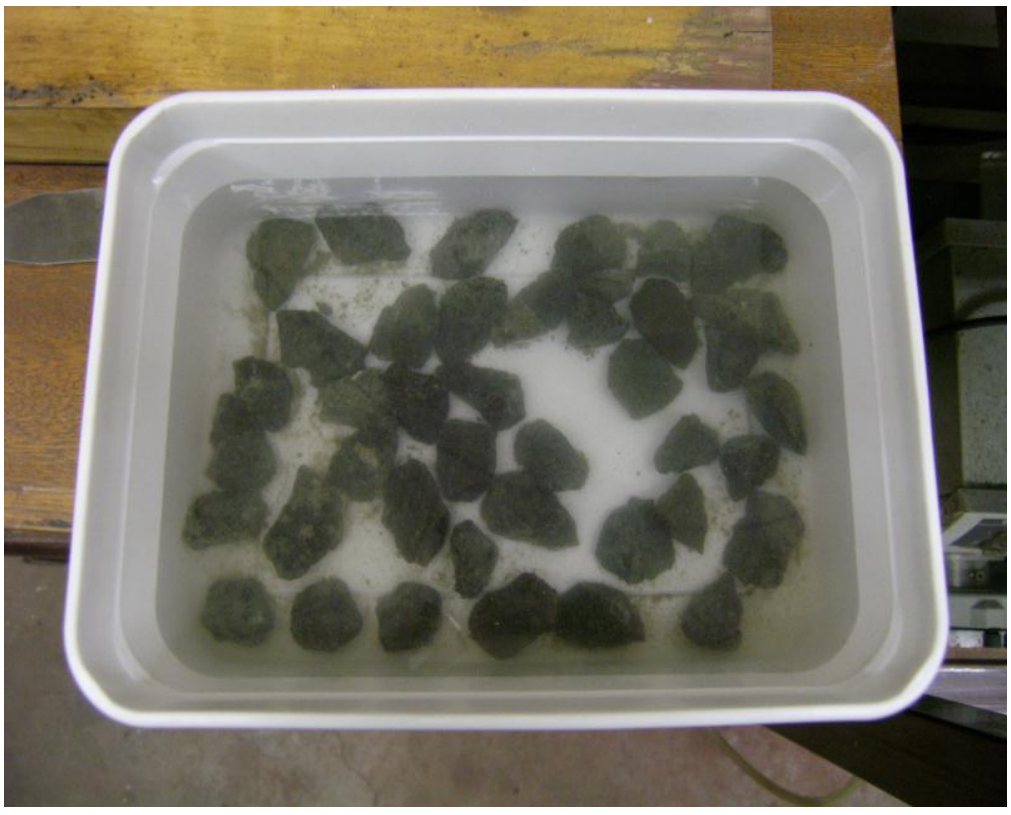

Figure 19: The standard weathering test utilising $300 \mathrm{~g}$ of $-16+13.2 \mathrm{~mm}$ Finsch kimberlite exposed to $1 \mathrm{~L}$ of various organic weathering media.

Other variables tested were:

- The effect of time on weathering.

- The effect of organic concentration on weathering.

- The effect of temperature on weathering.

- The effect of pretreatment prior to organic weathering.

Oxalic acid was utilised to tests these variables as it had shown better weathering results. 


\section{The effect of time on weathering}

The Finsch ore sample was utilised for these tests. The procedure for the test was similar to the base case test procedure in section 6.2.3. The $300 \mathrm{~g}$ of $-16+13.2 \mathrm{~mm}$ material was immersed in $1 \mathrm{~L}$ of the organic medium in flat bottomed plastic containers. The test was conducted at room temperature $\left(\sim 25^{\circ} \mathrm{C}\right)$, utilising oxalic acid at a solution concentration of $0.5 \mathrm{M}$ and for immersion periods of 2, 6, 15 and 30 days. After weathering for a given time period, the weathered samples were air dried for 1 day. After drying each test sample, dry sieving was performed to determine the particle size distribution (PSD). A comparison was made of the particle size distributions as a function of weathered time.

\section{The effect of concentration on weathering}

Investigations of the effect of organic concentration on weathering were performed utilising $300 \mathrm{~g}$ of the $-16+13.2 \mathrm{~mm}$ Finsch ore sample in $1 \mathrm{~L}$ of the organic medium in flat bottomed containers. The test was conducted at room temperature $\left(\sim 25^{\circ} \mathrm{C}\right)$, utilising oxalic acid at solution concentrations of $0.025,0.1$ and $0.5 \mathrm{M}$. The samples were removed after 6 days and air dried for 1 day. Results from dry sieving to determine the PSD after weathering were utilised for comparison.

\section{The effect of temperature on weathering}

The Finsch ore sample was utilised to test the effect of temperature utilising the standard organic weathering procedure. Weathering was conducted in one test at room temperature $\left(\sim 25^{\circ} \mathrm{C}\right)$ and another in a water bath that regulated the temperature at $40{ }^{\circ} \mathrm{C}$, both tests lasting 6 days. The weathering solution was $0.5 \mathrm{M}$ oxalic acid. The PSD after dry sieving was also utilised to compare the two temperatures with results obtained from the distilled water 6 day test.

\subsubsection{Kinetic evaluation of cation exchange}

The kinetic evaluation of cation exchange was performed in a similar way to the kinetic tests by Morkel (2006), but in this case, organic solutions were utilised. The $300 \mathrm{~g}$ Finsch ore samples of $-16+13.2 \mathrm{~mm}$ size fraction were immersed in $1 \mathrm{~L}$ oxalic acid solutions at 
0.025, 0.1, 0.5 $\mathrm{M}$ in flat bottomed plastic containers, as shown in Figure 19. Tests were conducted at room temperature $\left(\sim 25^{\circ} \mathrm{C}\right)$. About $50 \mathrm{ml}$ of the weathering solutions were extracted during the course of each of the three experiments at 0 hours, 4 hours, 24 hours, 72 hours, 360 hours and 720 hours, for Inductively Coupled Plasma (ICP) analysis. The ICP analysis measured the quantities of $\mathrm{Mg}^{2+}, \mathrm{Ca}^{2+}, \mathrm{Na}^{+}, \mathrm{K}^{+}$and $\mathrm{Al}^{3+}$ released into solution as a function of time. ICP analysis was performed at Set Point Laboratories in Johannesburg, South Africa.

Kinetic evaluation was repeated for $0.025,0.1$ and $0.5 \mathrm{M} \mathrm{Cu}^{2+}$ solutions, for comparison with the oxalic kinetic tests.

\subsubsection{Repeatability of results}

A test in triplicate was performed on the Finsch ore with a procedure similar to the one used in section 6.2.4. A $300 \mathrm{~g}$ Finsch ore sample of $-16+13.2 \mathrm{~mm}$ particle size range was immersed in $1 \mathrm{~L}$ oxalic acid solution at $0.025 \mathrm{M}$ at room temperature $\left(\sim 25^{\circ} \mathrm{C}\right)$ in a flat bottomed plastic container, as shown in Figure 19. Approximately $50 \mathrm{ml}$ of the weathering solution was extracted at time intervals 0 hours, 4 hours, 24 hours and 360 hours for ICP analysis at Set Point Laboratories in Johannesburg, South Africa, for the first two tests, and at UIS Analytical Services in Centurion, South Africa, for the third set. The ICP analysis measured the amounts of $\mathrm{Mg}^{2+}, \mathrm{K}^{+}$and $\mathrm{Al}^{3+}$ released into the weathering solution as a function of time. The three results were compared in order to check the repeatability of results, and to establish the error range.

\subsubsection{Mineral alteration tests}

The Venetia K1 and the VUE ore samples were utilised to investigate the alteration of minerals in kimberlite under weathering conditions. Two tests were performed: (i) Agitation tests, and (ii) Immersion tests. 


\subsubsection{Agitation tests}

Samples of $300 \mathrm{~g}$ Venetia K1 ore, produced after crushing to $-26 \mathrm{~mm}$ and splitting, were milled to $80 \%$ passing $100 \mu \mathrm{m}$ utilising a laboratory ball mill. The product was split utilising the Eriez rotary splitter into $50 \mathrm{~g}$ samples. In each test, a $50 \mathrm{~g}$ sample was saturated in $800 \mathrm{ml}$ of weathering solution at $0.1 \mathrm{M}$, to form $\sim 6 \%$ solids by mass. The tests were performed at room temperature $\left(\sim 25^{\circ} \mathrm{C}\right)$ for 24 hours while stirring at $600 \mathrm{rpm}$. The setup is shown in Figure 20. The weathering media tested were distilled water, oxalic acid, ethanol, formamide, n-hexane, pyridine and urea. After weathering, the product was filtered, and the residue air dried for 1 day. The sample was then submitted for XRD analysis.

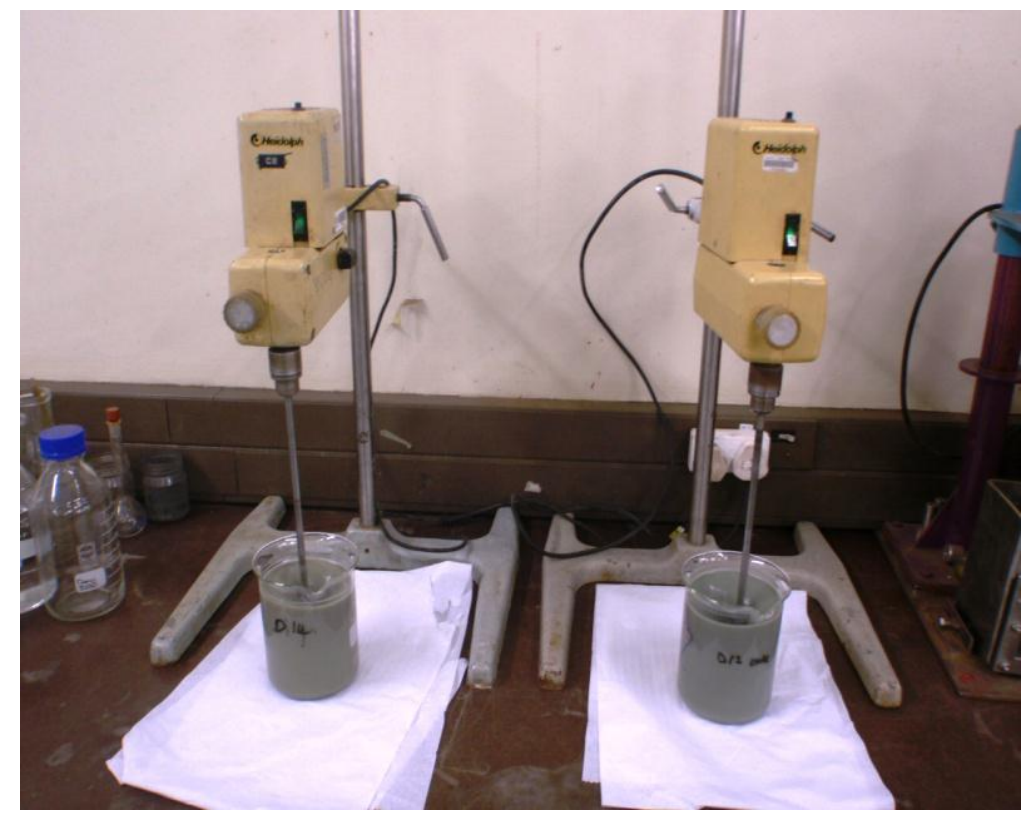

Figure 20: Experimental setup for weathering tests utilising $50 \mathrm{~g}$ of $80 \%$ passing $100 \mu \mathrm{m}$ Venetia K1 sample agitated in $800 \mathrm{ml}$ of various organic solutions for 24 hours.

\section{The effect of pre-cationic and organic treatment on mineral alteration}

In addition to the standard agitation tests, the effect of pre-cationic saturation prior to organic saturation was also investigated, utilising the same agitation test setup. Samples weighing $50 \mathrm{~g}$, obtained from milling ( $80 \%$ passing $100 \mu \mathrm{m}$ ) and splitting of the Venetia $\mathrm{K} 1$ ore, were saturated in $800 \mathrm{ml}$ of a $0.1 \mathrm{M}$ cation solution. The test was run at room temperature $\left(\sim 25^{\circ} \mathrm{C}\right)$ while stirring at $600 \mathrm{rpm}$. Cations tested were chlorides of $\mathrm{Cs}^{+}$, $\mathrm{NH}_{4}{ }^{+}, \mathrm{Na}^{+}, \mathrm{Ca}^{2+}$, and $\mathrm{Mg}^{2+}$. After 24 hours, the samples were filtered and the residue air dried for 1 day. After drying, the samples were further saturated in $800 \mathrm{ml}$ of $0.1 \mathrm{M}$ 
oxalic acid, while stirring at $600 \mathrm{rpm}$. After 24 hours the samples were filtered and air dried for 1 day, and submitted for XRD analysis.

\subsubsection{Immersion tests}

As discussed in section 5, kimberlite that does not contain swelling clays is not as susceptible to accelerated weathering as that which contains swelling clays. The option of alteration of mica, forsterite and serpentine to swelling clays was investigated. Drillcore samples of VUE ore samples were utilised. The phase composition of each of the drillcore samples was provided by De Beers Group and is shown in Table 10. Three samples with the highest mica, the highest forsterite and the highest serpentine contents were selected. These were the following drillcores: UCM 200, 14, 3, 30, 153, 168, 107, 147, and 106. The detail of each drillcore which includes position, depth and type of kimberlite was provided. These 9 samples did not report any smectite upon initial XRD analysis.

The selected samples were crushed to $-26 \mathrm{~mm}$ utilising a laboratory jaw crusher followed by milling to $80 \%$ passing $100 \mu \mathrm{m}$ utilising a laboratory ball mill. The samples were split into $20 \mathrm{~g}$ samples, utilising the Eriez rotary splitter. Three different tests were performed, namely: (i) $\mathrm{Mg}^{2+}$ treatment, (ii) $\mathrm{Mg}^{2+}-\mathrm{HCL}$ treatment and (iii) Pre- $\mathrm{NaClO}$ oxidation followed by $\mathrm{Mg}^{2+}-\mathrm{HCl}$ treatment. The three alteration treatments are discussed below.

\section{$\mathrm{Mg}^{2+}$ treatment}

A $20 \mathrm{~g}$ sample from each of the nine kimberlites from VUE were immersed in $250 \mathrm{ml}$ of $0.5 \mathrm{M} \mathrm{Mg}^{2+}$ chloride solution at room temperature $\left(\sim 25^{\circ} \mathrm{C}\right)$ for 14 days, in flat bottomed plastic containers. After the test, the sample was air dried and submitted for XRD analysis.

\section{$\mathrm{Mg}^{2+}-\mathrm{HCl}$ treatment}

Again, $20 \mathrm{~g}$ samples of the nine VUE was immersed in $250 \mathrm{ml}$ of a solution containing a mixture of $0.5 \mathrm{M} \mathrm{Mg}^{2+}$ (chloride) and $0.5 \mathrm{M} \mathrm{HCL}$ at room temperature $\left(\sim 25^{\circ} \mathrm{C}\right)$ for 
14 days in flat bottomed plastic containers. After the test, the samples were air dried and submitted for XRD analysis.

\section{Pre-NaClO oxidation followed by $\mathrm{Mg}^{2+}-\mathrm{HCl}$ treatment}

Another set of $20 \mathrm{~g}$ of the nine VUE samples were immersed in $250 \mathrm{ml}$ of a sodium hypochlorite $(\mathrm{NaClO})$ solution in plastic containers, for 4 hours at $70^{\circ} \mathrm{C}$, in a water bath (Figure 21). The samples were then cooled to room temperature $\left(\sim 25^{\circ} \mathrm{C}\right)$. A mixture of $0.5 \mathrm{M} \mathrm{Mg}^{2+}$ (chloride) and 0.5 M HCL was then added. The test continued at room temperature for another 14 days. After the test, the samples were air dried and submitted for XRD analysis.

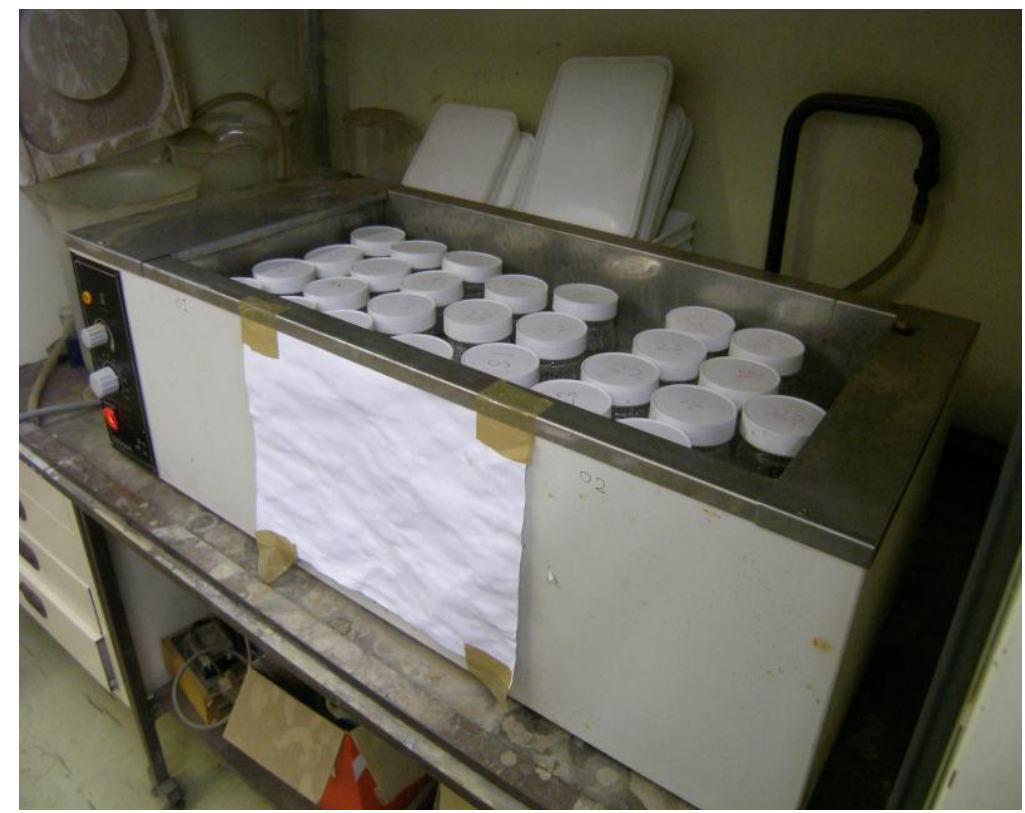

Figure 21: Oxidation treatment with $\mathrm{NaOCl}$ in a waterbath at $70{ }^{\circ} \mathrm{C}$.

\section{RESULTS AND DISCUSSION}

\subsection{Mineralogy}

The mineralogical fractions of the various kimberlites were investigated by XRF, XRD and CEC analysis and these will be discussed. 


\subsubsection{XRF Analysis}

The XRF analysis was performed at the University of Pretoria on the Finsch, the Koffiefontein and the Venetia K1 ores. The major elemental results are shown in Table 8. The results are typical of kimberlites as they are comparable to the data reported by Dawson (1980), as well as by Morkel (2006). The kimberlites displayed high amounts of magnesium. The calcium content in the Finsch ore was higher than in the Koffiefontein and Venetia $\mathrm{K} 1$ ores suggesting the presence of a calcium containing material such as dolomite.

Table 8: XRF analysis results for Finsch, Koffiefontein and Venetia K1 samples.

\begin{tabular}{|l|c|c|c|c|c|c|c|c|c|c|c|}
\hline \multirow{2}{*}{ Ore Sample } & $\mathbf{N a}_{2} \mathbf{O}$ & $\mathbf{M g}$ & $\mathbf{A l}_{\mathbf{2}} \mathbf{O}$ & $\mathbf{S i O}_{\mathbf{2}}$ & $\mathbf{P}_{\mathbf{2}} \mathbf{O}$ & $\mathbf{K}_{\mathbf{2}}$ & $\mathbf{C a O}$ & $\mathbf{T i O}$ & $\mathbf{F e}_{2} \mathbf{O}$ & $\mathbf{M n}$ & $\mathbf{S O}_{\mathbf{2}}$ \\
\cline { 2 - 13 } & $\mathbf{\%}$ & $\boldsymbol{\%}$ & $\mathbf{\%}$ & $\mathbf{\%}$ & $\mathbf{\%}$ & $\mathbf{\%}$ & $\mathbf{\%}$ & $\mathbf{\%}$ & $\mathbf{\%}$ & $\mathbf{\%}$ & $\mathbf{p p m}$ \\
\hline Finsch & 1.45 & 19.6 & 6.2 & 34.8 & 0.24 & 2.4 & 13.2 & 0.56 & 7.55 & 0.28 & - \\
\hline Koffiefontein & 0.82 & 24.4 & 9.8 & 48.1 & 0.29 & 1.4 & 5.61 & 0.66 & 7.91 & 0.13 & - \\
\hline Venetia K1 & - & 24.9 & 4.66 & 39.2 & 0.27 & 2.4 & 7.44 & 0.93 & 9.79 & 0.15 & 104 \\
\hline
\end{tabular}

-Denotes that the value was not reported from the lab

\subsubsection{XRD analysis}

The XRD analysis results for Finsch, Koffiefontein and Venetia K1 ores are provided in Table 9. The XRD scans of the analysis are included in Appendix A. The Finsch and the Koffiefontein ores contained predominantly smectite. The Koffiefontein ore had $\sim 62 \%$ compared to $\sim 35 \%$ for the Finsch ore. The Koffiefontein sample also contained a mica quantity of $\sim 14 \%$ compared to the Finsch ore, which contained $\sim 7 \%$. The Finsch sample showed a high dolomite content of $\sim 11 \%$, which was also visible from XRF results, indicating high calcium content. Venetia $\mathrm{K} 1$ ore reported relatively high mica quantity of $\sim 27 \%, \sim 17 \%$ chlorite, $\sim 22 \%$ serpentine and $6 \%$ vermiculite. From the XRD results, it was predicted that both the Finsch and Koffiefontein ores would be susceptible to weathering because of their higher smectite quantities, compared to the Venetia K1 ore which was dominated by serpentine and mica minerals. 
Table 9: XRD analysis results for samples utilised.

\begin{tabular}{|c|c|c|}
\hline Sample & Mineral Group & Weight \% \\
\hline \multirow{8}{*}{ Finsch } & Smectite & $\sim 35$ \\
\hline & Serpentine & $\sim 5$ \\
\hline & Mica & $\sim 7$ \\
\hline & Calcite & $\begin{array}{l}\sim 8 \\
\end{array}$ \\
\hline & Dolomite & $\sim 11$ \\
\hline & Plagioclase & $\sim 7$ \\
\hline & Quartz & $\sim 6$ \\
\hline & Pyroxene & $\sim 8$ \\
\hline \multirow{8}{*}{ Koffiefontein } & Smectite & $\sim 62$ \\
\hline & Serpentine & $\sim 3$ \\
\hline & Mica & $\sim 14$ \\
\hline & Calcite & $\sim 5$ \\
\hline & Kaolinite & $\sim 4$ \\
\hline & Talc & $\sim 3$ \\
\hline & Quartz & $\sim 2$ \\
\hline & Pyroxene & $\sim 6$ \\
\hline \multirow{8}{*}{ Venetia K1 } & Vermiculite & $\sim 6$ \\
\hline & Serpentine & 222 \\
\hline & Mica & $\sim 27$ \\
\hline & Chlorite & $\begin{array}{ll}\sim 17 \\
\end{array}$ \\
\hline & Calcite & $\sim 9$ \\
\hline & Amphibole & $\sim 2$ \\
\hline & Kaolinite & $\sim 5$ \\
\hline & Pyroxene & $\sim 13$ \\
\hline
\end{tabular}

The XRD analysis of the Venetia mine underground expansion project (VUE) samples is given in Table 10. The samples that were that were identified for mineral alteration tests, identified by their drillcore numbers, were categorized as high mica (samples 200, 14, and 3), high forsterite (samples 30, 153 and 168) and high serpentine samples (107, 147, and 106). These samples did not contain smectite. The remainder of the samples; 1,12 , $16,24,62,64,83,85,86,89,97,99,101,103,117,132,134$ and 138 generally did not report any forsterite or vermiculite except for sample 99, which contained $~ 7.30 \%$. 
Table 10: The phase compositions of the VUE samples (Courtesy of Venetia mine underground expansion project).

\begin{tabular}{|c|c|c|c|c|c|c|c|c|c|}
\hline $\begin{array}{c}\text { Drillcore } \\
\text { number }\end{array}$ & Mica & Forsterite & Serpentine & Smectite & Vermiculite & Diopside & Chlorite & Kaolinite & Talc \\
\hline 1 & 42.61 & 0.00 & 9.98 & 0.00 & 7.79 & 18.65 & 11.01 & 0.00 & 0.00 \\
\hline 3 & 46.38 & 0.00 & 8.34 & 0.00 & 5.45 & 20.44 & 9.35 & 0.00 & 0.00 \\
\hline 12 & 44.5 & 0.00 & 8.40 & 20.30 & 0.00 & 14.44 & 0.00 & 0.00 & 0.00 \\
\hline 14 & 55.04 & 0.00 & 13.17 & 0.00 & 0.00 & 8.35 & 0.00 & 0.00 & 0.00 \\
\hline 16 & 6.41 & 0.00 & 0.89 & 47.38 & 0.00 & 4.56 & 0.00 & 3.59 & 14.6 \\
\hline 24 & 14.18 & 0.00 & 4.95 & 26.00 & 0.00 & 16.88 & 14.30 & 1.80 & 0.00 \\
\hline 30 & 8.61 & 24.98 & 11.50 & 0.00 & 1.36 & 11.87 & 10.83 & 0.00 & 0.00 \\
\hline 62 & 49.30 & 0.00 & 4.90 & 31.00 & 0.00 & 0.00 & 0.00 & 0.00 & 0.00 \\
\hline 64 & 8.99 & 0.00 & 1.76 & 50.41 & 0.00 & 12.70 & 5.61 & 1.37 & 0.00 \\
\hline 83 & 23.76 & 0.00 & 10.95 & 35.00 & 0.00 & 18.72 & 6.04 & 0.00 & 0.00 \\
\hline 85 & 7.04 & 0.00 & 3.5 & 49.83 & 0.00 & 18.05 & 11.01 & 0.00 & 0.00 \\
\hline 86 & 10.41 & 0.00 & 8.28 & 45.40 & 0.00 & 16.90 & 11.50 & 0.00 & 0.00 \\
\hline 89 & 33.08 & 0.00 & 7.79 & 15.87 & 0.00 & 0.00 & 13.47 & 1.77 & 0.00 \\
\hline 97 & 11.12 & 0.00 & 4.71 & 38.67 & 0.00 & 0.00 & 11.04 & 0.00 & 12.64 \\
\hline 99 & 11.06 & 0.00 & 7.58 & 23.40 & 7.30 & 17.75 & 4.28 & 0.25 & 16.60 \\
\hline 101 & 12.94 & 0.00 & 2.00 & 42.01 & 0.00 & 0.00 & 8.32 & 0.86 & 13.66 \\
\hline 103 & 12.85 & 0.00 & 36.7 & 7.95 & 0.00 & 5.57 & 0.00 & 0.00 & 26.80 \\
\hline 106 & 27.26 & 0.00 & 54.99 & 0.00 & 0.00 & 1.21 & 0.00 & 0.00 & 0.00 \\
\hline 107 & 18.26 & 0.00 & 56.20 & 0.00 & 4.34 & 8.05 & 0.00 & 0.00 & 0.00 \\
\hline 117 & 16.24 & 0.00 & 2.84 & 48.04 & 0.00 & 10.16 & 1.54 & 0.00 & 12.32 \\
\hline 132 & 10.21 & 0.00 & 0.00 & 0.00 & 0.00 & 3.70 & 4.61 & 0.00 & 3.63 \\
\hline 134 & 18.26 & 0.00 & 0.00 & 51.57 & 0.00 & 0.00 & 0.00 & 0.00 & 8.04 \\
\hline 138 & 12.80 & 0.00 & 2.53 & 31.51 & 0.00 & 0.00 & 7.36 & 0.00 & 12.03 \\
\hline 147 & 28.60 & 0.00 & 55.31 & 0.00 & 0.00 & 0.94 & 0.00 & 0.00 & 0.00 \\
\hline 153 & 33.15 & 24.90 & 10.21 & 0.00 & 0.00 & 12.20 & 0.00 & 0.00 & 0.00 \\
\hline 168 & 18.74 & 23.29 & 17.02 & 0.00 & 0.00 & 9.71 & 0.00 & 0.00 & 0.00 \\
\hline 200 & 56.73 & 0.00 & 8.87 & 0.00 & 0.00 & 0.00 & 10.89 & 0.00 & 0.00 \\
\hline
\end{tabular}

\subsubsection{Cation exchange capacity (CEC)}

The CEC values for Finsch, Koffiefontein and Venetia K1 ores are provided in Table 11 and were reported respectively as $28.21,54.91$ and $16.61 \mathrm{cmol} / \mathrm{kg}$. According to Morkel (2006) a correlation can be shown between CEC and the smectite values which, to some extent, can be utilised to predict weathering behaviour. The smectite values are also shown in Table 11. The CEC value of $\sim 17 \%$ for Venetia K1 ore together with the absence of smectite suggests that this kimberlite will not be very susceptible to weathering. The CEC value of $28 \%$ for Finsch, together with $\sim 35 \%$ smectite, suggests an intermediate ore, and the very high CEC value of $\sim 55 \mathrm{cmol} / \mathrm{kg}$ together with $62 \%$ smectite, suggests an extremely weatherable Koffiefontein kimberlite. 
Table 11: The CEC and the smectite content of Finsch, Koffiefontein and Venetia K1 samples.

\begin{tabular}{|l|c|c|}
\hline Ore sample & CEC (cmol/kg) & Smectite content (\%) \\
\hline Finsch & 28.21 & $\sim 35$ \\
\hline Koffiefontein & 54.91 & $\sim 62$ \\
\hline Venetia K1 & 16.61 & 0 \\
\hline
\end{tabular}

\subsubsection{Correlation between smectite content and TGA analysis}

As temperature increases, phases are destroyed (or formed) at various stages of the temperature profile increments and this translates to the weight loss of the material over a given temperature range. Therefore, any given material should produce a signature weight loss profile with an increase in temperature depending upon its composition. In this investigation, the total weight loss in the temperature range 125 to $1000{ }^{\circ} \mathrm{C}$ will be matched with the amount of smectite present in each ore sample, in order to establish if a relationship exists.

The VUE ore samples, namely UCM 1, 12, 16, 24, 62, 64, 83, 85, 86, 89, 97, 99, 101, 103, 117, 132, 134 and 138, were milled to $80 \%$ passing $100 \mu \mathrm{m}$. Samples of $20 \mathrm{~g}$ each, were sent for TGA analysis. The samples were heated from 25 to $1000{ }^{\circ} \mathrm{C}$ at $10{ }^{\circ} \mathrm{C} / \mathrm{min}$ with a gas flow rate of $50 \mathrm{ml} / \mathrm{min}$ in a nitrogen environment. Results were reported as $\%$ weight loss as a function of temperature in ${ }^{\circ} \mathrm{C}$ and are shown in Figure 22. 


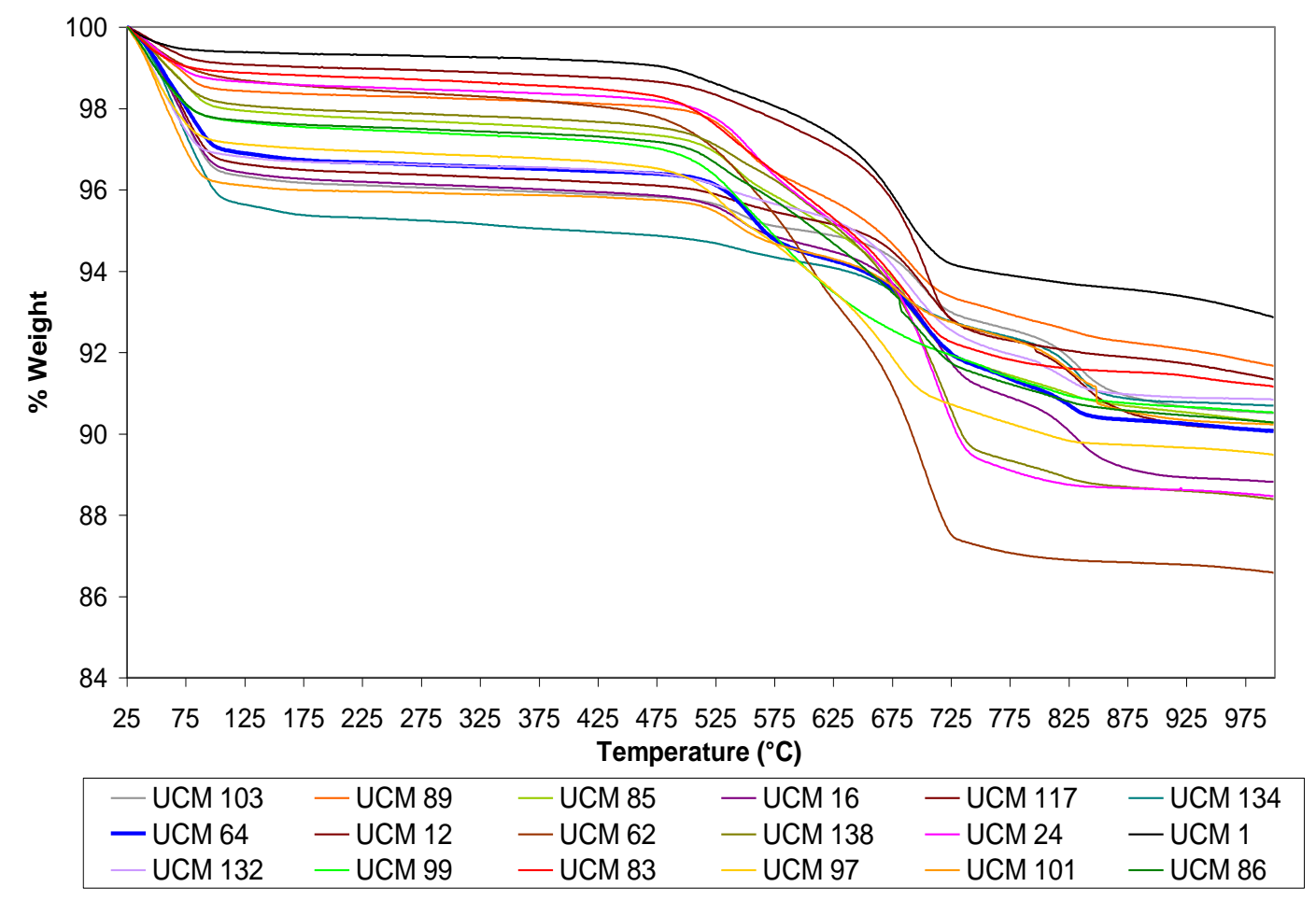

Figure 22: TGA analysis results for the various VUE ore drillcores.

The results show an array of curves ranging from UCM 1 as the top curve, to UCM 62 as the bottom curve. The results show that the kimberlites did not vary significantly even though the curves did not coincide with each other. The curves show a similar profile, with a small difference in the \% weight loss between 5-12 \%. This means that a definite trend could not be established from the closely spaced curves.

The $\%$ weight loss from 125 to $1000{ }^{\circ} \mathrm{C}$ was reported for the test, utilising data from Figure 22, and is shown in Figure 23. The graph shows the various weight losses for the given ore samples; and the plot was done in such a way that the smectite content increased from left to right along the x-axis (from UCM 103 to UCM 86). UCM 62 reported the highest weight loss of $\sim 12 \%$, and UCM 134 reported the lowest of $\sim 5 \%$. 


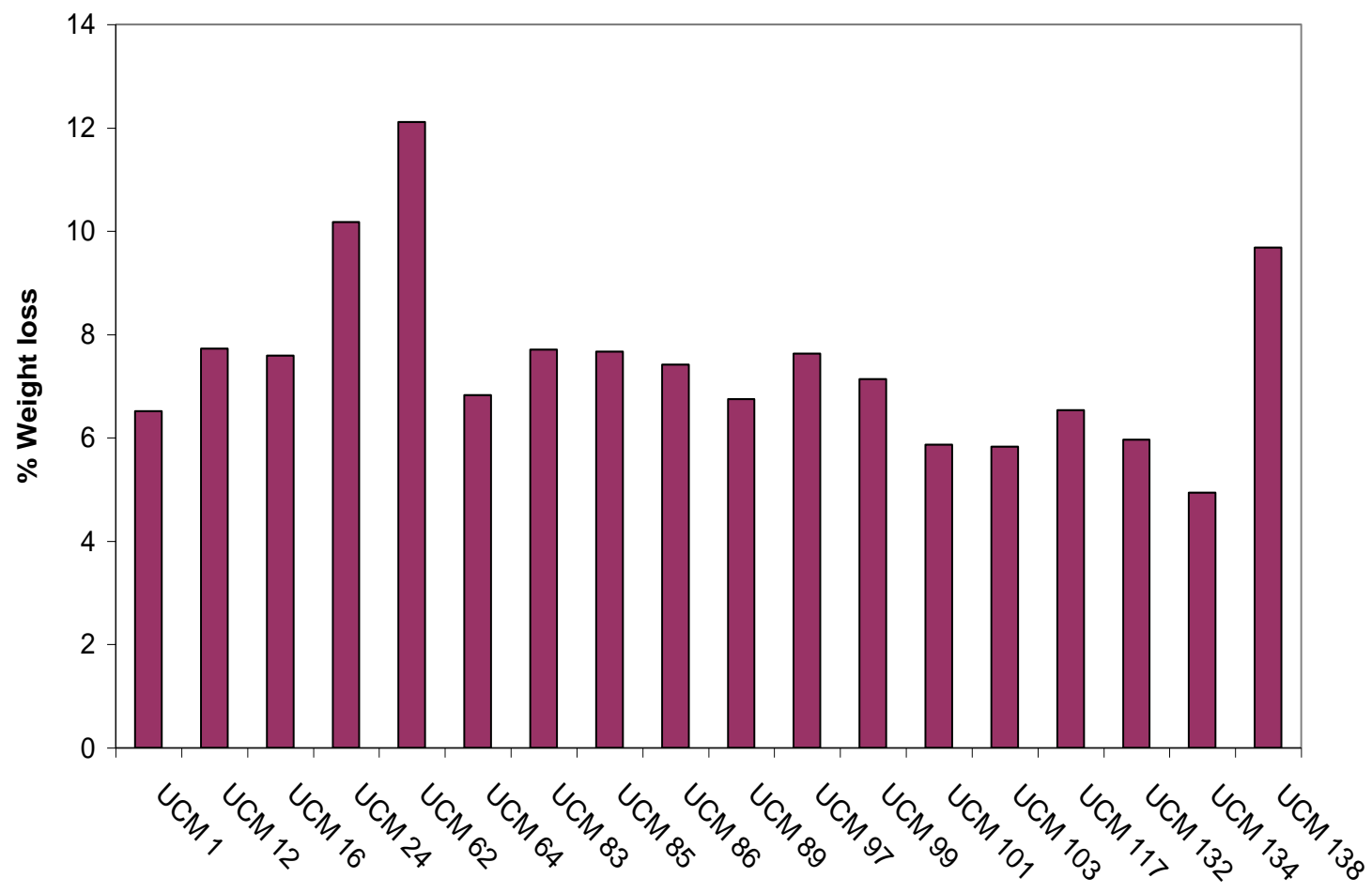

Figure 23: The $\%$ weight loss at $1000{ }^{\circ} \mathrm{C}$ for respective drillcore Ids.

The $\%$ weight loss at $1000{ }^{\circ} \mathrm{C}$ was tabulated (Appendix B) with the corresponding smectite content as well as the $\mathrm{d}_{75}$ (an indicator of weatherability provided by De Beers Group VUE project i.e. the lower the $\mathrm{d}_{75}$, the more the material is prone to weathering). A graph of the weight loss in relation to the smectite content was generated, and is shown in Figure 24. The graph indicates that there is no real observable correlation between the smectite content and the $\%$ weight loss at $1000{ }^{\circ} \mathrm{C}$ from TGA analysis. This means that one cannot predict the smectite content of a kimberlite based upon TGA analysis results. However, it was interesting to observe that the $d_{75}$ values had a slightly positive correlation with the \% weight loss; shown in Figure 25. 


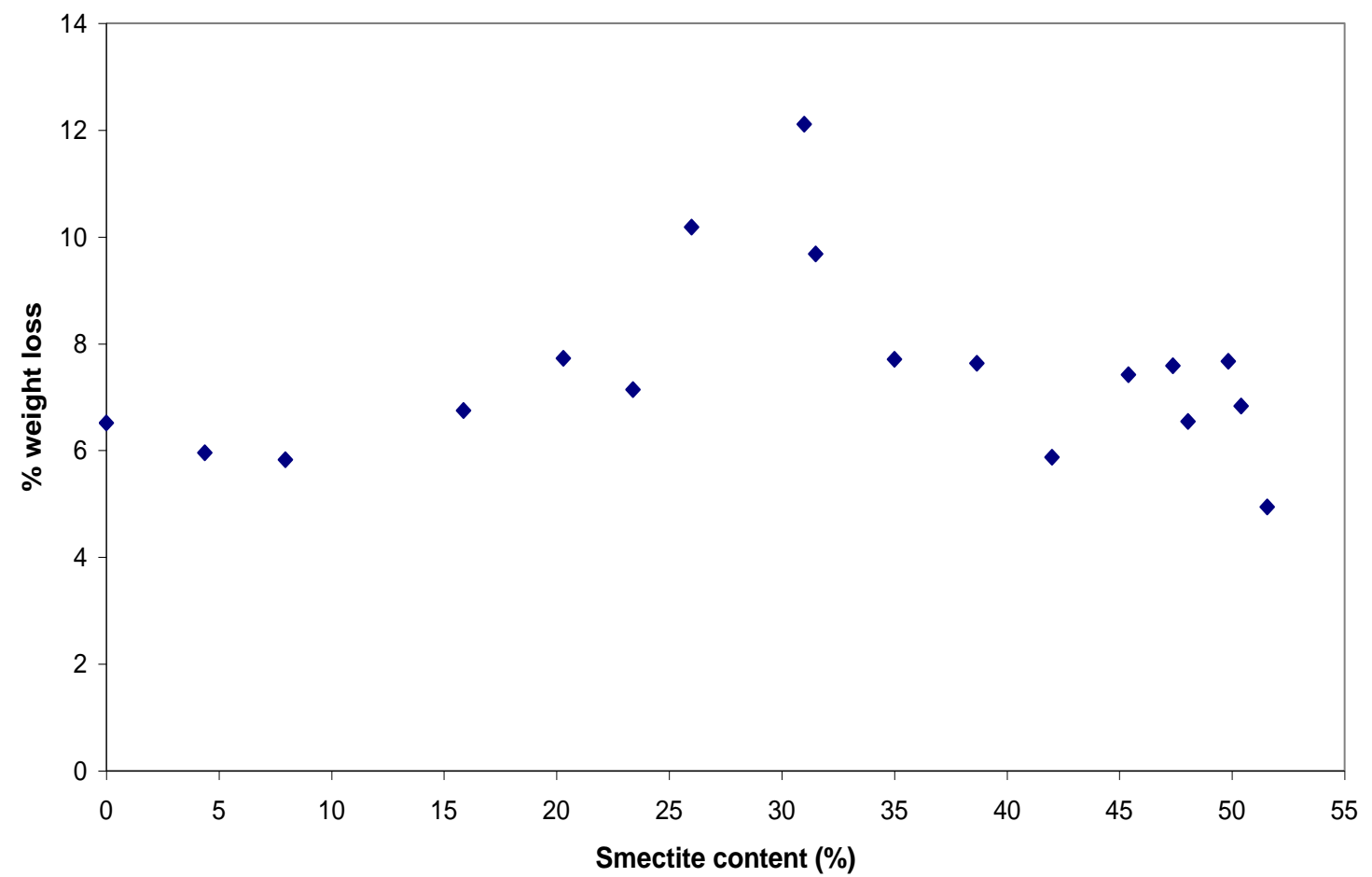

Figure 24: The $\%$ weight loss at $1000{ }^{\circ} \mathrm{C}$ as a function of smectite content.

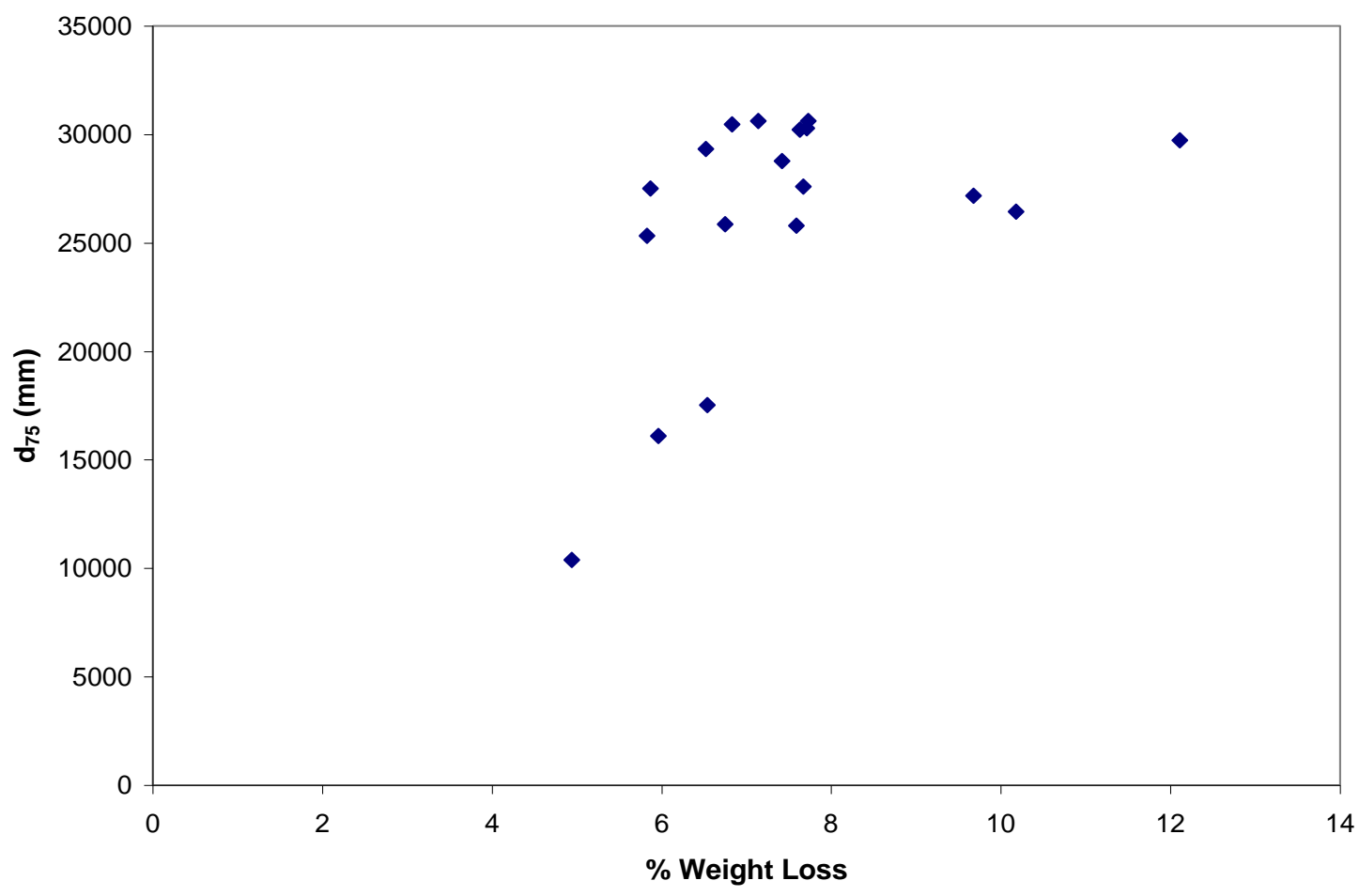

Figure 25: The $\mathrm{d}_{75}$ as a function of $\%$ weight loss at $1000{ }^{\circ} \mathrm{C}$. 


\subsection{The investigation of organic medium adsorption}

The Koffiefontein ore was identified to investigate the organic medium adsorption on kimberlite. The CEC of the Koffiefontein ore was $54.91 \mathrm{cmol} / \mathrm{kg}$ and the smectite content reported as $\sim 62 \%$. This ore was specifically chosen as the high CEC and smectite content would allow for adsorption by cation exchange. Tests were conducted by utilising $16 \mathrm{~g}$ of the $80 \%$ passing $100 \mu \mathrm{m}$ Koffiefontein samples and exposing them to $250 \mathrm{ml}$ of $0.5 \mathrm{M}$ organic solutions for 7 days at room temperature $\left(\sim 25^{\circ} \mathrm{C}\right)$. Analysis after the test included XRD, TGA and FTIR analysis. Part of an untreated sample was also submitted for analysis and was utilised for comparison.

Table 12 shows results of the $\mathrm{d}_{001}$-spacings obtained by XRD analysis for the various organic treatments. The untreated sample had a d-spacing of $14.88 \AA$ and this value was made the reference to compare the effects of various treatments. The XRD results showed that the d-spacing varied with the organic type, between $14.54 \AA$ and $15.06 \AA$. Generally, organic solutions at $0.5 \mathrm{M}$ did not significantly alter the d-spacing. The values were similar and there was a minimal difference in comparison to an untreated sample. The results also show that organic reagents did not exceed 1 water layer (1 water layer is between 12.6 and $15.6 \AA$ ). The largest d-spacing on $0.5 \mathrm{M}$ organic solutions was produced by formamide $(15.06 \AA)$, and the smallest was produced by oxalic acid (14.54 A) treatment. The d-spacings did not necessarily predict the extent of weathering due to the limitations XRD analysis has on determining the d-spacing under the tested conditions. XRD analysis can only measure up to 2 water layers (15.6 - 18.6 $\mathrm{A})$ on air dried samples under ambient conditions (Ferrage et al., 2005). An in-situ XRD analysis (d-spacing measurement on wet samples) could have revealed the actual d-spacing. Ethanol and n-hexane have low boiling points $\left(78.4\right.$ and $69{ }^{\circ} \mathrm{C}$ respectively) and therefore are volatile. This also explained the low d-spacings produced by these two reagents. 
Table 12: XRD analysis ( $\mathrm{d}_{001}$-spacing results) on the effect of organic solutions on the $80 \%$ passing 100 $\mu \mathrm{m}$ Koffiefontein ore sample.

\begin{tabular}{|c|c|}
\hline Treatment & d-spacing $(\mathbf{\AA})$ \\
\hline Untreated & 14.88 \\
\hline Ethanol & 15.00 \\
\hline Formamide & 15.06 \\
\hline n-Hexane & 14.89 \\
\hline Oxalic acid & 14.54 \\
\hline Urea & 14.89 \\
\hline Pentanoic acid & 14.66 \\
\hline Acetic acid & 14.92 \\
\hline
\end{tabular}

Further analyzing the tested organic solutions, as shown in Table 13, the polarity of the molecules did not have any effect: for instance oxalic acid, and urea are both polar (polarity of $3.0 \mathrm{D}$ and $4.46 \mathrm{D}$, respectively), but both were still comparable to an untreated sample. Clay minerals are regarded as polar (Grim, 1968), therefore a more polarised molecule should have a greater interaction with the clay minerals in kimberlite. This, however, was not the case for the Koffiefontein sample.

Table 13: Properties of the organic reagents utilised in the test work.

\begin{tabular}{|c|c|c|c|c|c|c|}
\hline Organic & Molecular formula & $\begin{array}{c}\text { Carbon } \\
\text { chain } \\
\text { length }\left(\mathbf{n}_{\mathbf{c}}\right)\end{array}$ & $\begin{array}{c}\text { Molar } \\
\text { mass }\end{array}$ & Polarity & $\begin{array}{c}\text { d-spacing } \\
\text { Produced } \\
(\AA)\end{array}$ & $\begin{array}{c}\text { Water* } \\
\text { layers }\end{array}$ \\
\hline Ethanol & $\mathrm{C}_{2} \mathrm{H}_{6} \mathrm{O}$ & 2 & 46.07 & $\begin{array}{c}\text { Polar } \\
(1.69 \mathrm{D})^{\dagger}\end{array}$ & 15.00 & 1 \\
\hline Formamide & $\mathrm{H}_{3} \mathrm{CON}$ & 1 & 45.04 & $\begin{array}{c}\text { Polar } \\
(3.73 \mathrm{D})^{\dagger}\end{array}$ & 15.06 & 1 \\
\hline n-Hexane & $\mathrm{C}_{6} \mathrm{H}_{14}$ & 6 & 86.18 & $\begin{array}{c}\text { Neutral } \\
(0 \mathrm{D})^{\dagger}\end{array}$ & 14.89 & 1 \\
\hline Oxalic acid & $\mathrm{H}_{2} \mathrm{C}_{2} \mathrm{O}_{4}$ & 2 & 126.07 & $\begin{array}{c}\text { Polar } \\
(3.00 \mathrm{D})^{\dagger}\end{array}$ & 14.54 & 1 \\
\hline Urea & $\left(\mathrm{NH}_{2}\right)_{2} \mathrm{CO}$ & 1 & 60.07 & $\begin{array}{c}\text { Polar } \\
(4.46 \mathrm{D})^{\dagger}\end{array}$ & 14.89 & 1 \\
\hline Pentanoic acid & $\mathrm{C}_{5} \mathrm{H}_{10} \mathrm{O}_{2}$ & 5 & 102.13 & $\begin{array}{c}\text { Polar } \\
(1.61 \mathrm{D})^{\dagger}\end{array}$ & 14.66 & 1 \\
\hline Acetic acid & $\mathrm{C}_{2} \mathrm{H}_{3} \mathrm{CO}_{2}$ & 2 & 60.05 & $\begin{array}{c}\text { Polar } \\
(1.70 \mathrm{D})^{\dagger}\end{array}$ & 14.92 & 1 \\
\hline
\end{tabular}

* Below $10 \AA$ corresponds to 0 water layers, $12.6 \AA$ to 1 water layer, $15.6 \AA$ with 2 layers, $18.6 \AA$ to 3 layers $21.6 \AA$ to 4 layers and above this to more water layers; ${ }^{\dagger}$ (Lide, 2005)

TGA analysis was utilised to measure the extent to which various organic reagents were adsorbed by the Koffiefontein kimberlite. The untreated TGA curve served as a baseline from which to determine whether a treatment resulted in adsorption or not. A curve that 
reported results below this reference curve confirmed adsorption of the medium, where as a curve reporting results above it, signified rejection of the medium. The results in Figure 26 show all organic solutions (not in respective order of labeling), except oxalic acid, had a similar curve profile to that of an untreated sample and this meant that little or no adsorption occurred for these organic solutions. Oxalic acid was adsorbed more than any other organic as the results show up to $23 \%$ more weight loss. The oxalic acid is similar to the thermal decomposition of $\mathrm{Ca}$-oxalate. This showed that the predominant product of oxalic acid disolution was $\mathrm{Ca}$-oxalate, which forms at low concentrations as its Ksp is equal to $2.34 \times 10^{-9}$ (Lide, 2005).

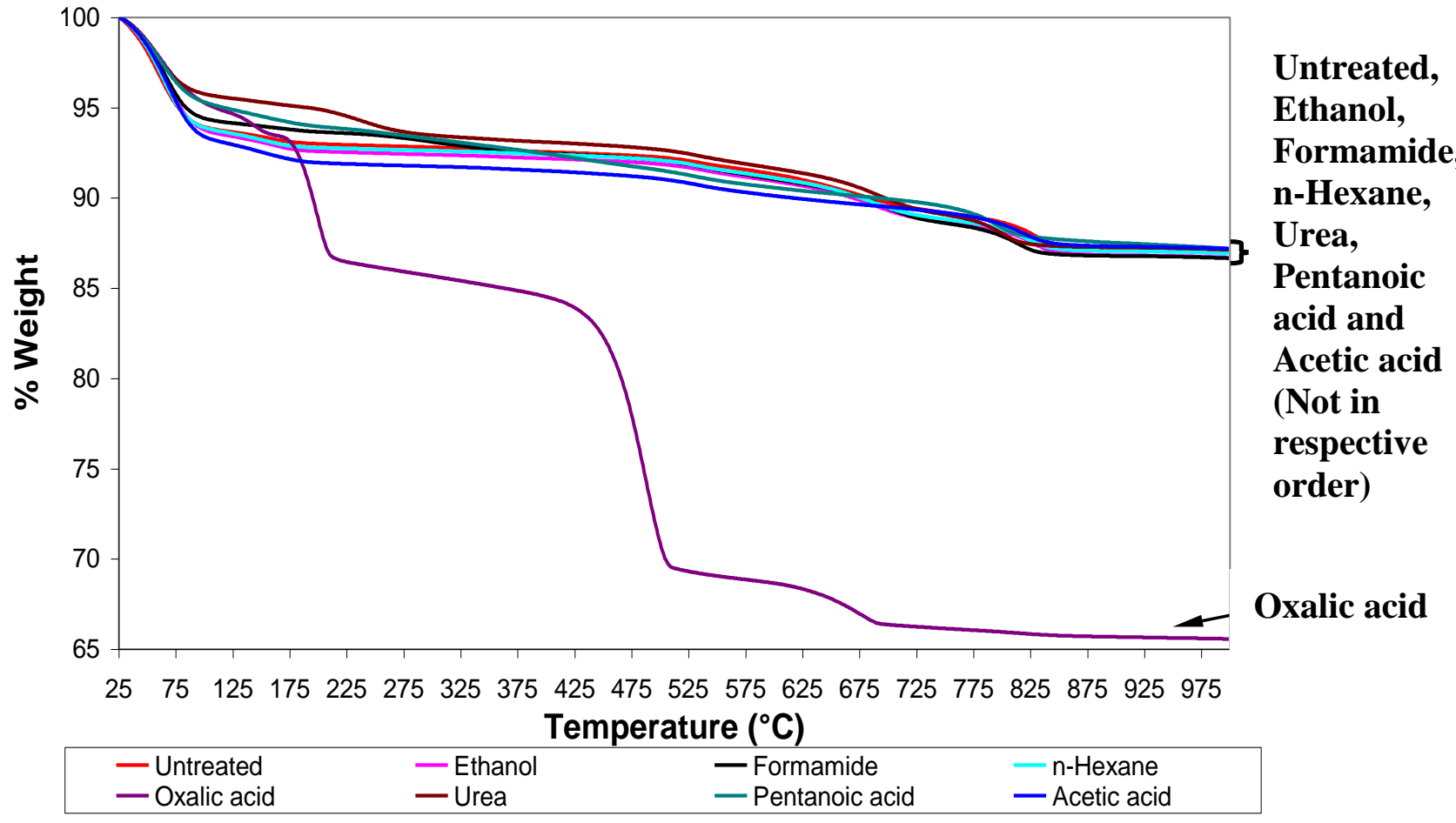

Figure 26: TGA results of $0.5 \mathrm{M}$ organic solutions on the $80 \%$ passing $100 \mu \mathrm{m}$ Koffiefontein ore sample.

Figure 27 illustrates relative \% weight losses translated to \% organic adsorbed obtained from Figure 26. The $\%$ adsorbed was calculated as the $\%$ mass difference between the treated samples and the untreated sample, for the weight loss occurring between $125^{\circ} \mathrm{C}$ and $1000{ }^{\circ} \mathrm{C}$. Negative values can be obtained on the bar graphs due to the fact that the $\%$ adsorbed was calculated relative to the untreated ore sample TGA curve. The highest adsorption was observed on oxalic acid at $\sim 23 \%$, compared to other organic reagents reporting less than $4 \%$ adsorption. The low $\%$ adsorption exhibited by ethanol and n-hexane could have been the volatility of these two organic solutions. The results the 
following decreasing order for organic adsorbed; oxalic acid > urea > pentanoic acid > formamide $>$ ethanol $>$ n-hexane $>$ acetic acid.

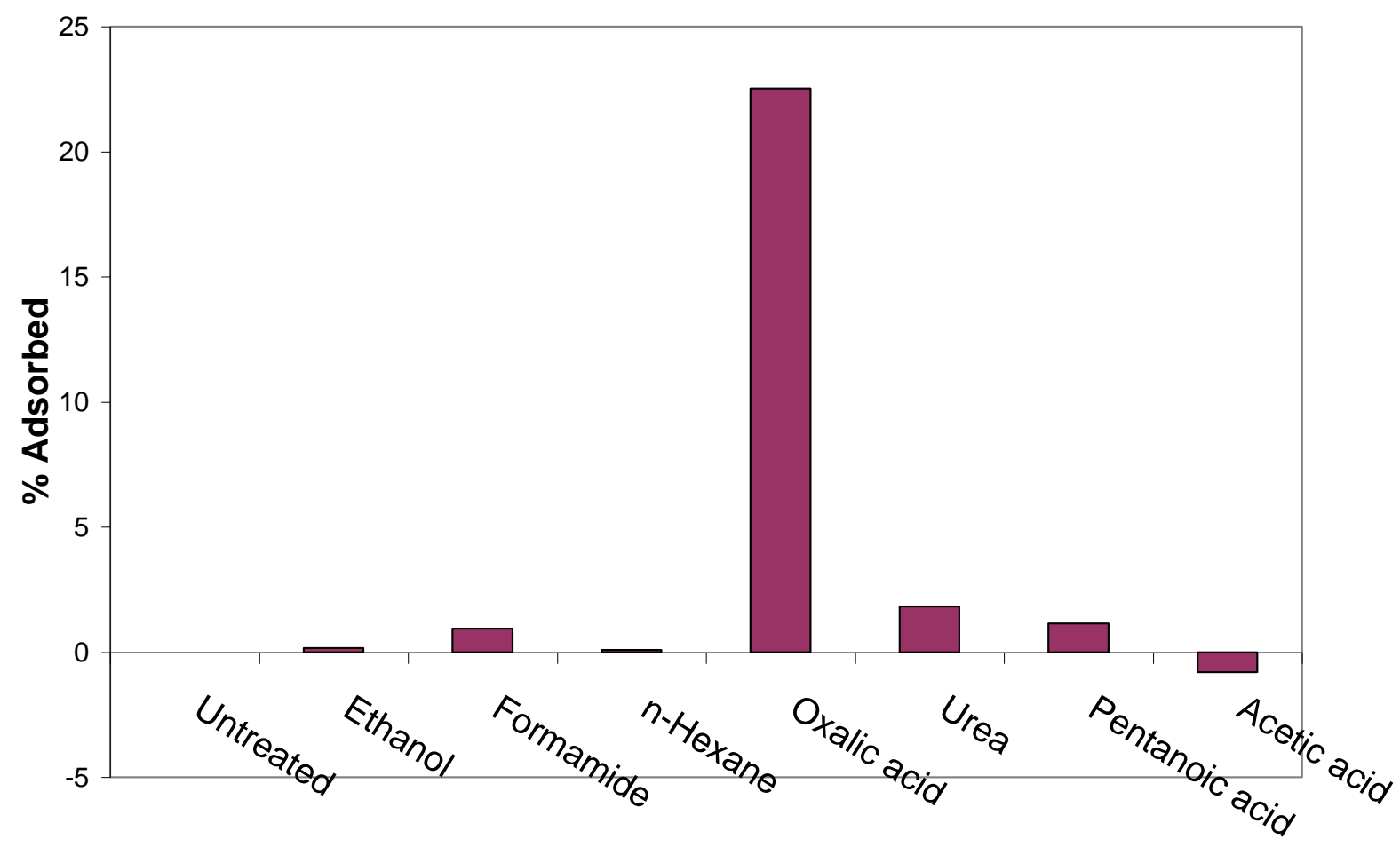

Figure 27: An illustration of the TGA results on the $80 \%$ passing $100 \mu \mathrm{m}$ Koffiefontein ore sample showing relative amounts adsorbed for the organic reagents tested, with the untreated sample as the reference.

In order to investigate the mechanisms of adsorption, FTIR analysis was utilised on the organic treated Koffiefontein samples. Figure 28 shows the results. According to Grim (1968), smectites contain interlayer water, responsible for their swelling, as one of the three types of water present in clay minerals. The interlayer water is attached to the structure through $\mathrm{H}$-bonding, either to $\mathrm{O}_{2}$ or to $\mathrm{OH}$ groups of the silicates, or by hydration of exchangeable cations. This water is normally represented in FTIR analysis by the sharp peak at $3625 \mathrm{~cm}^{-1}$ due to free water, a broad band at $3440 \mathrm{~cm}^{-1}$ due to intermolecular H-bonds (Breen et al., 1997) and a sharp peak at $1630 \mathrm{~cm}^{-1}$ also due to intermolecular H-bonding (Grim, 1968). Reduction in the intensities of these peaks means a reduction of the water content due to replacement by other molecules. A shift in these peaks, to higher frequencies, means that the water will be loosely retained in the structure, as a result of interference by other molecules. Both facts have been discussed by Breen et al. (1997). These peaks occurred in an untreated Koffiefontein sample at $3611 \mathrm{~cm}^{-1}, 3435 \mathrm{~cm}^{-1}$ and $1639 \mathrm{~cm}^{-1}$ respectively. 


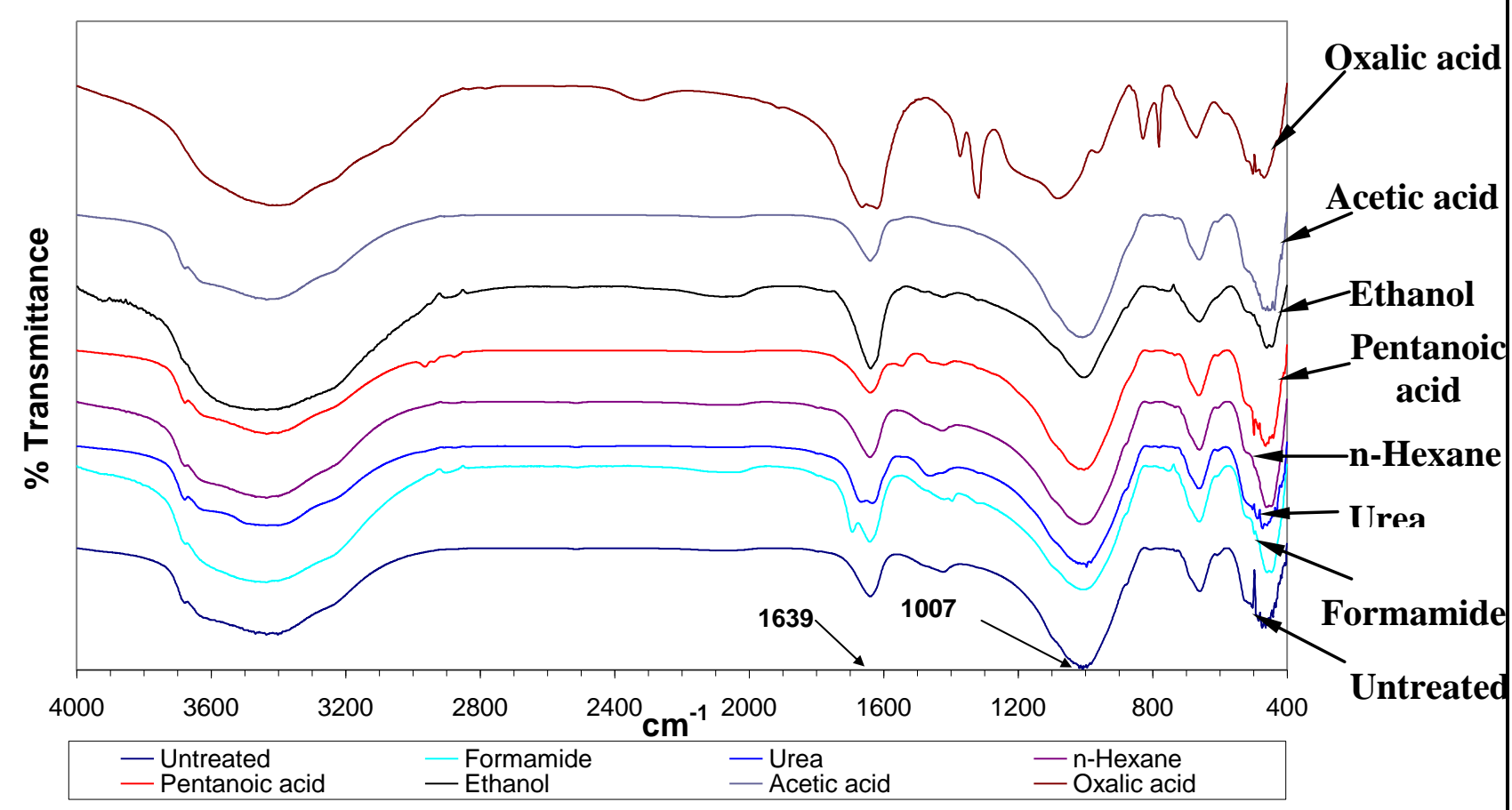

Figure 28: FTIR scans for Koffiefontein samples treated with $0.5 \mathrm{M}$ organic solutions.

The untreated sample, and samples treated in ethanol, n-hexane, pentanoic acid and acetic acid had peaks corresponding to $3611 \mathrm{~cm}^{-1}, 3435 \mathrm{~cm}^{-1}$ and $1639 \mathrm{~cm}^{-1}$. The other organic reagents (formamide, oxalic acid and urea) caused a shift in the $1639 \mathrm{~cm}^{-1}$ peak position (to 1641,1619 and $1633 \mathrm{~cm}^{-1}$ respectively), and a formation of the second peak due to organic adsorption at 1693,1663 and $1658 \mathrm{~cm}^{-1}$ respectively. It is possible that the shift was due to the stronger interaction of the more polar organic reagents with the mineral surface, through a formation of H-bonds and these bonds which then had dominance over the interlayer water. This was not observed on the relatively low polar ethanol, pentanoic acid and acetic acid and the non-polar n-hexane.

The Si-O stretching band for the Koffiefontein ore sample was represented by $1007 \mathrm{~cm}^{-1}$ peak. For all organic solutions, with the exception of oxalic acid, there was a peak that corresponded to $1007 \mathrm{~cm}^{-1}$. This peak was at $1081 \mathrm{~cm}^{-1}$ for the oxalic acid treated sample. This could indicate a possibility of a structural change, due to proton attack by the oxalic acid. Breen et al. (1997) highlighted this upward shift of the Si-O peak as an illustration of acid leaching. It was therefore concluded that oxalic acid could potentially be utilised for further tests on kimberlite weathering. 


\section{The effect of pure organic reagents on adsorption}

The Koffiefontein ore was utilised to test the effect of pure organic reagents. Tests were conducted, utilising $16 \mathrm{~g}$ of the $80 \%$ passing $100 \mu \mathrm{m}$ Koffiefontein ore samples, and exposing them to $250 \mathrm{ml}$ of pure organic solutions for 7 days at room temperature $\left(\sim 25^{\circ} \mathrm{C}\right)$. The analysis performed on dry samples after the test included XRD, TGA and FTIR analysis. Part of an untreated sample was also submitted for analysis, and was utilised for comparison. Organic reagents that were tested under these conditions were ethanol, n-hexane, formamide, pentanoic acid and acetic acid

Table 14 shows results of the $\mathrm{d}_{001}$-spacings obtained by XRD analysis for the various pure organic treatments; with the untreated sample having a d-spacing of $14.88 \AA$. The use of pure organic reagents did not increase the d-spacing more than the untreated sample, as indicated by pure organic reagents d-spacing values; these did not differ from the untreated sample. This has also been confirmed by Morkel and Pieters (2007) in their tests of the Dutoitspan kimberlite. In this case, the d-spacings of the tested pure organic reagents treatments were rather lower than the untreated sample $(14.88 \AA)$, with the exception of the formamide treatment, which produced $16.02 \AA$ spacing which was equivalent to 2 water layers. Again there was not direct correlation between weathering and d-spacing under the tested conditions as the d-spacing values were similar.

Table 14: XRD analysis $\left(\mathrm{d}_{001}\right.$-spacing) results for the effect of pure organic reagents on the $80 \%$ passing $100 \mu \mathrm{m}$ Koffiefontein ore sample.

\begin{tabular}{|c|c|}
\hline Treatment & Spacing $(\mathbf{\AA})$ \\
\hline Untreated & 14.88 \\
\hline Ethanol & 14.81 \\
\hline Formamide & 16.02 \\
\hline n-Hexane & 14.84 \\
\hline Oxalic acid & - \\
\hline Urea & - \\
\hline Pentanoic acid & 14.50 \\
\hline Acetic acid & 14.80 \\
\hline
\end{tabular}

- Denotes that the organic reagents were not tested as their pure forms are powder and not in liquid form

Figure 29 shows that all organic treatments reported lower than the untreated sample TGA curve. This means all pure organic reagents were adsorbed onto the kimberlite. The formamide curve was the furthest below the rest of the curves and this showed that it was adsorbed the most amongst the tested organic solutions. 


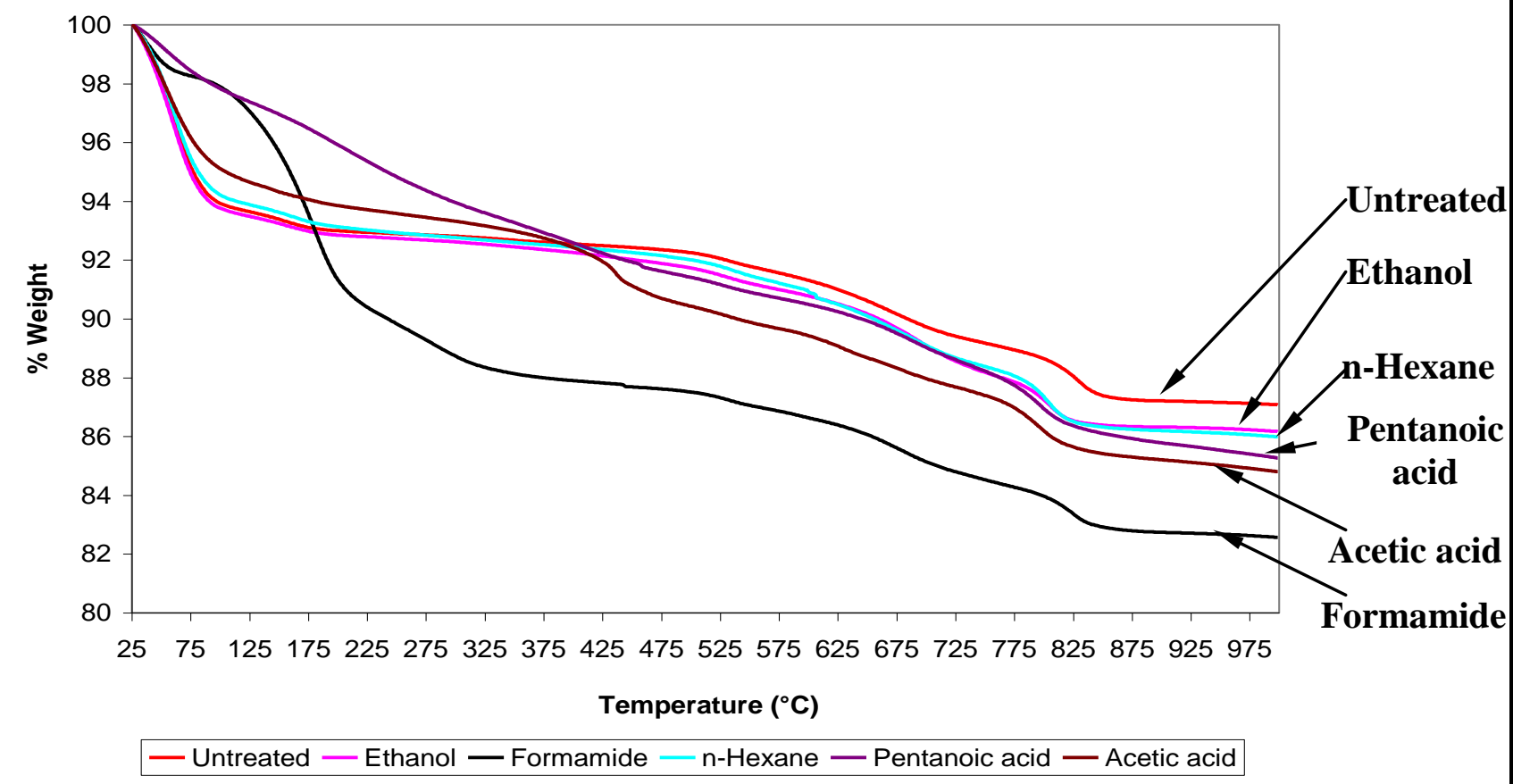

Figure 29: TGA results of pure organic reagents on the $80 \%$ passing $100 \mu \mathrm{m}$ Koffiefontein ore sample showing a higher $\%$ weight loss on formamide treated sample.

The results shown in Figure 30 are relative \% weight losses translated to \% organic adsorbed. The $\%$ adsorbed was calculated as the $\%$ mass difference between the treated and untreated samples for the weight loss between $125{ }^{\circ} \mathrm{C}$ and $1000{ }^{\circ} \mathrm{C}$, calculated from Figure 29. Formamide showed the greatest of about $8 \%$, followed by pentanoic acid at about $5 \%$. The remainder of the pure organic reagents was below $5 \%$. These results indicate that the adsorption of pure organic reagents decreased in the order: formamide > pentanoic acid > acetic acid >n-hexane > ethanol. This also shows that the more polar organic reagents were adsorbed to a greater extent in the kimberlite material. In addition, the more volatite reagents ethanol and n-hexane were shown to be adsorbed to a less extent. 


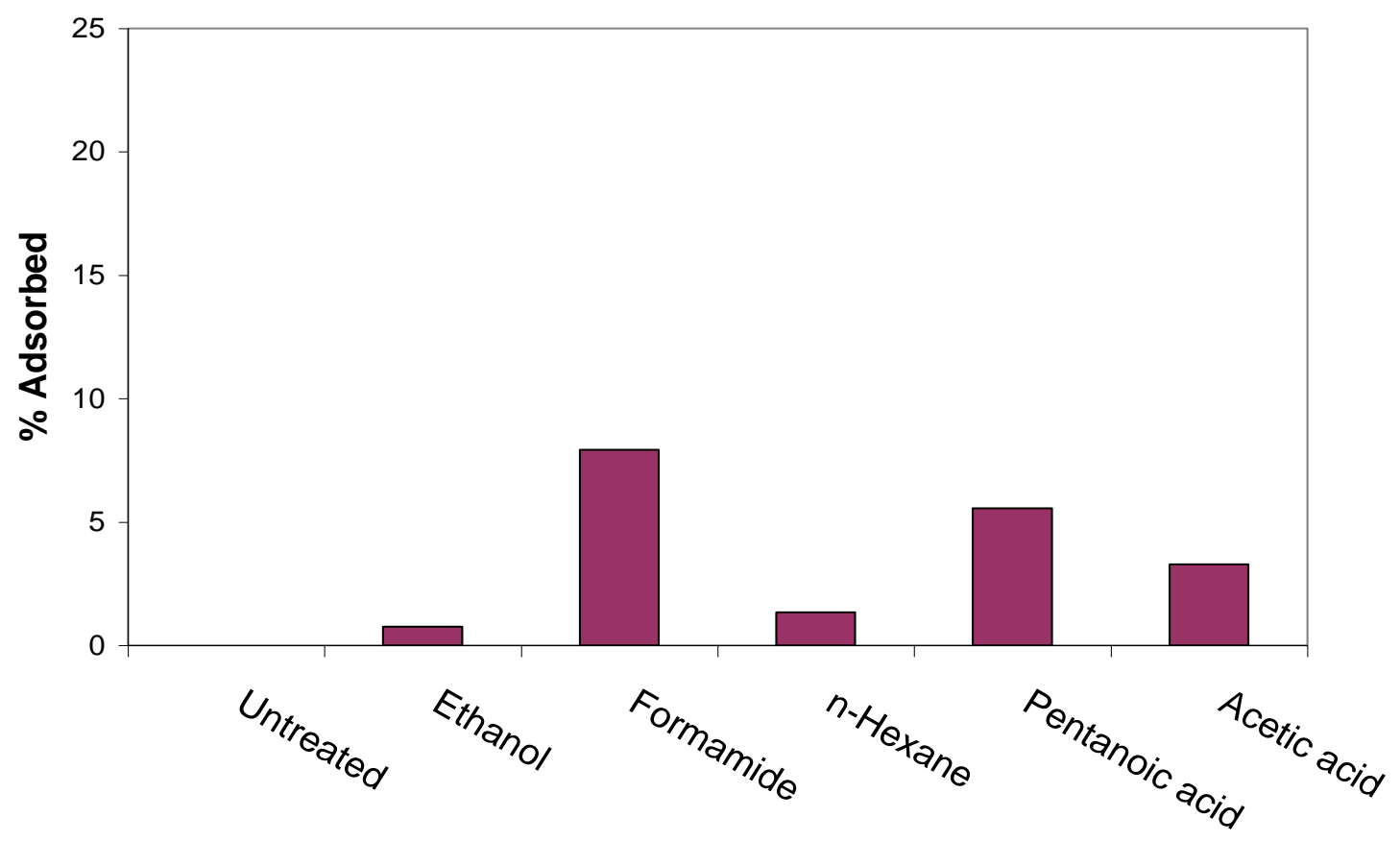

Figure 30: An illustration of the TGA results on Koffiefontein ore sample showing relative adsorbed pure organic reagents, with the untreated sample as the baseline reference.

From FTIR analysis shown in Figure 31, results are similar to the ones obtained from 0.5 M organic solutions treatments (Figure 27). For all reagents the $\mathrm{Si}-\mathrm{O}$ stretching band $\left(1007 \mathrm{~cm}^{-1}\right)$ was not affected and this reported no structural change to the kimberlite. There was a shift in the $1639 \mathrm{~cm}^{-1}$ peak position to a higher frequency of $\sim 1700 \mathrm{~cm}^{-1}$ in the case of formamide. It is possible that this was due to the strong H-bond interaction of formamide with the mineral surface, at the expense of the interlayer water. This peak may also be due to the adsorption of formamide itself. The broad water band at $3435 \mathrm{~cm}^{-1}$, due to intermolecular H-bonding, was present in all organic solutions. However, the intensities were rather shallow on acetic acid, pentanoic acid and n-hexane treatments. This might have meant a reduction in the water content within the mineral structure due to the relatively stronger effect of these pure organic reagents. In general, because pure organic reagents were present in a relatively high concentration, they did show a significant degree of water expulsion. 


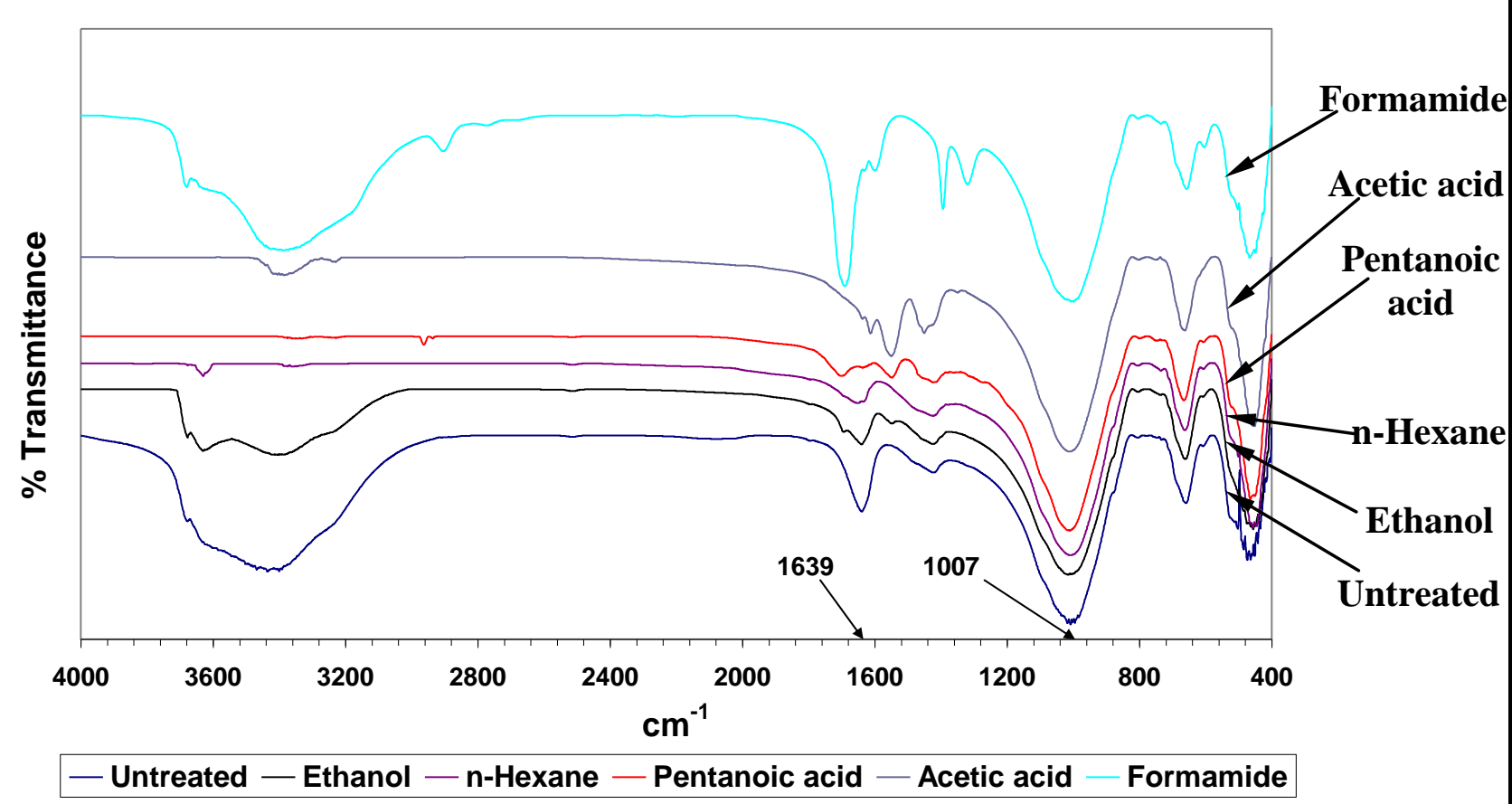

Figure 31: FTIR scans for Koffiefontein samples treated with pure organic reagents.

\section{The effect of pre-cationic treatment on organic adsorption}

Tests for the effect of pre-cationic treatment prior to organic solutions were conducted utilising $16 \mathrm{~g}$ of the $80 \%$ passing $100 \mu \mathrm{m}$ Koffiefontein ore samples. This was first exposed to $250 \mathrm{ml}$ of various cationic solutions, for 7 days at room temperature $\left(\sim 25^{\circ} \mathrm{C}\right)$, as a pretreatment. It was then immersed in various organic solutions. Cations tested were $\mathrm{Mg}^{2+}, \mathrm{Ca}^{2+}, \mathrm{Na}^{+}$and $\mathrm{K}^{+}$; organic solutions tested were ethanol, $\mathrm{n}$-hexane, formamide, oxalic acid, urea, pentanoic acid and acetic acid. The analysis on dry samples after the tests included XRD, TGA and FTIR analysis.

Table 15 shows the $\mathrm{d}$-spacing obtained from XRD results for these tests. The d-spacing values for cation treatment only was smallest for $\mathrm{K}^{+}$at $12.48 \AA$, which increased to 12.60 $\AA$ for $\mathrm{Na}^{+}$. It increased further to $14.72 \AA$ for $\mathrm{Mg}^{2+}$ and 14.79 for $\mathrm{Ca}^{2+}$. The values for $\mathrm{K}^{+}$ and $\mathrm{Na}^{+}$corresponded to a single water layer compared to two water layers for $\mathrm{Mg}^{2+}$ and $\mathrm{Ca}^{2+}$. Comparison of all results show a tendency for the smallest d-value for $\mathrm{K}^{+}$which increases with $\mathrm{Na}^{+}$and the largest interlayer spacings with $\mathrm{Mg}^{2+}$ and $\mathrm{Ca}^{2+}$ cations, similar to the results by Morkel (2006). In general divalent cations $\left(\mathrm{Mg}^{2+}\right.$ and $\left.\mathrm{Ca}^{2+}\right)$, increased the d-spacings whereas, monovalent cations $\mathrm{Na}^{+}$and $\mathrm{K}^{+}$decreased the spacing. The largest interlayer spacing obtained with $\mathrm{Mg}^{2+}$ and urea was $17.58 \AA$ and $16.77 \AA$ with 
$\mathrm{Ca}^{2+}$ and urea. The d-spacing for oxalic acid was not detected, as the $14 \AA$ peak was not present on the XRD scan (Appendix $\mathrm{C}$ shows the $\mathrm{Na}^{+}$pretreatment scan). This was thought to be the formation of an amorphous structure due to oxalic acid reacting with cations in the interlayers as well as those within the crystal structure resulting in the formation of a different phases such as Ca-oxalate. The resulting d-spacings formed due to subsequent organic treatments after cationic pretreatment generally decreased in the order: urea $>$ formamide $>$ ethanol $>$ pentanoic acid $>$ acetic acid $>$ n-hexane.

Table 15: XRD analysis $\left(\mathrm{d}_{001}\right.$-spacing) results for the effect of pre-cationic treatment prior to organic weathering on the $80 \%$ passing $100 \mu \mathrm{m}$ Koffiefontein ore sample.

\begin{tabular}{|c|c|c|c|c|c|c|c|c|}
\hline \multirow{2}{*}{ Treatment } & \multicolumn{9}{|c|}{ d-spacing $(\AA)$} \\
\cline { 2 - 9 } & No organic & Ethanol & Formamide & n-Hexane & $\begin{array}{c}\text { Oxalic } \\
\text { acid }\end{array}$ & Urea & $\begin{array}{c}\text { Pentanoic } \\
\text { acid }\end{array}$ & $\begin{array}{c}\text { Acetic } \\
\text { acid }\end{array}$ \\
\hline $\mathrm{K}^{+}$ & 12.48 & 12.46 & 12.87 & 12.40 & 13.33 & 12.53 & 13.29 & 12.48 \\
\hline $\mathrm{Na}^{+}$ & 12.60 & 14.73 & 12.41 & 12.29 & - & 12.40 & 14.33 & 14.68 \\
\hline $\mathrm{Mg}^{2+}$ & 14.72 & 14.80 & 16.02 & 14.52 & - & 17.58 & 14.37 & 14.75 \\
\hline $\mathrm{Ca}^{2+}$ & 14.79 & 14.96 & 15.43 & 15.12 & - & 16.77 & 14.96 & 14.95 \\
\hline
\end{tabular}

-Denotes value could not be determined

TGA analysis was performed on formamide treated samples presaturated in $\mathrm{Mg}^{2+}, \mathrm{Ca}^{2+}$, $\mathrm{Na}^{+}$and $\mathrm{K}^{+}$cations. Figure 32 shows the TGA results for these tests. The curves for the $\mathrm{Mg}^{2+}$ and $\mathrm{Ca}^{2+}$ pretreated samples reported below the untreated curve, and therefore showed a higher weight loss than the $\mathrm{Na}^{+}$and $\mathrm{K}^{+}$pretreated samples that reported above the base case. The \% weight loss is directly proportional to the amount of organic adsorbed, which is affected by the type of cation preconditioning. The \% adsorbed was calculated as the $\%$ mass difference between the treated samples and the untreated sample for the weight loss that occurred between $125^{\circ} \mathrm{C}$ and $1000{ }^{\circ} \mathrm{C}$. The cations $\mathrm{Mg}^{2+}$ and $\mathrm{Ca}^{2+}$ increased the adsorption of the organic (with $\mathrm{Mg}^{2+}$ having the greatest effect), whereas $\mathrm{Na}^{+}$and $\mathrm{K}^{+}$pretreatments resulted in a more stable structure that did not allow further adsorption of formamide. The reason why $\mathrm{Mg}^{2+}$ produced a greater organic adsorption is due to the larger ionic radii (Figure 10 in section 2.4.4.1) that produced an expansion that allowed more organic to be adsorbed. Figure 33 shows calculated adsorption percentages obtained from Figure 32. The $\mathrm{Mg}^{2+}$ precondition resulted in a high adsorption of $12 \%$. The other preconditioning cations reported values below $5 \%$, with $\mathrm{K}^{+}$preconditioning being lowest at about $0.5 \%$. It can be concluded from these results that the order of organic weathering, due to cation pretreatment, is assumed to 
decrease as follows: $\mathrm{Mg}^{2+}>\mathrm{Ca}^{2+}>\mathrm{Na}^{+}>\mathrm{K}^{+}$. This trend follows the decrease in the hydration radii of these cations. This was a similar trend to that observed in the decrease of the d-spacings from XRD analysis, as shown in Table 15.

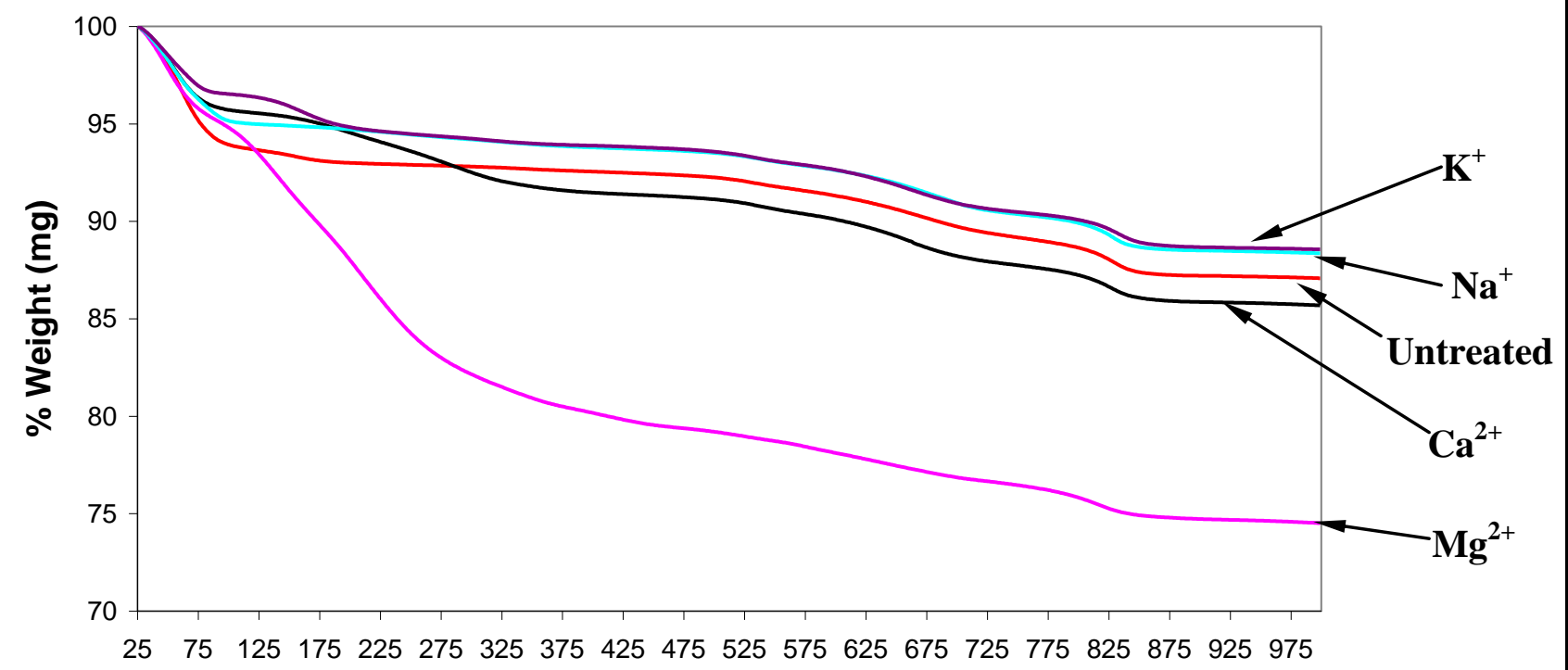

Temperature $\left({ }^{\circ} \mathrm{C}\right)$

$$
\text { - Untreated }-\mathrm{Mg} 2+-\mathrm{Ca} 2+-\mathrm{Na}+-\mathrm{K}+
$$

Figure 32: TGA results of formamide adsorption after cation conditioning of Koffiefontein ore sample.

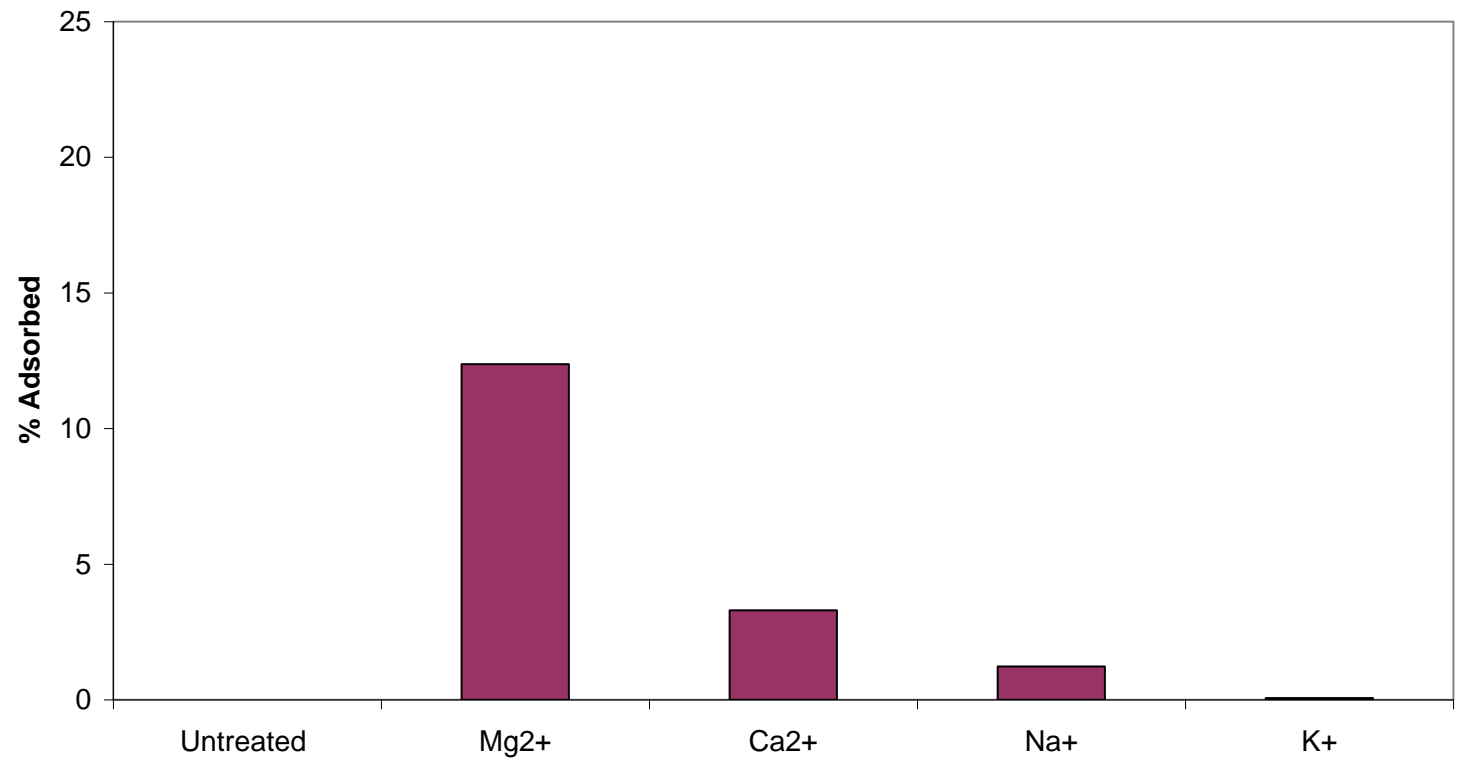

Figure 33: An illustration of the \% formamide adsorbed with various pre-cation treatments, on the Koffiefontein ore sample with reference to an untreated sample. 
Because $\mathrm{Mg}^{2+}$ showed the highest adsorption (12\%) from the previous test (Figure 33), this cation was utilised as a preconditioning cation prior to various organic treatments. The effect of prior $\mathrm{Mg}^{2+}$ treatment of Koffiefontein ore sample on the adsorption of various organic solutions was reported by TGA analysis, and is shown in Figure 34. All the organic curves showed higher weight loss than the untreated sample (organic curves are all below the untreated curve), and this showed an improvement in the amount of organic reagents adsorbed as a result of $\mathrm{Mg}^{2+}$ pretreatment, compared to those that had no pre-cationic treatment, as shown in Figure 26. Figure 35 also shows the improvement with $\mathrm{Mg}^{2+}$ pre-treated, compared to non- $\mathrm{Mg}^{2+}$ pretreatment results. Oxalic acid improved from 23 to $30 \%$, urea from 2 to $24 \%$, formamide from 1 to $12 \%$, pentanoic acid from 1 to $9 \%$, acetic acid from below 0 to $5 \%$, n-hexane from 0.1 to $3 \%$ and ethanol from 0.2 to $3.2 \%$ relative to the untreated sample. According to Figure 35, the quantity of organic reagents adsorbed (on $\mathrm{Mg}^{2+}$ pretreatment) decreased in the order: oxalic acid > urea > formamide $>$ pentanoic acid $>$ acetic acid $>$ ethanol $>$ n-hexane.

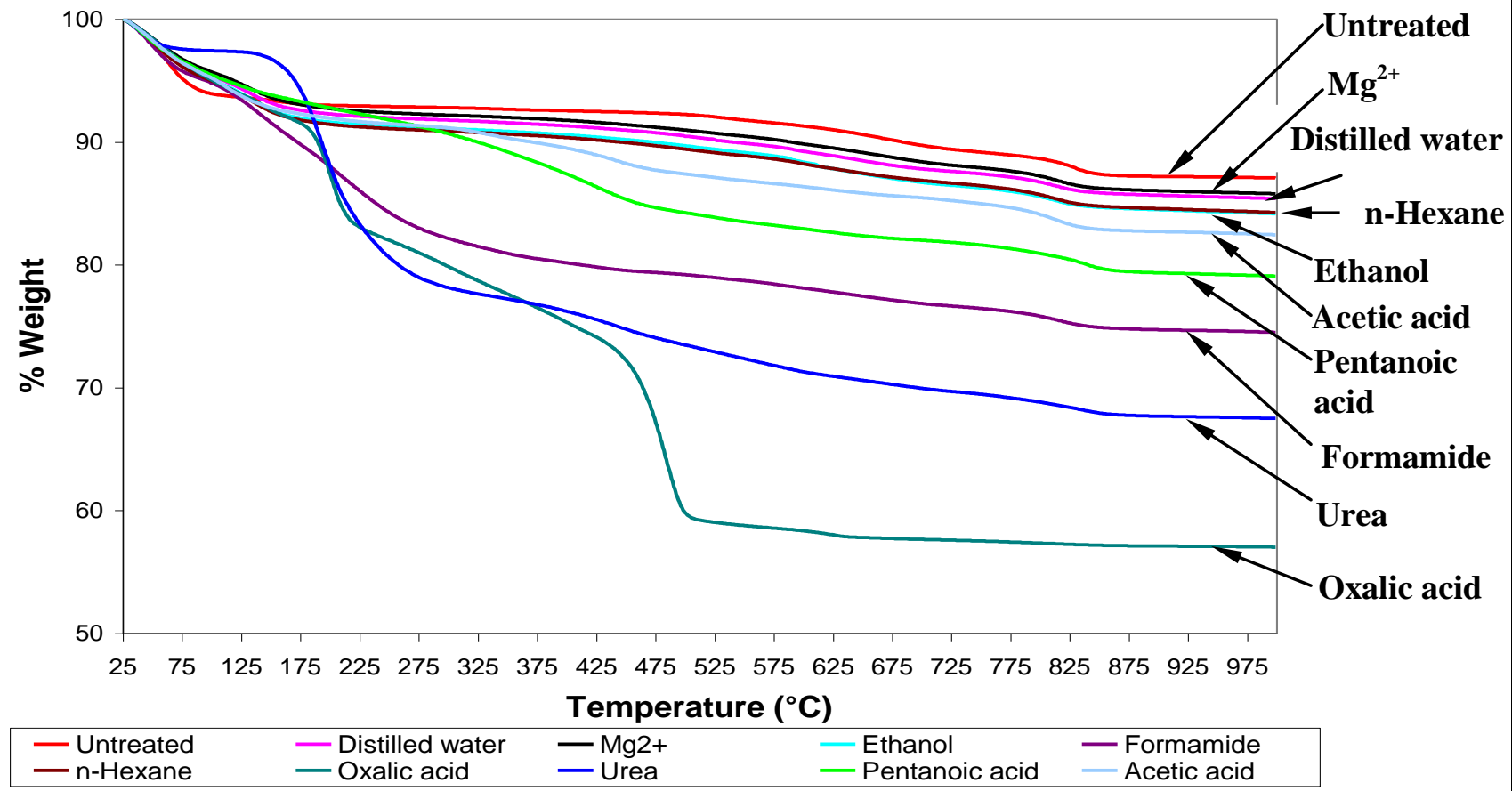

Figure 34: TGA results of the adsorption of various organic solution treatments on $\mathrm{Mg}^{2+}$ pre-treated Koffiefontein ore sample. 


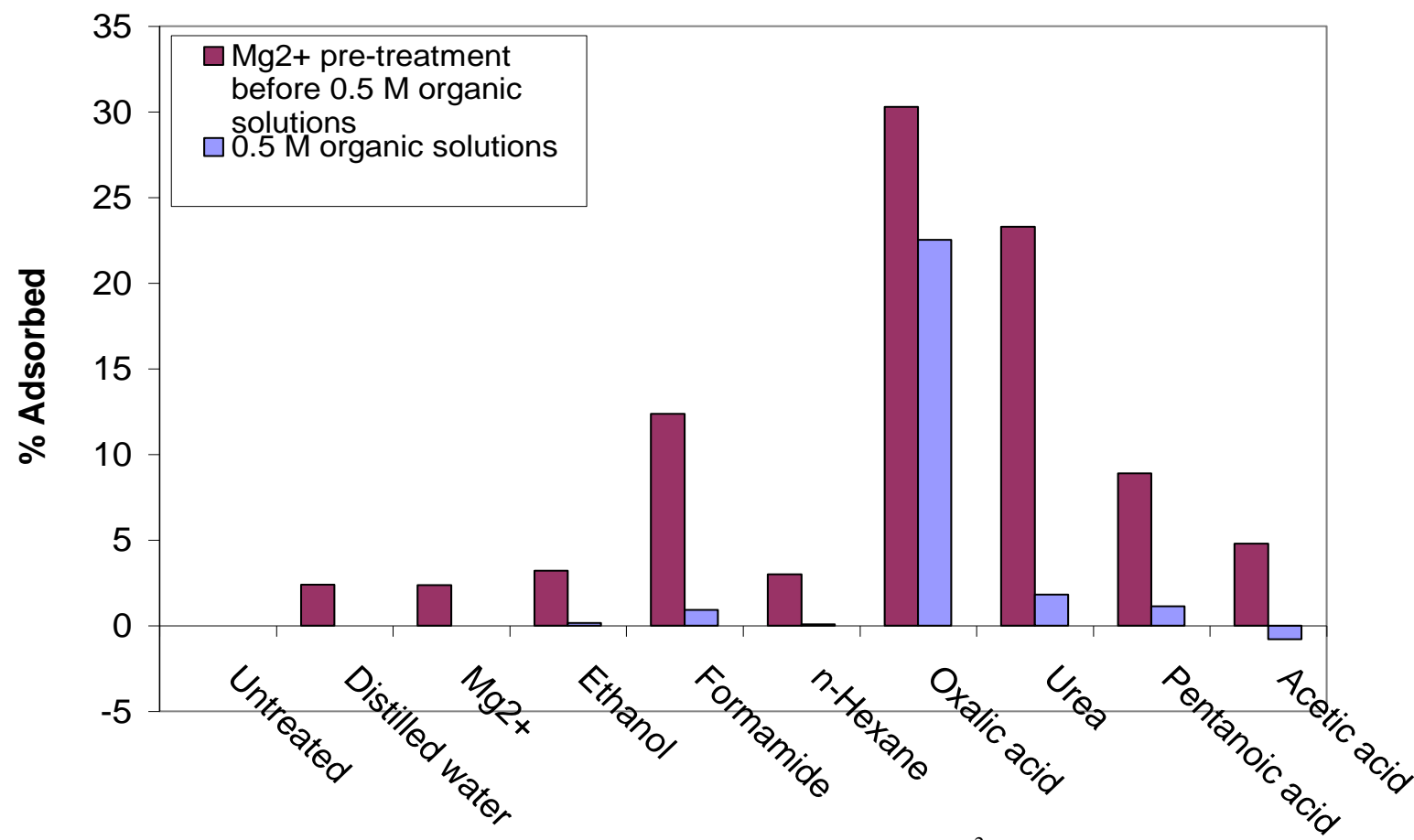

Figure 35: Amounts of adsorbed organic reagents, as percentages, on $\mathrm{Mg}^{2+}$ pre-treated before $0.5 \mathrm{M}$ organic solutions and only $0.5 \mathrm{M}$ organic solution treatments of Koffiefontein ore sample.

According to Grim (1968), the extent of organic adsorbed onto the clay mineral interlayer depends upon the type of cation pre-present, and the amount of water pre-present. Therefore various organic reagents will react differently to a particular type of cation pre-present. Grim (1968) showed that with the adsorption of an organic onto a clay surface, the process does not displace the inorganic cations, but rather interacts with the cationic species. In section 2.4.4.1 it was mentioned that the strength of the organic attachment will depend upon the amount of water already in the interlayer; and is associated with the pre-present cation hydration status. Larger size cations are less hydrated than smaller ones, therefore organic reagents tend to attach in higher quantities on larger sized cationic environments. For the cations observed, the order of the bonded amount of water will be $\mathrm{Mg}^{2+}>\mathrm{Ca}^{2+}>\mathrm{Na}^{+}>\mathrm{K}^{+}$, which is similar to TGA results on the effect of cation pretreatment (Figure 32 and 33).

Figures 36, 37, 38 and 39 show, respectively, FTIR results of $\mathrm{Mg}^{2+}, \mathrm{Ca}^{2+}, \mathrm{Na}^{+}$and $\mathrm{K}^{+}$ pre-treated Koffiefontein samples prior to various organic treatments. The graphs show that the water was maintained in all treatments around the wavelengths $3625 \mathrm{~cm}^{-1}$ and $1630 \mathrm{~cm}^{-1}$, which means that there were no $\mathrm{OH}$ groups that were necessarily more tightly bound for a certain treatment than another. The $\mathrm{OH}$ peak on the formamide treated 
samples however shifted to $1690 \mathrm{~cm}^{-1}$ in all the cation pretreatments and this indicates the formation of $\mathrm{H}$-bonds between the formamide and the surface regardless of the preconditioning cation. The other observation made is that $\mathrm{Na}^{+}$pre-treated curves were the only ones that exhibited a water peak at $3440 \mathrm{~cm}^{-1}$ which indicates intramolecular $\mathrm{H}$-bonds amongst the organic reagents. On the $\mathrm{K}^{+}$pretreatments, the organic reagents formamide, urea and pentanoic acid did not produce peaks between $2400 \mathrm{~cm}^{-1}$ and 4000 $\mathrm{cm}^{-1}$ which means that most of the free water was driven off and that no intramolecular H-bonds occurred. This could also be an explanation why divalent cations have a larger hydration radius than monovalent cations.

The Si-O peak at $1007 \mathrm{~cm}^{-1}$ did not shift for any of the treatments except for oxalic acid which shifted to a higher value in all the precationic treatments. This again showed that oxalic acid dissolved the structure.

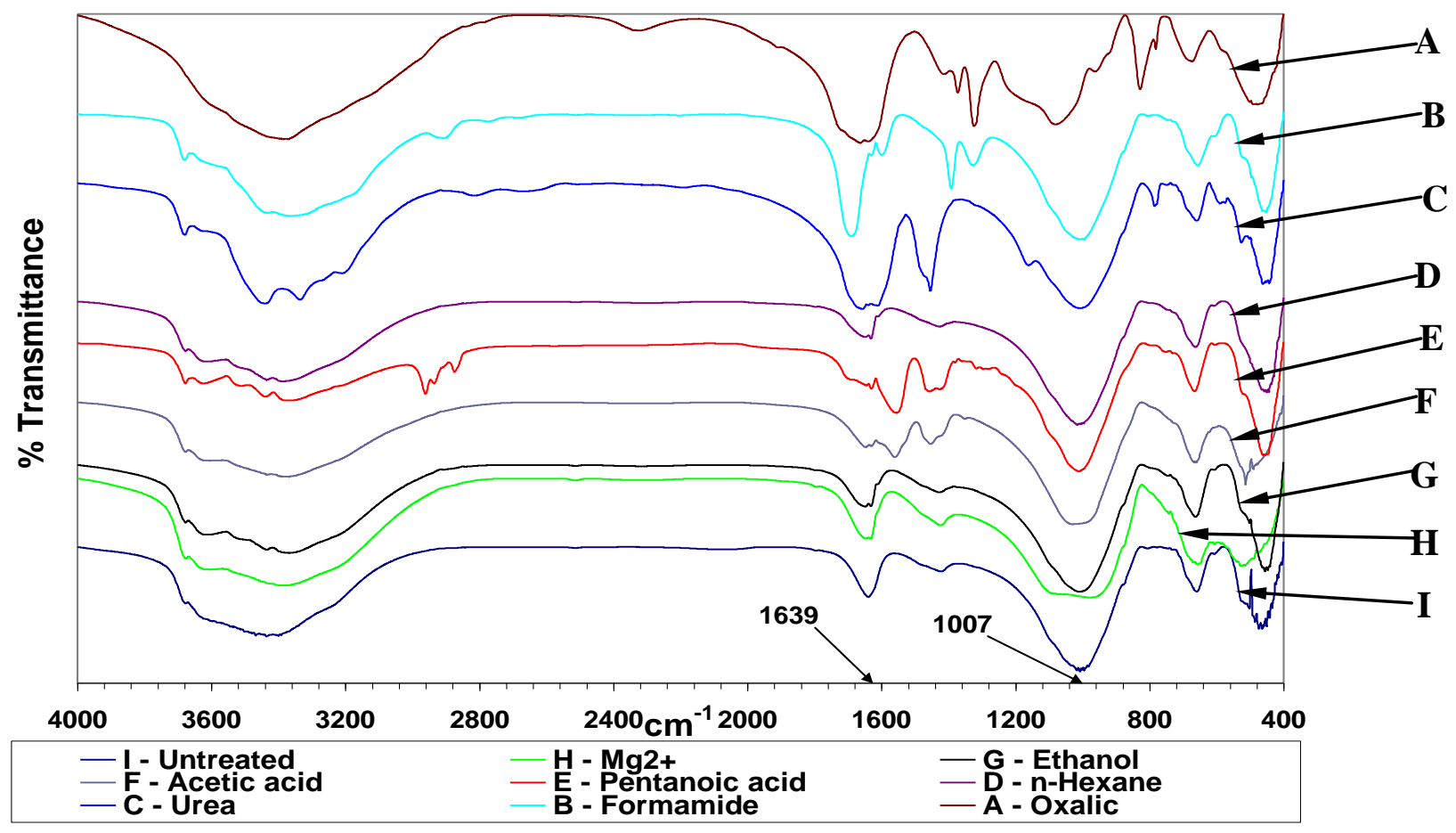

Figure 36: FTIR scans for Koffiefontein samples treated with $0.5 \mathrm{M}$ organic solutions after pretreatments in $0.5 \mathrm{M}$ solution of $\mathrm{Mg}^{2+}$ in comparison to an untreated sample. 


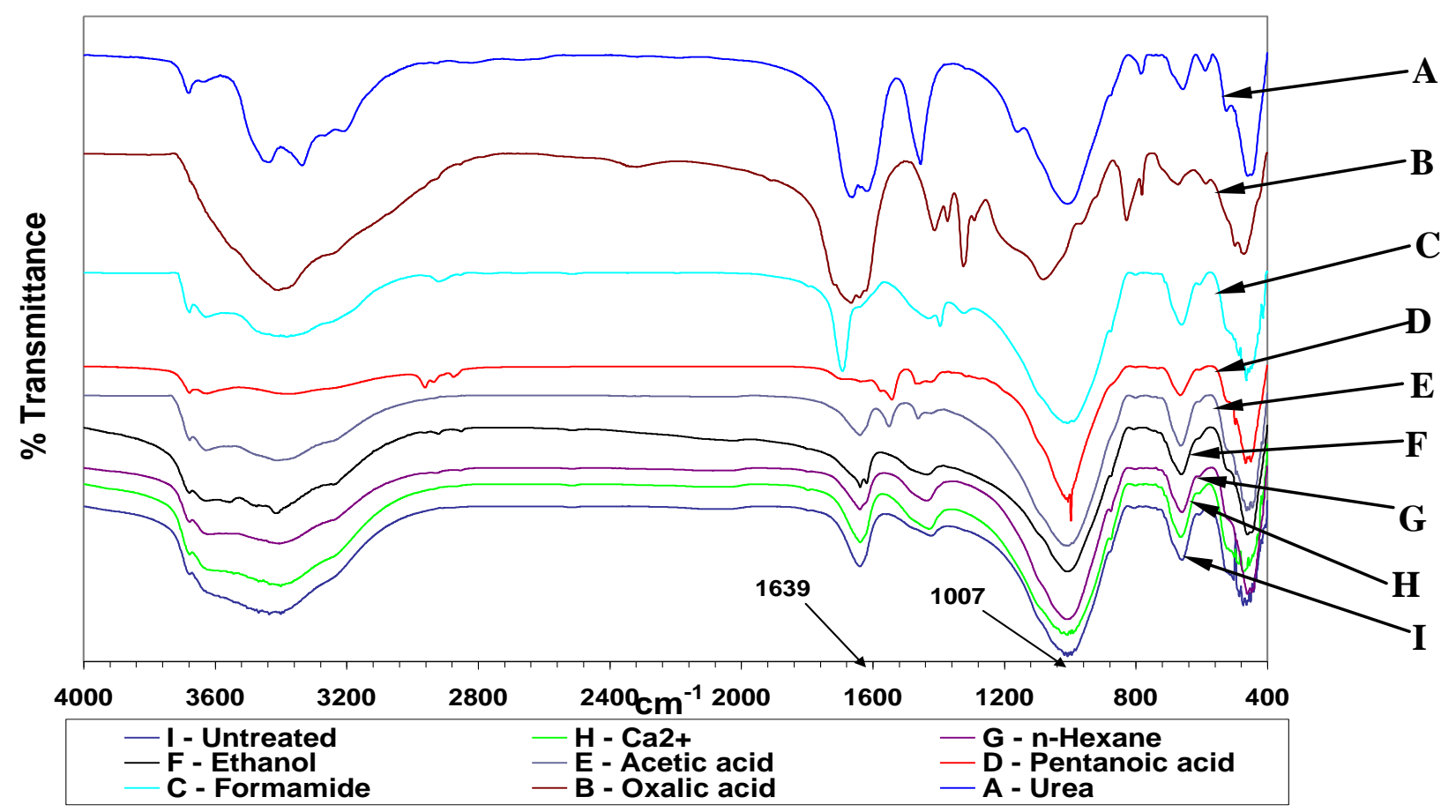

Figure 37: FTIR scans for Koffiefontein samples treated with $0.5 \mathrm{M}$ organic solutions after pretreatments in $0.5 \mathrm{M}$ solution of $\mathrm{Ca}^{2+}$ in comparison to an untreated sample.

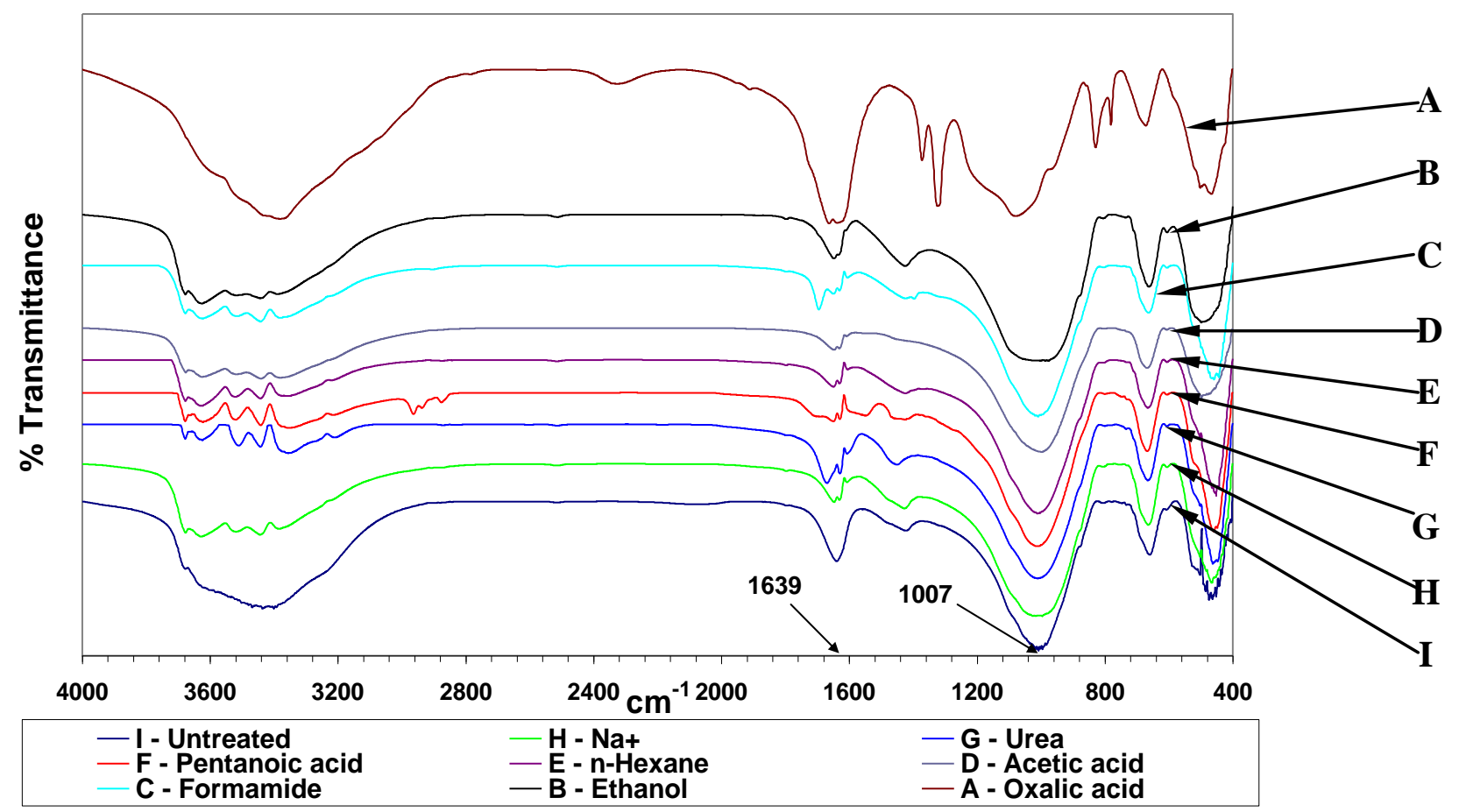

Figure 38: FTIR scans for Koffiefontein samples treated with $0.5 \mathrm{M}$ organic solutions after pretreatments in $0.5 \mathrm{M}$ solution of $\mathrm{Na}^{+}$in comparison to untreated sample. 


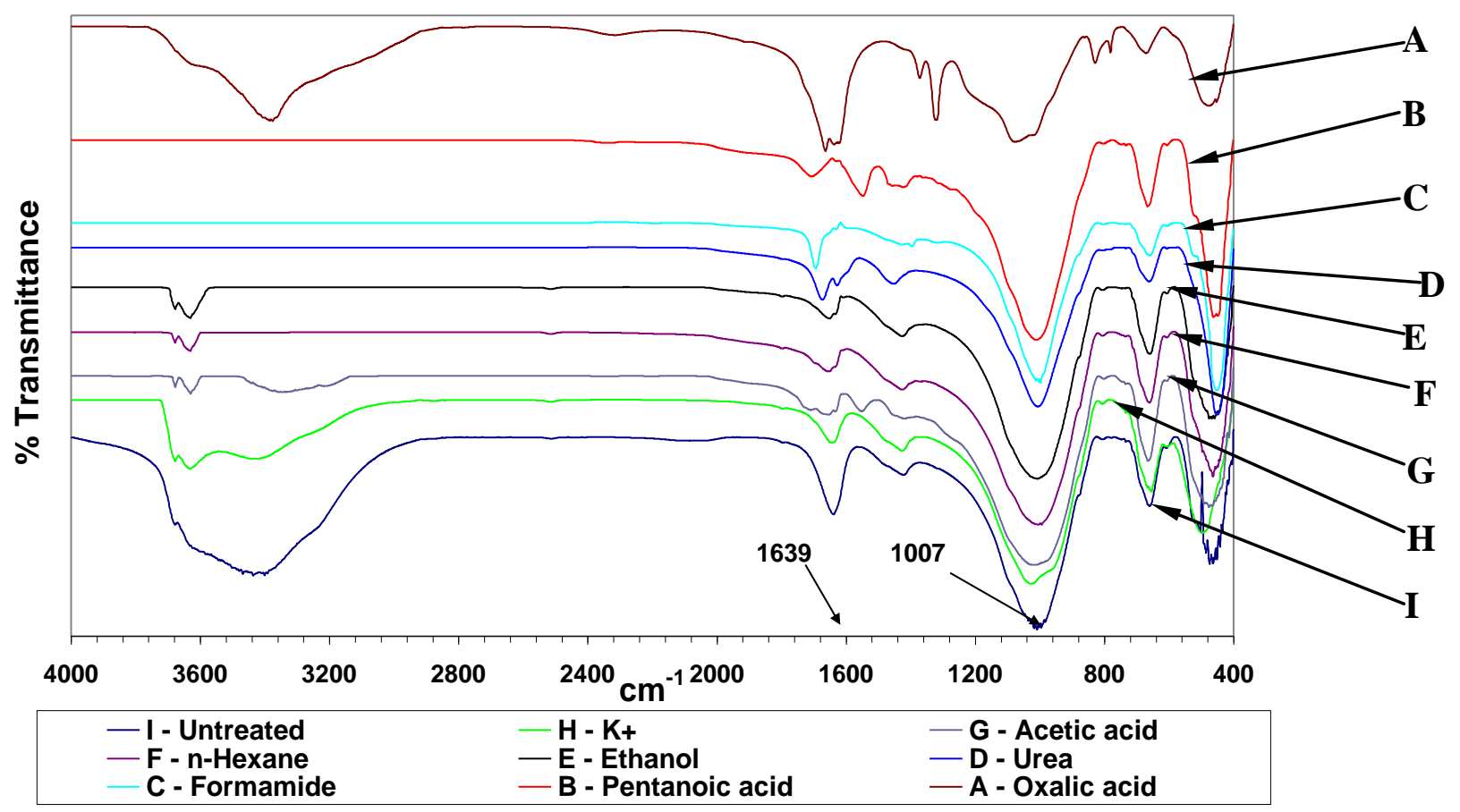

Figure 39: FTIR scans for Koffiefontein samples treated with $0.5 \mathrm{M}$ organic solutions after pretreatments in $0.5 \mathrm{M}$ solutions of $\mathrm{K}^{+}$in comparison to untreated sample.

A comparison between only organic reagents and only cation adsorption was investigated by TGA analysis. The weight loss results for cation treatment are shown in Figure 40, and the calculated adsorptions are shown in Figure 41 . The $\mathrm{K}^{+}$curve was the only one that was above the untreated sample curve. This indicated that the structure was more tightly bound to release any components within, and so $\mathrm{K}^{+}$can be said to act as a kimberlite stabilizer, as shown by Morkel (2006). A similar effect could be considered for $\mathrm{Na}^{+}$, as the sample showed a negative adsorption relative to the untreated sample, as illustrated in Figure 41. Comparing Figure 27 for the organic reagents, with Figure 41 for the inorganic reagents, oxalic acid (which was the highest adsorbed organic), was better adsorbed at $\sim 23 \%$ compared to $\sim 2.5 \%$ for $\mathrm{Mg}^{2+}$, which came out as the highest adsorbed inorganic. However the second highest adsorbed organic, urea, was $\sim 1.82 \%$ and this was lower than the highest adsorbed cation, $\mathrm{Mg}^{2+}$. This served to further indicate the potential use of oxalic acid as an organic that can be utilised in kimberlite weathering. 


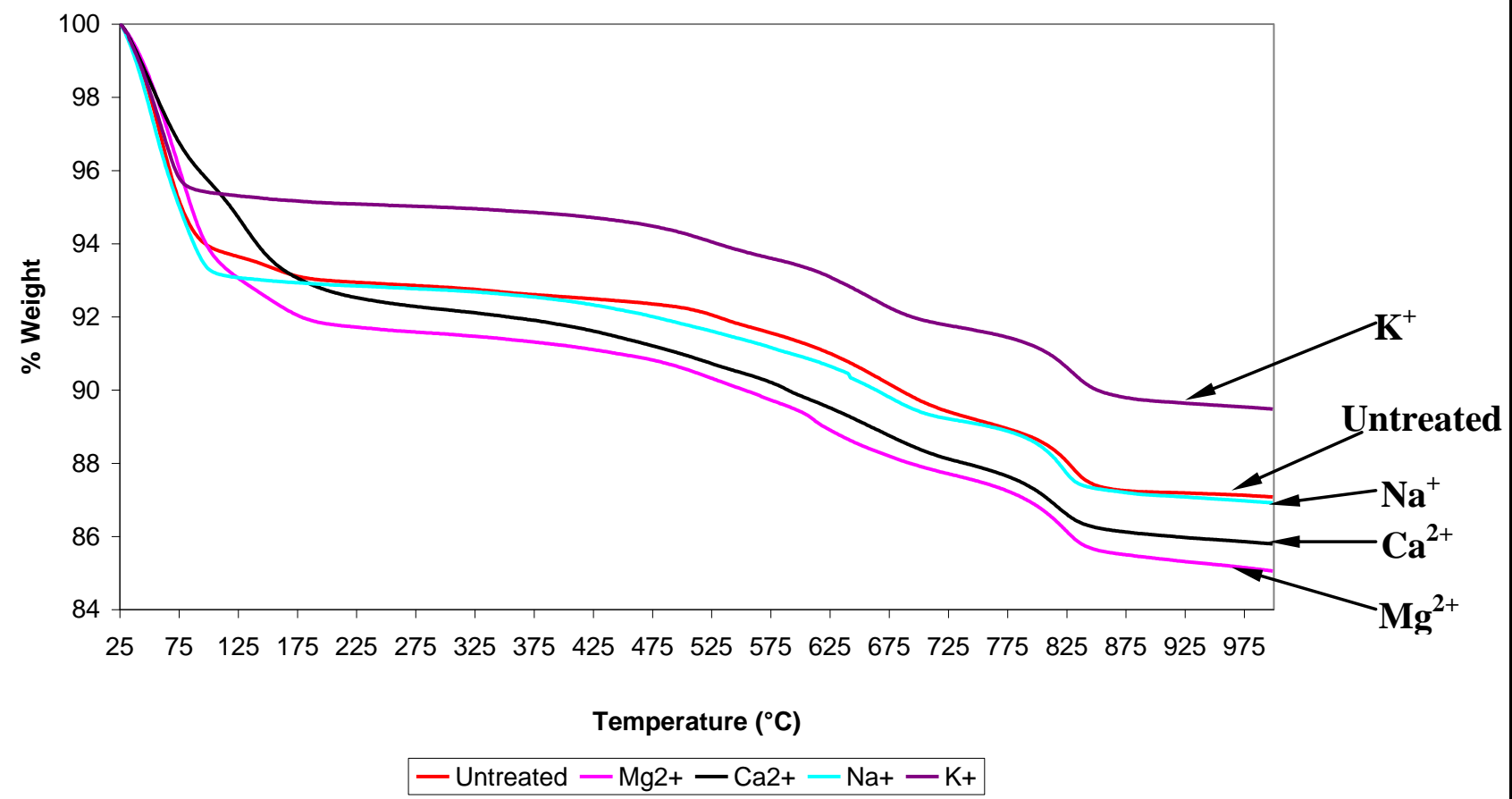

Figure 40: TGA results of the Koffiefontein ore sample treated with $0.5 \mathrm{M} \mathrm{Mg}^{2+}, \mathrm{Ca}^{2+}, \mathrm{Na}^{+}$and $\mathrm{K}^{+}$.

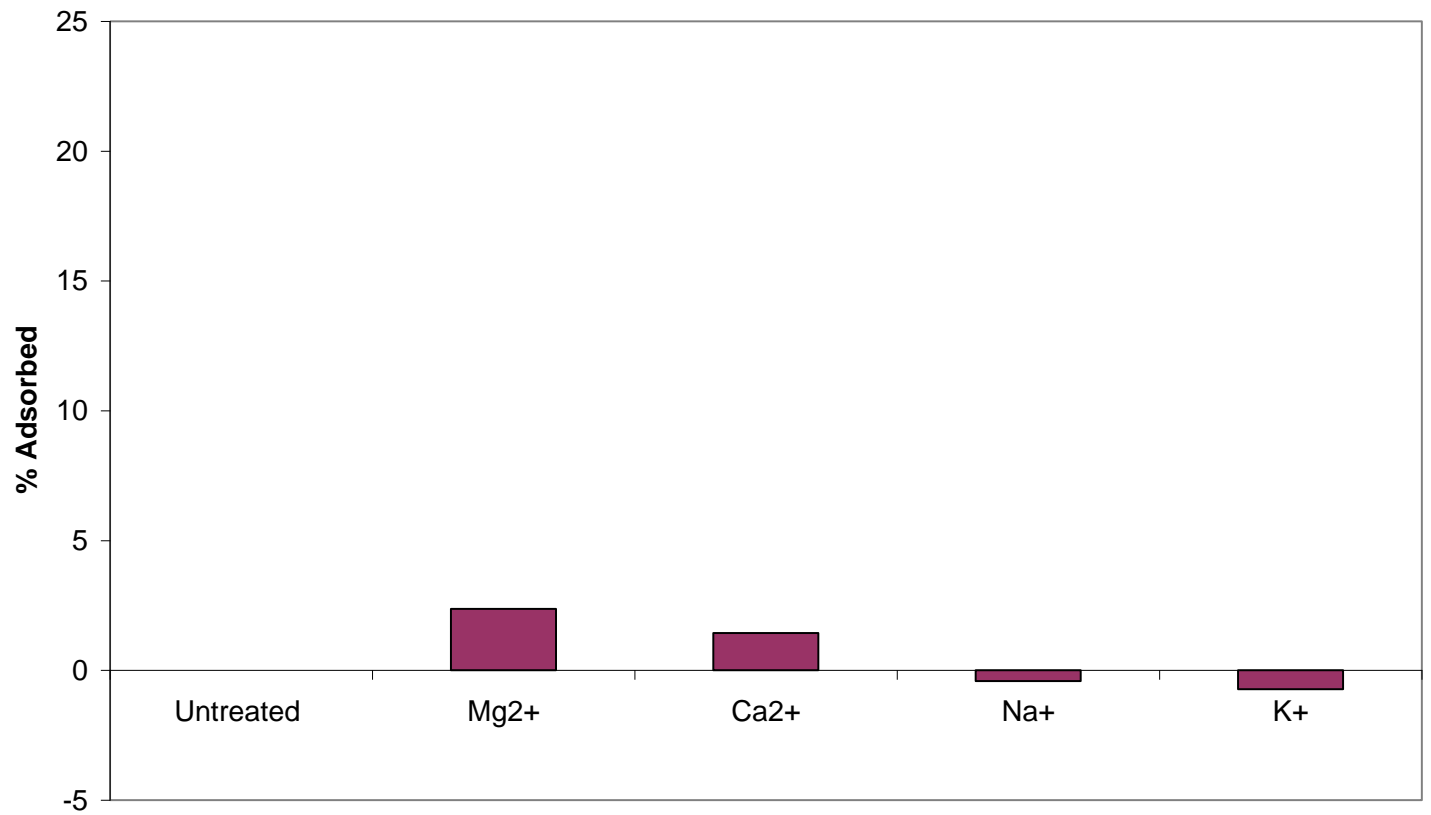

Figure 41: An illustration of TGA results on the Koffiefontein ore sample showing relative adsorbed cations in comparison to an untreated sample.

\section{The effect of pre-organic treatment on organic adsorption}

Tests for the effect of pre-organic treatment, prior to organic adsorption, were conducted utilising Koffiefontein ore samples ( $16 \mathrm{~g}$ of the $80 \%$ passing $100 \mu \mathrm{m})$. These were first 
exposed to $250 \mathrm{ml}$ of various organic species, for 7 days at room temperature $\left(\sim 25^{\circ} \mathrm{C}\right)$, and later immersed in $0.5 \mathrm{M}$ formamide. The pretreatment organic reagents tested were pyridine $(\mathrm{P})$, cetylpyridium chloride (CPC), dimethyldioctadecylammonium chloride (DDAC) and dodecylamine (DDA). These were selected as they are long chain organic reagents, expected to form organoclays that improve the adsorption behavior of clay minerals towards other organic reagents (Refer to section 2.4.1). The analysis on dry samples after the test included XRD, TGA and FTIR analysis.

Table 16 shows the d-spacings produced for the organic pretreated Koffiefontein samples. The highest d-spacing was obtained with DDAC at $20.09 \AA$, followed by 19.14 $\AA$ for CPC, then $17.83 \AA$ for DDA and finally $15.66 \AA$ for P. The d-spacing for only formamide, at $0.5 \mathrm{M}$, was reported earlier in the discussion as $15.06 \AA$. This value was less than the $15.66 \AA$ produced by pyridine pretreatment, which was the lowest d-spacing in this test. The interlayer spacing for DDAC and CPC corresponded to 3 water layer distances, and for DDA and P, it corresponded to 2 water layers. The order of decreasing d-spacings was DDAC $>$ CPC $>$ DDA $>$ P.

Table 16: XRD analysis ( $\mathrm{d}_{001}$-spacing) results for the effect of organic pretreatment prior to formamide treatment on the $80 \%$ passing $100 \mu \mathrm{m}$ Koffiefontein ore sample.

\begin{tabular}{|c|c|}
\hline Treatment & $\AA$ \\
\hline Untreated & 14.88 \\
\hline Pyridine & 15.66 \\
\hline Dodecylamine & 17.83 \\
\hline Cetylpyridium & 19.14 \\
\hline Dimethyl- & 20.09 \\
\hline
\end{tabular}

The TGA results in Figure 42 show that all pretreatments experienced a greater mass loss than the untreated sample after organic adsorption as all the organic curves reported below the untreated curve. The extent of adsorption is illustrated in Figure 43, with a \% adsorption of $\sim 21 \%$ for DDAC, $\sim 18 \%$ for CPC, $\sim 14 \%$ for DDA and $\sim 7.5 \%$ for P. It was reported earlier that only $\sim 1 \% \quad 0.5 \mathrm{M}$ formamide was adsorbed into Koffiefontein ore sample (Figure 27). This value is less than the $7.5 \%$ reported for pyridine which had the least adsorption amount amongst the pretreatments. This indicates an improvement made by organic pretreatments; however the $\sim 21 \%$ DDAC-formamide treatment was still less than the $\sim 23 \%$ obtained for $0.5 \mathrm{M}$ oxalic acid only (Figure 27 ). The general 
order of the decrease in adsorption of formamide due to these pretreatments was DDAC > $\mathrm{CPC}>\mathrm{DDA}>\mathrm{P}$. This corresponded with the order of d-spacings from XRD results shown in Table 16, and possibly with the extent of weathering.

Some other examples of pre-conditioning chemicals have been mentioned by Grim (1968). These are mostly large organic ions that strongly attach to the clay interlayer space because of larger van der Waals forces that lead to adsorptions even higher than the CEC.

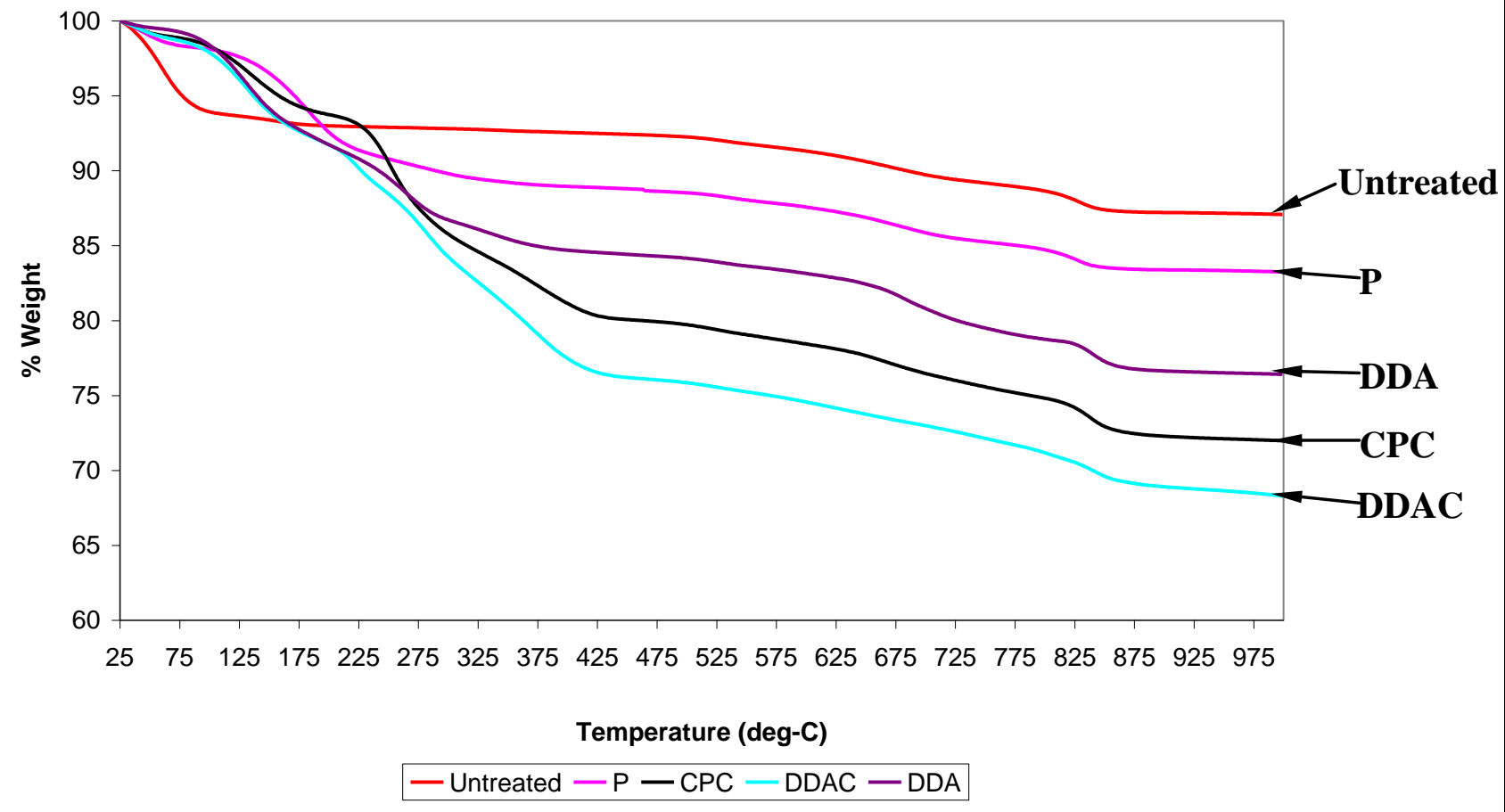

Figure 42: TGA results of various organic reagents treatments with a prior P, CPC, DDAC and DDA before formamide on the Koffiefontein ore sample. 


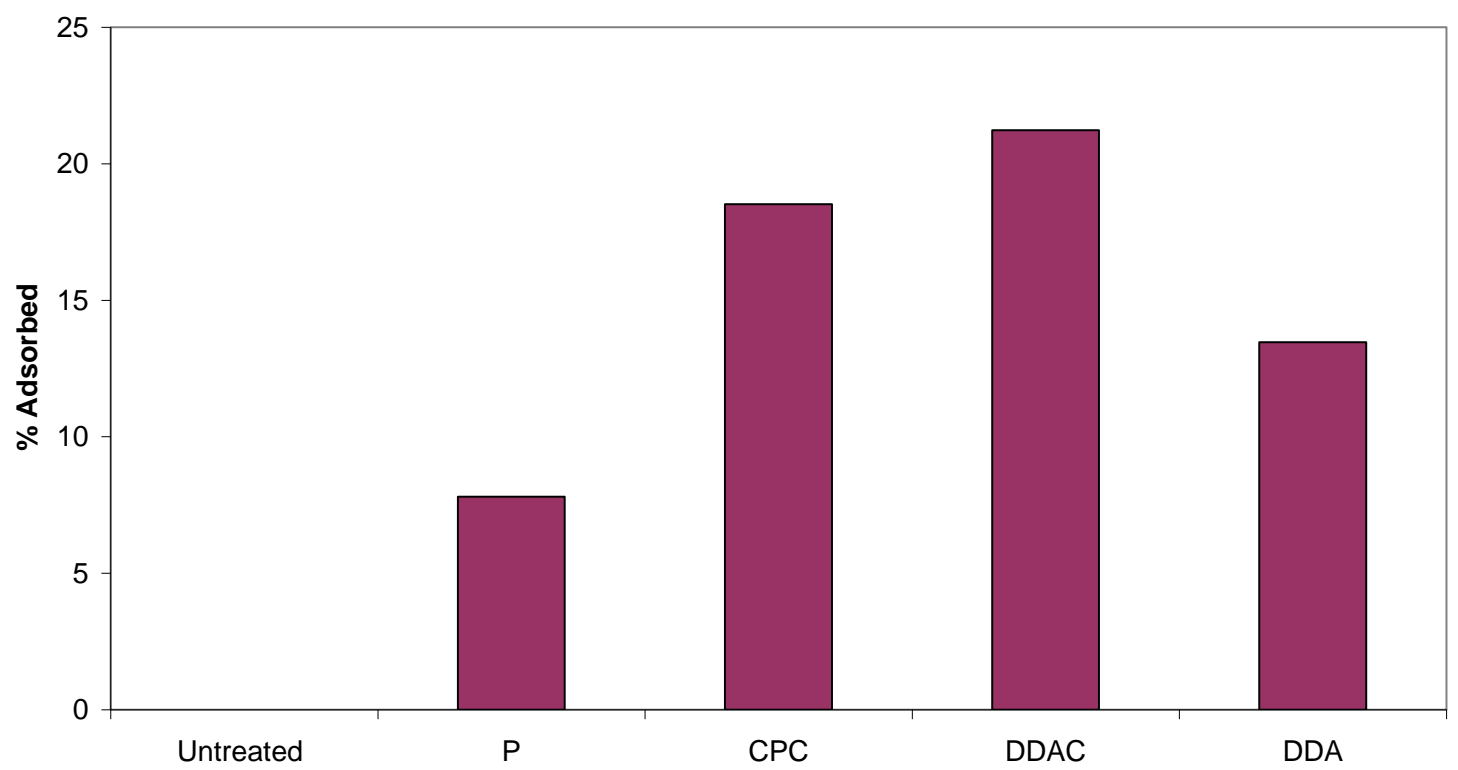

Figure 43: An illustration of the amount of formamide adsorbed due to pretreatment of P, CPC, DDAC and DDA on the Koffiefontein ore sample.

FTIR results for the organic pretreatments are shown in Figure 44. The treatments show that the water peak at $1630 \mathrm{~cm}^{-1}$ shifted to about $1683 \mathrm{~cm}^{-1}$, which indicated elimination of water in the interlayers, resulting in strong H-bonds occurring between the organic molecules and the particle surface. Organic concentration in the samples became dominant to such an extent that the $\mathrm{CH}$ stretch $\left(2916 \mathrm{~cm}^{-1}\right.$ and $\left.2849 \mathrm{~cm}^{-1}\right)$ and bending $\left(1466 \mathrm{~cm}^{-1}\right)$ became more apparent. This best explains the improved organic adsorption caused by organic pretreatments. The Si-O peaks remained constant at approximately $1007 \mathrm{~cm}^{-1}$ and so there were no structural changes. 


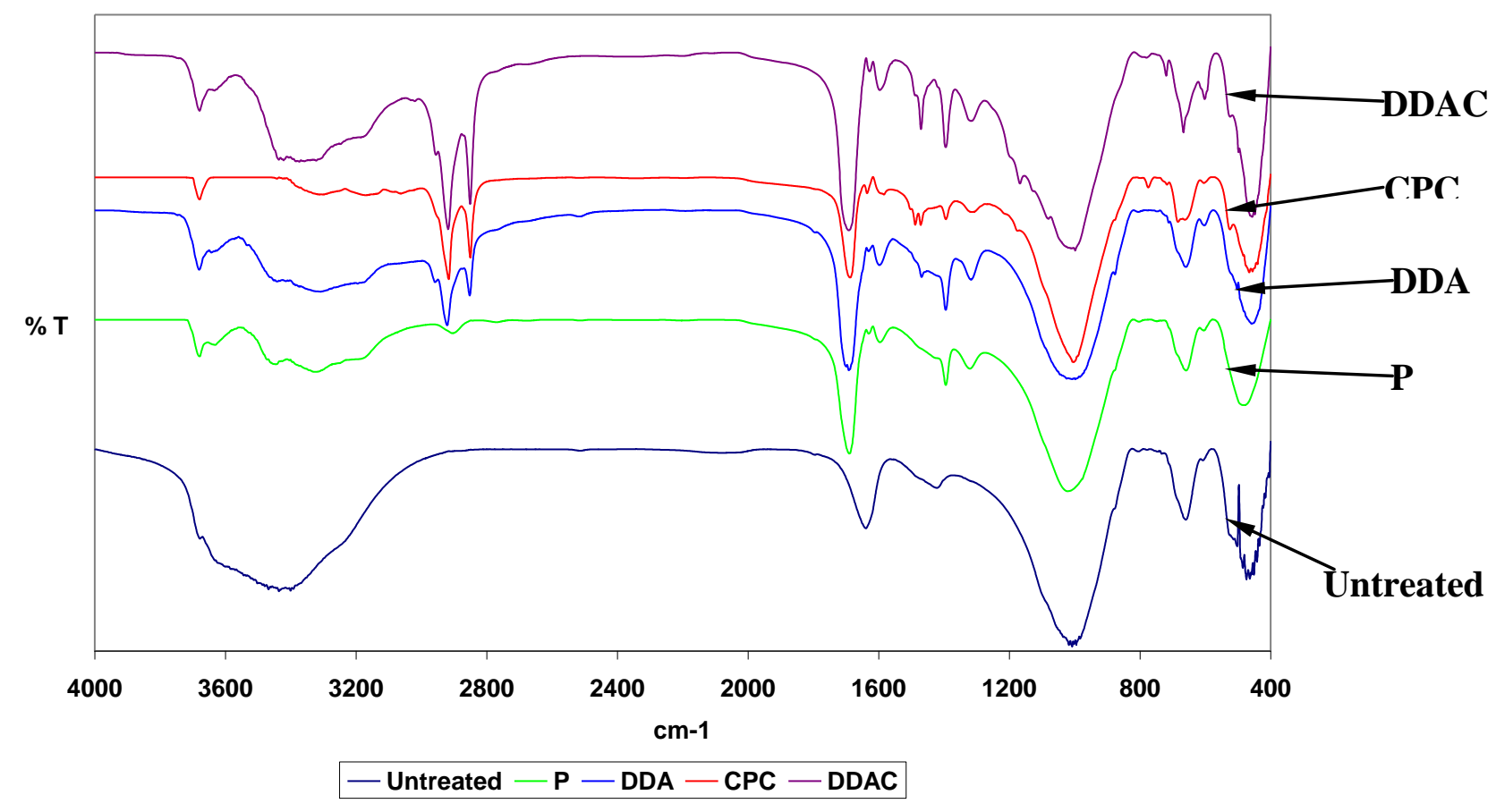

Figure 44: FTIR scans for untreated Koffiefontein sample in comparison to the P, DDA, CPC and DDAC organic reagents treatment prior to formamide saturation on the Koffiefontein ore sample.

\subsection{Standard weathering tests}

The test utilised $300 \mathrm{~g}$ of $-16+13.2 \mathrm{~mm}$ Finsch ore samples that were exposed to $0.5 \mathrm{M}$ organic solutions, for 6 days, at room temperature $\left(\sim 25^{\circ} \mathrm{C}\right)$. The organic media utilised for these tests were ethanol, formamide, n-hexane, oxalic acid, urea and acetic acid. Samples were also exposed to distilled water and $0.5 \mathrm{M} \mathrm{Cu}^{2+}$ for comparison. After the weathering test, the samples were removed, air dried, and sieved to obtain PSD graphs. The PSD data is included in Appendix D. The reference PSD was given by the distilled water results, also known as the water line. 


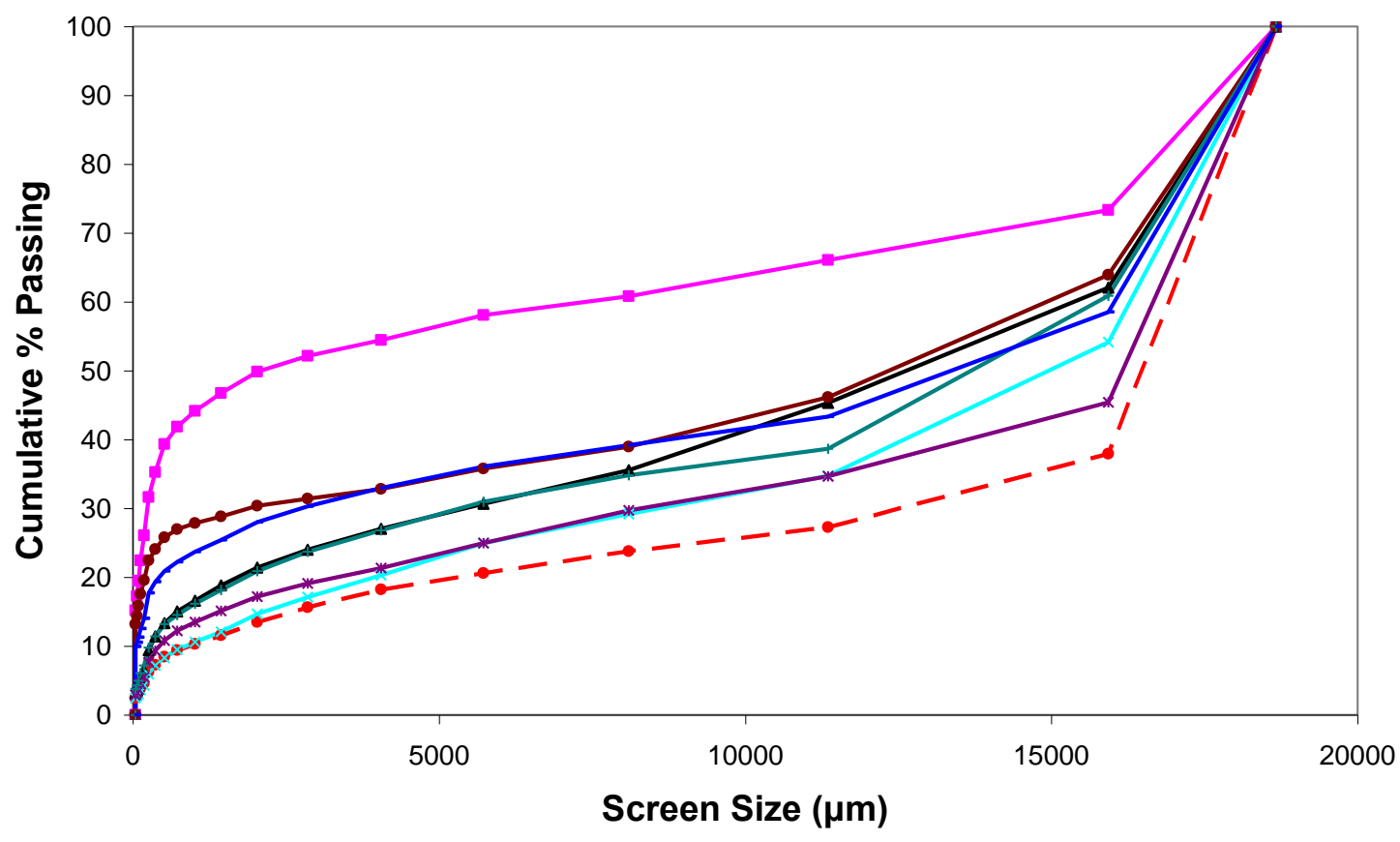

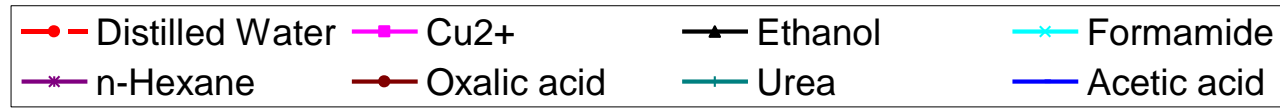

Figure 45: The particle size distribution for weathering of Finsch ore $(-16+13.2 \mathrm{~mm})$ for 6 days at room temperature with $0.5 \mathrm{M} \mathrm{Cu}^{2+}$ and $0.5 \mathrm{M}$ ethanol, formamide, $\mathrm{n}$-hexane, oxalic acid, urea and acetic acid.

The organic weathering results are shown in Figure 45 and indicate the largest particle sizes (least weathering) for water medium with $\sim 25 \%$ passing $12 \mathrm{~mm}$. All organic media increased the weathering, compared to water, in the following order: n-hexane ( 35\% passing $12 \mathrm{~mm}$ ), formamide ( 38\% passing $12 \mathrm{~mm}$ ), urea ( 42\% passing $12 \mathrm{~mm}$ ), acetic acid ( 45\% passing $12 \mathrm{~mm})$, ethanol ( 47 \% passing $12 \mathrm{~mm})$, oxalic acid $(\sim 4 \%$ passing $12 \mathrm{~mm}$ ) and $\mathrm{Cu}^{2+}$ at $\sim 67 \%$ passing $12 \mathrm{~mm}$. The cumulative $\%$ passing $12 \mathrm{~mm}$ for each of the reagents was plotted and the results are shown in Figure 46. For this test, the $\mathrm{Cu}^{2+}$ cation was the most effective accelerated weathering medium, with an increase of $19 \%$ percent points, compared to the best organic medium, oxalic acid, at $48 \%$ passing $12 \mathrm{~mm}$. Figure 45 shows that the extent of weathering caused by these solutions decreased in the order: $\mathrm{Cu}^{2+}>$ oxalic acid > ethanol > acetic acid > urea > formamide > n-hexane > distilled water. This series, however, did not correspond to the extent of organic adsorption reported as oxalic acid > urea > pentanoic acid > formamide $>$ ethanol $>$ n-hexane > acetic acid on Figure 26, except for oxalic acid which still came at the top of the list. 


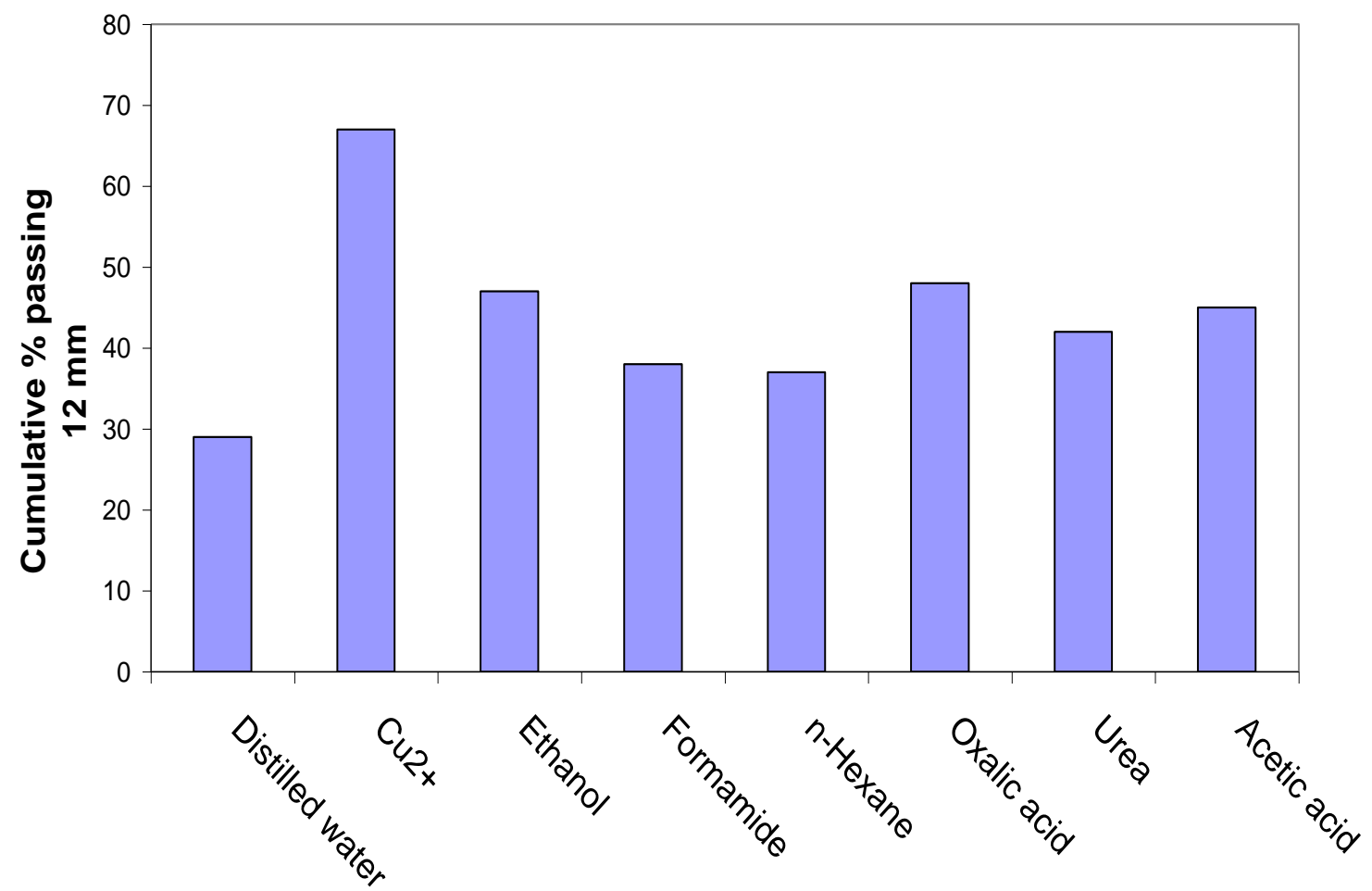

Figure 46: The $\%$ passing $12 \mathrm{~mm}$ for the Finsch sample $(-16+13.2 \mathrm{~mm})$ treated with distilled water, $\mathrm{Cu}^{2+}$, ethanol, formamide, $\mathrm{n}$-hexane, oxalic acid, urea and acetic acid all at $0.5 \mathrm{M}$ and at room temperature.

Figure 46 also indicates that about $67 \%$ of the material passed $12 \mathrm{~mm}$ after $\mathrm{Cu}^{2+}$ treatment. This was approximately $19 \%$ more than the oxalic acid results. Morkel (2006) highlighted that $\mathrm{Cu}^{2+}$ has the ability to adsorb not only at interlayers of the particle crystal structure, but also on other sites such as crystal edges. This process reduces the surface energy, which in turn reduces the energy required to produce fresh crack surfaces during weathering. According to Lerf (2004), organic reagents adsorb only into the interlayer space which causes an expansion and are held by coulombic as well as van der Waals forces. Organic reagents therefore only attach to the interlayer space, whereas inorganic reagents can also adsorb on other sites. The effectiveness of oxalic acid on mineral weathering has however been confirmed by Varadachari et al. (1994). It was mentioned that the combined action of $\mathrm{H}^{+}$attack as well as oxalate complex formation due to dissociation (Bigham et al., 2001; Barman et al., 1992; Chin \& Mills, 1991) is one of the reasons for the aggressive effects observed by oxalic acid. This could explain the improved weathering results for oxalic acid in comparison with the other organic solutions. 


\subsubsection{The effect of time on weathering}

The Finsch ore samples ( $300 \mathrm{~g}$ of $-16+13.2 \mathrm{~mm}$ ) were exposed to oxalic acid at $0.5 \mathrm{M}$ for 2, 6, 15, and 30 days (data is shown in Appendix B). Oxalic acid was chosen as the weathering medium, as it was shown to be the most efficient organic weathering medium from the previous analysis results that included results of TGA and FTIR analyses. Figure 47 displays the results obtained for the time dependence tests in comparison to the 6 day distilled water reference plot.

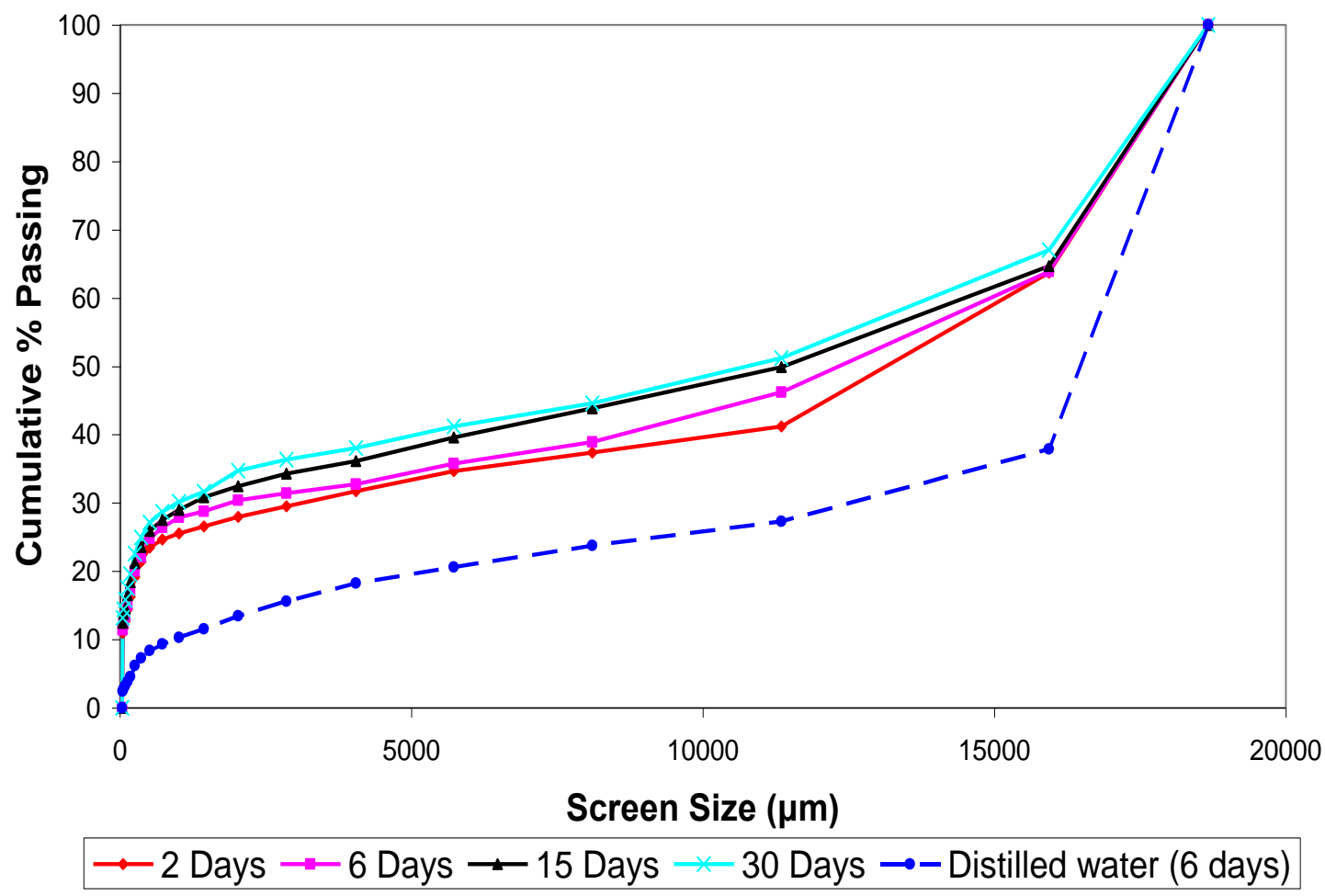

Figure 47: Results of the effect of exposure time on the weathering of Finsch samples $(-16+13.2 \mathrm{~mm})$ utilising $0.5 \mathrm{M}$ oxalic acid at room temperature.

Oxalic acid accelerated the weathering behaviour compared to distilled water, within

2 days of exposure. The results also indicate a general increase in weathering with exposure over time. However, the increase is not so remarkable; a maximum difference of $7 \%$ was observed between 2 days and 30 days of exposure. A small increase of $4 \%$ was observed between 2 and 6 days and an even smaller increase of $\sim 3 \%$ is observed up to 15 days. The $\%$ passing $12 \mathrm{~mm}$ was approximately $29 \%$ for distilled water, and $44 \%$, $48 \%, 52 \%$ and $53 \%$ for 2 days, 6 days, 15 days and 30 days, respectively in the oxalic 
acid medium. Because the original particles were between 16 and $13.2 \mathrm{~mm}$, the various exposure times did not significantly improve weathering.

\subsubsection{The effect of concentration on weathering}

Figure 48 shows results for Finsch samples $(300 \mathrm{~g}$ of $-16+13.2 \mathrm{~mm})$ that were weathered for 6 days in $0.025,0.1$ and $0.5 \mathrm{M}$ oxalic acid. There was no significant difference in the PSD observed for $0.025 \mathrm{M}$ and $0.1 \mathrm{M}$ concentration in comparison with the water line. The concentration of $0.5 \mathrm{M}$, however, yielded a finer weathered product and therefore improved the weathering. An increase of $~ 20$ percentage points (from $~ 30 \%$ to $~ 50 \%$ ) of the cumulative \% passing $12 \mathrm{~mm}$ was reported, with the increase in concentration from $0.025 \mathrm{M}$ to $0.5 \mathrm{M}$ of oxalic acid.

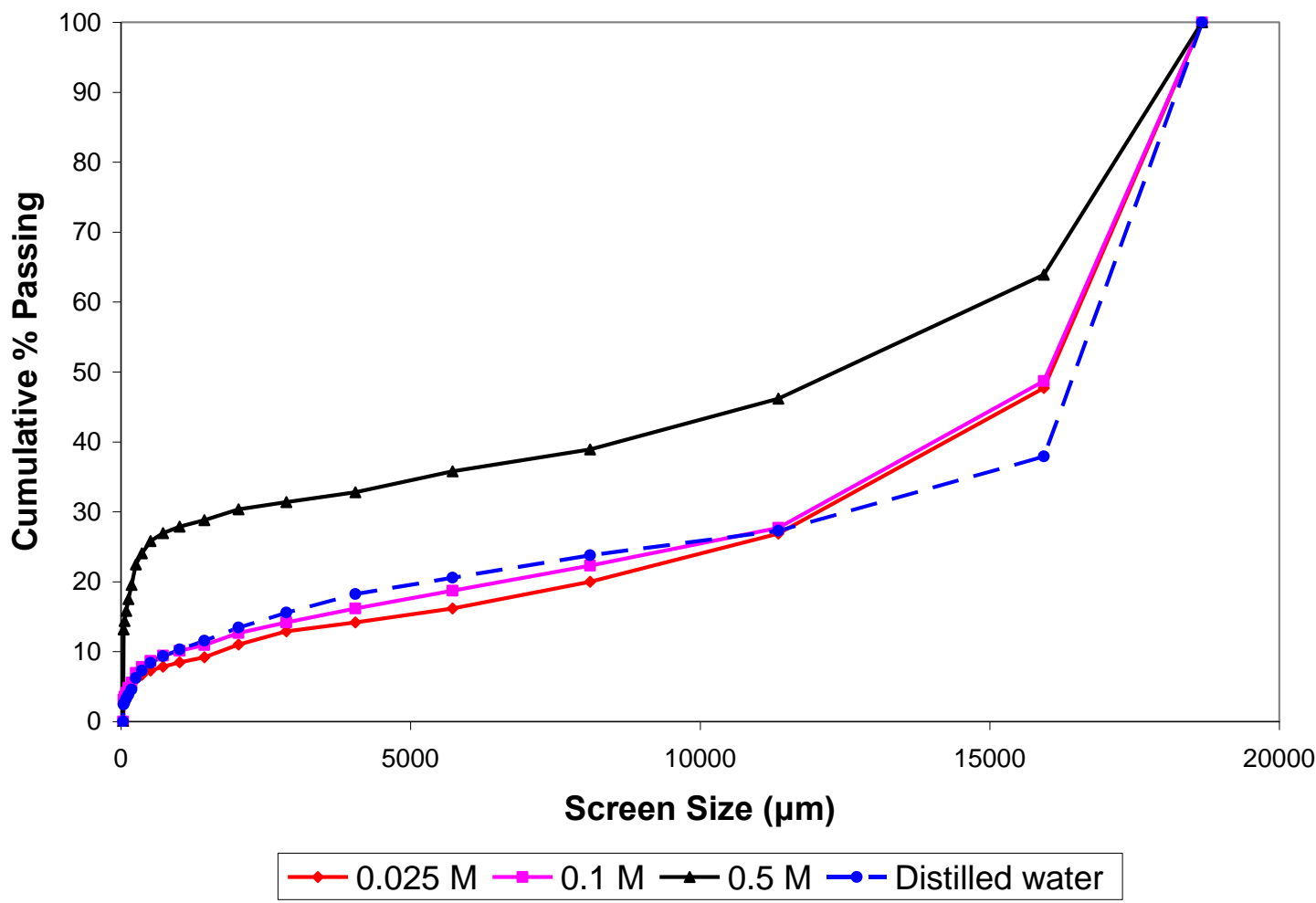

Figure 48: Results of the effect of oxalic acid concentration on Finsch samples $(-16+13.2 \mathrm{~mm})$ weathered for 6 days at room temperature. 


\subsubsection{The effect of temperature on weathering}

The effect of temperature on weathering was investigated by utilising $300 \mathrm{~g}$ Finsch ore, at $-16+13.2 \mathrm{~mm}$ particle size, weathered in $0.5 \mathrm{M}$ oxalic acid at 25 to $40{ }^{\circ} \mathrm{C}$. Figure 49 shows the standard water weathering test at $\sim 25 \%$ passing $12 \mathrm{~mm}$. The results for weathering in $0.5 \mathrm{M}$ oxalic acid at room temperature and at $40{ }^{\circ} \mathrm{C}$ are very similar and reported a value $\sim 45 \%$ passing $12 \mathrm{~mm}$. No marked improvement resulted when the temperature of the weathering solution was raised.

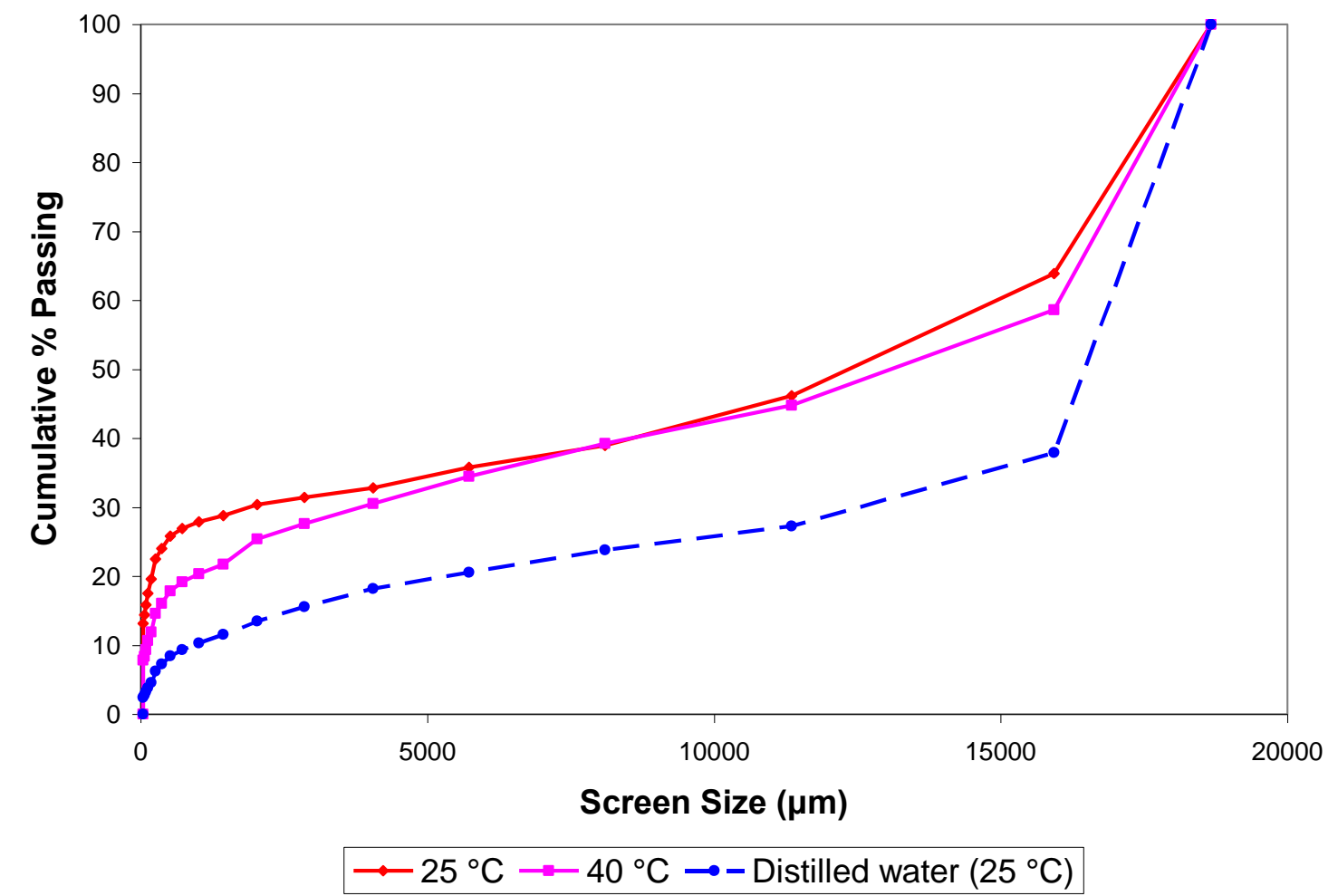

Figure 49: Results of the effect of temperature tested at 25 and $40{ }^{\circ} \mathrm{C}$ on Finsch samples $(-16+13.2 \mathrm{~mm})$ in $0.5 \mathrm{M}$ oxalic acid weathered for 6 days.

\subsection{Kinetic evaluation of weathering}

In the study of the kinetics of weathering, oxalic acid was selected (based upon the results that showed it to be an effective weathering agent), for comparison with the $\mathrm{Cu}^{2+}$ solution. The kinetics of weathering in oxalic acid and $\mathrm{Cu}^{2+}$ media were evaluated by utilising the Finsch ore sample. The $300 \mathrm{~g}$ of the $-16+13.2 \mathrm{~mm}$ particle size of the ore samples were immersed in $1 \mathrm{~L}$ of the weathering solutions, at $0.025,0.1,0.5 \mathrm{M}$, in flat bottomed plastic containers. Tests were conducted at room temperature $\left(\sim 25{ }^{\circ} \mathrm{C}\right)$. 
Approximately $50 \mathrm{ml}$ of the weathering solutions were extracted during the course of each of the three experiments at times 0 hours, 4 hours, 24 hours, 72 hours, 360 hours and 720 hours for ICP analysis. Cations that were monitored over time were $\mathrm{Mg}^{2+}, \mathrm{Ca}^{2+}, \mathrm{Na}^{+}$, $\mathrm{K}^{+}$and $\mathrm{Al}^{3+}$ and the results are shown in Table 17.

\subsection{1 $\mathrm{Cu}^{2+}$ Medium}

Graphical plots for the dissolution of cations in the $\mathrm{Cu}^{2+}$ medium at $0.025,0.1$ and $0.5 \mathrm{M}$ are illustrated in Figure 50. There was a high rate of cation dissolution in the first 24 hours of kimberlite contact with the medium. The release of elements generally increased with an increase in $\mathrm{Cu}^{2+}$ concentration. $\mathrm{Na}^{+}$was the main cation exchanged from the ore for all concentrations. This meant that $\mathrm{Na}^{+}$was easily replaced by $\mathrm{Cu}^{2+}$ compared with other cations. These results confirm the findings by Morkel (2006), in which $\mathrm{Na}^{+}$was also observed to be the dominant dissolved cation for all $\mathrm{Cu}^{2+}$ concentrations (the concentrations were the same as those tested in this current study) in the dissolution of Dutoitspan kimberlite.

The mechanism used by $\mathrm{Cu}^{2+}$ to weather kimberlite is suggested as interlayer cation exchange, which results in the reduction of the surface energy that encourages further crack propagation (Morkel, 2006). Moore and Reynolds (1989) stated that the relative ease with which one cation will replace or exchange another is not so predictable. In the current study, it was observed that the ease by which $\mathrm{Cu}^{2+}$ replaced the cations followed the general trend of $\mathrm{Na}^{+}>\mathrm{K}^{+}>\mathrm{Ca}^{2+}>\mathrm{Mg}^{2+}>\mathrm{Al}^{3+}$, with $\mathrm{Na}^{+}$easily replaced as indicated by the highest concentration in solution. $\mathrm{Ca}^{2+}$ and $\mathrm{K}^{+}$behaved similarly; their concentration was almost identical under various $\mathrm{Cu}^{2+}$ concentrations. 
Table 17: ICP analysis results of $\mathrm{Cu}^{2+}$ and oxalic acid weathering of Finsch $(-16+13.2 \mathrm{~mm})$.

\begin{tabular}{|c|c|c|c|c|c|}
\hline \multicolumn{6}{|c|}{$0.025 \mathrm{M} \mathrm{Cu}^{2+}$} \\
\hline Time & $\mathrm{Mg}$ & $\mathrm{Ca}$ & $\mathrm{Na}$ & K & Al \\
\hline (hours) & $\mathrm{mmol} / \mathrm{L}$ & $\mathrm{mmol} / \mathrm{L}$ & $\mathrm{mmol} / \mathrm{L}$ & $\mathrm{mmol} / \mathrm{L}$ & $\mathrm{mmol} / \mathrm{L}$ \\
\hline 0 & 0.00 & 0.02 & 0.01 & 0.00 & 0.00 \\
\hline 4 & 0.22 & 2.47 & 11.71 & 3.53 & 0.00 \\
\hline 24 & 0.56 & 5.16 & 19.14 & 5.48 & 0.00 \\
\hline 72 & 0.84 & 7.05 & 24.61 & 6.60 & 0.00 \\
\hline 360 & 0.83 & 5.94 & 27.47 & 6.83 & 0.00 \\
\hline 720 & 0.82 & 5.97 & 28.14 & 6.94 & 0.00 \\
\hline \multicolumn{6}{|c|}{$0.1 \mathrm{M} \mathrm{Cu}^{2+}$} \\
\hline Time & Mg & $\mathrm{Ca}$ & $\mathrm{Na}$ & $\mathbf{K}$ & $\mathbf{A l}$ \\
\hline (hours) & $\mathrm{mmol} / \mathrm{L}$ & $\mathrm{mmol} / \mathrm{L}$ & $\mathrm{mmol} / \mathrm{L}$ & $\mathrm{mmol} / \mathrm{L}$ & $\mathrm{mmol} / \mathrm{L}$ \\
\hline 0 & 0.04 & 0.06 & 0.08 & 0.01 & 0.00 \\
\hline 4 & 0.39 & 4.39 & 14.06 & 4.35 & 0.00 \\
\hline 24 & 1.18 & 9.84 & 25.55 & 9.30 & 0.00 \\
\hline 72 & 2.03 & 9.95 & 30.91 & 11.12 & 0.00 \\
\hline 360 & 2.89 & 11.11 & 41.13 & 11.29 & 0.00 \\
\hline 720 & 2.99 & 10.79 & 40.26 & 10.76 & 0.00 \\
\hline \multicolumn{6}{|c|}{$0.5 \mathrm{M} \mathrm{Cu}^{2+}$} \\
\hline Time & Mg & $\mathrm{Ca}$ & $\mathrm{Na}$ & $\mathbf{K}$ & Al \\
\hline (hours) & $\mathrm{mmol} / \mathrm{L}$ & $\mathrm{mmol} / \mathrm{L}$ & $\mathrm{mmol} / \mathrm{L}$ & $\mathrm{mmol} / \mathrm{L}$ & $\mathrm{mmol} / \mathrm{L}$ \\
\hline 0 & 0.01 & 0.04 & 0.08 & 0.00 & 0.00 \\
\hline 4 & 1.23 & 7.28 & 28.90 & 8.32 & 0.19 \\
\hline 24 & 3.44 & 10.48 & 89.88 & 14.98 & 0.61 \\
\hline 72 & 5.63 & 12.52 & 139.73 & 20.14 & 1.19 \\
\hline 360 & 9.50 & 20.99 & 202.87 & 32.72 & 2.78 \\
\hline 720 & 10.79 & 21.37 & 219.48 & 34.81 & 3.70 \\
\hline \multicolumn{6}{|c|}{ 0.025M Oxalic acid } \\
\hline Time & $\mathrm{Mg}$ & $\mathbf{C a}$ & $\mathrm{Na}$ & $\bar{K}$ & $\mathbf{A l}$ \\
\hline (hours) & $\mathrm{mmol} / \mathrm{L}$ & $\mathrm{mmol} / \mathrm{L}$ & $\mathrm{mmol} / \mathrm{L}$ & $\mathrm{mmol} / \mathrm{L}$ & $\mathrm{mmol} / \mathrm{L}$ \\
\hline 0 & 0.03 & 0.01 & 0.06 & 0.01 & 0.01 \\
\hline 4 & 0.66 & 0.50 & 3.57 & 0.89 & 0.42 \\
\hline 24 & 0.90 & 0.53 & 8.05 & 1.68 & 0.61 \\
\hline 72 & 0.80 & 0.17 & 10.35 & 1.81 & 0.49 \\
\hline 360 & 0.16 & 0.38 & 9.40 & 1.42 & 0.02 \\
\hline 720 & 0.80 & 0.52 & 10.31 & 1.82 & 0.61 \\
\hline \multicolumn{6}{|c|}{0.1 M Oxalic acid } \\
\hline Time & $\mathrm{Mg}$ & $\mathbf{C a}$ & $\mathrm{Na}$ & $\mathbf{K}$ & $\mathbf{A l}$ \\
\hline (hours) & $\mathrm{mmol} / \mathrm{L}$ & $\mathrm{mmol} / \mathrm{L}$ & $\mathrm{mmol} / \mathrm{L}$ & $\mathrm{mmol} / \mathrm{L}$ & $\mathrm{mmol} / \mathrm{L}$ \\
\hline 0 & 0.02 & 0.19 & 0.20 & 0.02 & 0.00 \\
\hline 4 & 5.73 & 0.30 & 11.15 & 2.76 & 2.17 \\
\hline 24 & 11.74 & 0.64 & 19.35 & 4.63 & 4.02 \\
\hline 72 & 5.46 & 0.13 & 24.13 & 5.09 & 5.19 \\
\hline 360 & 2.95 & 1.07 & 17.29 & 2.40 & 0.12 \\
\hline 720 & 2.17 & 0.63 & 17.97 & 2.37 & 0.18 \\
\hline \multicolumn{6}{|c|}{0.5 M Oxalic acid } \\
\hline Time & $\mathrm{Mg}$ & $\mathrm{Ca}$ & $\mathrm{Na}$ & $\mathbf{K}$ & $\mathbf{A l}$ \\
\hline (hours) & $\mathrm{mmol} / \mathrm{L}$ & $\mathrm{mmol} / \mathrm{L}$ & $\mathrm{mmol} / \mathrm{L}$ & $\mathrm{mmol} / \mathrm{L}$ & $\mathrm{mmol} / \mathrm{L}$ \\
\hline 0 & 0.04 & 0.09 & 0.22 & 0.02 & 0.00 \\
\hline 4 & 19.31 & 0.66 & 14.85 & 5.33 & 6.05 \\
\hline 24 & 30.72 & 0.32 & 23.53 & 10.52 & 17.35 \\
\hline 72 & 33.51 & 0.73 & 29.32 & 15.05 & 33.61 \\
\hline 360 & 40.60 & 0.63 & 28.88 & 12.41 & 40.10 \\
\hline 720 & 36.18 & 0.91 & 29.00 & 11.56 & 36.88 \\
\hline
\end{tabular}



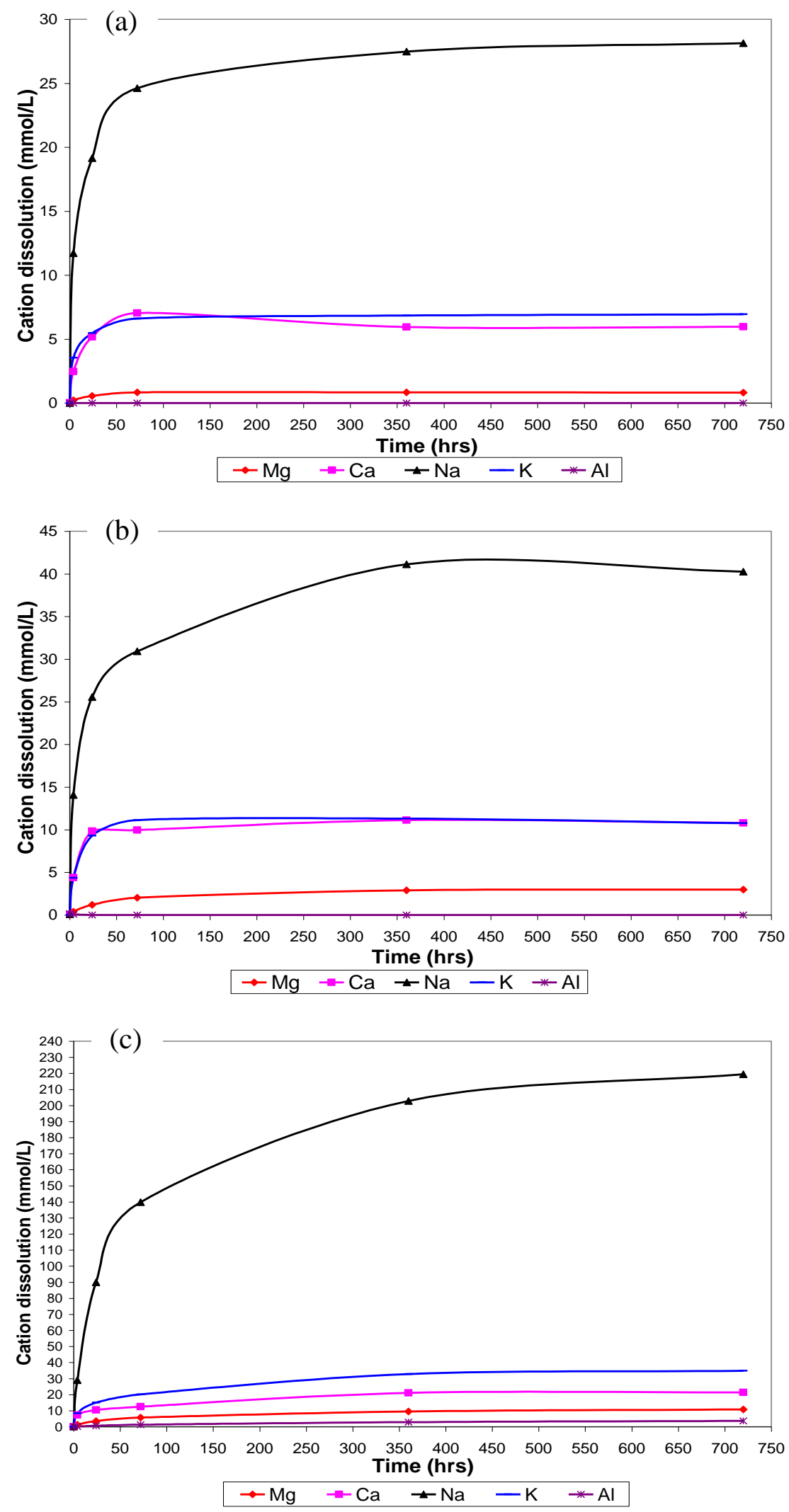

Figure 50: ICP results displaying the release of $\mathrm{Mg}^{2+}, \mathrm{Ca}^{2+}, \mathrm{Na}^{+}, \mathrm{K}^{+}$and $\mathrm{Al}^{3+}$ for (a) $0.025 \mathrm{M}$, (b) $0.1 \mathrm{M}$, (c) $0.5 \mathrm{M} \mathrm{Cu}^{2+}$ solution. 
The release of $\mathrm{Na}^{+}$from Finsch kimberlite was evaluated in various $\mathrm{Cu}^{2+}$ concentrations in a similar manner to the method utilised by Morkel (2006). The results are shown in Figure 51. The release of $\mathrm{Na}^{+}$increased with the increase in $\mathrm{Cu}^{2+}$ concentration, which was a similar observation to that of Morkel (2006) on Dutoitspan kimberlite. The $\mathrm{n}^{\text {th }}$-order kinetic equation (3) was utilised to fit the data of the change in $\mathrm{Na}^{+}$ concentration. The graphical method (Figure 52) of plotting $\log (\mathrm{dC} / \mathrm{dt}$ ) against $\log \left(\mathrm{C}-\mathrm{C}_{\infty}\right)$ was utilised to determine the reaction constants $\mathrm{n}$ and $\mathrm{k}$ for the initial dissolution rate in the first 72 hours.

$$
\frac{d C}{d t}=-k\left(C-C_{\infty}\right)^{n}
$$

where $\mathrm{C}$ is the concentration in solution at time $\mathrm{t}, \mathrm{k}$ the rate constant, $\mathrm{C}_{\infty}$ the equilibrium concentration (assumed in this study as the concentration after 720 hours), and $\mathrm{n}$ is the apparent reaction order. Regression results for graphically fitting the data are shown in Table 18.

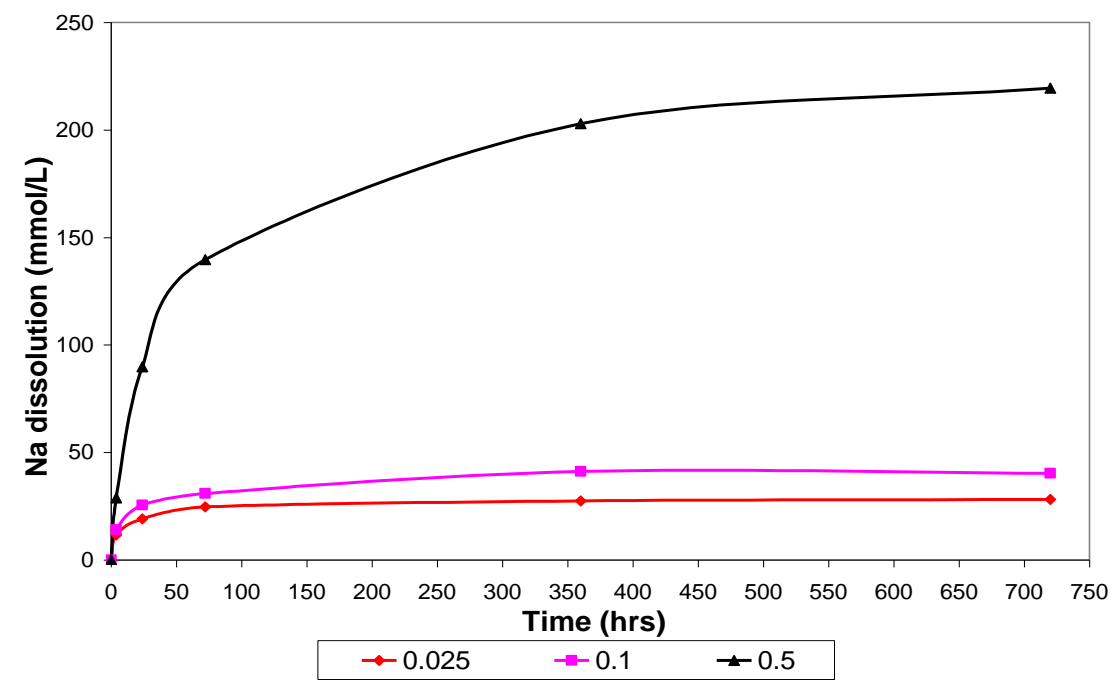

Figure 51: ICP results displaying the release of $\mathrm{Na}^{+}$from Finsch ore into solution at $0.025 \mathrm{M}, 0.1 \mathrm{M}$, and $0.5 \mathrm{M} \mathrm{Cu}^{2+}$ concentrations. 

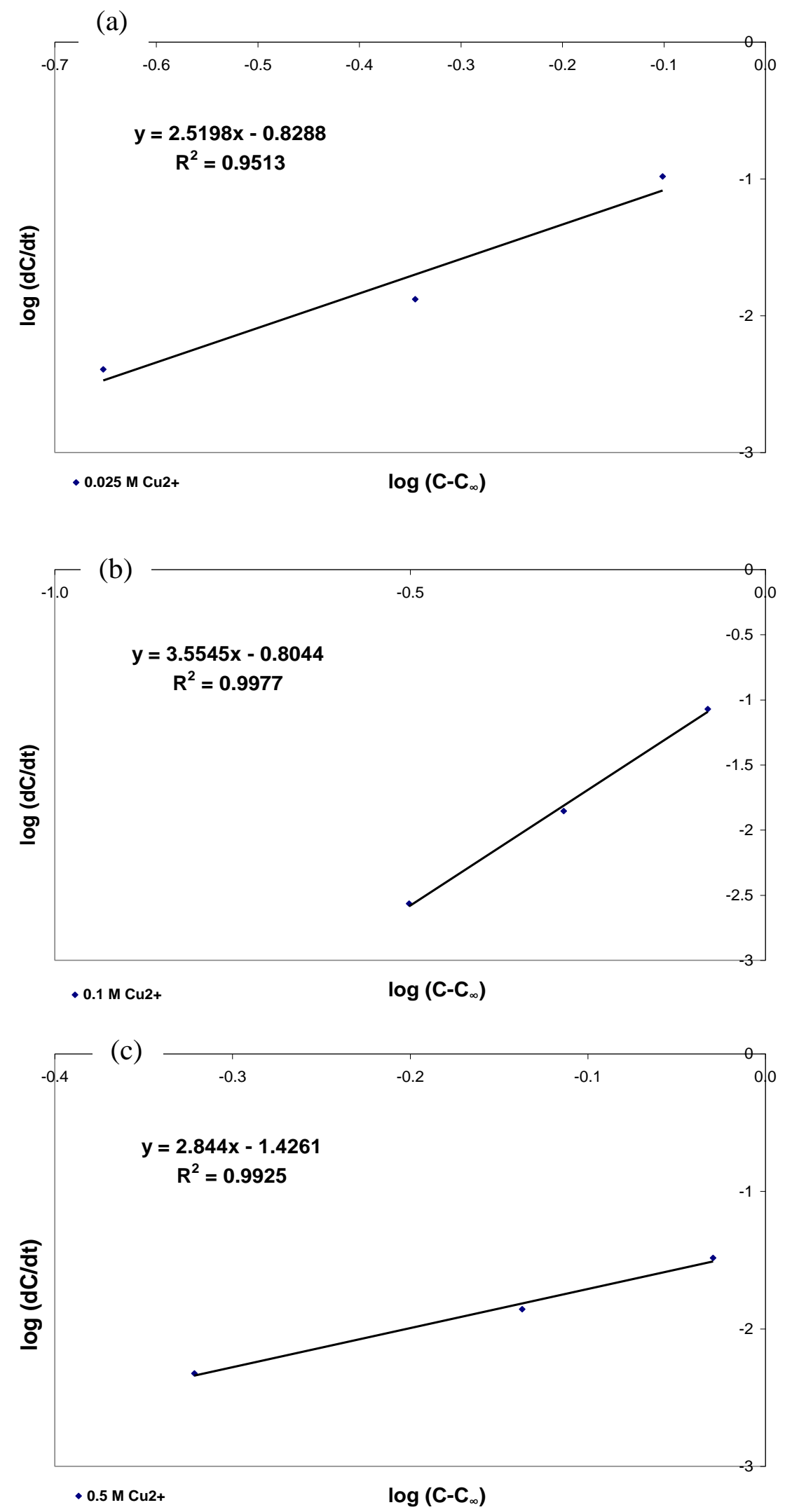

Figure 52: Plots of $\log (\mathrm{dC} / \mathrm{dt})$ against $\log \left(\mathrm{C}-\mathrm{C}_{\infty}\right)$ for (a) 0.025 , (b) 0.1 and (c) $0.5 \mathrm{M} \mathrm{Cu}^{2+}$ solution. 
Table 18: Results of fitting kinetic equation (3) on a straight line for $\mathrm{Cu}^{2+}$ tests.

\begin{tabular}{|c|c|c|c|c|c|}
\hline Medium & Concentration & Equation & $\mathbf{R}^{2}$ & $\mathbf{n}$ & $\mathbf{k}$ \\
\hline \multirow{3}{*}{$\mathrm{Cu}^{2+}$} & 0.025 & $\mathrm{y}=2.520 \mathrm{x}-0.829$ & 0.951 & 2.52 & 6.745 \\
\cline { 2 - 6 } & 0.1 & $\mathrm{y}=3.555 \mathrm{x}-0.804$ & 0.998 & 3.56 & 6.368 \\
\cline { 2 - 6 } & 0.5 & $\mathrm{y}=2.844 \mathrm{x}-1.426$ & 0.993 & 2.84 & 26.668 \\
\hline
\end{tabular}

The $\mathrm{R}^{2}$ for all $\mathrm{Cu}^{2+}$ concentrations were at least 0.9 , indicating a good fit for the equations. The order of reaction for $0.025 \mathrm{M}$ concentration was closer to 2 indicating the possibility of a second order reaction type, although it was higher for $0.1 \mathrm{M}$ and $0.5 \mathrm{M}$, indicating a different mechanism. In the study by Morkel (2006), mass transfer controlled reaction was suggested on $0.025 \mathrm{M} \mathrm{Cu}^{2+}$ medium, and a different rate controlling step for the higher $\mathrm{Cu}^{2+}$ concentrations.

\subsubsection{Oxalic acid medium}

Figure 53 presents results obtained in the dissolution of the cations $\mathrm{Mg}^{2+}, \mathrm{Ca}^{2+}, \mathrm{Na}^{+}, \mathrm{K}^{+}$ and $\mathrm{Al}^{3+}$ in oxalic acid medium. Fiantis et al. (2010) obtained similar curves for studies on a volcanic deposit, and it was shown that these graphs generally indicate the trend of silicate dissolution in oxalic acid solutions. In the current study, there was a general increase in dissolution of cations with an increase in oxalic acid concentration. The rate of dissolution was high in the first 24 hours of contact in all oxalic acid conditions. The peaks that occurred, usually at the 24 hour mark, were of much interest. These occurred for all cations at $0.5 \mathrm{M}$ oxalic acid, with an exception of $\mathrm{Mg}^{2+}$ and $\mathrm{Al}^{3+}$, and were followed by a gradual decrease, which was evident at the $72^{\text {nd }}$ hour onwards. The reason for this profile was the dissolution of cations, and a subsequent formation of oxalate salts, which formed a passive layer and slowed down further dissolution. There was no stirring involved in conducting the test and so the passive layer was not essentially removed. Oxalic acid is known to dissolve minerals by proton attack. This attack causes a release of cations from the ore's crystal structure, which then forms a cation-organic complex with the oxalic anion known as oxalates (Chen et al., 2000). All cations, except $\mathrm{Si}^{4+}$, are said to form oxalate salts at any given $\mathrm{pH}$ (Gylienè et al., 1997). Mono- and trivalent cations form soluble salts, while divalent cations form insoluble salts (Chen et al., 2000). These facts explained the observed increase in the amounts of $\mathrm{Al}^{3+}, \mathrm{K}^{+}$and $\mathrm{Na}^{+}$in solution, as their oxalate salts are soluble, while $\mathrm{Ca}^{2+}$ content was low in solution due to 
the insoluble nature of the salt formed. However, $\mathrm{Mg}^{2+}$ did not seem to be bound to the oxalic acid anion, despite the fact that it is a bivalent cation. Oxalic acid forms an insoluble Ca-oxalate with a $\mathrm{K}_{\mathrm{sp}}$ of $2.34 \times 10^{-9}$ (value obtained from Lide, 2005) and this explains the sudden drop in $\mathrm{Ca}^{2+}$ concentration in the first 24 hours. The $\mathrm{Mg}^{2+}$ ion quantity in solution peaked at 24 hours (about $1.3 \mathrm{mmol} / \mathrm{L}$ and $12 \mathrm{mmol} / \mathrm{L}$, for 0.025 and $0.1 \mathrm{M}$ oxalic acid concentration respectively), and thereafter it dropped due to the precipitation of an insoluble oxalate that slowed down further dissolution. However, at higher oxalic concentration, the amount of dissolved $\mathrm{Mg}^{2+}$ is observed to be even higher, reaching values of about $40 \mathrm{mmol} / \mathrm{L}$. Gadd (1999) mentioned that Mg-oxalate is the most soluble amongst the insoluble divalent metal oxalates and this may be the reason why $\mathrm{Mg}^{2+}$ precipitates appeared more soluble at high oxalic acid concentrations. The results seem to indicate that $\mathrm{Mg}^{2+}$ forms an oxalate precipitate at low oxalate concentration, but seem to redissolve to form oxalate complex ion at higher concentrations. This is also evidenced by comparing $\mathrm{Ca}^{2+}$ - and $\mathrm{Mg}^{2+}$-oxalate salts' $\mathrm{Ksp}$ values, which are $2.34 \times 10^{-9}$ and $8.5 \times 10^{-5}$ respectively (Lide, 2005), showing that $\mathrm{Mg}^{2+}$ - oxalate is more soluble given the relatively higher $\mathrm{K}_{\mathrm{sp}}$ value.

In general, the eventual release of cations in oxalic acid at $0.5 \mathrm{M}$ oxalic acid concentration was of the following order: $\mathrm{Ca}^{2+}<\mathrm{K}^{+}<\mathrm{Na}^{+}<\mathrm{Mg}^{2+}, \mathrm{Al}^{3+}$. This was the opposite of the results produced by $\mathrm{Cu}^{2+}$ medium which was of the order; $\mathrm{Al}^{3+}<\mathrm{Mg}^{2+}<$ $\mathrm{K}^{+}<\mathrm{Na}^{+}<\mathrm{Ca}^{2+}$. This indicates a different weathering mechanism for the two media types, and will be discussed further. 

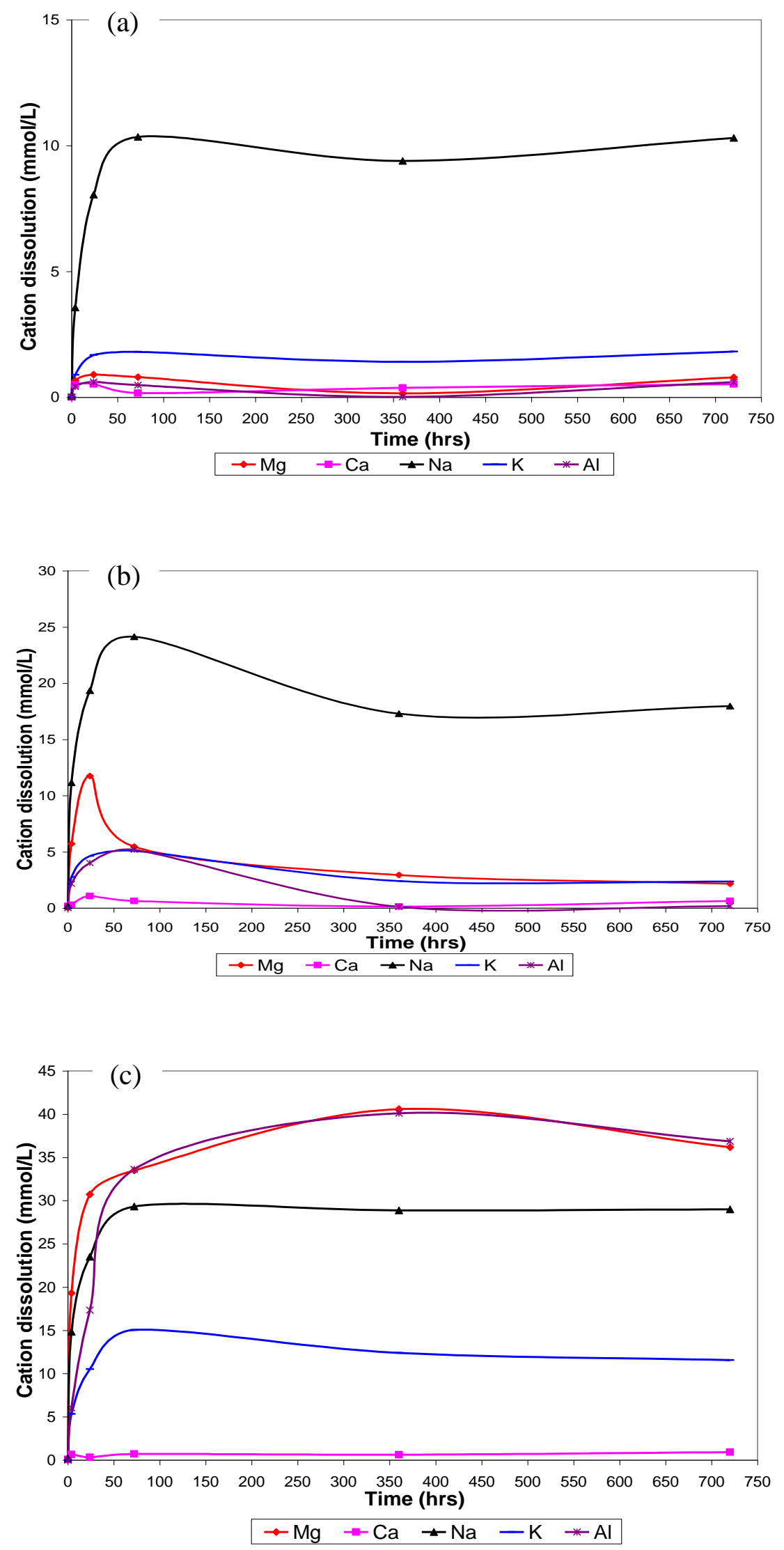

Figure 53: ICP results displaying the release of $\mathrm{Mg}^{2+}, \mathrm{Ca}^{2+}, \mathrm{Na}^{+}, \mathrm{K}^{+}$and $\mathrm{Al}^{3+}$ for (a) $0.025 \mathrm{M}$, (b) $0.1 \mathrm{M}$, (c) $0.5 \mathrm{M}$ oxalic acid. 
The release of $\mathrm{Na}^{+}$was again compared for various oxalic acid concentrations (Figure 54). Note that the maximum release of $\mathrm{Na}^{+}$in oxalic acid was $\sim 30 \mathrm{mmol} / \mathrm{L}$ and this was $\sim 100 \mathrm{mmol} / \mathrm{L}$ less than the release in the $\mathrm{Cu}^{2+}$ medium. This also showed improved dissolution by $\mathrm{Cu}^{2+}$.

There was a general increase in $\mathrm{Na}^{+}$dissolution with an increase in oxalic concentration. The $\mathrm{n}^{\text {th }}$-order kinetic equation (3) was again utilised to fit the data for the change in $\mathrm{Na}^{+}$ concentration for the initial dissolution rate in the first 72 hours. Figure 55 shows the results.

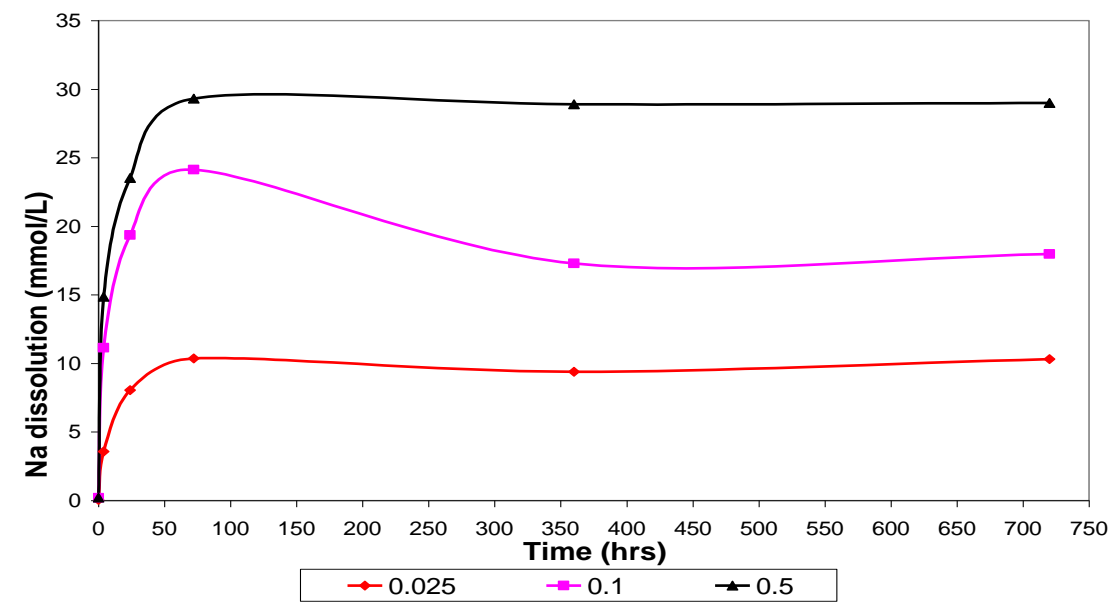

Figure 54: ICP results displaying the release of $\mathrm{Na}^{+}$from Finsch ore into solution at $0.025 \mathrm{M}, 0.1 \mathrm{M}$, and $0.5 \mathrm{M}$ oxalic acid concentrations. 

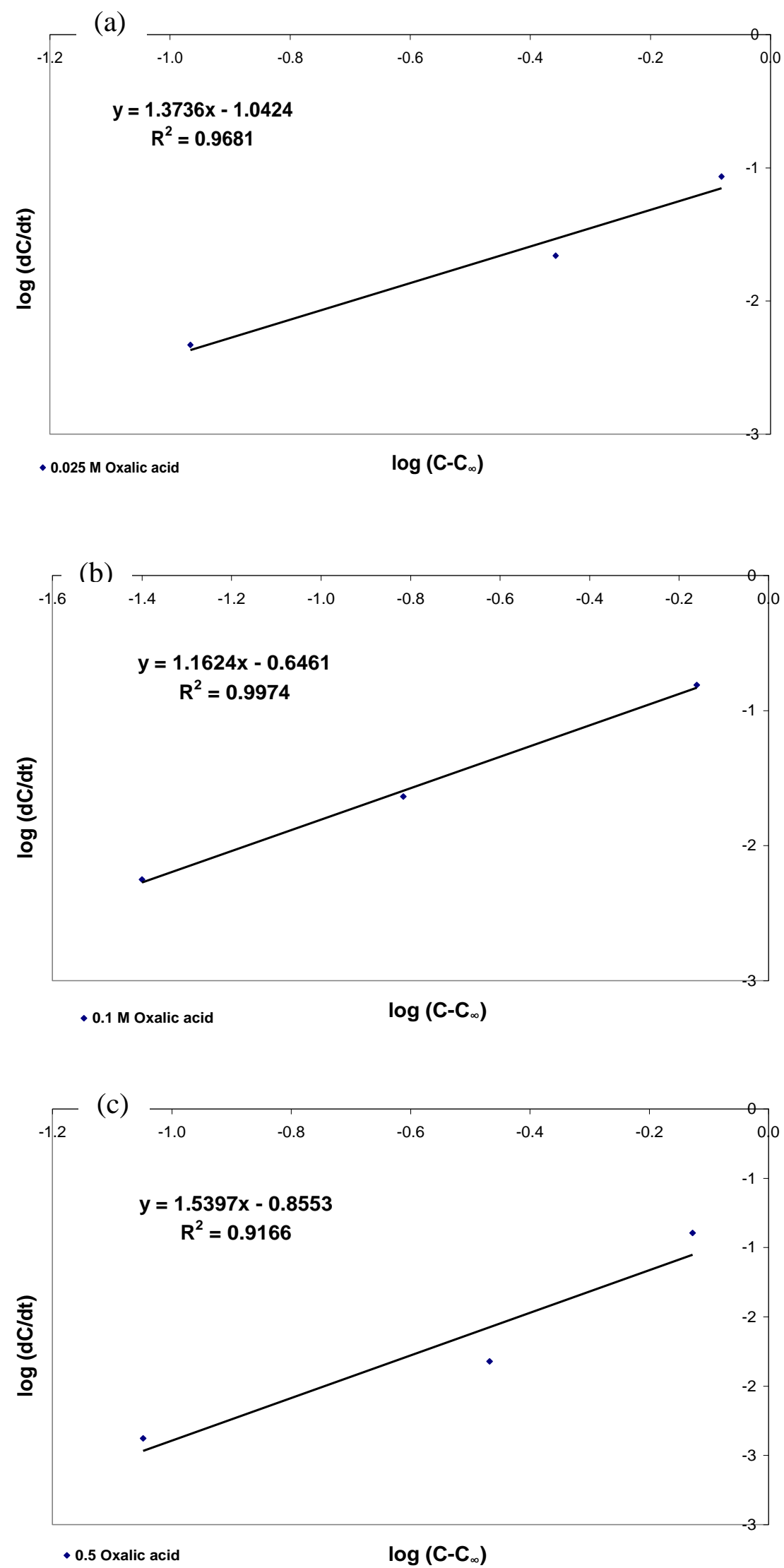

Figure 55: Plots of $\log (\mathrm{dC} / \mathrm{dt})$ against $\log \left(\mathrm{C}-\mathrm{C}_{\infty}\right)$ for (a) 0.025 , (b) 0.1 and (c) $0.5 \mathrm{M}$ oxalic acid solution. 
Table 19: Results of fitting kinetic equation (3) on a straight line for oxalic acid tests.

\begin{tabular}{|c|c|c|c|c|c|}
\hline Medium & Concentration & Equation & $\mathbf{R}^{2}$ & $\mathbf{n}$ & $\mathbf{k}$ \\
\hline \multirow{3}{*}{$\begin{array}{c}\text { Oxalic } \\
\text { acid }\end{array}$} & 0.025 & $\mathrm{y}=1.374 \mathrm{x}-1.042$ & 0.968 & 1.37 & 11.015 \\
\cline { 2 - 6 } & 0.1 & $\mathrm{y}=1.162 \mathrm{x}-0.646$ & 0.997 & 1.16 & 4.425 \\
\cline { 2 - 6 } & 0.5 & $\mathrm{y}=1.540 \mathrm{x}-0.855$ & 0.917 & 1.54 & 7.161 \\
\hline
\end{tabular}

Shown in Table 19 are results after fitting the data to a linear equation. The $\mathrm{R}^{2}$ for all oxalic acid concentrations showed a good fit. The reaction order at lower oxalic concentrations, 0.025 and $0.1 \mathrm{M}$, was closer to 1 . This indicated the possibility of a first order mechanism. At a higher oxalic concentration, the order of reaction was closer to 2 , and this indicates a different reaction mechanism. Drever and Stillings (1997) raised the issue that many authors do not agree on the mechanism of organic acid mineral weathering due to varying results, even if tests occur under similar conditions. The general consensus, though, is that the rate of organic dissolution is controlled by surface reactions that involve dissolution of cations, accompanied by the precipitation of secondary minerals (Fiantis et al., 2010, Drever \& Stillings, 1997, Barman et al., 1992). Thus, the same was concluded to have taken place for kimberlite weathering in oxalic acid, which resulted in the formation of a passive precipitated layer that slowed down further dissolution.

The fact that there is an increase in the amount of $\mathrm{Mg}^{2+}$ as well as $\mathrm{Al}^{3+}$ dissolution for $0.5 \mathrm{M}$ oxalic acid may well be the reason why oxalic acid has improved results compared to those of the other organic reagents tested. The Finsch samples had approximately $35 \%$ smectite (Table 9). Assuming that the dissolution of smectite was dominant amongst other phases present, its geochemistry may be considered in the analysis of the dissolution mechanism. Smectites are 2:1 clays with $\mathrm{Al}^{3+}$ and $\mathrm{Mg}^{2+}$ generally occupying the octahedral sites. Both cations became apparent at higher oxalic acid concentration (Figure 53). Barman et al. (1992) mentioned that the overall relative cation dissolution from minerals depends upon the positions they occupy within crystal structures. $\mathrm{Mg}^{2+}$ and $\mathrm{Al}^{3+}$ are present in the less accessible octahedral layer. This allows the $\mathrm{Ca}^{2+}$ to be taken by most of the oxalic acid to form an insoluble salt, allowing more of the $\mathrm{Mg}^{2+}, \mathrm{a}$ complexing cation competitor, to remain in solution. The release of $\mathrm{Mg}^{2+}$ and $\mathrm{Al}^{3+}$ from octahedral sites may well be the limiting factor in Finsch oxalic acid weathering. This can also be confirmed by Figure 48 in section 7.3.2, where significant weathering occurred at $0.5 \mathrm{M}$ oxalic concentration. This corresponded to the concentration at which most $\mathrm{Mg}^{2+}$ 
and $\mathrm{Al}^{3+}$ was dissolved, as well as results shown for TGA and FTIR analysis in section 7.2 .

\subsubsection{Repeatability tests}

The repeatability of results was established by performing a triplicate kinetic evaluation test for $0.025 \mathrm{M}$ oxalic acid and then sending samples for ICP analysis to two different laboratories. The first two were submitted to Set Point Laboratories in Johannesburg, South Africa, and the third one to UIS Analytical Services in Centurion, South Africa. The test was done on a $300 \mathrm{~g}$ Finsch ore sample of $-16+13.2 \mathrm{~mm}$ size range that was immersed in $1 \mathrm{~L}$ oxalic acid solution at $0.025 \mathrm{M}$, at room temperature $\left(\sim 25^{\circ} \mathrm{C}\right)$, in a flat bottomed plastic container. Approximately $50 \mathrm{ml}$ of the weathering solution was extracted at time intervals 0 hours, 4 hours, 24 hours and 360 hours for ICP analysis. The ICP analysis measured the amounts of $\mathrm{Mg}^{2+}, \mathrm{K}^{+}$and $\mathrm{Al}^{3+}$ released into the weathering solution over time. A comparison of the three tests was made, for a similar time interval and similar cations, between results obtained from Set Point Laboratories and those from UIS Analytical Services. This is shown in Figure 56. Results indicate a similar trend for each of the cations analysed, with values almost coinciding in the lower and higher time intervals and a $0.5 \mathrm{mmol} / \mathrm{L}$ difference at the 24 hour mark.

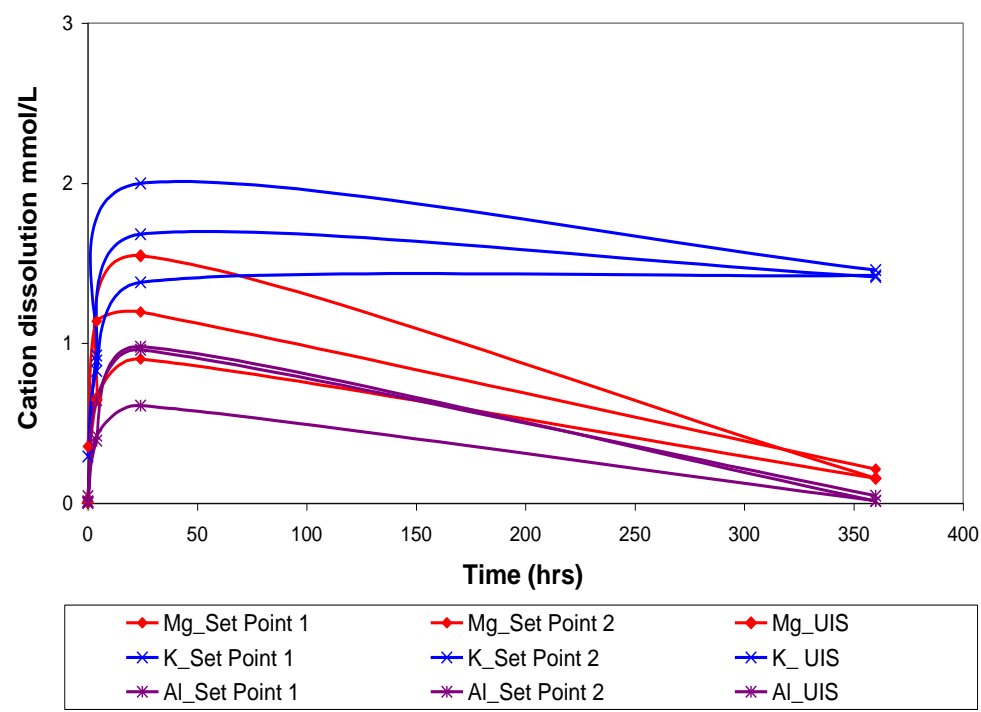

Figure 56: $\mathrm{ICP}$ results showing the release of $\mathrm{Mg}^{2+}, \mathrm{K}^{+}$and $\mathrm{Al}^{3+}$ with time from Set Point Laboratories and from UIS Analytical Service. 
Statistical analysis of the repeats is shown in Table 20, with a $95 \%$ confidence limits established. There were small deviations at the lower and higher time interval. The larger standard deviation values occurred at the 24 hour mark for all cations, with $0.32 \mathrm{mmol} / \mathrm{L}$ being the largest for $\mathrm{Mg}^{2+}$. The same time interval also resulted in the relatively larger differences between the $95 \%$ confidence limits, with $0.73 \mathrm{mmol} / \mathrm{L}$ once again the largest for $\mathrm{Mg}^{2+}$. The large differences could have been reduced by performing several tests, but in general the tests had a high degree of repeatability.

Table 20: Statistical analysis of repeatability tests.

\begin{tabular}{|c|c|c|c|c|c|c|c|c|}
\hline & \multirow[t]{2}{*}{ Time (hrs) } & \multicolumn{3}{|c|}{$\mathrm{mmol} / \mathrm{L}$} & \multirow[t]{2}{*}{ Mean } & \multirow{2}{*}{$\begin{array}{l}\text { Standard } \\
\text { Deviation }\end{array}$} & \multirow{2}{*}{$\begin{array}{c}95 \% \text { Confidence } \\
\text { Lower Limit }\end{array}$} & \multirow{2}{*}{$\begin{array}{c}95 \% \text { Confidence } \\
\text { Upper Limit }\end{array}$} \\
\hline & & $\begin{array}{c}\text { Set Point } 1 \\
\text { Lab }\end{array}$ & $\begin{array}{c}\text { Set Point } 2 \\
\text { Lab }\end{array}$ & $\begin{array}{l}\text { UIS } \\
\text { Lab }\end{array}$ & & & & \\
\hline \multirow{4}{*}{$\mathrm{Mg}^{2+}$} & 0 & 0.36 & 0.03 & 0.01 & 0.13 & 0.20 & 0.00 & 0.35 \\
\hline & 4 & 1.14 & 0.66 & 0.65 & 0.82 & 0.28 & 0.50 & 1.13 \\
\hline & 24 & 1.20 & 0.90 & 1.55 & 1.21 & 0.32 & 0.85 & 1.58 \\
\hline & 360 & 0.21 & 0.16 & 0.16 & 0.18 & 0.03 & 0.14 & 0.21 \\
\hline \multirow{4}{*}{$\mathrm{K}^{+}$} & 0 & 0.29 & 0.01 & 0.00 & 0.10 & 0.16 & 0.00 & 0.29 \\
\hline & 4 & 0.83 & 0.89 & 0.92 & 0.88 & 0.05 & 0.83 & 0.94 \\
\hline & 24 & 1.38 & 1.68 & 2.00 & 1.69 & 0.31 & 1.34 & 2.04 \\
\hline & 360 & 1.42 & 1.42 & 1.46 & 1.43 & 0.02 & 1.41 & 1.46 \\
\hline \multirow{4}{*}{$\mathrm{Al}^{3+}$} & 0 & 0.04 & 0.01 & 0.00 & 0.02 & 0.02 & 0.00 & 0.04 \\
\hline & 4 & 0.65 & 0.42 & 0.39 & 0.49 & 0.14 & 0.33 & 0.64 \\
\hline & 24 & 0.96 & 0.61 & 0.98 & 0.85 & 0.21 & 0.62 & 1.08 \\
\hline & 360 & 0.05 & 0.02 & 0.02 & 0.03 & 0.02 & 0.01 & 0.05 \\
\hline
\end{tabular}

\subsection{Mineral alteration tests}

A study into possible kimberlite mineral alterations was investigated by 1) agitation and, 2) immersion tests as discussed in the following sections.

\subsubsection{Agitation tests}

The Venetia K1 was utilised to test for accelerated weathering through mineral alteration. Table 9 shows that the Venetia K1 ore did not contain smectite with a corresponding CEC value of $16.61 \mathrm{cmol} / \mathrm{kg}$ reported in Table 11 . The possibility of weathering by mineral alteration on this sample was investigated, as it was expected that it would show resistance to weathering. 
Agitation tests were performed on $50 \mathrm{~g}$ Venetia $\mathrm{K} 1$ ore samples milled to $80 \%$ passing $100 \mu \mathrm{m}$. The samples were saturated in $800 \mathrm{ml}$ of $0.1 \mathrm{M}$ organic solutions, at room temperature $\left(\sim 25^{\circ} \mathrm{C}\right)$, for 24 hours while stirring at $600 \mathrm{rpm}$. The organic solutions tested were dimethyldioctadecylammonium chloride (dimethyl), ethanol, formamide, n-hexane, oxalic acid, pyridine and urea. After the test, samples were air dried and then submitted for XRD analysis to evaluate any mineralogical changes.

Figure 57 shows the XRD scans for the organic treated samples. The results show no change in the peak positions when scans of the original sample were compared with the other treatments. Therefore it is assumed that no mineralogical changes took place during the 24 hour test period with these organic species. A longer period of exposure of more than 24 hours and an increased solution concentration at a higher value than $0.1 \mathrm{M}$ might have shown mineral changes. However, upon ethylene glycol (EG) treatment (utilized during XRD analysis to test the presence of swelling clays) of the same samples, a shift in

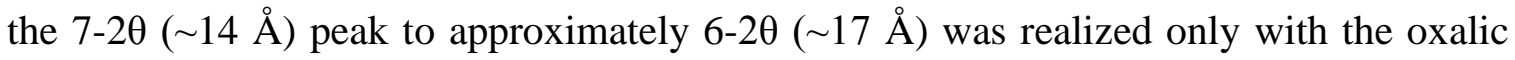
acid treated sample (Figure 58). The shift was postulated to be two fold, due either to the effectiveness of oxalic acid in the enhancement of the presence of a swelling phase, or to the formation of oxalate salts. The former assumption can be supported through information found in Bühmann (1998). According to the mineralogy presented in Table 9, Venetia K1 contains a small amount of swelling clay, provided by vermiculite $(\sim 6 \%)$. This means that oxalic acid interacted with vermiculite and therefore the change in the peak position upon EG treatment. This was also observed in the next section, on samples that received pre-cationic treatment prior to oxalic acid saturation. 


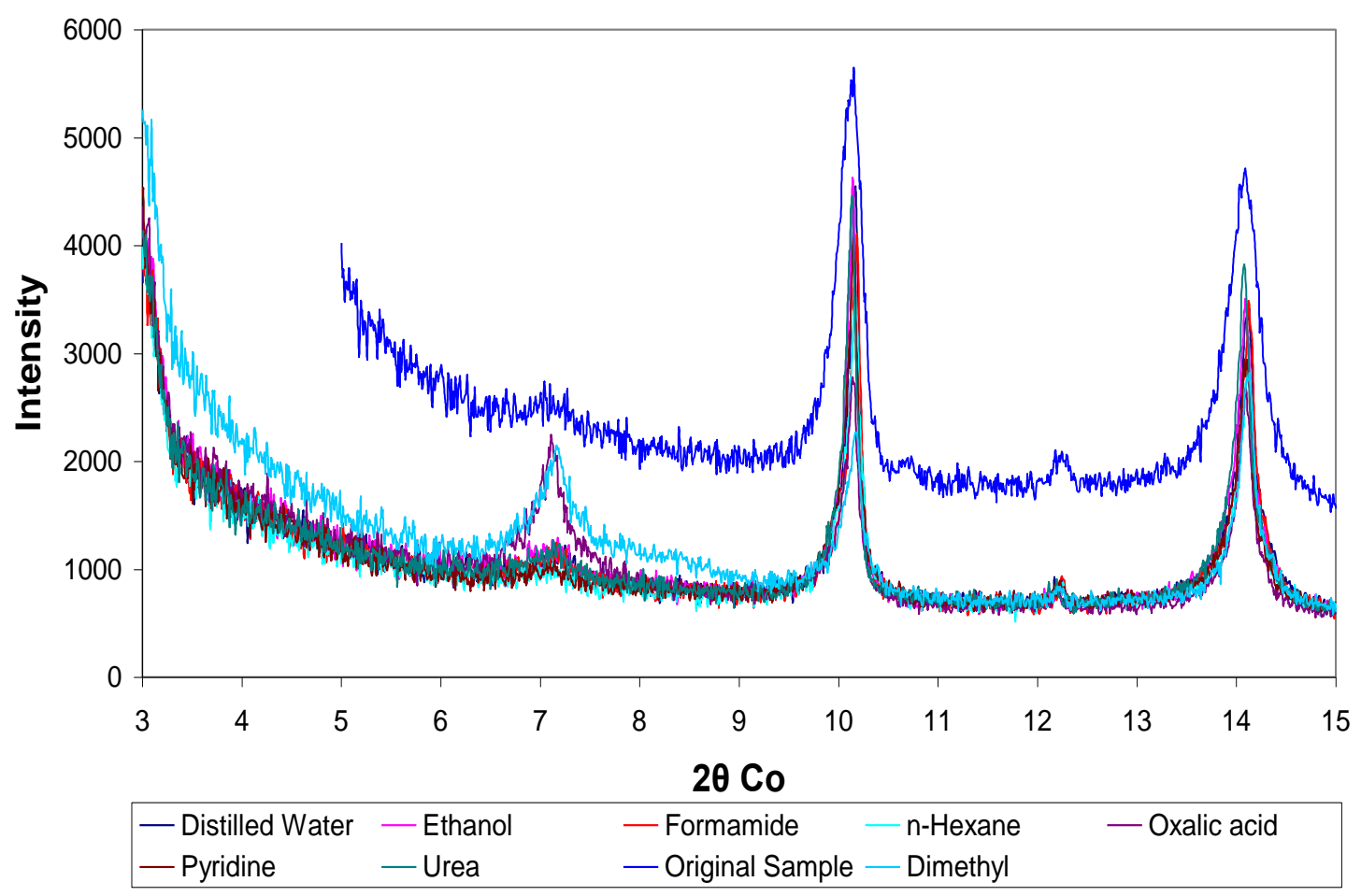

Figure 57: XRD scans for Venetia K1 sample treated with organic reagents.

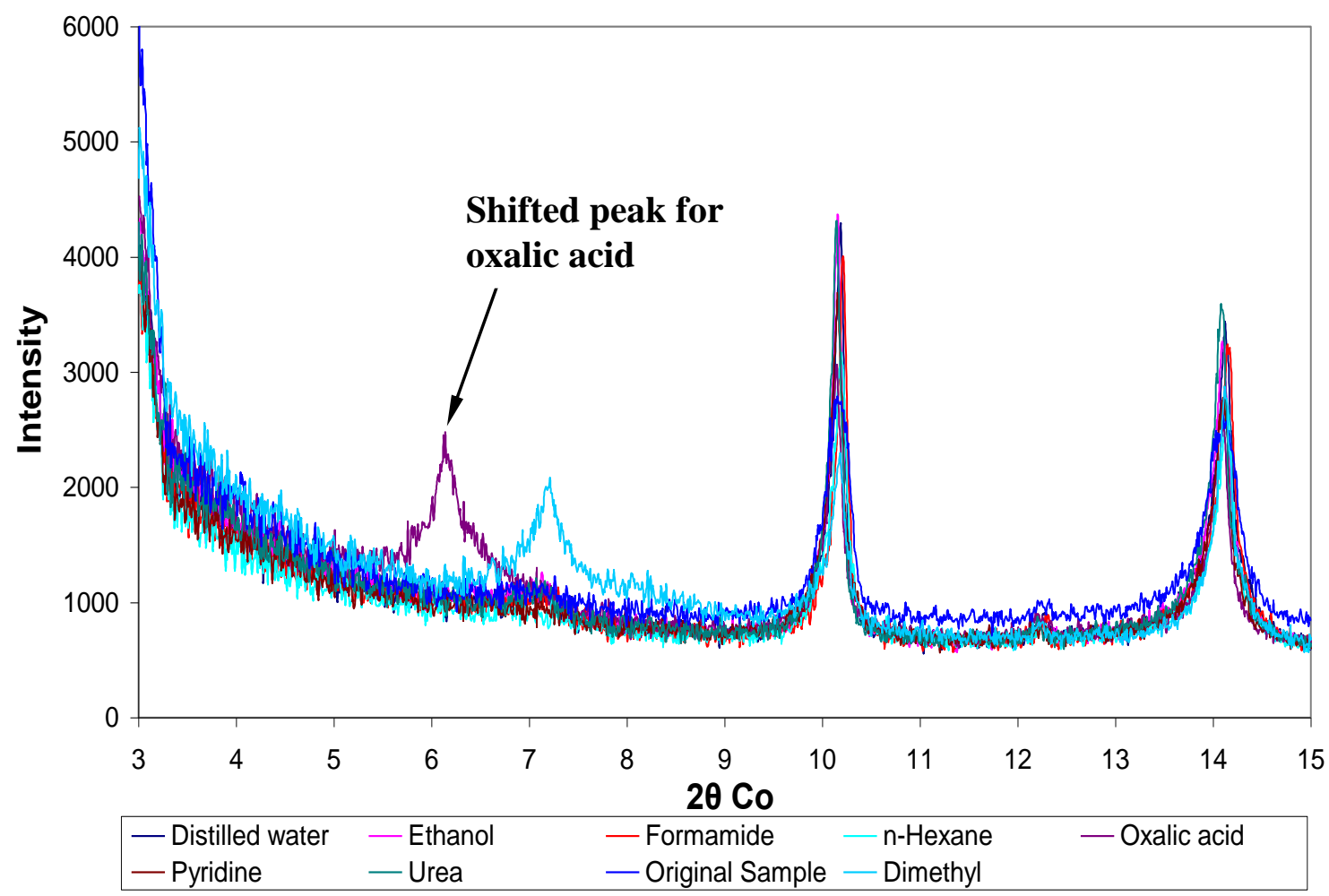

Figure 58: XRD scans for Venetia K1 sample treated with organic reagents after EG treatment. 


\section{The effect of pre-cationic and oxalic acid treatment on mineral alteration}

The effect of pre-cationic saturation prior to organic saturation, was investigated utilising $50 \mathrm{~g}(80 \%$ passing $100 \mu \mathrm{m})$ Venetia $\mathrm{K} 1$ ore samples in $800 \mathrm{ml}$ of a $0.1 \mathrm{M}$ cation solution, at room temperature $\left(\sim 25^{\circ} \mathrm{C}\right)$, while stirring at $600 \mathrm{rpm}$. Cations tested were chlorides of $\mathrm{Cs}^{+}, \mathrm{NH}_{4}^{+}, \mathrm{Na}^{+}, \mathrm{Ca}^{2+}$, and $\mathrm{Mg}^{2+}$. After drying, the samples were further saturated in $800 \mathrm{ml}$ of $0.1 \mathrm{M}$ oxalic acid, while stirring at $600 \mathrm{rpm}$. After 24 hours, the samples were filtered and air dried for 1 day, then submitted for XRD analysis. The effect of these treatments in mineralogical changes was observed with EG treatment by XRD. The results are presented in Appendix E.

There was no shift of the $14 \AA$ peak after EG treatment on samples pretreated in $\mathrm{Cs}^{+}$and $\mathrm{NH}_{4}{ }^{+}$. Samples pretreated with $\mathrm{Na}^{+}, \mathrm{Ca}^{2+}$ and $\mathrm{Mg}^{2+}$ did show a shift in the $14 \AA$ peak. A possible reason for this is that oxalic acid (a carboxylic acid) has a greater electrostatic interaction with these relatively highly charged, pre-attached small cations. This is due to the close proximity of the oxalic acid charged side with these cations, as opposed to the larger $\mathrm{Cs}^{+}$and $\mathrm{NH}_{4}{ }^{+}$cations. This greater electrostatic interaction will cause the ingress of the oxalic acid to enhance the swelling of the clay. The cations $\mathrm{Cs}^{+}$and $\mathrm{NH}_{4}{ }^{+}$have a rather strong coulombic force of attraction with the tetrahedral charge (Morkel et al., 2005) and were therefore stable enough within the interlayers, to collapse the interlayer, and therefore excluded the oxalic acid.

\subsubsection{Immersion tests}

Alteration tests by behaviour were performed on the VUE ore samples. Three samples with the highest mica, the highest forsterite and the highest serpentine contents were selected. The drillcores that were tested are UCM 200, 14, 3, 30, 153, 168, 107, 147, and 106. The selected samples were crushed to $-26 \mathrm{~mm}$ followed by milling to $80 \%$ passing $100 \mu \mathrm{m}$. Samples of $20 \mathrm{~g}$, in weight, were exposed to three different tests, namely: (i) $\mathrm{Mg}^{2+}$ treatment, (ii) $\mathrm{Mg}^{2+}-\mathrm{HCL}$ treatment and (iii) Pre-NaClO oxidation followed by $\mathrm{Mg}^{2+}-\mathrm{HCl}$ treatment. After each test, dried samples were submitted for XRD analysis. Conclusions were made based on the shift in the 7.3-20 (14 $\AA$ ) peak of the initial scan to

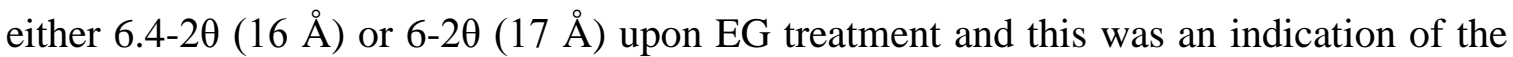


formation of swelling clays (Bühmann, 1998). These tests aimed to exchange the assumed interlayer $\mathrm{K}^{+}$, by $\mathrm{Mg}^{2+}$; alternatively, to encourage the release of $\mathrm{K}^{+}$through $\mathrm{HCl}$ addition, or by oxidizing $\mathrm{Fe}^{2+}$ utilising $\mathrm{NaClO}$ followed by $\mathrm{Mg}^{2+}$ exchange in an $\mathrm{HCl}$ solution to encourage mineral alterations.

The XRD analysis results are shown in Appendix F and summarized in Table 21. Please note that for the XRD analysis results in Appendix F, the red scans represent the sample before EG treatment and the blue represents the scans after EG treatment. Results indicate that the effectiveness of the three treatments followed the order: Pre- $\mathrm{NaClO}$ oxidation $-\mathrm{Mg}^{2+}-\mathrm{HCl}$ treatment $>\mathrm{Mg}^{2+}-\mathrm{HCL}$ treatment $>\mathrm{Mg}^{2+}$ treatment. That is, the $\mathrm{Mg}^{2+}-\mathrm{HCl}-\mathrm{NaClO}$ treatment generally resulted in the formation of swelling clays for most samples, including those that did not form under either $\mathrm{Mg}^{2+}$ only, or $\mathrm{Mg}^{2+}-\mathrm{HCl}$ treatments. The $\mathrm{Mg}^{2+}$ treatment also showed that a cation exchange method can actually alter high mica containing kimberlite, although high serpentine containing kimberlite was more resistant to alteration in any of the tested conditions. This may be due to the fact that serpentine is a primary silicate in the alteration process and may require more time or more vigorous conditions for alteration to occur.

Table 21: A summary of the XRD analysis results on VUE samples that were subjected to various treatments.

\begin{tabular}{|c|c|c|c|c|c|c|c|c|c|}
\hline \multirow{2}{*}{ Treatment } & \multicolumn{3}{|c|}{ Mica samples drillcore ID } & \multicolumn{2}{c|}{ Forsterite samples drillcore ID } & \multicolumn{3}{c|}{ Serpentine samples drillcore ID } \\
\cline { 2 - 10 } & $\mathbf{2 0 0}$ & $\mathbf{1 4}$ & $\mathbf{3}$ & $\mathbf{3 0}$ & $\mathbf{1 5 3}$ & $\mathbf{1 6 8}$ & $\mathbf{1 0 7}$ & $\mathbf{1 4 7}$ & $\mathbf{1 0 6}$ \\
\hline $\mathrm{Mg}^{2+}$ & Swelling & None & Swelling & None & None & None & None & Swelling & None \\
\hline $\mathrm{Mg}^{2+}-\mathrm{HCl}$ & Swelling & Swelling & Swelling & None & None & Swelling & None & None & None \\
\hline $\mathrm{NaClO}-\mathrm{Mg}^{2+}-\mathrm{HCl}$ & Swelling & Swelling & Swelling & Swelling & Swelling & Swelling & None & Swelling & None \\
\hline
\end{tabular}

\section{CONCLUSION}

The proposed idea, that the susceptibility of kimberlite to weathering could be predicted, based on TGA analysis, was not successfully demonstrated. No correlation between the smectite content and the \% weight losses from TGA analysis, was found. The TGA analysis method was utilised to determine the extent of organic adsorption on the kimberlite material. 
XRD analysis studies to relate d-spacing expansion with the extent of kimberlite weathering, indicated that the tested organic reagents resulted in various interlayer spacings (d-spacing). The resulting spaces did not vary significantly from the original untreated sample's d-space of $14.88 \AA$. In the case of utilising pure organic solutions, it was observed that switching from diluted to pure organic solutions did not increase the d-spacing, but lowers it. Cation pretreatment prior to organic weathering resulted in various d-spacings with a maximum of 2 water layers. The general trend was that divalent cations $\left(\mathrm{Mg}^{2+}\right.$ and $\mathrm{Ca}^{2+}$, with $\mathrm{Mg}^{2+}$ having the greatest effect) increased the d-spacing whereas monovalent cations $\mathrm{Na}^{+}$and $\mathrm{K}^{+}$decreased the d-spacings. In the case of pre-organic treatment prior to organic weathering utilising formamide, it was observed that the resulting d-spacing increased to 2 and 3 water layers. This showed that pre-organic saturation by long chain organic solutions pyridine, cetylpyridium chloride, dimethyldioctadecylammonium chloride and dodecylamine assisted in conditioning the particle surface for a further organic expansion. The d-spacing investigation showed a single interlayer thickness for $\mathrm{K}^{+}$and $\mathrm{Na}^{+}$and double interlayer spacing for $\mathrm{Ca}^{2+}$ and $\mathrm{Mg}^{2+}$ in line with the values expected for ambient conditions, as the samples were air dried. The sensitivity in this technique is not high enough to enable direct prediction of the kimberlite weathering behaviour.

TGA analysis confirmed that the kimberlite structure did adsorb organic reagents during weathering. Generally more polar organic reagents were adsorbed to a greater extent than the less polar and also the volatile reagents. The highest adsorption was observed with oxalic acid at $\sim 23 \%$ compared to other organic reagents reporting less than $4 \%$ adsorption. Results indicated that the decrease in the amounts of organic reagents adsorbed followed the order oxalic acid > urea > pentanoic acid > formamide > ethanol > n-hexane $>$ acetic acid. The trend was similar to the extent of weathering caused by these organic reagents, owing to the fact that oxalic acid was seen to produce a relatively high weathered product, as compared to other organic solutions. Results indicated that oxalic acid was adsorbed the most by the kimberlite and for this reason it was also the most effective organic amongst all that were tested. In the pre-cation treatment tests, divalent cations encouraged organic adsorption, while monovalent cations discouraged further intake of organic reagents. When $\mathrm{Mg}^{2+}$ was utilised as a pretreatment cation, it was observed that the extent of organic adsorbed improved from 23 to $30 \%$ for oxalic acid, 
urea from 2 to $24 \%$, formamide from 1 to $12 \%$, pentanoic acid from 1 to $9 \%$, acetic acid from below 0 to $5 \%$, n-hexane from 0.1 to $3 \%$ and ethanol from 0.2 to $3.2 \%$, relative to the untreated sample. TGA analysis also showed that organic pretreatments encouraged subsequent organic adsorption and the effectiveness followed the order: dimethyldioctadecylammonium chloride > cetylpyridium chloride > dodecylamine > pyridine. This corresponded with the observation made during d-spacing determinations.

In The FTIR analysis it was observed that there was a disturbance of the bond between water in the interlayer and the silicate structure by a stronger $\mathrm{H}$-bond gained by organic molecules. The effect was strongest when a pre-organic treatment was performed prior to subsequent organic weathering. Pre-cation treatment did not follow a defined trend to determine the mechanism, as organic reagents reacted in various ways to the pretreatment cation. This was a confirmation of the results of Grim's study (Grim, 1968) that organic attachment is not determined by the cation present in the interlayer, but varies with different organic solutions. In addition, an oxalic acid treatment in the current study was shown by FTIR results to dissolve the cations in the structure. This also explained why oxalic acid was a more effective weathering agent for kimberlite weathering.

In general, this study of kimberlite organic weathering showed that kimberlites containing swelling clay minerals (smectites and vermiculites) can be weathered utilising organic solution to some extent. In as much as weathering took place, the weathering of kimberlite utilising organic solutions generally did not show an improvement as compared to inorganic solutions. The reason for this, adopted from Morkel (2006), was that inorganic cations are not only adsorbing onto interlayer spaces, as shown for organic solutions, but also onto other sites such as crystal edges. None the less, oxalic acid was found to be the most effective weathering agent in comparison to the other tested organic solutions due to its mechanism of weathering. Oxalic acid was observed to follow the mechanism of dissolving the silicate structure by $\mathrm{H}^{+}$attack, accompanied by the precipitation of oxalate salts that would slow down further dissolution. The mechanism was diffusion controlled. The acid attack gave oxalic acid more leverage with which to weather the kimberlite, than the rest of the tested organic solutions. Comparing $\mathrm{Cu}^{2+}$ and oxalic acid treatments, results showed that $67 \%$ of the particles passed $12 \mathrm{~mm}$ screen size due to $\mathrm{Cu}^{2+}$ weathering as opposed to $48 \%$ in oxalic acid weathering. The effect on 
kimberlite weathering by the tested solutions followed the order $\mathrm{Cu}^{2+}>$ oxalic acid > ethanol $>$ acetic acid $>$ formamide $>$ n-hexane $>$ distilled water.

Investigations of the effects of some variables in kimberlite weathering, utilising oxalic acid, showed a small improvement to weathering with an increased exposure time. However, the effect was not that significant, as the relative difference between a 2 day and a 30 day exposure in the amount of particles passing the $12 \mathrm{~mm}$ screen size, was only $7 \%$. Increasing oxalic acid concentration from $0.025 \mathrm{M}$ to $0.5 \mathrm{M}$ saw an increase in the amount of particles passing the $12 \mathrm{~mm}$ screen size by $19 \%$. This suggests that an increase in organic concentration increased the weathering of the kimberlite to a greater extent. However, there was no improved weathering when the weathering temperature was increased from approximately $25{ }^{\circ} \mathrm{C}$ to $40{ }^{\circ} \mathrm{C}$.

In kinetic studies utilising oxalic acid, a high mineral dissolution was observed in the first 24 hours of contact with the weathering solution. The dissolution gradient became negative for most of the cations due to re-precipitation of cations forming oxalate salts. The mechanism of oxalic acid weathering differed from that of $\mathrm{Cu}^{2+}$ and was generally assumed to be controlled by mineral surface reactions, as adopted from Drever and Stilling (1997). This involved cations being put into solution by the oxalic acid, followed by precipitation of secondary phases that form a passive layer, which in turn slows down further dissolution. In addition, oxalic acid was observed to put into solution the cations $\mathrm{Mg}^{2+}$ and $\mathrm{Al}^{3+}$ that are usually positioned in the octahedral layers of silicates. This was assumed to be another reason why oxalic acid is an effective organic in weathering.

Agitation tests were conducted on Venetia K1 ore, which had a low swelling clay content, and was therefore highly resistant to weathering. Oxalic acid was observed to enhance the presence of swelling clays in the Venetia $\mathrm{K} 1$ ore. In pre-cation saturation prior to oxalic treatment, it was found that the cations $\mathrm{Cs}^{+}$and $\mathrm{NH}_{4}{ }^{+}$suppressed the oxalic acid's effectiveness in enhancing the swelling clays, whereas $\mathrm{Na}^{+}, \mathrm{Ca}^{2+}$ and $\mathrm{Mg}^{2+}$ encouraged the effect. This was explained with the reasoning that because oxalic acid is a carboxylic acid, it has a stronger electrostatic interaction with the small, highly charged $\mathrm{Na}^{+}, \mathrm{Ca}^{2+}$ and $\mathrm{Mg}^{2+}$ cations than the larger $\mathrm{Cs}^{+}$and $\mathrm{NH}_{4}{ }^{+}$cations, and can therefore cause a change. 
Immersion tests showed that cation exchange treatment in conjunction with acid and oxidation treatments, on non-swelling containing kimberlites with high amounts (at least $30 \%$ ) of mica or forsterite minerals, resulted in the presence of swelling clays. Kimberlite with a high serpentine content was more resistant to alteration under the tested conditions. In as much as the alteration options indicated promising results, the possibility of kimberlite alteration, still needs further study.

\section{POSSIBLE FUTURE WORK}

Interlayer spacing determinations after organic treatment were not strictly conclusive to relate to weatherability. An in situ XRD analysis can be a suggested method.

The aim of this study was to investigate and show that kimberlite ore that contains swelling clay minerals can be weathered utilising organic reagents. This was tested by utilising a number of organic solutions and also by performing specific testing methods on a specific type of kimberlite. Amongst the tested reagents, oxalic acid emerged as the most effective organic reagent. Even though these organic solutions showed weathering ability to a certain degree, they were not as effective as the $\mathrm{Cu}^{2+}$-containing inorganic solution. Further work would be to test other possible organic reagents that may be more aggressive and compare the results with the results from a list of other, inorganic, solutions. The test on organic molecules with $\mathrm{n}_{\mathrm{C}}$ of at least 10 can also be considered as highlighted in section 2.5. The effect of $\mathrm{pH}$ on kimberlite weathering may also be considered. These tests should be performed on various types of kimberlites so as to observe their reaction. This means performing similar tests on various kimberlites. In addition, TGA results for $\%$ weight loss at $125^{\circ} \mathrm{C}$ can also be analysed futher as this may provide information for the influence of organic reagents on the water of crystallisation.

Kinetic evaluations were performed on ore particles that were immersed in stagnant solution. Possible future work will be to stir up the contents so as to remove the passive layer formed during dissolution, and constantly produce fresh surfaces for the reaction to take place . 
Consolidation of the investigation of possible mineral alteration should be considered in future work. The possibility of the use of heated aluminium salt solutions, as tested by Hopwood and Webb (1975) (refer to section 4), in altering serpentine to phyllosilicates, can also be put on trial.

\section{REFERENCES}

Barman, A.K., Varadachari, C., \& Ghosh, K., 1992, Weathering of silicate minerals by organic acids. I. Nature of cation solubilization, Geoderma, 53, pp. 45-63.

Bigham, J.M., Bhatti, T.M., Vuorinen, A., Tuovinen, O.H., 2001, Dissolution and structural alteration of phlogopite mediated by proton attack and bacterial oxidation of ferrous iron, Hydrometallurgy, 59, pp. 301-309.

Benvie, B., 2007, Mineralogical imaging of kimberlites utilising SEM-based techniques, Minerals Engineering 20, pp. 435-443.

Bland, W., \& Rolls, D., 1998, Weathering: An introduction to the scientific principles, Oxford University Press Inc., New York.

Boshoff, E.T., Morkel, J., Vermaak, M.K.G., \& Pistorius, P.C., 2007, Kimberlite degradation: The role of cation type, Minerals Engineering 20 (2007), pp. 1351-1359.

Breen, C., Watson, R., Madejova, J., Komadel, P., \& Klapyta, Z., 1997, Acid-activated organoclays: Preparation, characterization and catalytic activity of acid-treated tetraalkylammonium-exchanged smectites, Langmuir, 1997, 13, pp. 6473-6479.

Bühmann, D., 1998, The phyllosilicates of clays and their X-ray identification, The mineralogical association of South Africa Clay workshop, Council for Geoscience.

Caballero, F,R.P., \& Poncelet, G., 2000(a), Preparation and characterization of microporous $18 \AA$ Al-pillared structures from natural phlogopite micas, Microporous and Mesoporous Materials, 41, pp. 169-181. 
Caballero, F, R. P., \& Poncelet, G., 2000(b), Microporous 18 A Al-pillared vermiculites: preparation and characterization, Microporous and Mesoporous Materials, 37, pp. 313327.

Campos, A., Gagea, B., Moreno, S., Jacobs, P., \& Molina, R., 2008, Decane hydroconversion with Al-Zr, Al-Hf, Al-Ce-pillared vermiculites, Applied Catalysis A: General, 345, pp. 112-118.

Chappell, M.A., Laird, D.A., Thompson, M.L., Li, H., Teppen, B.J., Aggarwal, V., Johnston, C.T., \& Boyd, S.A., 2005, Influence of smectite hydration and swelling on atrazine sorption behavior, Environmental Science Technology 2005, 39, pp. 3150-3156.

Chen, J., Blume, H.P., \& Beyer, L., 2000, Weathering of rocks induced by lichen colonization - a review, Catena, 39, pp. 121-146.

Chin, P. K. F., \& Mills, G.L., 1991, Kinetics and mechanisms of kaolinite dissolution: effects of organic ligands, Chemical Geology, 90, pp. 307-317.

Clement, C.R., \& Skinner, E.M.W., 1985, A textural-genetic classification of kimberlites, Transaction of Geological Society of South Africa, Vol. 88, Issue 2, pp. 403-409.

Crawford, R.J., Smalley, M.V., \& Thomas, R.K., 1991, The effect of uniaxial stress on the swelling of n-butylammonium vermiculite, Advances in Colloid and Interface Science, 34, pp. 537-560.

Cuadros, J., \& Linares, J., 1996, Experimental kinetic study of the smectite-to-illite transformation, Geochemica et Cosmochimica Acta, Volume 60, No. 3, pp 439-453.

Daryn, S.W., \& Thomas, R.K., 2002, The intercalation of vermiculite by cationic surfactants and its subsequent swelling with organic solvents, Journal of Colloid and Interface Science 255, pp. 303-311. 
Dawson, J.B., 1980, Kimberlites and their xenoliths, Minerals and rocks, Springs-Verlag Berlin · Heidelberg · New York.

Deer, F.R.S., W.E., Howie, R.A., \& Zussman, J., 1966, An introduction to the rockforming minerals, Longman group limited.

Drever, J.I., \& Stillings, L.L., 1997, The role of organic acids in mineral weathering, Colloids and Surface A: Physicochemical and Engineering Aspects, 120, pp. 167-181.

Egli, M., Mirabella, A., \& Fitze, P., 2003, Formation rates of Smectites derived from two Holocene chronosequences in the Swiss Alps, Geoderma, 117, pp. 81-98

Egli, M., Mirabella, A., \& Fitze, P., 2001, Clay mineral transformations in soils affected by fluorine and depletion of organic matter within a time span of 24 years, Geoderma, 103, pp. 307-334.

Favre, F., Bogdal, C., Gavillet, S., \& Stucki, J.W., 2006, Changes in the CEC of soil smectite-kaolinite clay fraction as induced by structural iron reduction and iron coatings dissolution, Applied Clay Science, 34, pp. 95-104.

Ferrage, E., Lanson, B., Sakharov, B.A., Drits, V.A., 2005, Investigation of smectite hydration properties by modeling experimental X-ray diffraction patterns: Part I. Montmorillonite hydration properties, American Mineralogist, Vol 90, pp. 1358-1374.

Fiantis, D., Nelson, M., Shamshuddin, Goh, T.B., \& Ranst, E.V., 2010, Leaching experiments in recent tephra deposits from Talang volcano (West Sumatra), Indonesia, Geoderma, 156, pp. $161-172$.

Field, M., Stiefenhofer, J., Robey, J., \& Kurszlaukis, S., 2008, Kimberlite-hosted diamond deposits of southern Africa: A review, Ore Geology Reviews. 
Gadd, G.M., 1999, Fungal production of citric and oxalic acid: Importance in metal speciation, physiology and biogeochemical process, Advances in microbial physiology, Volume 41, pp. 47-92.

Gates, W.P., Komadel, P., Madejová, J, Bujdák, J., Stucki, J.W., \& Kirkpatrick, R.J., 2000, Electronic and structural properties of reduced-charge montmorillonites, Applied Clay Science 16, pp. 257-271.

Gates, W.P., Anderson, J.S., Raven, M.D., \& Churchman, G.L., 2002, Mineralogy of a bentonite from Miles, Queensland, Australia and characterization of its acid activation products, Applied Clay Science, 20, pp 189-197.

Gates, W.P., 2004, Crystalline swelling of organo-modified clays in ethanol-water solutions, Applied Clay Science 27 (2004), pp. 1-12.

Gerryts, E., 1951, The petrology of the kimberlites at the Premier (Transvaal) diamond mine, South Africa, PhD thesis, Department of Geological Sciences, McGrill University.

Ghiaci, M., Kalbasi, R.J., Khani, H., Abbaspur, A., \& Shariatmadari, H, 2004, Freeenergy of adsorption of a cationic surfactant onto Na-bentonite (Iran): inspection of adsorption layer by X-ray spectroscopy, Journal of Chem. Thermodynamics, 36, pp. 707713.

Gilkes, R.J., 1973, The alteration products of potassium depleted oxybiotite, Clays and Clay Minerals, Vol. 21, Issue 5, pp. 303-313.

Glover, J.E., \& Groves, D.I., 1981, Kimberlites and diamonds, Department of Geology and University Extension, University of Western Australia Publications, no. 5.

Grim, R.E., 1968, Clay mineralogy, Second Edition, McGraw Hill International Series in the Earth and Planetary Sciences. 
Guggenheim, S., \& Martin, R.T., 1995, Definition report of clay and clay mineral: Joint the AIPEA and CMS nomenclature committees, Clay minerals (1995) 30, pp. 257-259.

Gylienė, O., Šalkauskas, M., \& Juškènas, R., 1997, The use of organic acids as precipitants for metal recovery from galvanic solutions, Journal Chemical Technology and Biotechnology, 70, pp. 111-115.

Hanna, R.A., \& Vieira, A.L., 2004, Franca’s smectites as organophilic clays, Applied mineralogy, pecchio et al. (eds), ICAM-BR, São Paulo.

Hart, C., 2003, Overview of diamond recovery techniques, The South Africa Institute of Mining and Metallurgy Colloquium: Diamonds-Source to Use, 29-30 October 2003.

Hedley, C.B., Yuan, G., \& Theng, B.K.G., 2007, Thermal analysis of montmorillonites modified with quaternary phosphonium and ammonium surfactants, Applied Clay Science, 35, pp. 180-188.

Hendrickson, J.B., Cram, D.J., \& Hammond, G.S., 1970, Organic chemistry, McGraw Hill, Inc., $3^{\text {rd }}$ Edn.

Hoda, S.N., \& Hood, W.C., 1972, Laboratory alteration of trioctahedral micas, Clays and clay minerals, Volume 20, Issue 6, pp 343-358.

Hodgson, I.M.J., 1981, Hydrothermal Alteration of Kimberlite, Imperial College of Science and Technology (LONDON SW7 2BP), Thesis in fulfillment of degree of Doctor of Philosophy, Department of Mineral Resource Engineering.

Hopwood, J.S., \& Webb, S.M., 1975, The accelerated weathering of kimberlite, De Beers technical note, No. 75/9/2, Diamond Research Laboratory- Mines division.

Jahn, L., 2008, Accelerated weathering of kimberlite utilising the Slake-durability test, University of Pretoria, Thesis in partial fulfillment of degree of Bachelor of Engineering in Metallurgical Engineering, Department of Materials Science and Metallurgy. 
Janse, A.J.A., \& Sheahan, P.A., 1995, Catalogue of worldwide diamond and kimberlite occurrences: a selective and annotative approach, Journal of Geochemical Exploration, 53, pp. 73-111.

Jordan, J.W., 1963, Organophilic clay-based thickeners. In: Swine-ford, A. (Ed.), Proceedings of the $10^{\text {th }}$ National Conference on Clays and Clay Minerals. Pergamon, Austin, pp. 299-308.

Kalinowski, B.E., \& Schweda, P., 1996, Kinetics of muscovite, phlogopite, and biotite dissolution and alteration at $\mathrm{pH} 1-4$, room temperature, Geochimica et Cosmochimica Acta, Vol. 60, No. 3, pp. 367-385.

Kavanagh, B.V., \& Quirk, J.P., 1978, The adsorption of polycationic Fe (III) species on Na-Illite, Geoderma, 21, pp. 225-238.

Kawamura, K., Ichikawa, Y., Nakano, M., Kitayama, K., \& Kawamura, H., 1999, Swelling properties of Smectites up to 90C: In situ X-ray diffraction experiments and molecular dynamic simulations, Engineering Geology 54 (1999), pp. 75-79.

Kim, J., Dong, H., Seabaugh, J., Newell, S.W., \& Eberl, D.D., 2004, Role of microbes in the smectite-to-illite reaction, Science, 303, pp. 830-832.

Klein, C., 2002, The $22^{\text {nd }}$ edition of the manual of mineral science, John Wiley and sons Inc, pp. 463-472.

Komadel, P., 2003, Chemically modified Smectites, Clay Minerals, 38, pp. 127-138.

Komadel, P., Madejová, J., \& Stucki, J.W., 2006, Structural Fe(III) reduction in Smectites, Applied Clay Science 34, pp. 88-94.

Kretzschmar, R., Robarge, W.P., Amoozergar, A., \& Vepraskas, M.J., 1997, Biotite alteration to halloysite and kaolinite in soil-saprolite profiles developed from mica schist and granite gneiss, Geoderma, 75, pp 155-170. 
Kukovskii, E.G., 1976, Principles of the weathering mechanism, Mineral.Osad.Obraz., Volume 3, pp 14-21.

Lagaly, G., \& Malberg, R., 1990, Disaggregation of alkylammonium montmorillonites in organic solvents, Colloids and Surface, 49, pp. 11-27.

Lee, J.F., Mortland, M.M., Chiou, C.T., Kile, D.E., Boyd, S.A., 1990, Adsorption of benzene, touluene, and xylene by two tetramethylammonium-smectites having different charge densities, Clays and Clay Minerals, 38, pp113-120.

Lee, S.Y., \& Kim, S.J., 2002, Delamination behavior of silicate layers by adsorption of cationic surfactants, Journal of Colloid and Interface Science, 248, pp. 231-238.

Lerf, A., 2004, Different modes and consequences of electron transfer in intercalation compounds, Journal of Physics and chemistry of solids, 65, pp. 553-563.

Li, S.Z., \& Xu, R.K., 2008, Electrical double layers' interaction between oppositely charged particles as related to surface charge density and ionic strength, Colloids and Surfaces A: Physicochemical and Engineering Aspects, 326, pp. 157-161.

Lide, D.R., 2005, CRC handbook of chemistry and physics: a ready-reference book of chemical and physical data, $86^{\text {th }}$ edition, Boca Raton, Fla. : Taylor $\&$ Francis.

Lin, F.-C. \& Clemency, C.V., 1981a, The dissolution kinetics of brucite, antigorite, talc and phlogopite at room temperature and pressure, The American mineralogist, Mineralogical Society of America, Volume 66, Issue 7-8, pp 801-806.

Lin F.-C., \& Clemency, C.V., 1981b, Dissolution kinetics of phlogopite: I. Closed system, Clays and clay minerals, Volume 29, Issue 2, pp 101-106.

Lin F.-C., \& Clemency, C.V., 1981c, Dissolution kinetics of phlogopite: II. Open system utilising ion exchange resin, Clays and clay minerals, Volume 29, Issue 2, pp 107-112. 
Madejová, J., Arvaiová, B., \& Komadel, P., 1999, FTIR spectroscopic characterization of thermally treated $\mathrm{Cu}^{2+}, \mathrm{Cd}^{2+}$ and $\mathrm{Li}^{+}$montmorillonites, Spectrochimica Acta Part A 55, pp. 2467-2476.

Maryott, A.A., \& Smith, E.R., 1951, Table of dielectric constants of pure liquids, United States Department of Commerce, National Bereau of Standards Circular 515.

M'bodj, O., Ariguib, N.K., Ayadi, M., T., \& Magnin, A., 2004, Plastic and elastic properties of the system interstratified clay-water-eletrolyte-xanthan, Journal of Colloid and interface Science 273 (2004), pp. 675-684.

Mitchell, R. H. (1986), Kimberlites: mineralogy, geochemistry and petrology, New York, Plenum Press.

Mohan, K.K., Reed, M.G., Fogler, \& H.Scott, 1999, Formation damage in smectitic sandstones by high ionic strength brines, Colloids and Surfaces A: Physicochemical and Engineering Aspects 154 (1999), pp. 249-257.

Moraru, V.N., 2001, Structure formation of alkylammonium montmorillonites in organic media, Applied Clay Science, 19, pp. 11-26.

Moore, D.M., \& Reynolds, R.C., 1989, X-Ray Diffraction and Identification and Analysis of Clay Minerals, Oxford New York, Oxford University Press.

Morkel, J., Saydam, S., \& Krüger, L., 2005, Chemical alteration of clay minerals to prevent kimberlite weathering - Utilising slake durability index tests, Technical Note 2005-07-04, De Beers

Morkel, J., 2006, Kimberlite weathering: Mineralogy and mechanism, University of Pretoria, Thesis in partial fulfillment of degree of Doctor of Philosophy, Department of Materials Science and Metallurgy. 
Morkel, J., Pistorius, P.C., \& Vermaak, M.K.G., 2007, Cation exchange behavior of kimberlite in solutions containing $\mathrm{Cu}^{2+}$ and $\mathrm{K}^{+}$, Mineral Engineering 20 (2007), pp. $1145-1152$.

Morkel, J., \& Pieters, R, 2007, The influence of organic species on kimberlite weathering, Technical Note 2007-04-01, De Beers.

Morkel, J., \& Saydam, S., 2008, Technical Note: The influence of potassium on the weathering properties of kimberlite and the information provided by different testing methods, International Journal of Rock Mechanics and Mining Science, 45, pp. 11871194.

Pal, D.K., Srivastava, P., Durge, S.L., \& Bhattacharyya, T., 2001, Role of weathering of fine-grained micas in potassium management of Indian soils, Applied Clay Science, 20, pp. 39-52.

Patzko, A., \& Dekany, I., 1993, Ion exchange and molecular adsorption of a cationic surfactant on clay minerals, Colloids and Surface A: Physicochemical and Engineering Aspects, Volume 71, Issue 3, pp. 299-307.

Pieters, R., Vermaak, M.K.G., \& Morkel, J., 2006, The effect of organic compounds on kimberlite weathering, University of Pretoria, Thesis in partial fulfillment of degree of Bachelor of Engineering in Metallurgical Engineering, Department of Materials Science and Metallurgy.

Roberts, R.H., \& Hopwood, J.S., 1975, The accelerated weathering of kimberlite, De Beers technical note, No. 75/12/2, Diamond Research Laboratory- Mines division.

Roberts, R.H., 1976, The accelerated weathering of kimberlite, De Beers technical note, No. E65/001/001, Diamond Research Laboratory- Mines division.

Ross, G.J., 1975, Experimental alteration of chlorites into vermiculite by chemical oxidation, Nature, Volume 255, pp 133-134. 
Ross, G.J., \& Kodama, H., 1976, Experimental alteration of chlorite into a regularly interstratified chlorite vermiculite by chemical oxidation, Clays and clay minerals, Volume 24, Issue 4, pp 183-190.

Salles, F., Bildstein, O., Douillard, J.M., Jullien, M., \& Van Damme, H., 2007, Determination of the driving force for the hydration of swelling clays from computation of the hydration energy of interlayer cations and clays layer, Journal of Physical Chemistry, 111, pp. 13170-13176.

Schlegel, M.L., Manceau, A., Chateigner, D., \& Charlet, L., 1999, Sorption of metal ions on clay minerals: Polarized EXAFS Evidence for the adsorption of Co on edges of hectorite particles, Journal of Colloid and Interface Science, 215, pp. 140-158.

Senkayi, A.L., Dixon, J.B., \& Hossner, L.R., 1981, Transformation of chlorite to smectite through regularly interstratified intermediates, Soil Science of America, Vol. 45, Issue 3, pp. 650-656.

Sild, S., \& Karelson, M., 2002, A general QSPR treatment for dielectric constants of organic compounds, J. Chem. Inf. Comput. Sci., 42, pp. 360-367.

Środoń, J., 1999, Nature of mixed-layer clays and mechanisms of their formation and alteration, Earth Planet Science, 27, pp. 19-53.

Šucha, V., Środoń, J., Clauer, N., Elsass, F., Eberl, D.D., Kraus, I., \& Madejová, J., 2001, Weathering of smectite and illite-smectite under temperate climate conditions, Clay Minerals, 36, pp. 403-419.

Tahani, A., Karroua, M., Van Damme, H., Levitz, P., \& Bergaya, F., 1999, Adsorption of a Cationic Surfactant on Na-Montmorillonite: Inspection of Adsorption Layer by X-Ray and Fluorescence Spectroscopies, Journal of Colloid and Interface Science 216, pp. 242249. 
Taylor, A.S., Blum, J.D., Lasaga, A.C., \& MacInnis, I.N., 2000, Kinetics of dissolution and $\mathrm{Sr}$ release during biotite and phlogopite weathering, Geochemica et cosmochimica acta, Volume 64, Issue 7, pp 1191-1208.

Theng, B.K.G., 1974, The chemistry of clay-organic reactions, Scientist, Soil Bureau, Department of Scientific and Industrial Research, Lower Hutt, New Zealand, A Halsted Press Book.

Tvardovski, A.V., Fomkin, A.A., Tarasevich, Y.I., Polyakova, I.G., Serpinski, V.V., \& Guseva, I.M., 1994, Investigation of cation-substituted vermiculite deformation upon water vapor sorption, Journal of Colloid and Interface Science 164, pp. 114-118.

Vali, H., \& Hesse, R., 1992, Arrangement of n-alkylammonium ions in phlogopite and vermiculite: an XRD and TEM study, Clays and clay minerals, Volume 40, No. 2, pp 240-245.

Van Olphen, H., 1963, An introduction to clay colloid chemistry: For clay technologists, geologists, and soil scientists, Interscience publishers, A division of John Wiley and sons, New York, London.

Van Olphen, H., 1968, Modification of the clay surface by pyridine-type compounds, Journal of Colloid and Interface Science, Vol. 28, No. 3/4, pp. 370-375.

Varadachari, C., Barman, A.K., \& Ghosh, K., 1994, Weathering of silicate minerals by organic acids. II. Nature of residual products, Geoderma, 61, pp. 251-268.

Wang, X., Li, Q., Hu, H., Zhang, T., \& Zhou, Y., 2005, Dissolution of kaolinite induced by citric, oxalic and malic acids, Journal of Colloid and Interface Science, 290, pp. 481488.

Weiss, A., 1963, Organic derivatives of mica-type layer silicates. Angew. Chem., Int. Edit. Engl., 2, pp. 134-143. 
Weiss, A., 1989, About sealing of waste disposal by clays with special consideration of organic compounds in percolating water, Applied Clay Science, 4, pp. 193-209.

Wills, B.A., 1997, Mineral processing technology: an introduction to the practical aspects of ore treatment and mineral recovery, Oxford; Boston: Butterworth-Heinemann, $6^{\text {th }}$ ed.

Yatsu, E., 1988, The nature of weathering: An introduction, Sozosha publishers, Tokyo, Japan.

Zemanová, M., Link, G., Takayama, S., Nüesch, R., \& Janek, M., 2006, Modification of layer charge in smectites by microwaves, Applied Clay Science 32 (2006), pp. 271-282. 


\section{APPENDICES}

APPENDIX A: XRD analysis results for the Finsch, the Koffiefontein and the Venetia K1 ores.

A1: XRD analysis results for the Finsch ore

A2: XRD analysis results for the Koffiefontein ore

A3: XRD analysis results for the Venetia K1 ore 


\section{A2: XRD analysis results for the Koffiefontein ore}

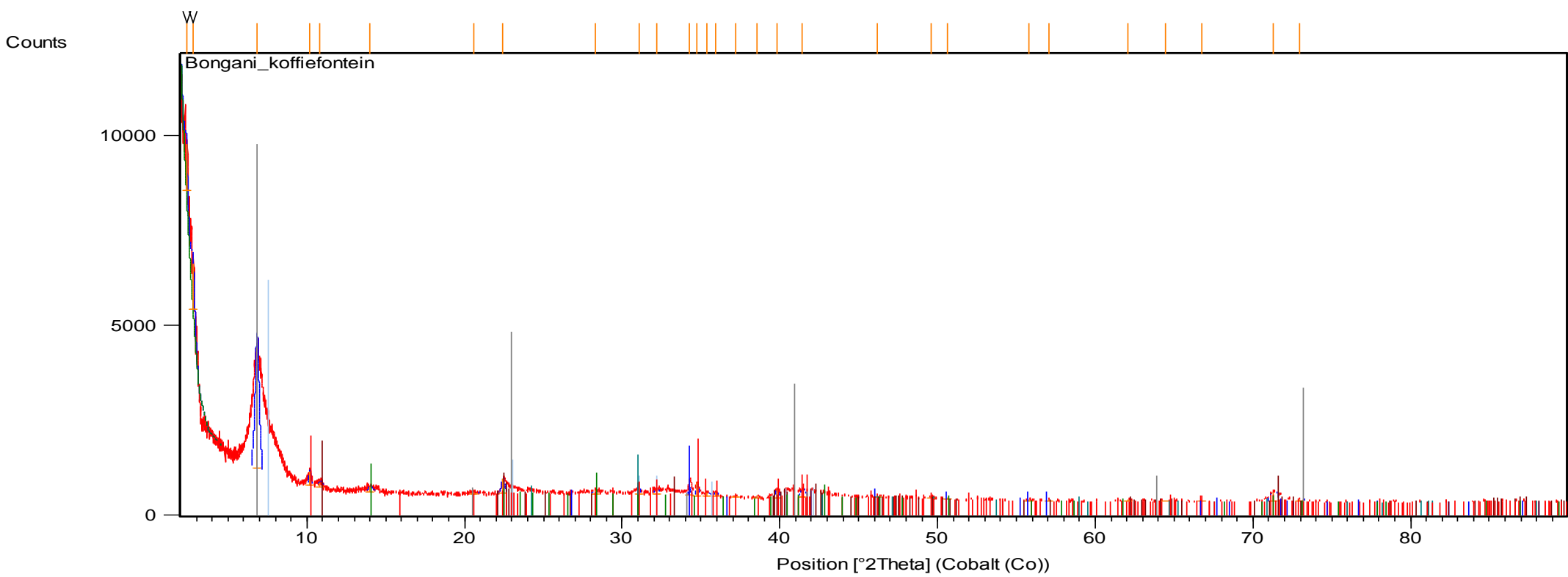

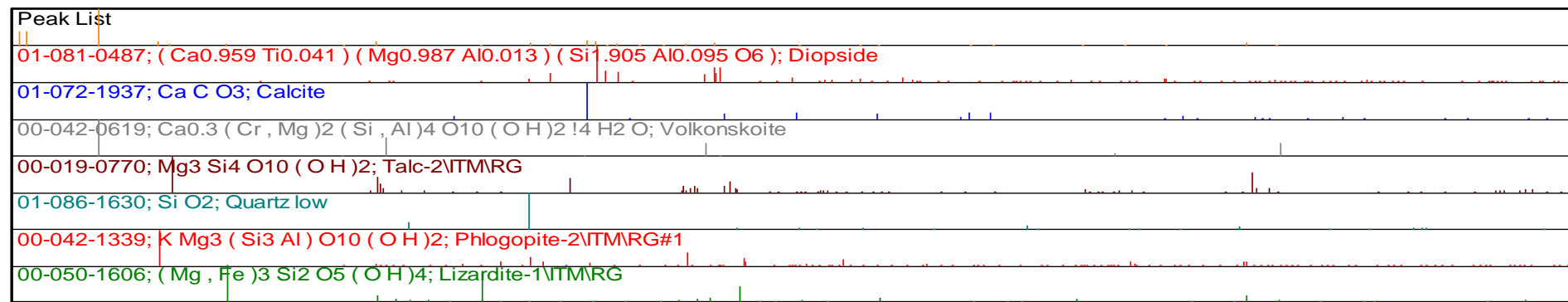




\section{A3: XRD analysis results for the Venetia K1 ore}

Counts

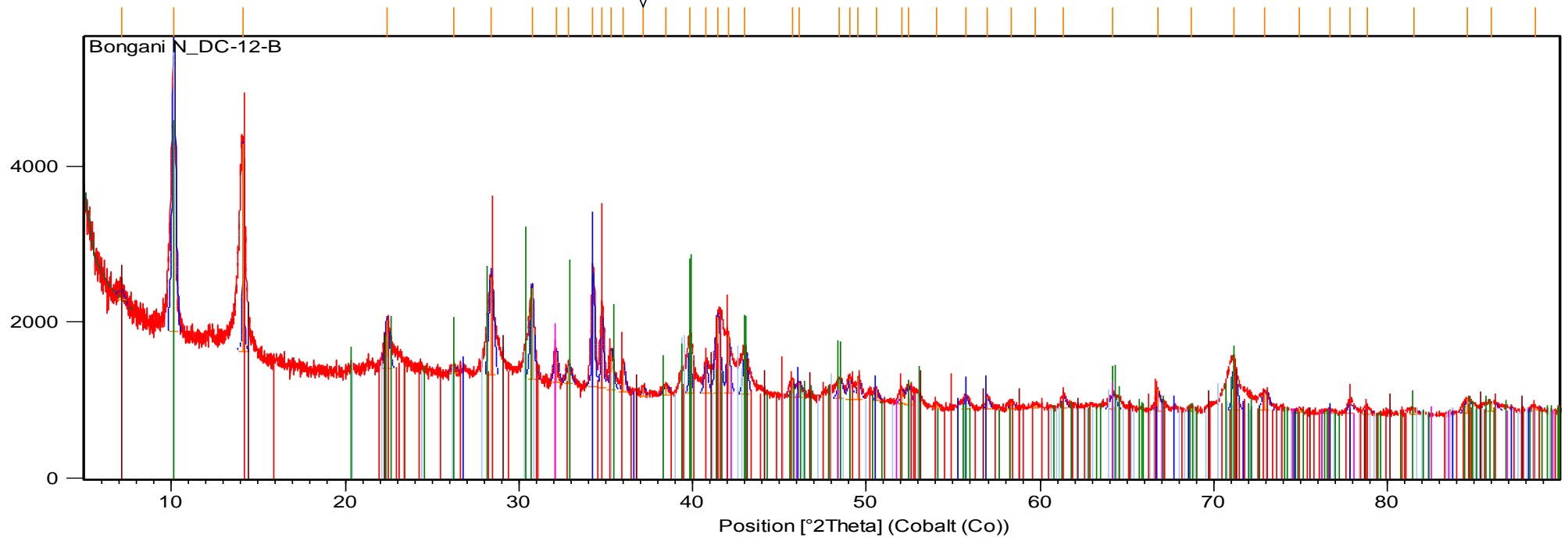

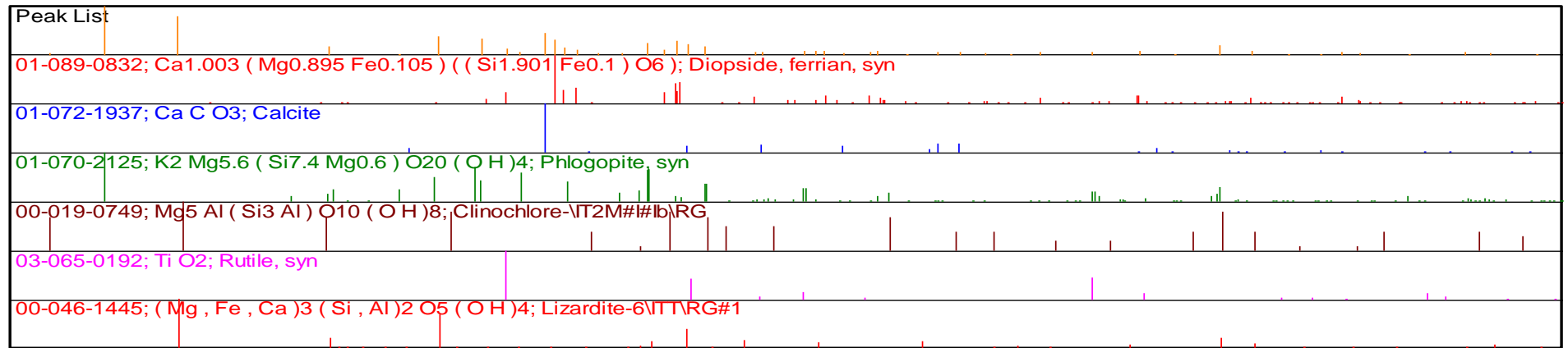


APPENDIX B: Correlation between smectite content and TGA analysis results

\begin{tabular}{|c|c|c|c|c|}
\hline Sample Drillcore ID & Weight loss (\%) & Smectite content (\%) & $\mathbf{d}_{\mathbf{7 5}}$ & Weathering \\
\hline UCM 1 & 6.52 & 0.00 & 39327.40 & Low \\
\hline UCM 12 & 7.73 & 20.30 & 30611.78 & Very low \\
\hline UCM 16 & 7.59 & 47.38 & 25784.65 & Moderate \\
\hline UCM 24 & 10.18 & 26.00 & 26433.76 & Low \\
\hline UCM 62 & 12.11 & 31.00 & 29723.08 & Low \\
\hline UCM 64 & 6.83 & 50.41 & 30461.03 & Very low \\
\hline UCM 83 & 7.71 & 35.00 & 30296.77 & Very low \\
\hline UCM 85 & 7.67 & 49.83 & 27603.50 & Moderate \\
\hline UCM 86 & 7.42 & 45.40 & 28772.55 & Low \\
\hline UCM 89 & 6.75 & 15.87 & 25867.54 & Moderate \\
\hline UCM 97 & 7.63 & 38.67 & 30215.02 & Low \\
\hline UCM 99 & 7.14 & 23.40 & 30619.10 & Very low \\
\hline UCM 101 & 5.87 & 42.01 & 27509.85 & Moderate \\
\hline UCM 103 & 5.83 & 7.95 & 25329.31 & Moderate \\
\hline UCM 117 & 6.54 & 48.04 & 17512.81 & High \\
\hline UCM 132 & 5.96 & 0.00 & 16090.76 & High \\
\hline UCM 134 & 4.94 & 51.57 & 10388.91 & Very high \\
\hline UCM 138 & 9.68 & 31.51 & 27171.80 & Low \\
\hline
\end{tabular}


APPENDIX C: XRD results for oxalic acid treatment that had a $\mathrm{Na}^{+}$pretreatment and with no d-spacing detection on the Koffiefontein ore

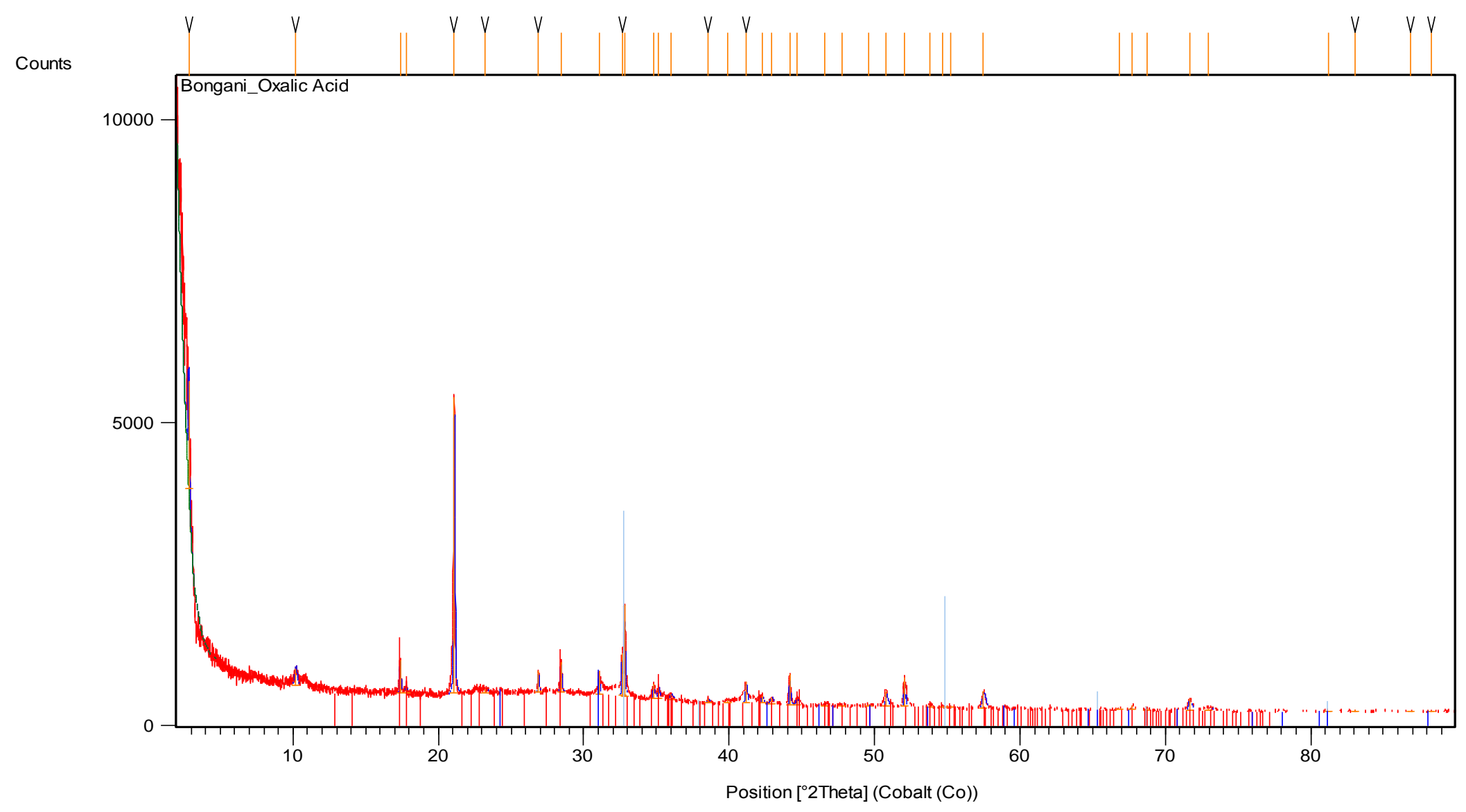


APPENDIX D: Standard weathering tests particle size distribution data for the Finsch ore

D1: Standard weathering tests

D2: Time dependence in weathering

D3: Effect of concentration

D4: Effect of temperature 


\section{D1: Standard weathering tests}

\begin{tabular}{|c|c|c|c|c|c|c|c|c|c|c|c|c|c|c|c|c|c|}
\hline & & \multicolumn{2}{|c|}{ Distilled water } & \multicolumn{2}{|c|}{$\mathrm{Cu}^{2+}$} & \multicolumn{2}{|c|}{ Ethanol } & \multicolumn{2}{|c|}{ Formamide } & \multicolumn{2}{|c|}{ n-hexane } & \multicolumn{2}{|c|}{ Oxalic acid } & \multicolumn{2}{|c|}{ Urea } & \multicolumn{2}{|c|}{ Acetic acid } \\
\hline $\begin{array}{c}\text { Screen } \\
\text { size }(\mu \mathrm{m})\end{array}$ & $\begin{array}{c}\text { Avg } \\
\text { Screen } \\
\text { size } \\
(\mu \mathrm{m})\end{array}$ & $\begin{array}{c}\text { Mass } \\
\text { on } \\
\text { screen } \\
\text { (g) }\end{array}$ & $\begin{array}{l}\text { Cum \% } \\
\text { Passing }\end{array}$ & $\begin{array}{c}\text { Mass } \\
\text { on } \\
\text { screen } \\
(\mathrm{g})\end{array}$ & $\begin{array}{l}\text { Cum \% } \\
\text { Passing }\end{array}$ & $\begin{array}{c}\text { Mass } \\
\text { on } \\
\text { screen } \\
\text { (g) }\end{array}$ & $\begin{array}{l}\text { Cum \% } \\
\text { Passing }\end{array}$ & $\begin{array}{c}\text { Mass } \\
\text { on } \\
\text { screen } \\
(\mathrm{g})\end{array}$ & $\begin{array}{c}\text { Cum \% } \\
\text { Passing }\end{array}$ & $\begin{array}{l}\text { Mass } \\
\text { on } \\
\text { screen } \\
\text { (g) }\end{array}$ & $\begin{array}{l}\text { Cum \% } \\
\text { Passing }\end{array}$ & $\begin{array}{l}\text { Mass on } \\
\text { screen } \\
\text { (g) }\end{array}$ & $\begin{array}{l}\text { Cum \% } \\
\text { Passing }\end{array}$ & $\begin{array}{c}\text { Mass } \\
\text { on } \\
\text { screen } \\
\text { (g) }\end{array}$ & $\begin{array}{c}\text { Cum \% } \\
\text { Passing }\end{array}$ & $\begin{array}{c}\text { Mass } \\
\text { on } \\
\text { screen } \\
\text { (g) }\end{array}$ & $\begin{array}{l}\text { Cum \% } \\
\text { Passing }\end{array}$ \\
\hline 18668 & 18668 & & 100.00 & & 100.00 & & 100.00 & & 100.00 & & 100.00 & & 100.00 & & 100.00 & & 100.00 \\
\hline 13200 & 15934 & 186.60 & 37.92 & 80.10 & 73.33 & 114.20 & 62.05 & 137.70 & 54.13 & 164.20 & 45.41 & 108.60 & 63.90 & 117.80 & 60.86 & 124.70 & 58.54 \\
\hline 9500 & 11350 & 32.00 & 27.27 & 21.70 & 66.10 & 50.20 & 45.36 & 58.20 & 34.74 & 32.40 & 34.64 & 53.30 & 46.18 & 66.70 & 38.70 & 45.70 & 43.34 \\
\hline 6700 & 8100 & 10.50 & 23.78 & 15.90 & 60.81 & 29.60 & 35.52 & 16.70 & 29.18 & 14.90 & 29.69 & 21.80 & 38.93 & 11.60 & 34.85 & 12.60 & 39.15 \\
\hline 4750 & 5725 & 9.60 & 20.59 & 8.30 & 58.04 & 14.70 & 30.64 & 12.70 & 24.95 & 14.30 & 24.93 & 9.50 & 35.78 & 11.70 & 30.96 & 9.20 & 36.09 \\
\hline 3350 & 4050 & 7.10 & 18.22 & 10.80 & 54.45 & 10.80 & 27.05 & 14.00 & 20.29 & 10.90 & 21.31 & 9.00 & 32.78 & 12.50 & 26.81 & 9.50 & 32.93 \\
\hline 2360 & 2855 & 7.90 & 15.60 & 6.80 & 52.18 & 9.10 & 24.03 & 9.50 & 17.12 & 6.70 & 19.08 & 4.20 & 31.39 & 9.40 & 23.68 & 7.90 & 30.31 \\
\hline 1700 & 2030 & 6.40 & 13.47 & 7.00 & 49.85 & 7.90 & 21.40 & 7.40 & 14.66 & 5.80 & 17.15 & 3.10 & 30.36 & 8.50 & 20.86 & 6.90 & 28.01 \\
\hline 1180 & 1440 & 5.70 & 11.57 & 9.30 & 46.76 & 7.70 & 18.84 & 7.70 & 12.09 & 6.10 & 15.13 & 4.70 & 28.79 & 8.10 & 18.17 & 7.80 & 25.42 \\
\hline 850 & 1015 & 3.80 & 10.31 & 7.80 & 44.16 & 6.70 & 16.61 & 4.40 & 10.63 & 4.90 & 13.50 & 2.80 & 27.86 & 6.10 & 16.14 & 5.20 & 23.69 \\
\hline 600 & 725 & 2.80 & 9.38 & 7.00 & 41.83 & 4.80 & 15.02 & 3.50 & 9.46 & 3.90 & 12.20 & 2.80 & 26.93 & 4.80 & 14.55 & 4.40 & 22.23 \\
\hline 425 & 513 & 2.90 & 8.41 & 7.50 & 39.33 & 5.10 & 13.32 & 3.40 & 8.33 & 4.10 & 10.84 & 3.40 & 25.80 & 4.20 & 13.15 & 4.10 & 20.86 \\
\hline 300 & 363 & 3.40 & 7.28 & 12.30 & 35.23 & 5.70 & 11.43 & 3.40 & 7.20 & 4.60 & 9.31 & 5.30 & 24.04 & 5.30 & 11.39 & 4.70 & 19.30 \\
\hline 212 & 256 & 3.20 & 6.21 & 10.90 & 31.60 & 6.00 & 9.44 & 3.90 & 5.90 & 5.10 & 7.61 & 4.70 & 22.48 & 4.90 & 9.76 & 4.90 & 17.67 \\
\hline 150 & 181 & 4.90 & 4.58 & 16.70 & 26.04 & 9.20 & 6.38 & 4.80 & 4.30 & 6.50 & 5.45 & 8.80 & 19.55 & 7.70 & 7.20 & 11.10 & 13.98 \\
\hline 106 & 128 & 2.30 & 3.82 & 10.80 & 22.45 & 3.90 & 5.08 & 1.90 & 3.66 & 2.90 & 4.49 & 6.10 & 17.53 & 3.50 & 6.04 & 4.30 & 12.55 \\
\hline 75 & 91 & 1.70 & 3.25 & 9.00 & 19.45 & 2.70 & 4.18 & 1.80 & 3.06 & 2.40 & 3.69 & 5.10 & 15.83 & 3.30 & 4.94 & 3.80 & 11.29 \\
\hline 53 & 64 & 1.50 & 2.75 & 6.50 & 17.29 & 1.80 & 3.59 & 0.90 & 2.76 & 1.40 & 3.22 & 4.30 & 14.40 & 1.90 & 4.31 & 2.30 & 10.52 \\
\hline 38 & 46 & 0.90 & 2.46 & 6.20 & 15.22 & 1.40 & 3.12 & 0.90 & 2.47 & 1.10 & 2.86 & 3.70 & 13.17 & 1.50 & 3.81 & 1.90 & 9.89 \\
\hline-38 & 38 & 7.38 & 0.00 & 45.71 & 0.00 & 9.39 & 0.00 & 7.40 & 0.00 & 8.60 & 0.00 & 39.62 & 0.00 & 11.48 & 0.00 & 29.75 & 0.00 \\
\hline & & 300.58 & & 300.31 & & 300.89 & & 300.20 & & 300.80 & & 300.82 & & 300.98 & & 300.75 & \\
\hline
\end{tabular}




\section{D2: Time dependence in weathering}

\begin{tabular}{|c|c|c|c|c|c|c|c|c|c|}
\hline & & \multicolumn{2}{|c|}{ 2 Days } & \multicolumn{2}{c|}{ 6 Days } & \multicolumn{2}{c|}{ 15 Days } & \multicolumn{2}{c|}{ 30 Days } \\
\cline { 2 - 10 } Screen size $(\boldsymbol{\mu m})$ & $\begin{array}{c}\text { Avg } \\
\text { Screen } \\
\text { size } \\
(\boldsymbol{\mu m})\end{array}$ & $\begin{array}{c}\text { Mass } \\
\text { on } \\
\text { screen } \\
(\mathbf{g})\end{array}$ & $\begin{array}{c}\text { Cum \% } \\
\text { Passing }\end{array}$ & $\begin{array}{c}\text { Mass } \\
\text { on } \\
\text { screen } \\
(\mathbf{g})\end{array}$ & $\begin{array}{c}\text { Cum \% } \\
\text { Passing }\end{array}$ & $\begin{array}{c}\text { Mass } \\
\text { on } \\
\text { screen } \\
(\mathbf{g})\end{array}$ & $\begin{array}{c}\text { Cum \% } \\
\text { Passing }\end{array}$ & $\begin{array}{c}\text { Mass } \\
\text { on } \\
\text { screen } \\
(\mathbf{g})\end{array}$ & $\begin{array}{c}\text { Cum \% } \\
\text { Passing }\end{array}$ \\
\hline 18668 & 18668 & & 100.00 & & 100.00 & & 100.00 & & 100.00 \\
\hline 13200 & 15934 & 109.00 & 63.75 & 108.60 & 63.90 & 106.29 & 64.67 & 99.13 & 67.05 \\
\hline 9500 & 11350 & 67.70 & 41.24 & 53.31 & 46.18 & 44.47 & 49.88 & 47.61 & 51.22 \\
\hline 6700 & 8100 & 11.60 & 37.38 & 21.81 & 38.93 & 18.17 & 43.84 & 19.88 & 44.61 \\
\hline 4750 & 5725 & 8.30 & 34.62 & 9.48 & 35.78 & 12.82 & 39.58 & 10.32 & 41.18 \\
\hline 3350 & 4050 & 8.80 & 31.69 & 9.02 & 32.78 & 10.41 & 36.12 & 9.38 & 38.06 \\
\hline 2360 & 2855 & 6.50 & 29.53 & 4.18 & 31.39 & 5.48 & 34.30 & 5.20 & 36.33 \\
\hline 1700 & 2030 & 4.80 & 27.94 & 3.10 & 30.36 & 5.60 & 32.44 & 4.90 & 34.70 \\
\hline 1180 & 1440 & 4.20 & 26.54 & 4.72 & 28.79 & 4.72 & 30.87 & 9.11 & 31.67 \\
\hline 850 & 1015 & 2.92 & 25.57 & 2.80 & 27.86 & 5.60 & 29.01 & 4.48 & 30.18 \\
\hline 600 & 725 & 2.67 & 24.68 & 4.39 & 26.40 & 4.57 & 27.49 & 4.42 & 28.71 \\
\hline 425 & 513 & 3.68 & 23.46 & 4.81 & 24.80 & 4.78 & 25.90 & 4.78 & 27.12 \\
\hline 300 & 363 & 6.23 & 21.39 & 8.27 & 22.05 & 7.10 & 23.54 & 6.65 & 24.92 \\
\hline 212 & 256 & 6.74 & 19.14 & 6.14 & 20.01 & 7.01 & 21.21 & 6.98 & 22.60 \\
\hline 150 & 181 & 8.76 & 16.23 & 8.30 & 17.25 & 8.40 & 18.41 & 9.17 & 19.55 \\
\hline 106 & 128 & 5.42 & 14.43 & 6.62 & 15.05 & 5.90 & 16.45 & 6.08 & 17.53 \\
\hline 75 & 91 & 5.13 & 12.72 & 4.99 & 13.39 & 5.63 & 14.58 & 5.11 & 15.83 \\
\hline 53 & 64 & 3.06 & 11.71 & 3.49 & 12.23 & 2.59 & 13.72 & 4.30 & 14.40 \\
\hline 38 & 46 & 2.24 & 10.96 & 2.59 & 11.37 & 3.91 & 12.42 & 3.70 & 13.17 \\
\hline-38 & 38 & 32.96 & 0.00 & 34.20 & 0.00 & 37.37 & 0.00 & 39.61 & 0.00 \\
\hline & & $\mathbf{3 0 0 . 7 1}$ & & $\mathbf{3 0 0 . 8 2}$ & & $\mathbf{3 0 0 . 8 2}$ & & $\mathbf{3 0 0 . 8 2}$ & \\
\hline & & & & & & & \\
\hline
\end{tabular}




\section{D3: Effect of concentration}

\begin{tabular}{|c|c|c|c|c|c|c|c|}
\hline & & \multicolumn{2}{|c|}{$\mathbf{0 . 0 2 5} \mathbf{M}$} & \multicolumn{2}{c|}{$\mathbf{0 . 1} \mathbf{M}$} & \multicolumn{2}{c|}{$\mathbf{0 . 5} \mathbf{M}$} \\
\cline { 2 - 8 } Screen size $(\boldsymbol{\mu m})$ & $\begin{array}{c}\text { Avg } \\
\text { Screen } \\
\text { size } \\
(\boldsymbol{\mu m})\end{array}$ & $\begin{array}{c}\text { Mass } \\
\text { on } \\
\text { screen } \\
(\mathbf{g})\end{array}$ & $\begin{array}{c}\text { Cum \% } \\
\text { Passing }\end{array}$ & $\begin{array}{c}\text { Mass } \\
\text { on } \\
\text { screen } \\
(\mathbf{g})\end{array}$ & $\begin{array}{c}\text { Cum \% } \\
\text { Passing }\end{array}$ & $\begin{array}{c}\text { Mass } \\
\text { on } \\
\text { screen } \\
(\mathbf{g})\end{array}$ & $\begin{array}{c}\text { Cum \% } \\
\text { Passing }\end{array}$ \\
\hline 18668 & 18668 & & 100.00 & & 100.00 & & 100.00 \\
\hline 13200 & 15934 & 157.10 & 47.68 & 154.00 & 48.68 & 108.60 & 63.90 \\
\hline 9500 & 11350 & 62.42 & 26.89 & 63.00 & 27.69 & 53.30 & 46.18 \\
\hline 6700 & 8100 & 20.66 & 20.01 & 16.20 & 22.29 & 21.80 & 38.93 \\
\hline 4750 & 5725 & 11.56 & 16.16 & 10.70 & 18.72 & 9.50 & 35.78 \\
\hline 3350 & 4050 & 5.92 & 14.19 & 7.70 & 16.16 & 9.00 & 32.78 \\
\hline 2360 & 2855 & 3.90 & 12.89 & 5.90 & 14.19 & 4.20 & 31.39 \\
\hline 1700 & 2030 & 5.64 & 11.01 & 4.60 & 12.66 & 3.10 & 30.36 \\
\hline 1180 & 1440 & 5.49 & 9.18 & 5.10 & 10.96 & 4.70 & 28.79 \\
\hline 850 & 1015 & 2.19 & 8.45 & 2.50 & 10.13 & 2.80 & 27.86 \\
\hline 600 & 725 & 1.80 & 7.85 & 2.10 & 9.43 & 2.80 & 26.93 \\
\hline 425 & 513 & 1.71 & 7.28 & 2.30 & 8.66 & 3.40 & 25.80 \\
\hline 300 & 363 & 1.80 & 6.68 & 2.50 & 7.83 & 5.30 & 24.04 \\
\hline 212 & 256 & 2.01 & 6.01 & 2.60 & 6.96 & 4.70 & 22.48 \\
\hline 150 & 181 & 3.48 & 4.85 & 4.20 & 5.56 & 8.80 & 19.55 \\
\hline 106 & 128 & 2.31 & 4.08 & 2.20 & 4.83 & 6.10 & 17.53 \\
\hline 75 & 91 & 1.98 & 3.42 & 2.20 & 4.10 & 5.10 & 15.83 \\
\hline 53 & 64 & 1.41 & 2.95 & 1.70 & 3.53 & 4.30 & 14.40 \\
\hline 38 & 46 & 1.00 & 2.62 & 1.20 & 3.13 & 3.70 & 13.17 \\
\hline-38 & 38 & 7.86 & 0.00 & 9.39 & 0.00 & 39.62 & 0.00 \\
\hline & & 300.26 & & 300.09 & & 300.82 & \\
\hline & & & & & & & \\
\hline
\end{tabular}




\section{D4: Effect of temperature}

\begin{tabular}{|c|c|c|c|c|c|}
\hline \multirow[b]{2}{*}{ Screen size $(\mu \mathrm{m})$} & \multirow[b]{2}{*}{$\begin{array}{c}\text { Avg Screen } \\
\text { size }(\mu \mathrm{m})\end{array}$} & \multicolumn{2}{|c|}{$25^{\circ} \mathrm{C}$} & \multicolumn{2}{|c|}{$40^{\circ} \mathrm{C}$} \\
\hline & & $\begin{array}{l}\text { Mass on } \\
\text { screen (g) }\end{array}$ & $\begin{array}{l}\text { Cum \% } \\
\text { Passing }\end{array}$ & $\begin{array}{l}\text { Mass on } \\
\text { screen (g) }\end{array}$ & $\begin{array}{c}\text { Cum \% } \\
\text { Passing }\end{array}$ \\
\hline 18668 & 18668 & & 100.00 & & 100.00 \\
\hline 13200 & 15934 & 108.60 & 63.90 & 124.4 & 58.59 \\
\hline 9500 & 11350 & 53.30 & 46.18 & 41.6 & 44.74 \\
\hline 6700 & 8100 & 21.80 & 38.93 & 16.5 & 39.25 \\
\hline 4750 & 5725 & 9.50 & 35.78 & 14.3 & 34.49 \\
\hline 3350 & 4050 & 9.00 & 32.78 & 11.9 & 30.53 \\
\hline 2360 & 2855 & 4.20 & 31.39 & 8.8 & 27.60 \\
\hline 1700 & 2030 & 3.10 & 30.36 & 6.6 & 25.40 \\
\hline 1180 & 1440 & 4.70 & 28.79 & 11.0 & 21.74 \\
\hline 850 & 1015 & 2.80 & 27.86 & 4.2 & 20.34 \\
\hline 600 & 725 & 2.80 & 26.93 & 3.6 & 19.15 \\
\hline 425 & 513 & 3.40 & 25.80 & 3.9 & 17.85 \\
\hline 300 & 363 & 5.30 & 24.04 & 5.3 & 16.08 \\
\hline 212 & 256 & 4.70 & 22.48 & 4.4 & 14.62 \\
\hline 150 & 181 & 8.80 & 19.55 & 8.2 & 11.89 \\
\hline 106 & 128 & 6.10 & 17.53 & 3.8 & 10.63 \\
\hline 75 & 91 & 5.10 & 15.83 & 3.9 & 9.33 \\
\hline 53 & 64 & 4.30 & 14.40 & 2.8 & 8.39 \\
\hline 38 & 46 & 3.70 & 13.17 & 1.7 & 7.83 \\
\hline-38 & 38 & 39.62 & 0.00 & 23.52 & 0.00 \\
\hline & & 300.82 & & 300.42 & \\
\hline
\end{tabular}


APPENDIX E: XRD analysis results of agitation tests for precation treatment prior to oxalic acid treatment for the Venetia K1 ore

E1: $\mathrm{Cs}^{+}$pretreatment

E2: $\quad \mathrm{NH}_{4}{ }^{+}$pretreatment

E3: $\mathrm{Na}^{+}$pretreatment

E4: $\mathrm{Ca}^{2+}$ pretreatment

E5: $\mathrm{Mg}^{2+}$ pretreatment 


\section{E1: $\mathrm{Cs}^{+}$pretreatment}

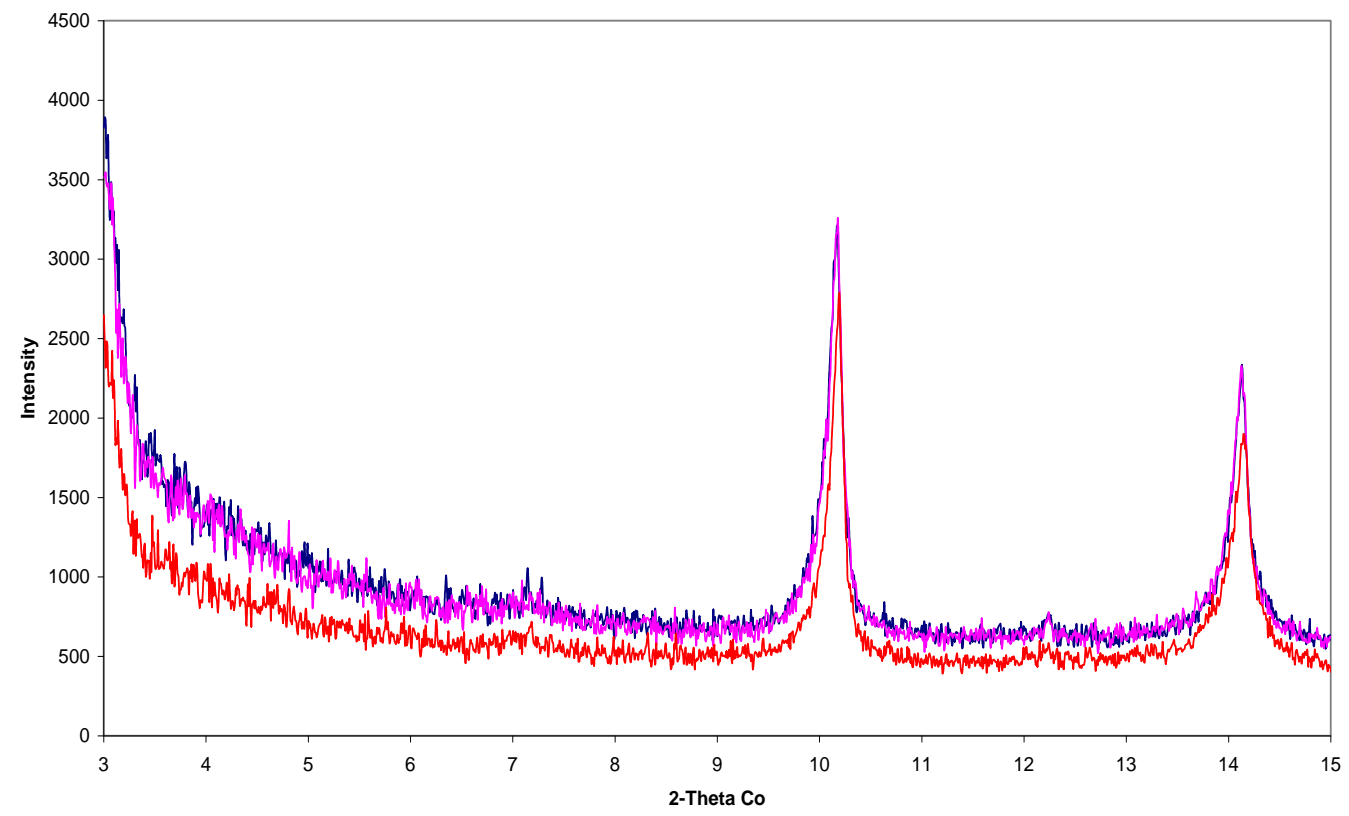

— No Glycol — Glycol — No Oxalic Treatment

\section{E2: $\mathrm{NH}_{4}{ }^{+}$pretreatment}

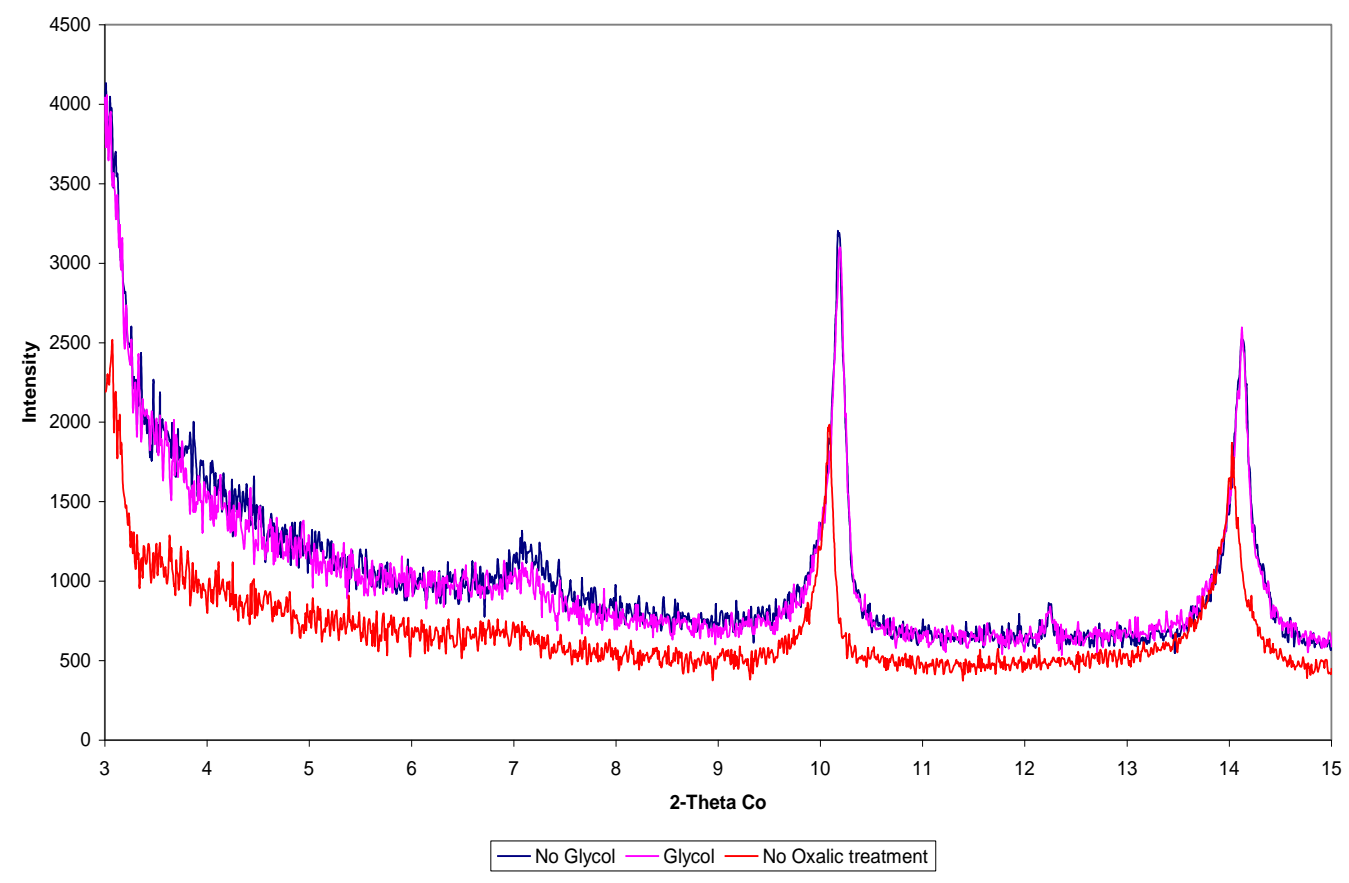

(C) University of Pretoria 


\section{E3: $\mathrm{Na}^{+}$pretreatment}

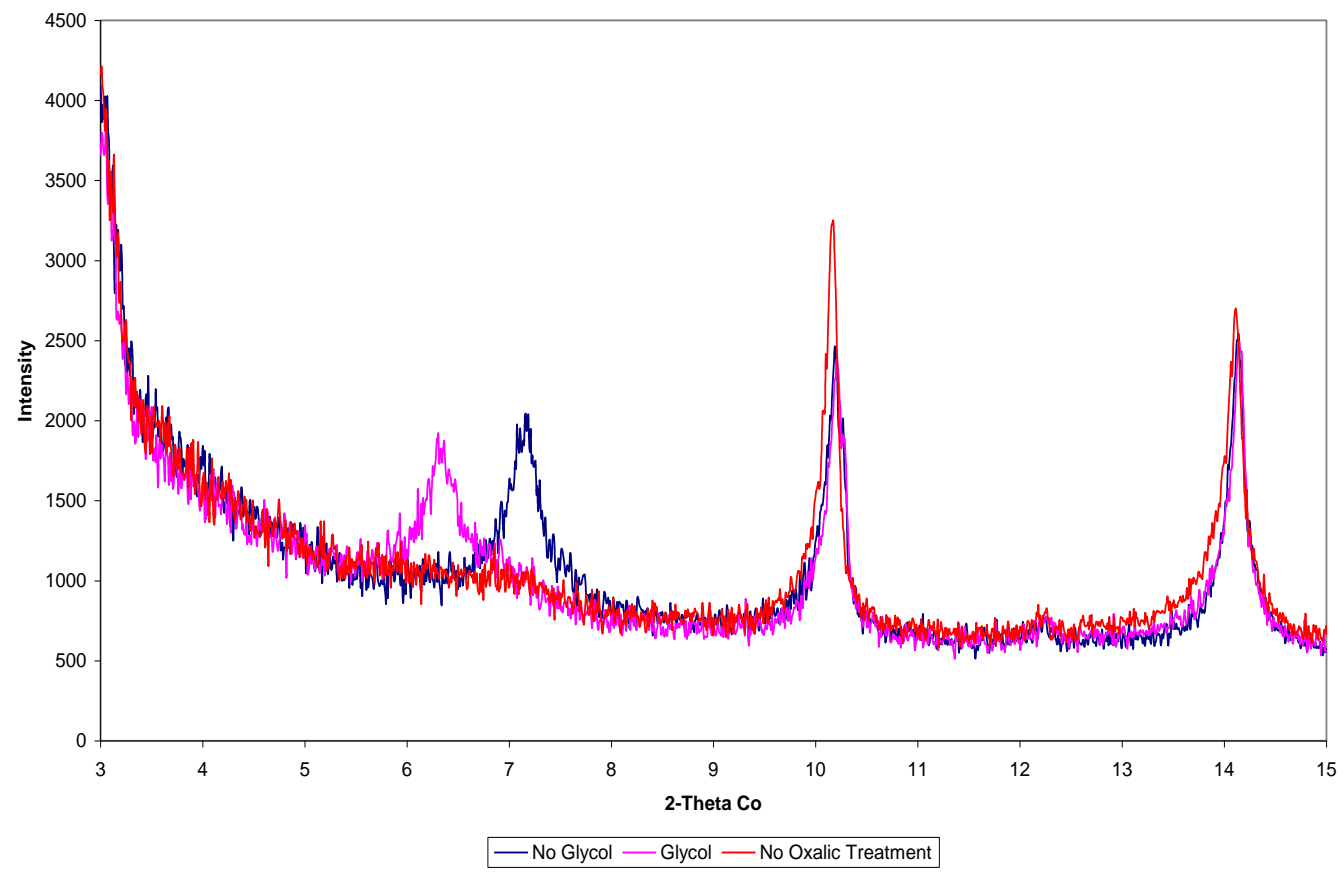

\section{E4: $\mathrm{Ca}^{2+}$ pretreatment}

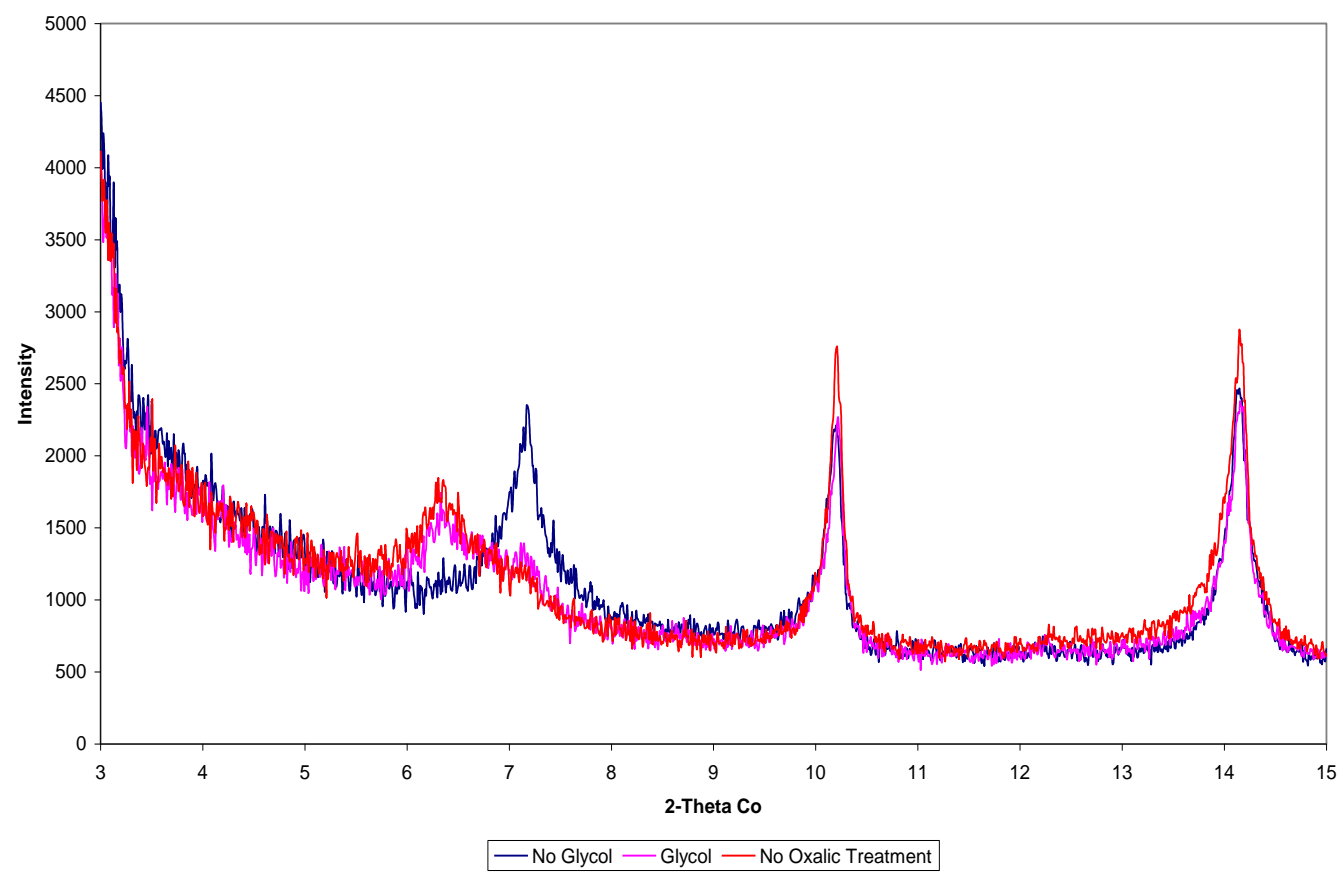

(C) University of Pretoria 


\section{E5: $\mathrm{Mg}^{2+}$ pretreatment}

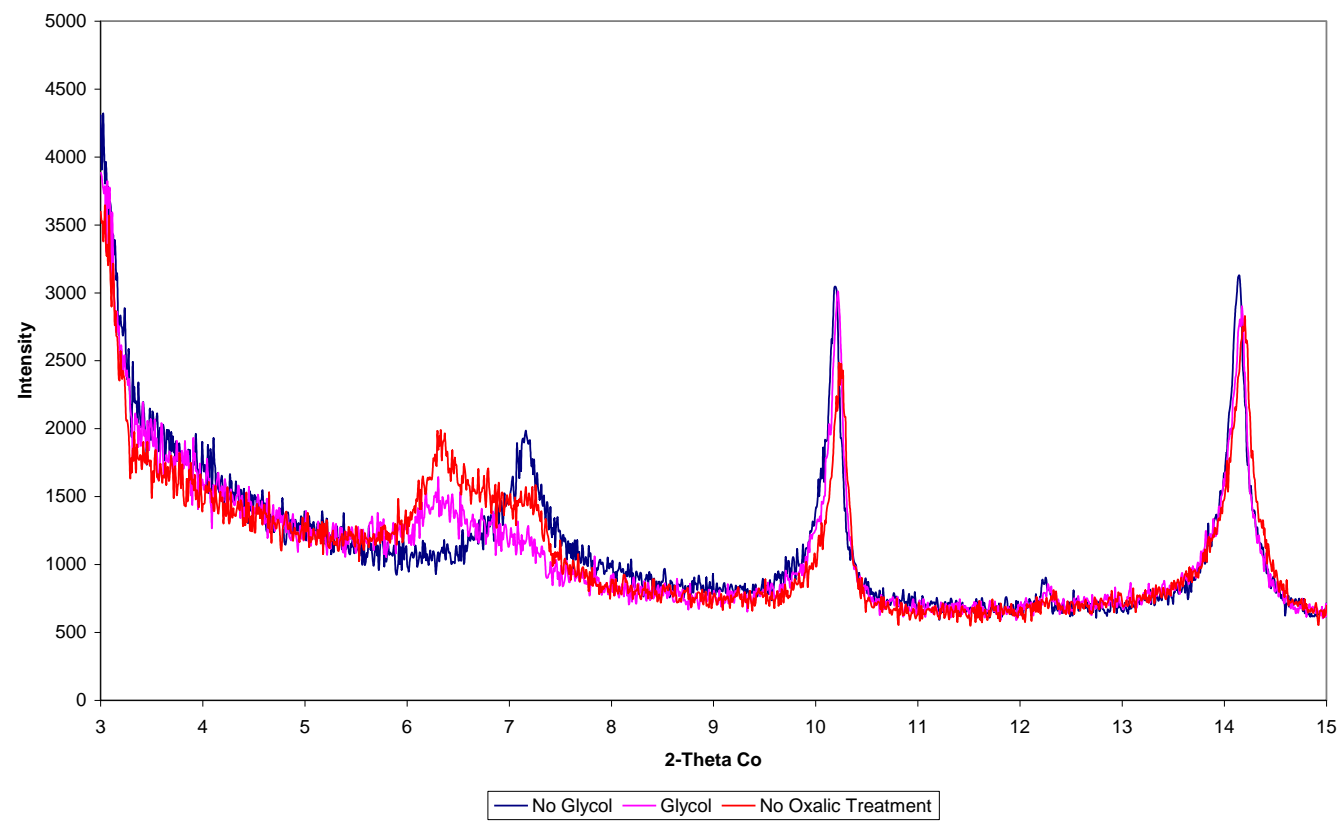




\section{APPENDIX F: XRD analysis results of alteration tests for the VUE ore}

F1: $\mathrm{Mg}^{2+}$ treatment

F2: $\mathrm{Mg}^{2+}-\mathrm{HCl}$ treatment

F3: $\mathrm{NaClO}-\mathrm{Mg}^{2+}-\mathrm{HCl}$ treatment

Please note that the red scans represent the sample before Ethylene Glycol (EG) treatment and the blue represents after EG treatment. 


\section{F1: $\mathrm{Mg}^{2+}$ treatment}

\section{F1: Drillcore ID: 200}

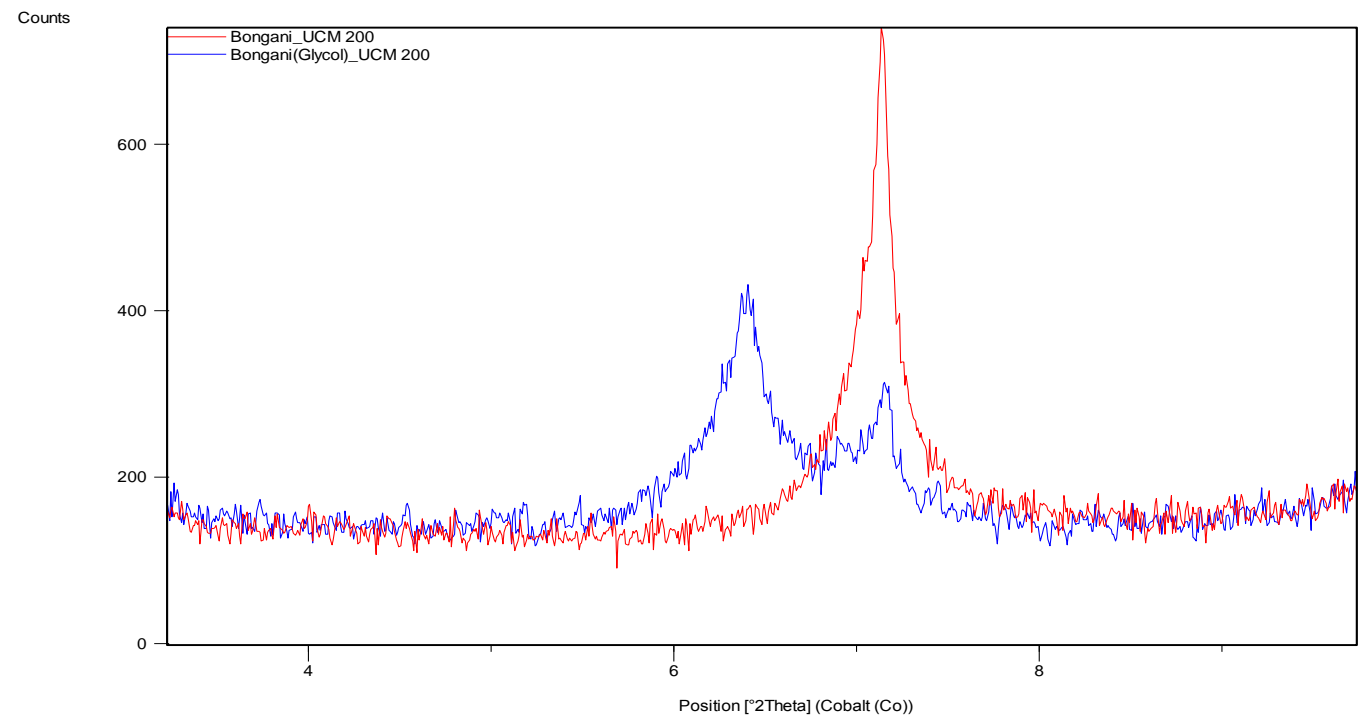

\section{F1: Drillcore ID: 14}

Counts

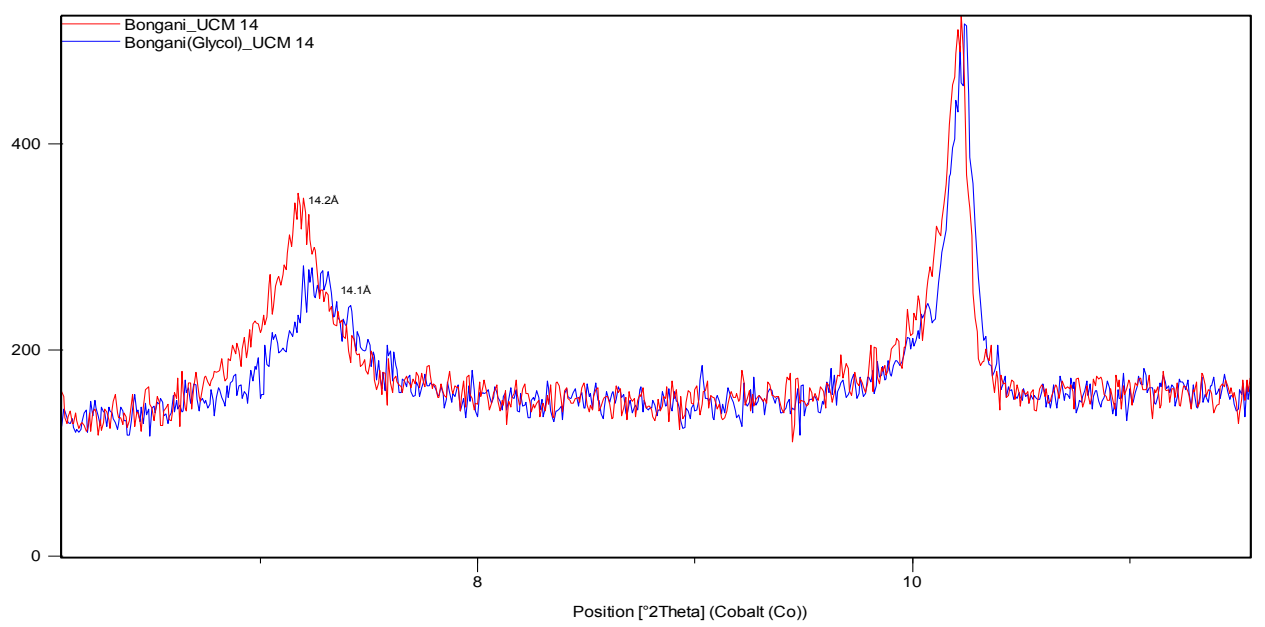




\section{F1: Drillcore ID: 3}

Counts

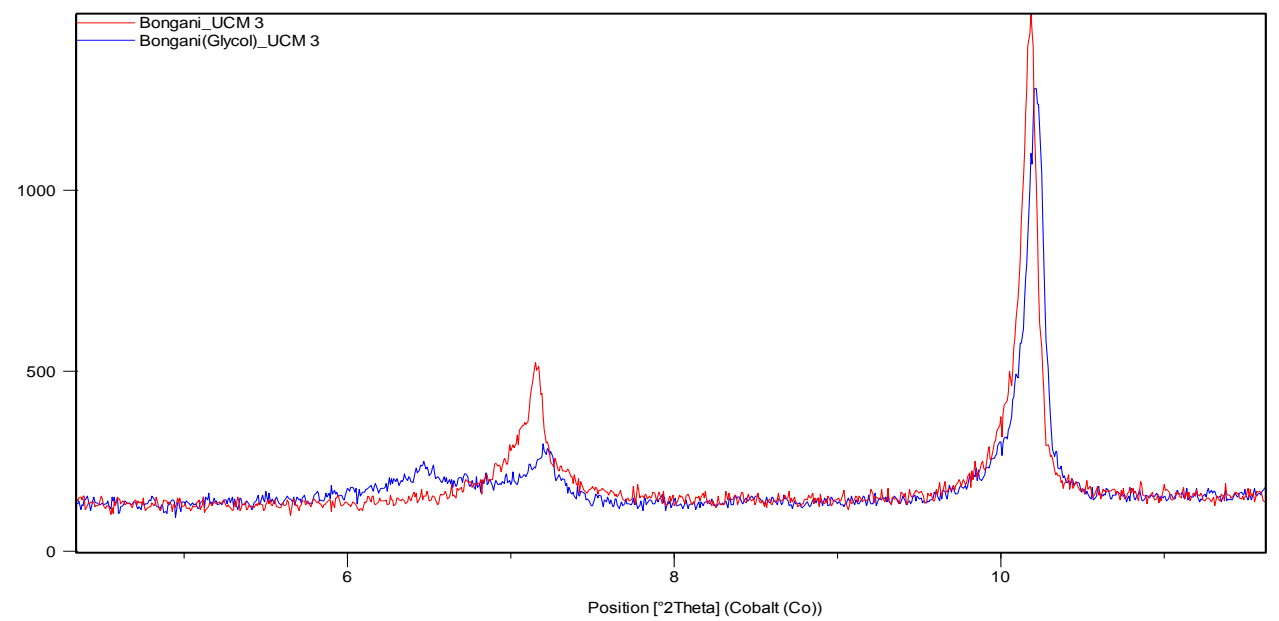

F1: Drillcore ID: 30

Counts

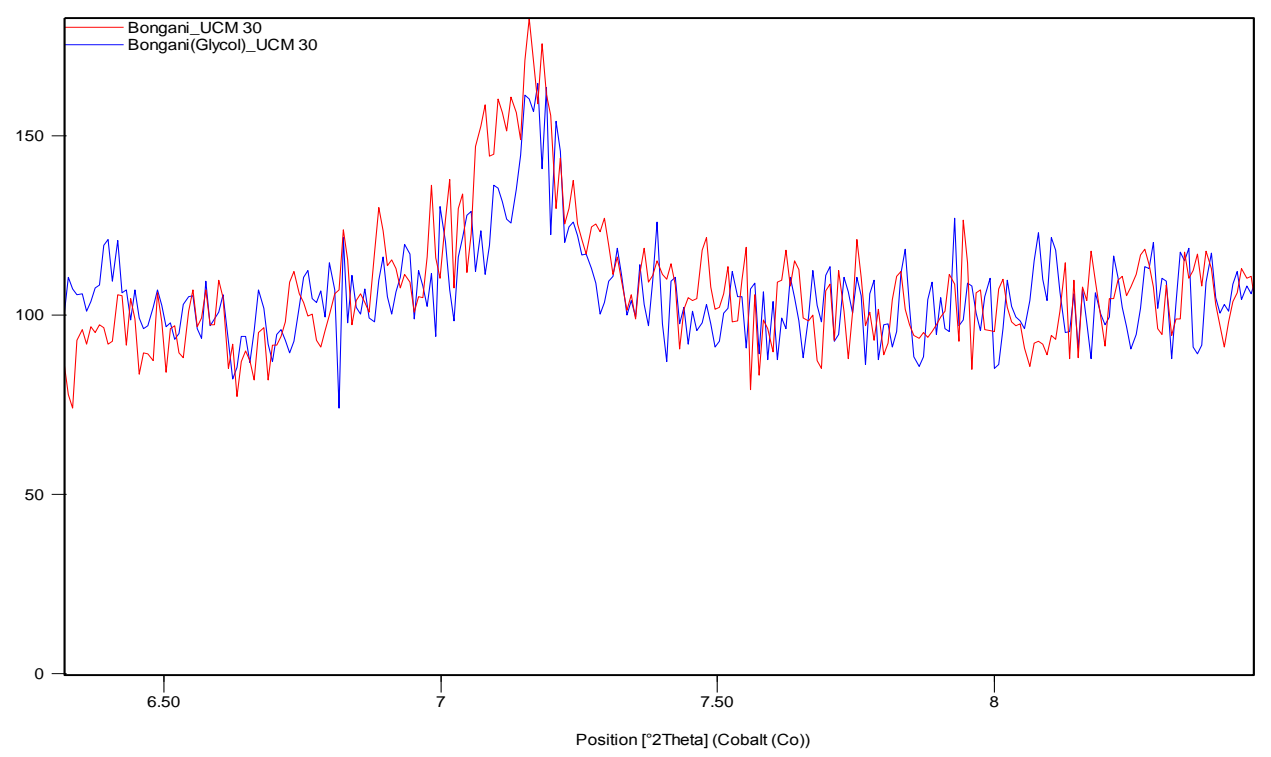




\section{F1: Drillcore ID: 153}

Counts

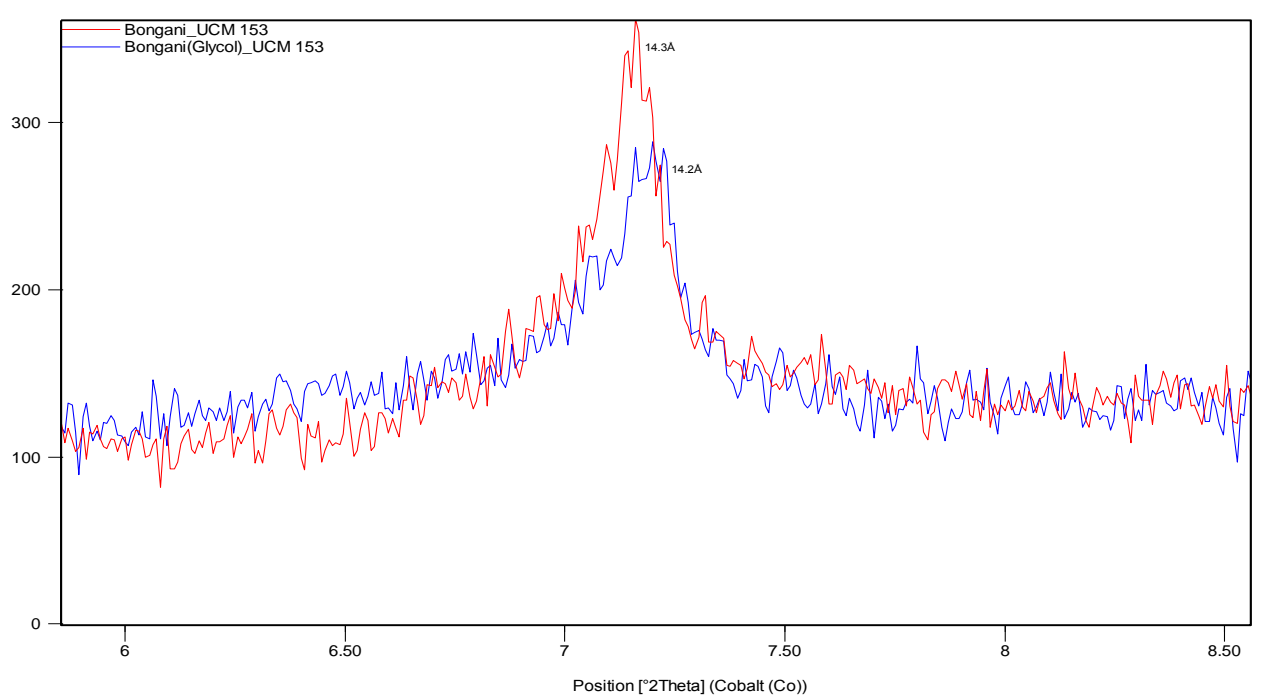

\section{F1: Drillcore ID: 168}

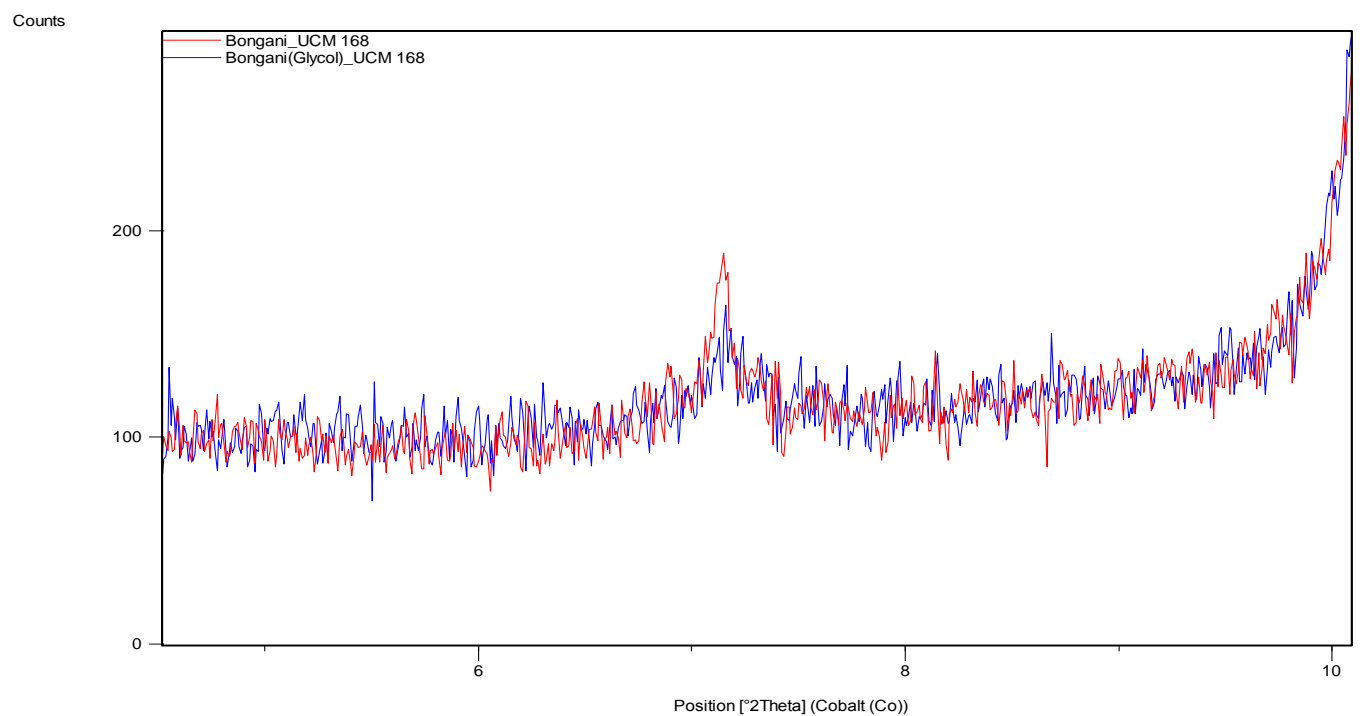




\section{F1: Drillcore ID: 107}

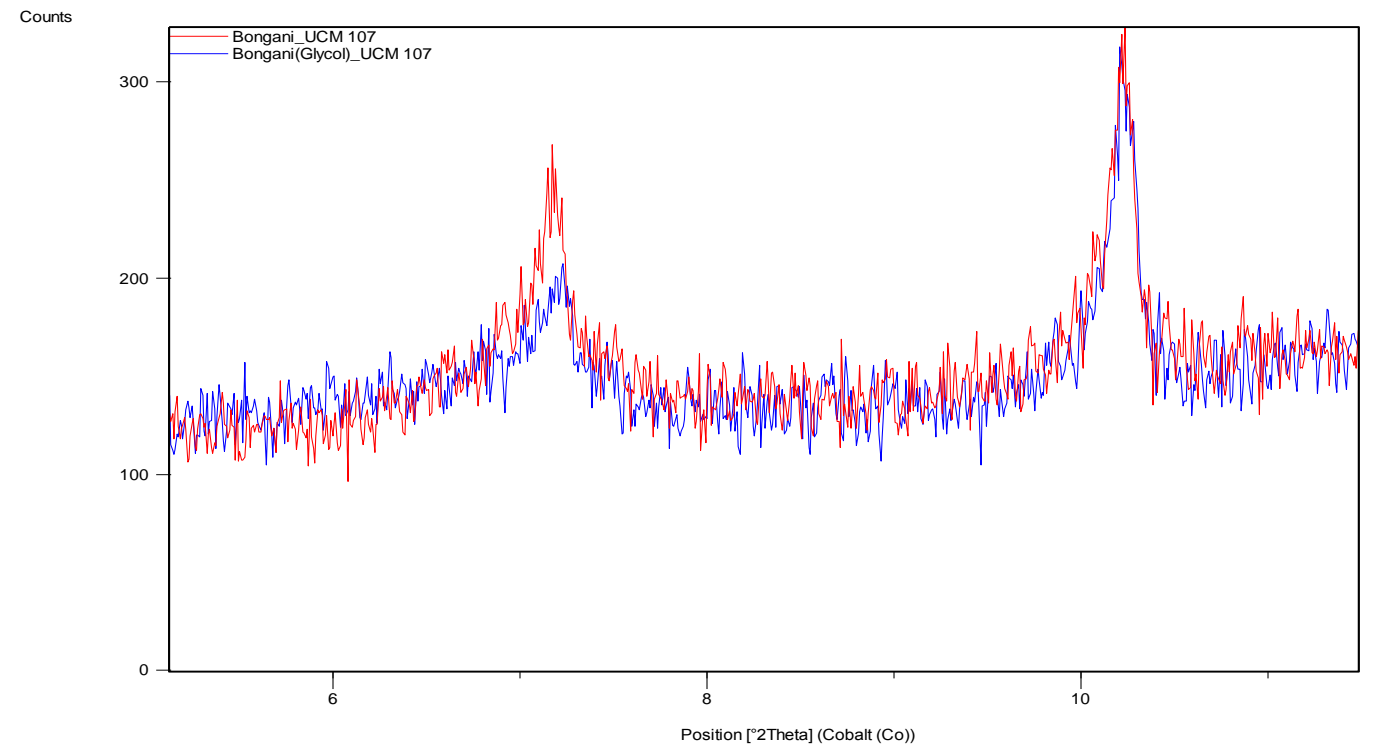

\section{F1: Drillcore ID: 147}

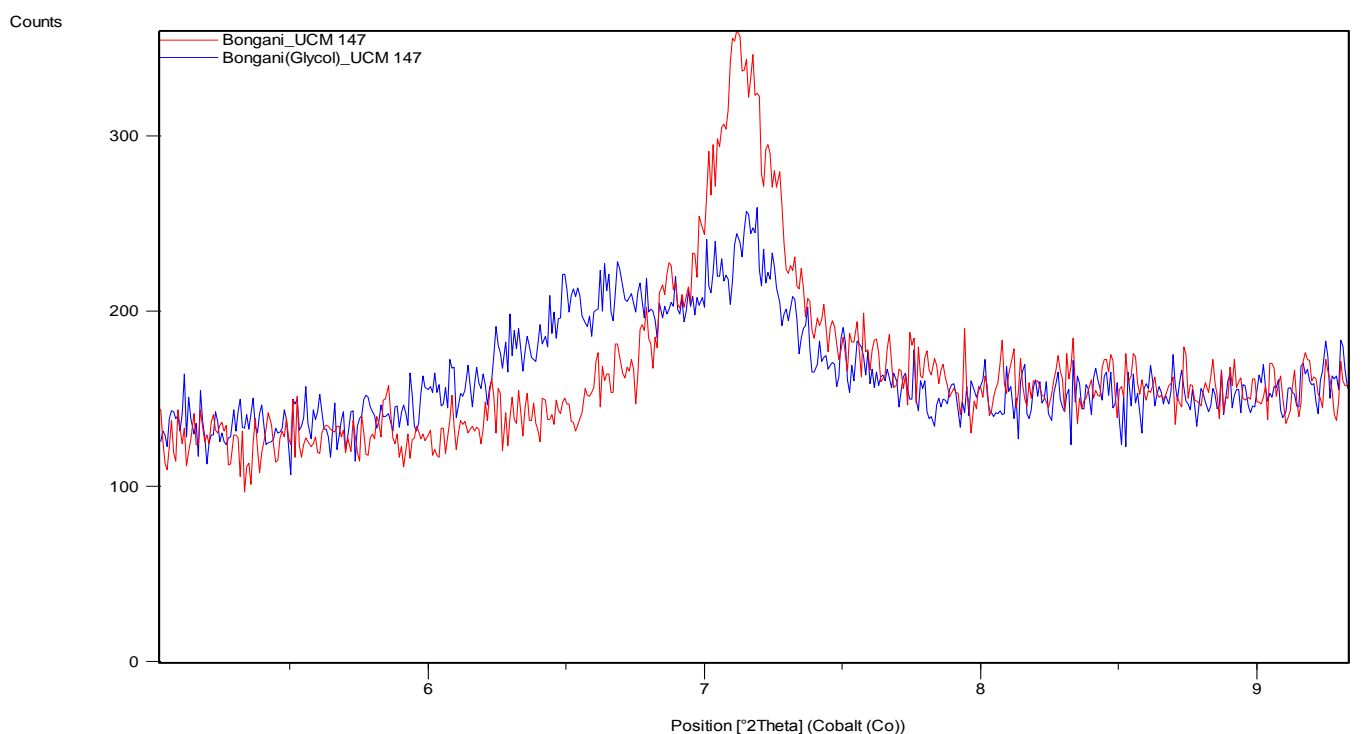


F1: Drillcore ID: 106

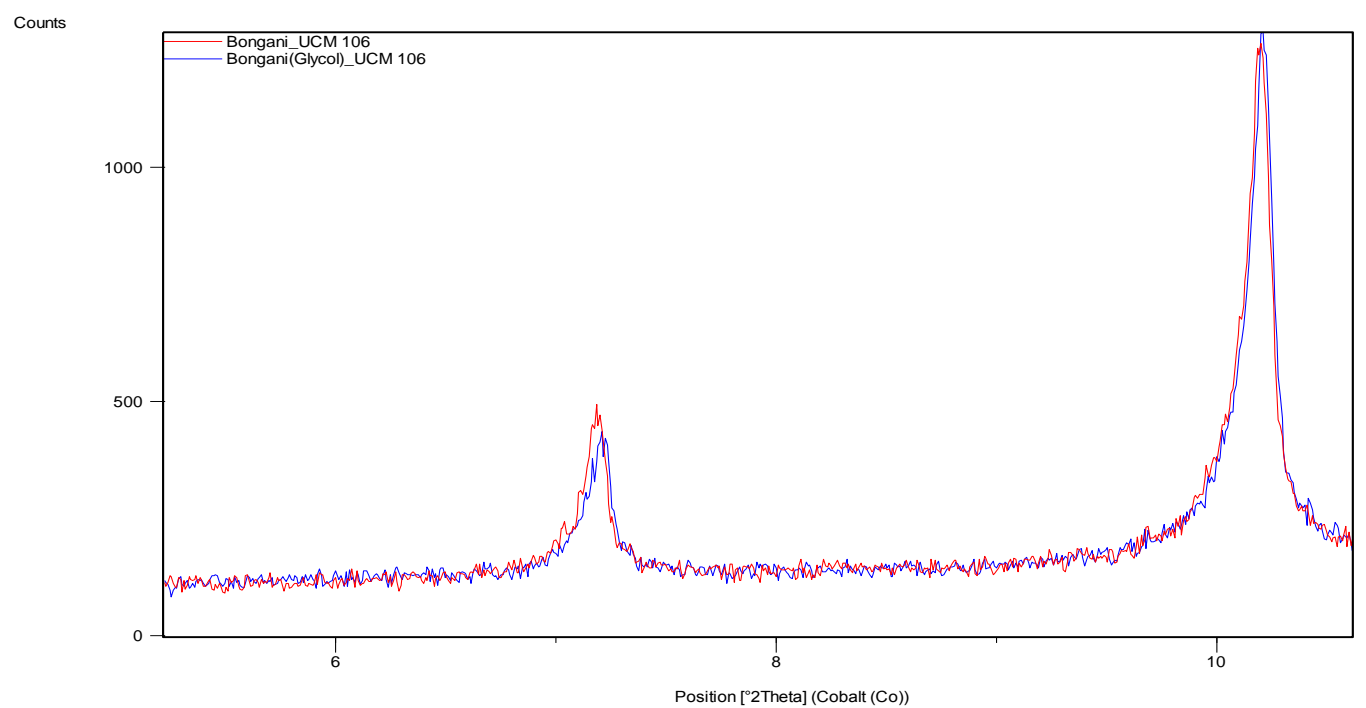




\section{F2: $\quad \mathrm{Mg}^{2+}-\mathrm{HCl}$ pretreatment}

\section{F2: Drillcore ID: 200}

Counts

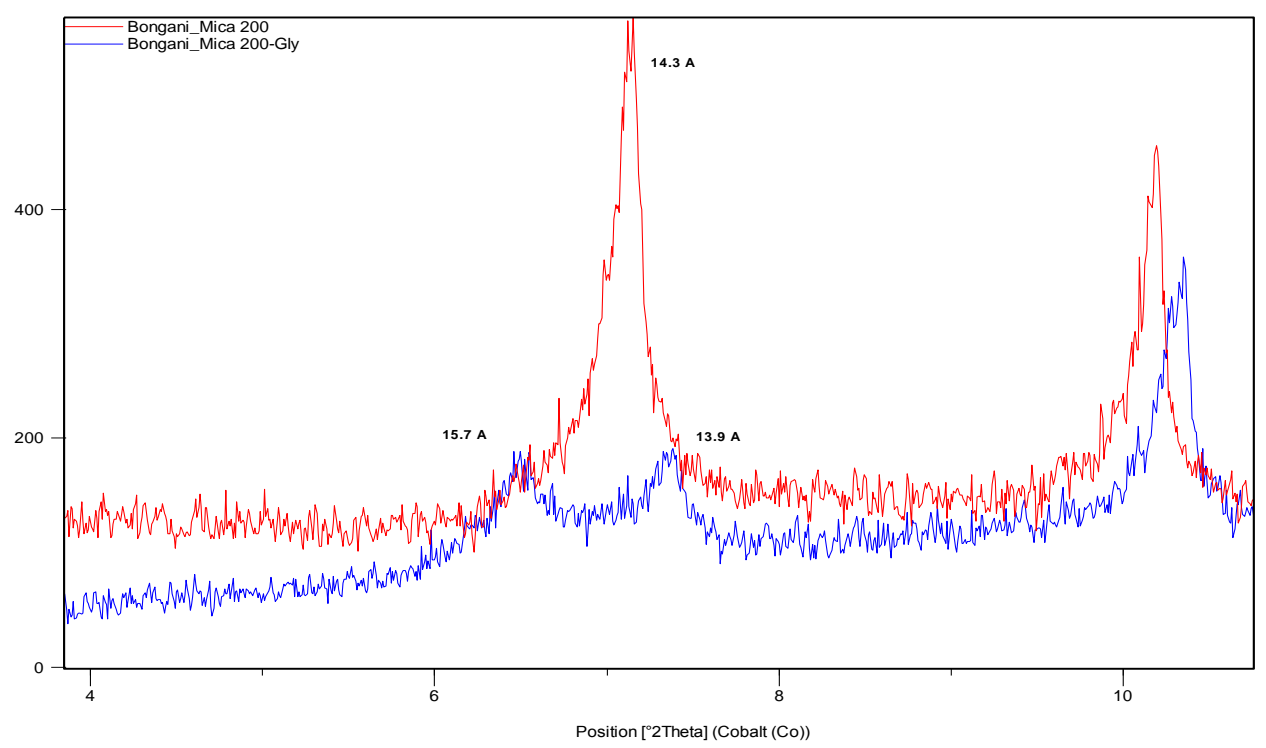

\section{F2: Drillcore ID: 14}

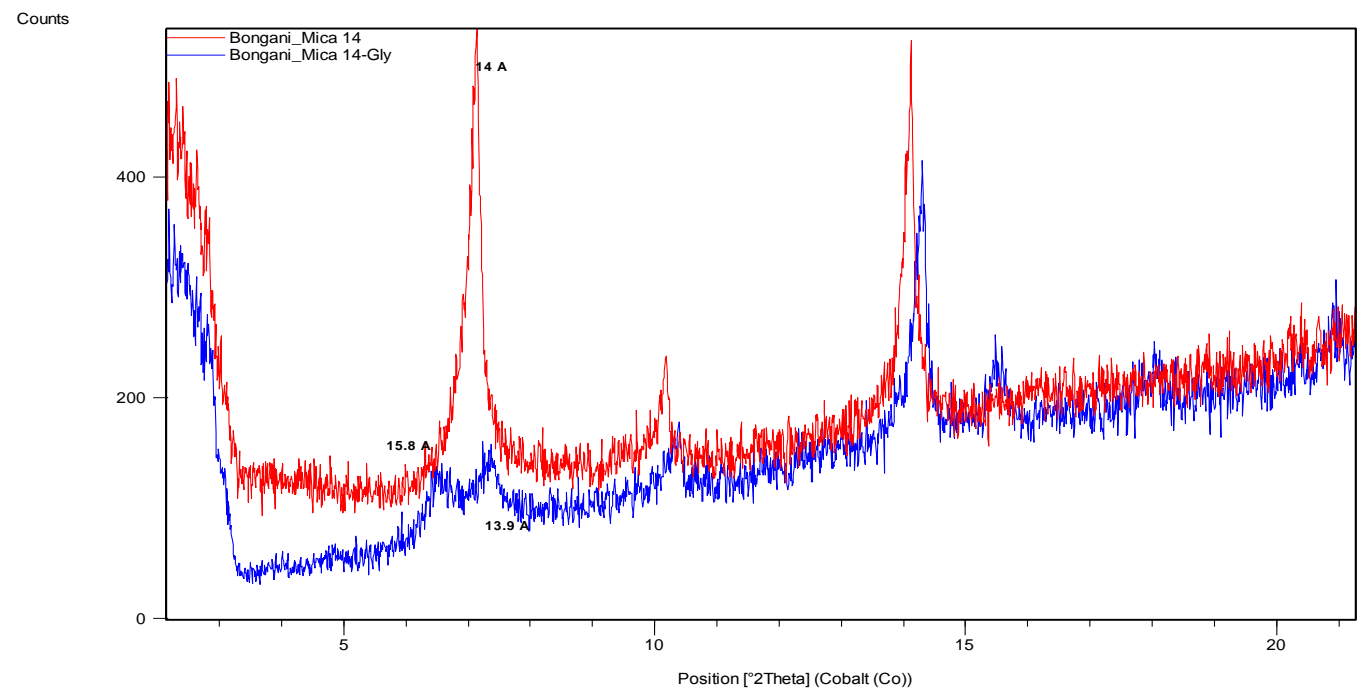




\section{F2: Drillcore ID: 3}

Counts

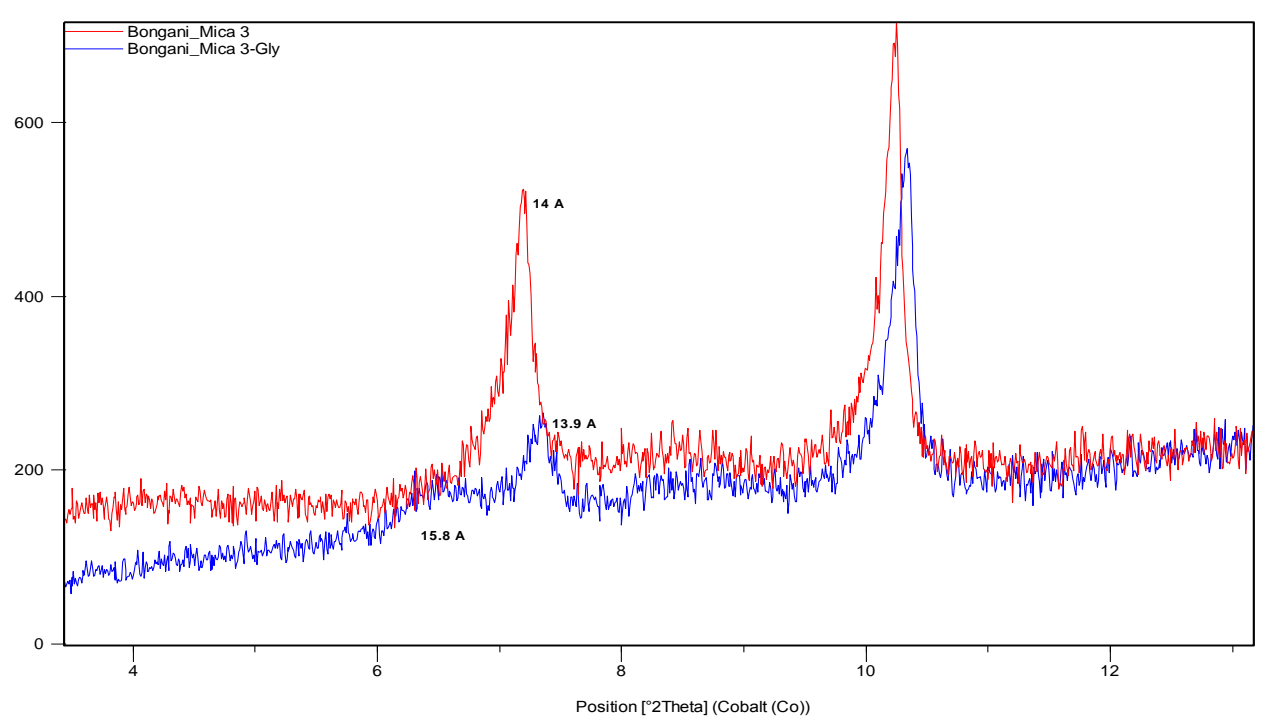

F2: Drillcore ID: 30

Counts

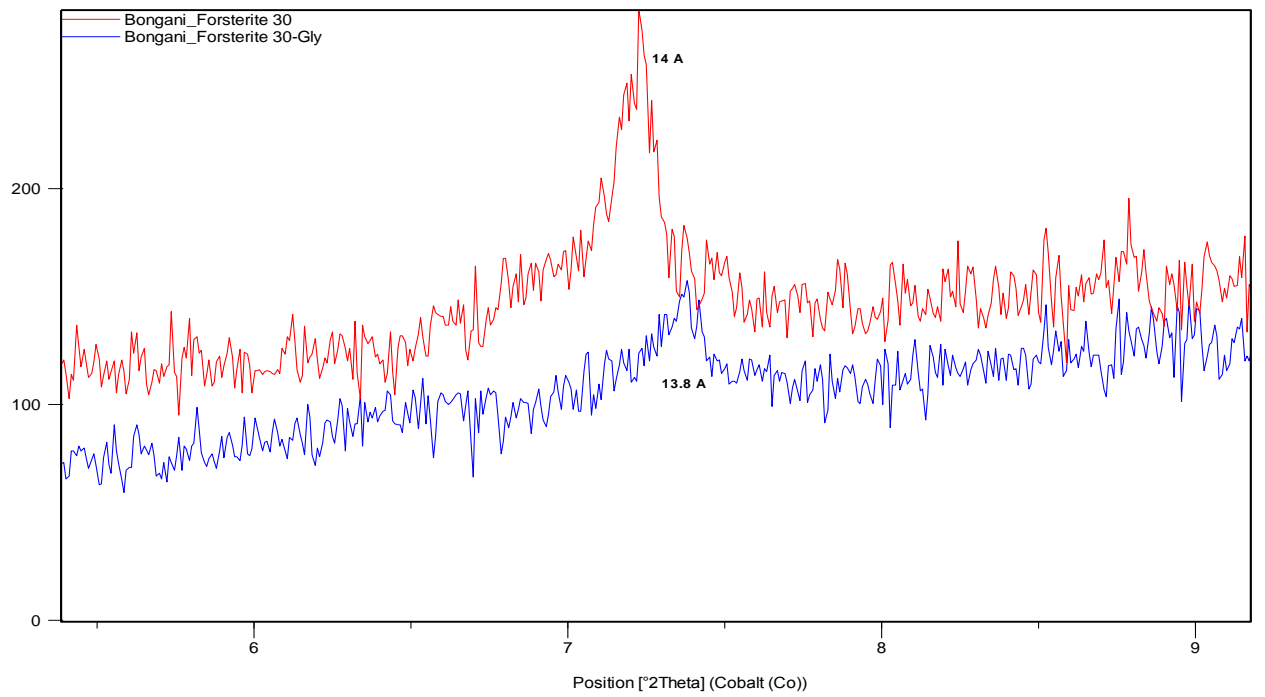




\section{F2: Drillcore ID: 153}

Counts

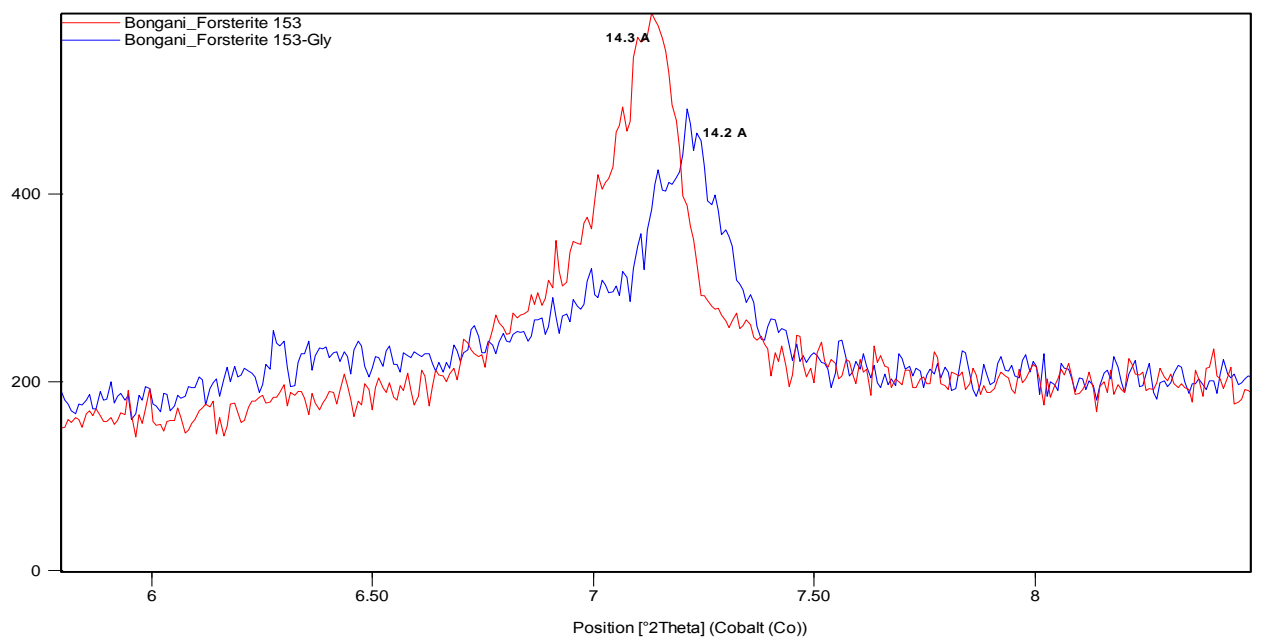

F2: Drillcore ID: 168

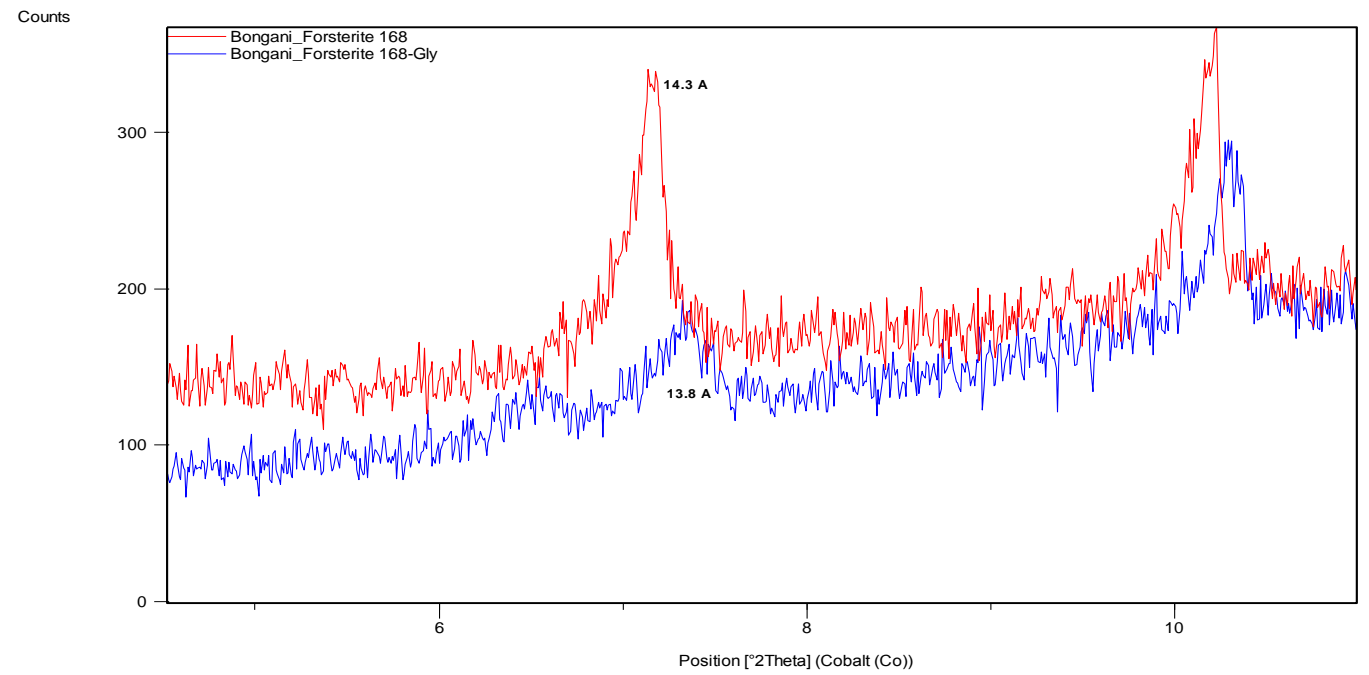




\section{F2: Drillcore ID: 107}

Counts

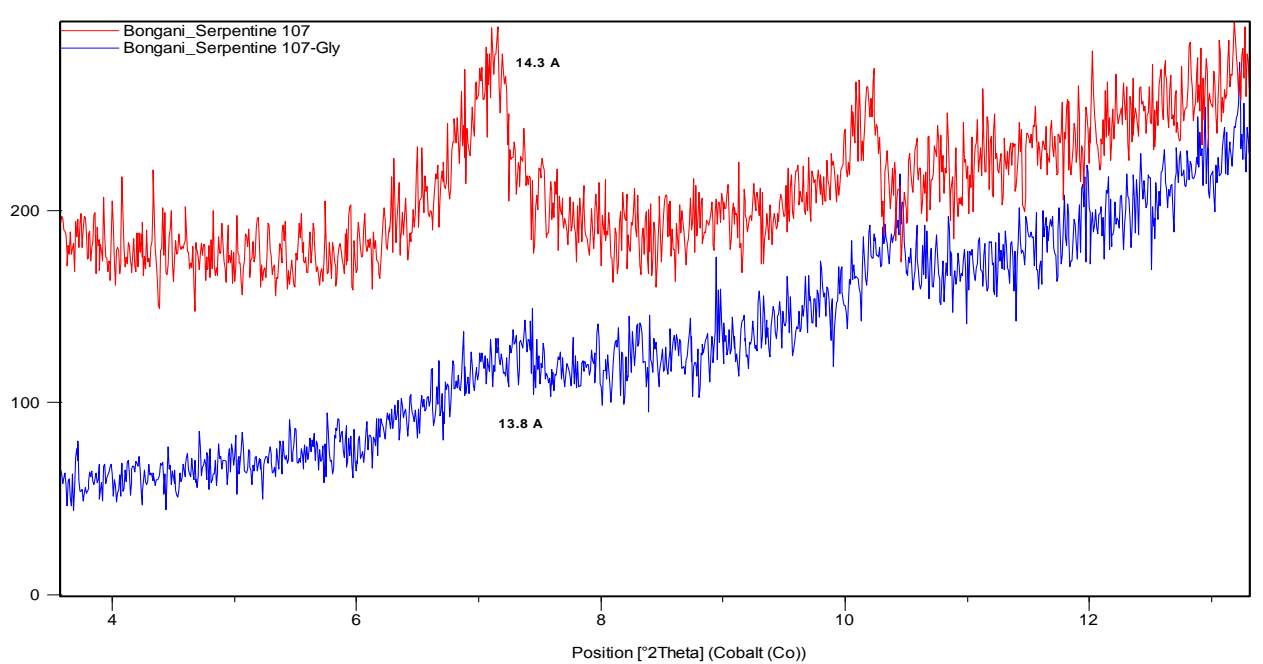

\section{F2: Drillcore ID: 147}

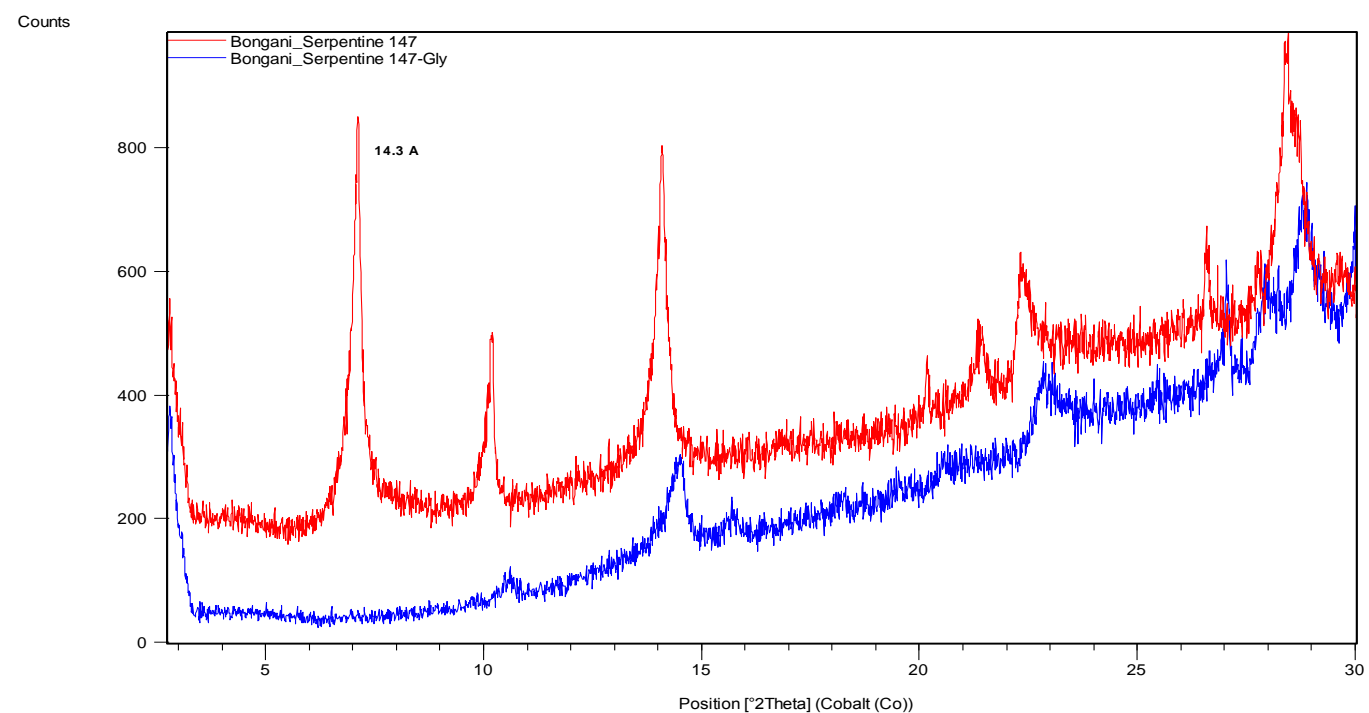


F2: Drillcore ID: 106

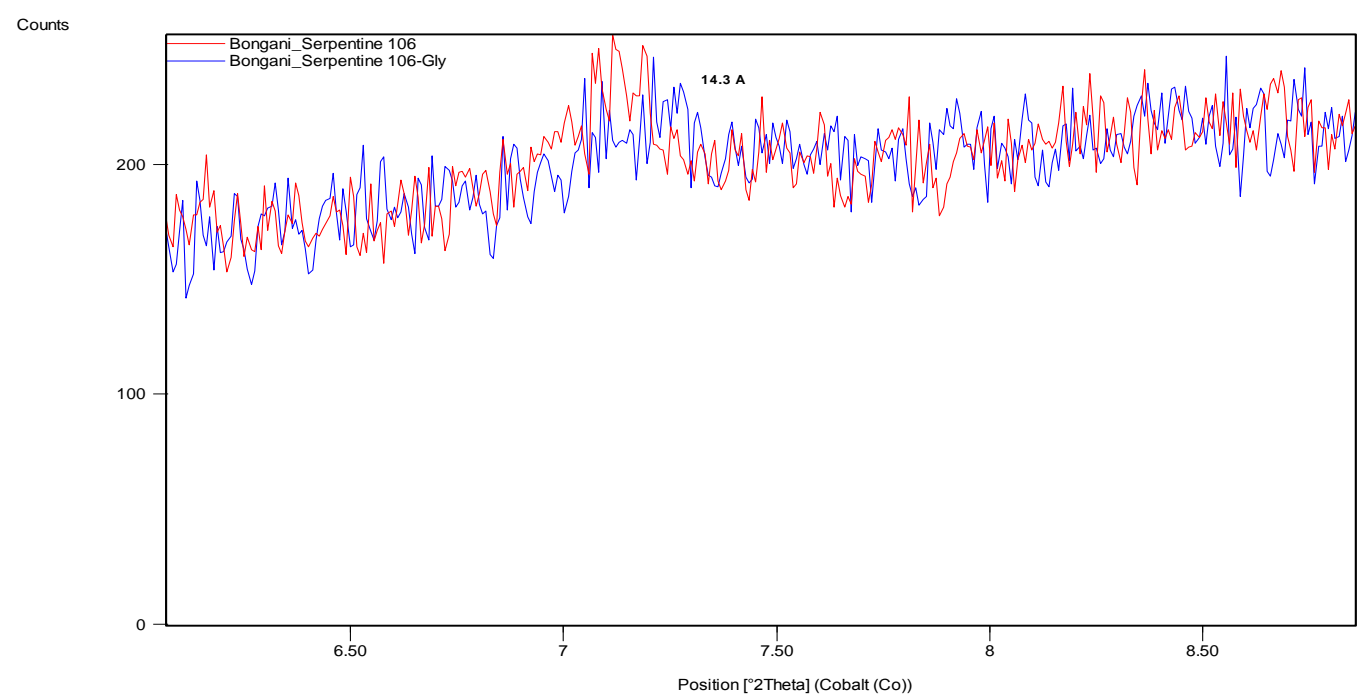




\section{F3: $\quad \mathrm{NaClO}-\mathrm{Mg}^{2+}-\mathrm{HCl}$ pretreatment}

\section{F3: Drillcore ID: 200}

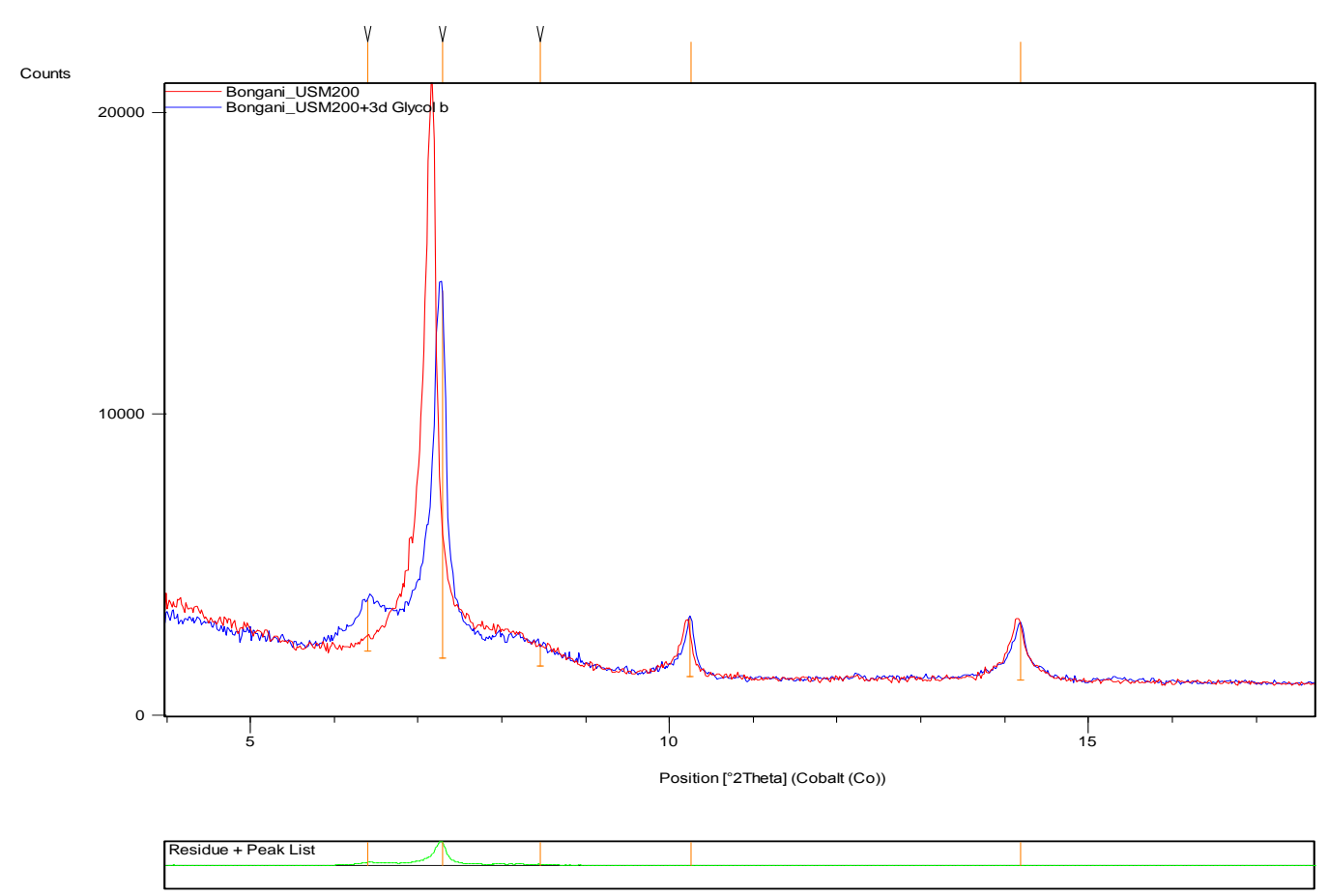

\section{F3: Drillcore ID: 14}

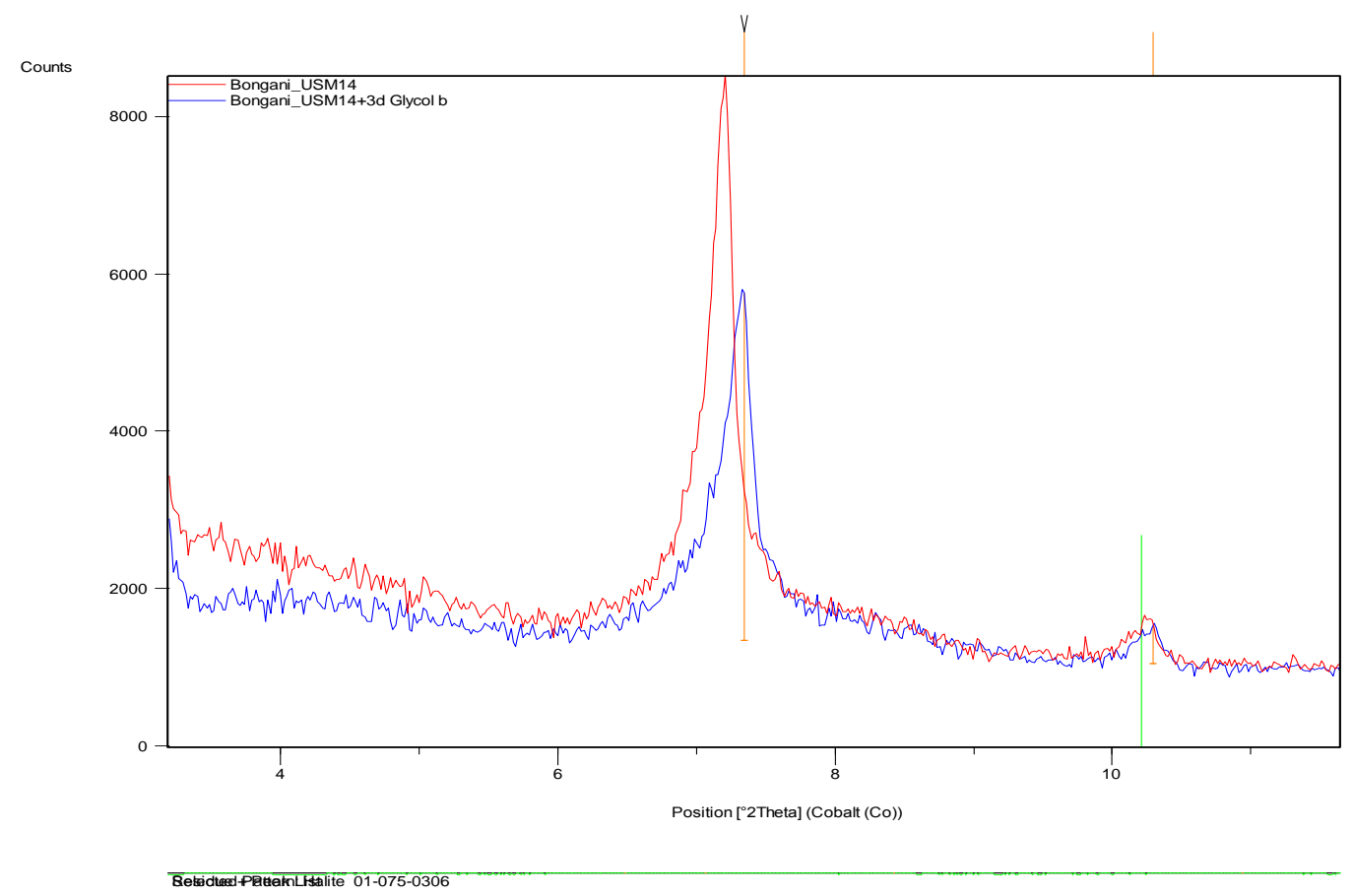




\section{F3: Drillcore ID: 3}

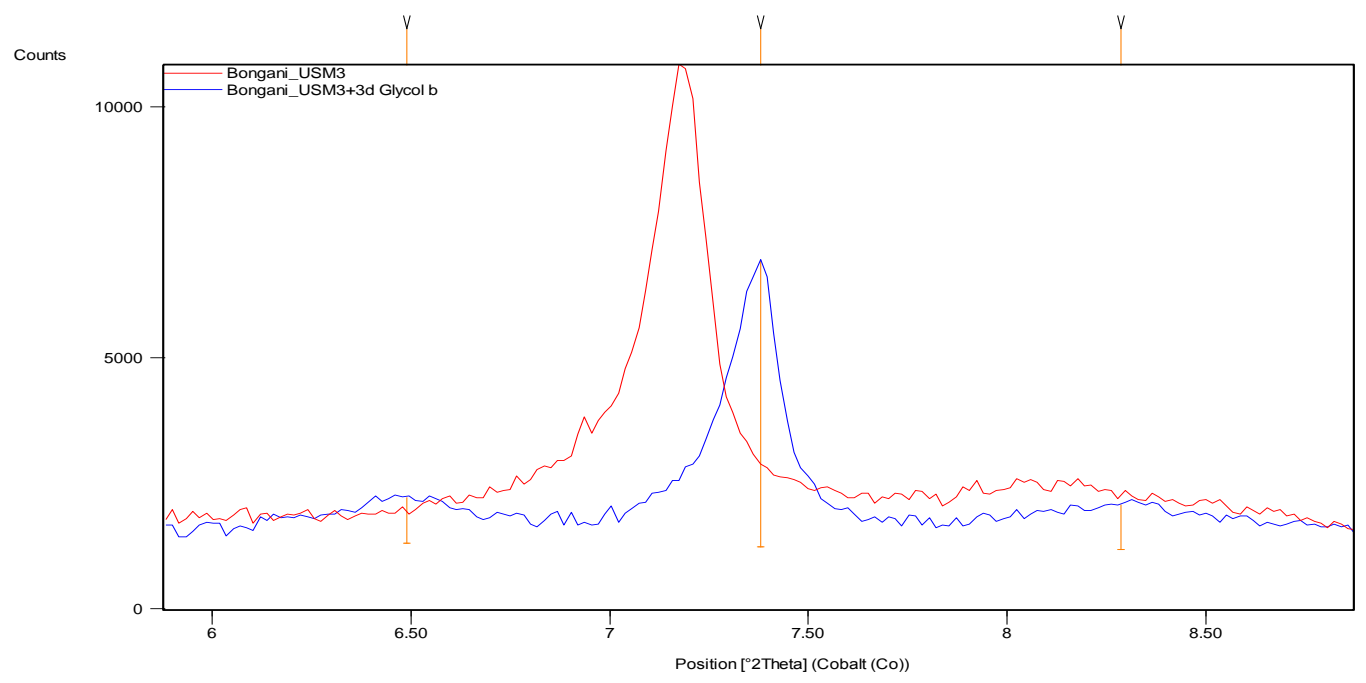

\section{F3: Drillcore ID: 30}

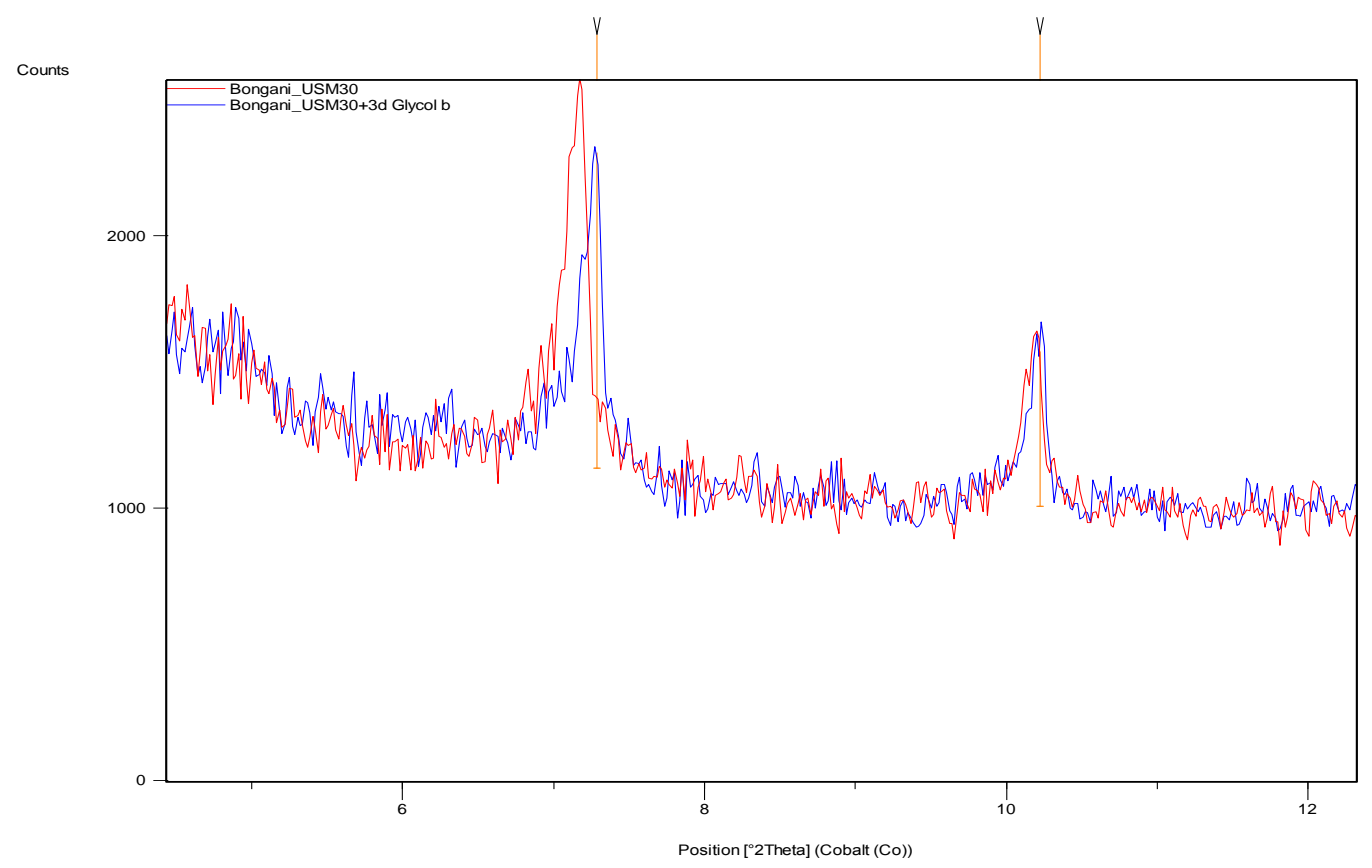




\section{F3: Drillcore ID: 153}

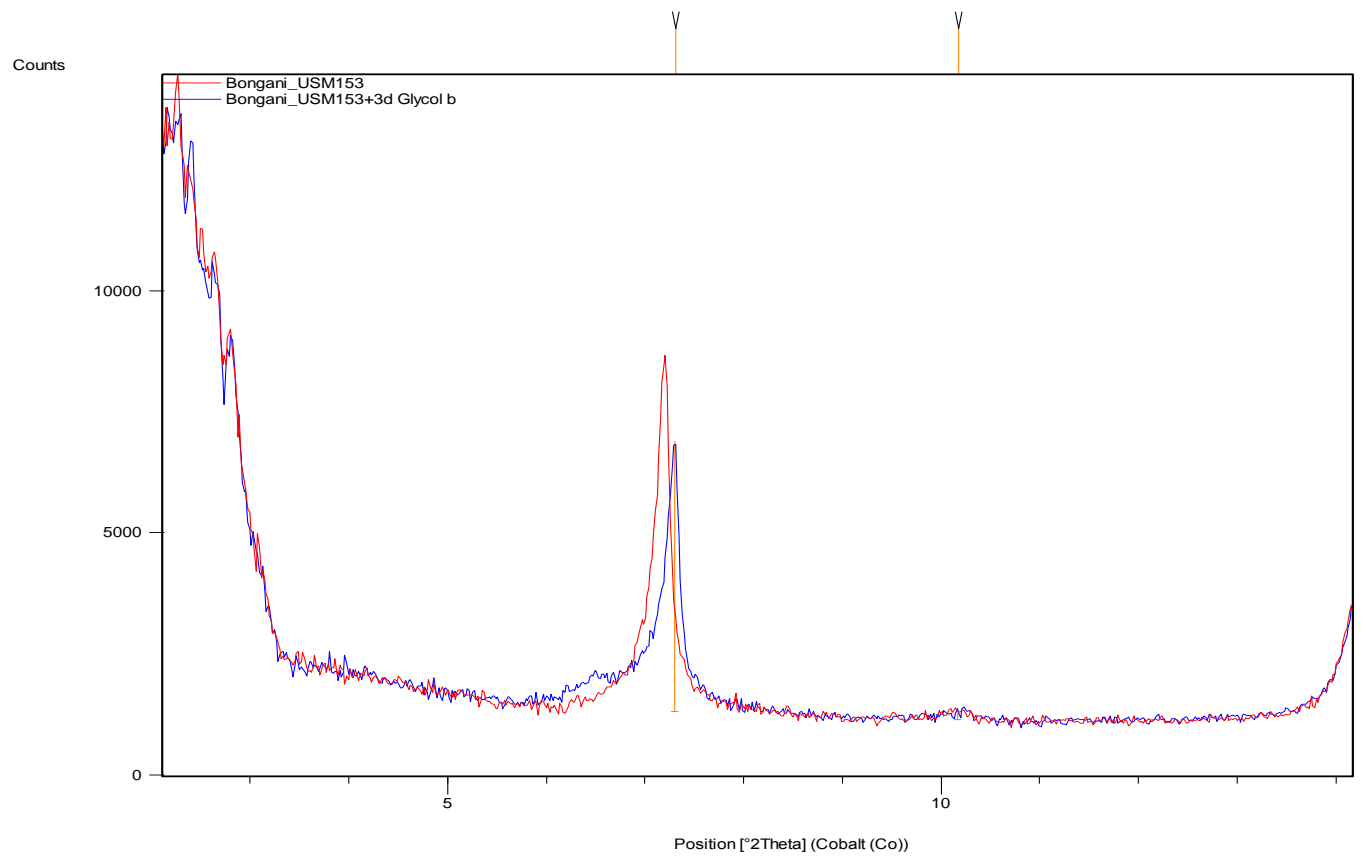

\section{F3: Drillcore ID: 168}

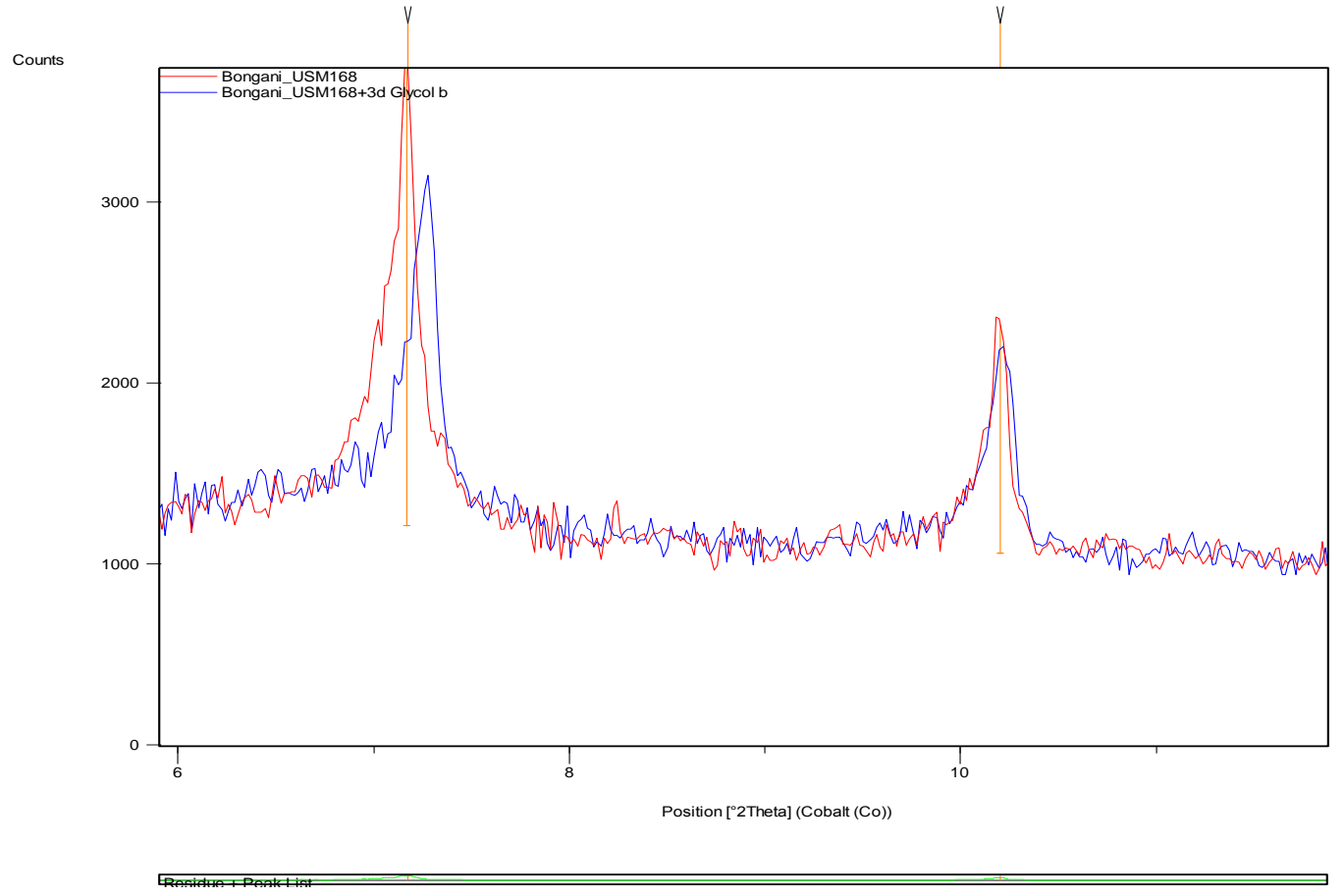




\section{F3: Drillcore ID: 107}

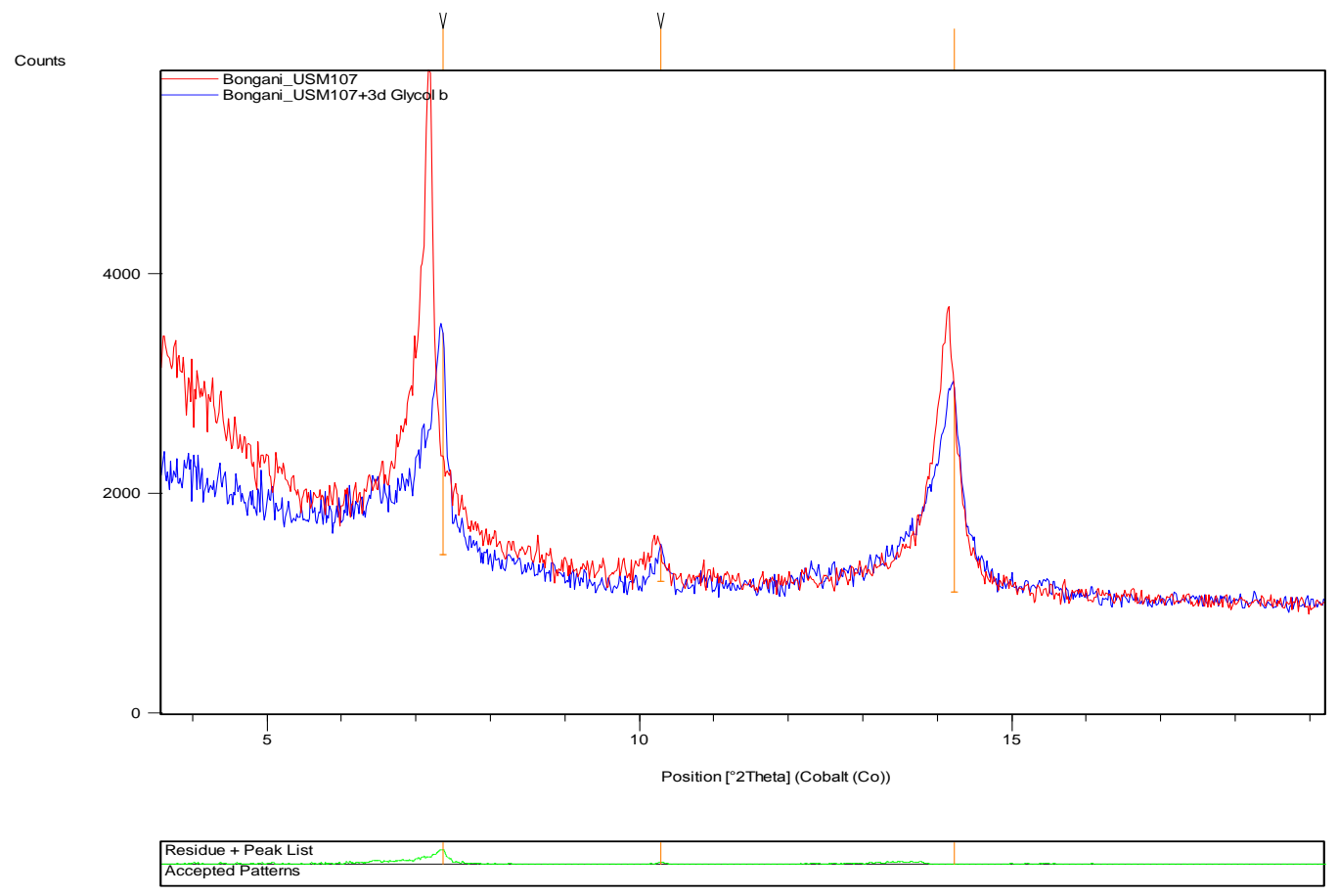

\section{F3: Drillcore ID: 147}

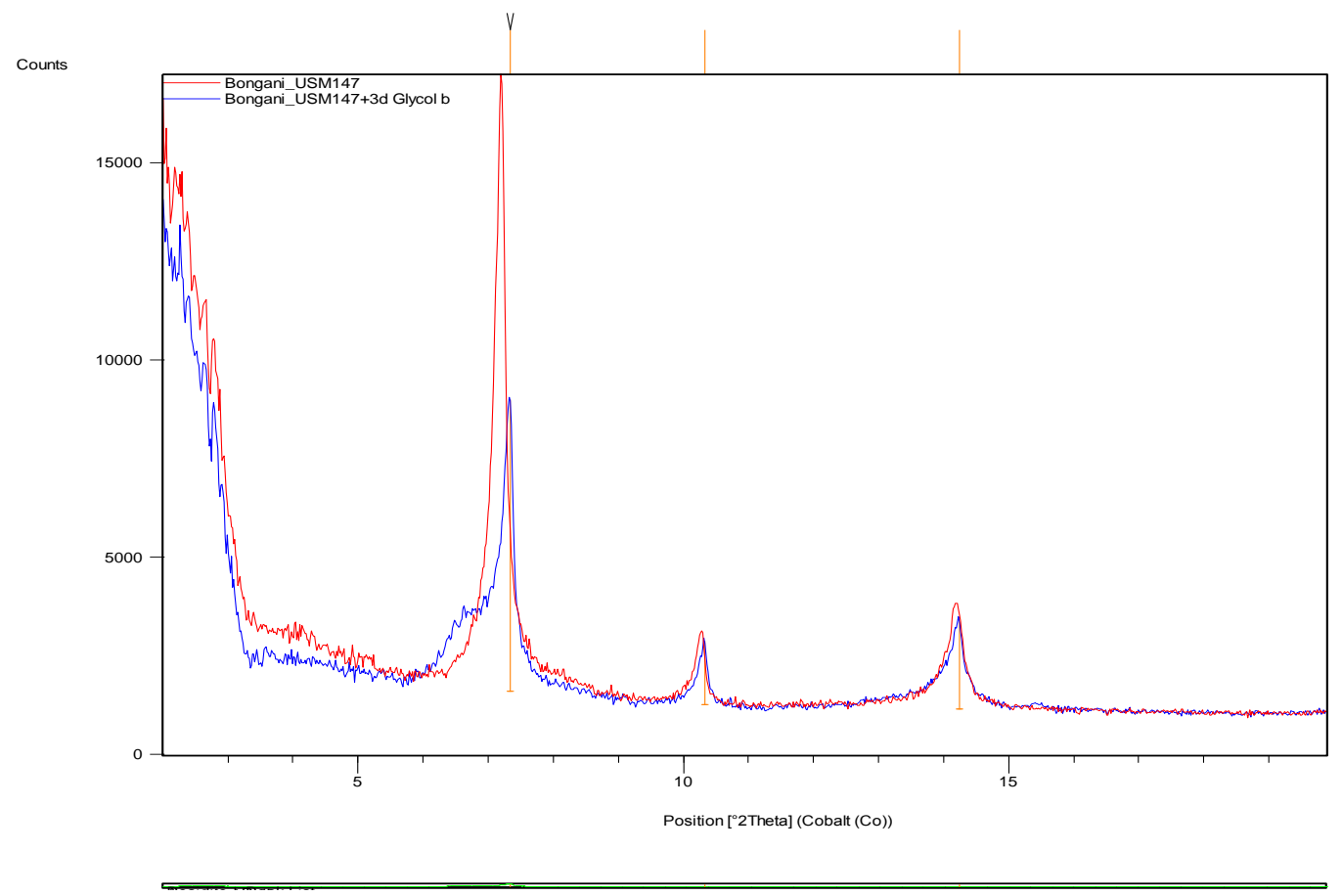




\section{F3: Drillcore ID: 106}

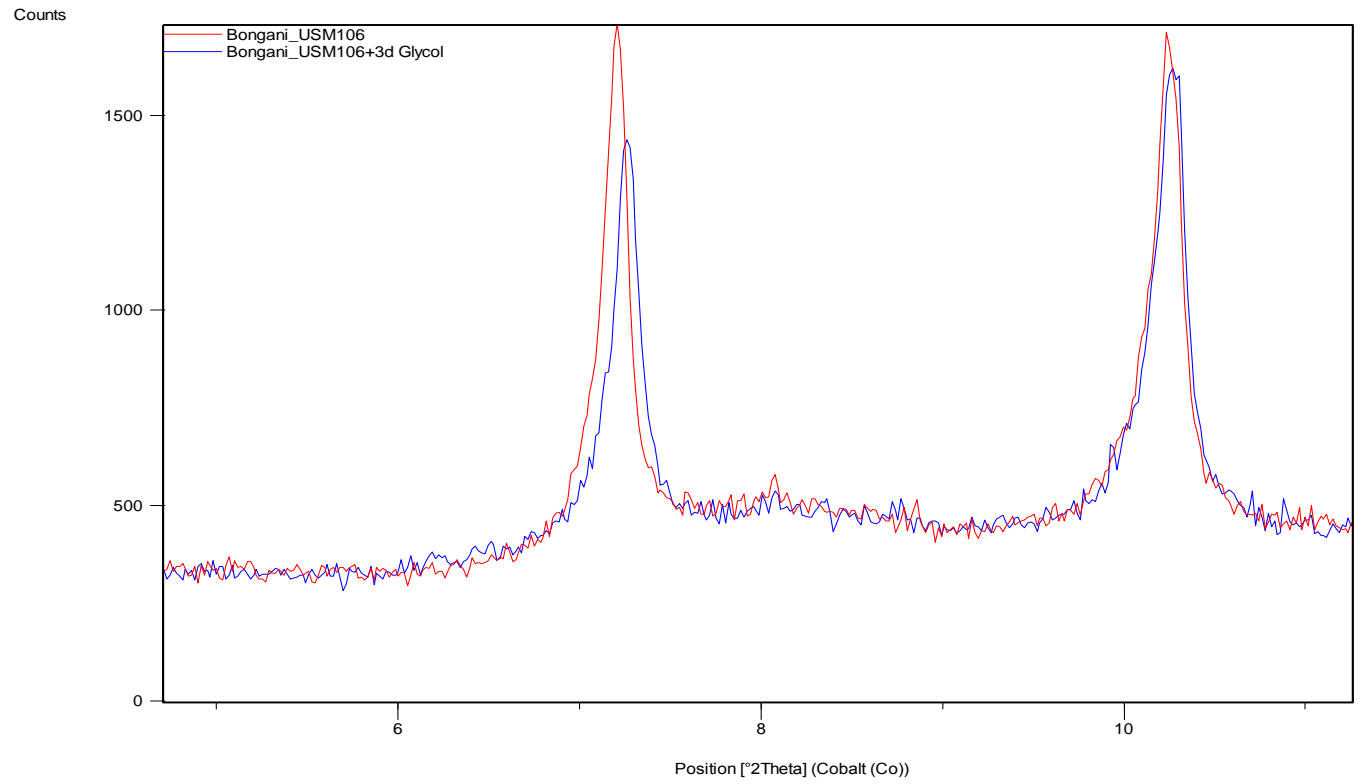

